UNIVERSIDADE DE SÃO PAULO

FACULDADE DE ECONOMIA, ADMINISTRAÇÃO E CONTABILIDADE DEPARTAMENTO DE ADMINISTRAÇÃO

PROGRAMA DE PÓS-GRADUAÇÃO EM ADMINISTRAÇÃO

\begin{abstract}
ORIENTAÇÃO PARA MERCADO E INTERFACE INTER-FUNCIONAL: UM ESTUDO NO CONTEXTO DO DESENVOLVIMENTO DE NOVOS PRODUTOS
\end{abstract}

Manuella de Oliveira Lima

Orientador: Prof. Dr. Roberto Sbragia

SÃO PAULO 
Prof. Dr. João Grandino Rodas

Reitor da Universidade de São Paulo

Prof. Dr. Carlos Roberto Azzoni

Diretor da Faculdade de Economia, Administração e Contabilidade

Prof. Dr. Adalberto Américo Fischmann

Chefe do Departamento de Administração

Prof. Dr. Lindolfo Galvão de Albuquerque

Coordenador do Programa de Pós-Graduação em Administração 


\section{ORIENTAÇÃO PARA MERCADO E INTERFACE INTER-FUNCIONAL: UM ESTUDO NO CONTEXTO DO DESENVOLVIMENTO DE NOVOS PRODUTOS}

Dissertação apresentada ao Departamento de Administração da Faculdade de Economia, Administração e Contabilidade, da Universidade de São Paulo, como requisito para a obtenção do título de Mestre em Administração.

Orientador: Prof. Dr. Roberto Sbragia

\section{SÃO PAULO}




\section{FICHA CATALOGRÁFICA}

\section{Elaborada pela Seção de Processamento Técnico do SBD/FEA/USP}

Lima, Manuella de Oliveira

Orientação para mercado e interface inter-funcional: um estudo no contexto do desenvolvimento de novos produtos / Manuella de Oliveira Lima. -- São Paulo, 2009.

$162 \mathrm{p}$.

Dissertação (Mestrado) - Universidade de São Paulo, 2010.

Bibliografia.

1. Marketing estratégico 2. Produtos novos - Desenvolvimento I. Universidade de São Paulo. Faculdade de Economia, Administração e Contabilidade II. Título.

CDD - 658.4010688 
Aos meus pais, amigos, mestres e a todos que sempre confiaram na minha capacidade de vencer. 


\section{AGRADECIMENTOS}

A realização de um trabalho acadêmico demanda a contribuição de diversas pessoas e instituições. Sendo assim, cabem aqui alguns agradecimentos.

Primeiramente, gostaria de agradecer a todas as empresas, e seus respectivos colaboradores, pela presteza e receptividade com que responderam à solicitação para participar deste estudo. A abordagem para a pesquisa foi realizada independentemente, empresa a empresa, contato a contato, sem utilização de qualquer artifício de gratificação aos respondentes; por esta razão, fico imensamente grata aos que acreditaram na veracidade e no propósito deste trabalho.

Cabe aqui também um agradecimento especial ao meu orientador, o Prof. Dr. Roberto Sbragia, pela confiança depositada em mim, desde o início do mestrado, e pela paciência com que sempre tratou meus dilemas científicos, que, muitas vezes, pareciam intermináveis. A precisão de seus apontamentos e a experiência traduzida em comentários sempre necessários foram determinantes para o sucesso desta empreitada.

Agradeço ainda aos Professores Doutores Isak Kruglianskas e José Afonso Mazzon, pelas relevantes contribuições feitas, no momento da banca de qualificação, e durante a fase de reformulação do projeto de pesquisa.

Eu não poderia deixar de agradecer ao apoio dos antigos e novos amigos. Muitos destes disponibilizaram seus contatos pessoais, para que eu obtivesse acesso mais rápido às empresas. Seria injusto citar nomes e esquecer alguém, portanto, faço votos de que, ao ler este parágrafo, os referidos amigos sintam-se tocados pela mensagem.

Sinto-me também no dever de agradecer aos representantes do Conselho Nacional de Desenvolvimento Científico e Tecnológico (CNPq), cujo apoio financeiro foi importantíssimo para o desenvolvimento e conclusão deste trabalho.

Por fim, gostaria de deixar registrada minha eterna gratidão aos meus pais, Aldo e Niedja, pelo amor e dedicação singulares. Essa conquista é nossa. 


\section{RESUMO}

A inovação vem sendo reconhecida como uma das atividades que mais contribuem para o crescimento e para a manutenção da competitividade das organizações. Para inovar, porém, alguns fatores importantes devem ser considerados. Estar atento ao que acontece no mercado e promover a interface entre as funções no ambiente intra-firma, são fatores que podem contribuir para o sucesso das inovações. Neste sentido, esta dissertação examina a relação entre os construtos de orientação para mercado e interface inter-funcional, no contexto de desenvolvimento de novos produtos. Para tanto, foi realizada uma pesquisa de natureza predominantemente correlacional, com abordagem quantitativa, por meio da utilização do método survey. Para análise dos dados, foram utilizadas técnicas estatísticas não-paramétricas descritivas e bivariadas. Os resultados do estudo apontaram para um alto grau de orientação para mercado e interface inter-funcional e correlações significativas entre a maioria das variáveis estudadas. Observou-se ainda que, as respostas dos indivíduos alocados em empresas que possuem escritório de projetos (EP), ou que já tenham exercido a função de gerente de projetos, tendem a obter maiores correlações entre as variáveis de orientação para mercado e interface inter-funcional. 


\begin{abstract}
Innovation has been recognized as one of the activities that most contribute to the growth and maintenance of the organizational competitiveness. Innovation, however, is associated to some important factors that must be considered. Paying attention to what happens in the market and promote the interface between functions in intra-firm environment, are factors that may contribute to the success of innovations. In this sense, this work examines the relationship between the constructs of market orientation and inter-functional interface in the context of new product development. It was conducted a correlational research, with a quantitative approach, through the use of survey method. Non-parametric statistics, bivariate and descriptive, were used as data analysis techniques. The survey results pointed to a high degree of market orientation and cross-functional interface and significant correlations between most of the variables of the study. Data revealed yet that the responses of individuals employed in companies with project management office (PMO), or have already worked as a project manager, tend to have greater correlations between the variables of market orientation and interface inter -functional.
\end{abstract}




\section{SUMÁRIO}

LISTA DE TABELAS _ 2

LISTA DE GRÁFICOS__ 3

LISTA DE FIGURAS

1 INTRODUÇÃO 5

1.1 A inovação e a necessidade de integração organizacional __ 5

1.2 O problema da pesquisa __ 7

1.3 Objetivos _ 9

1.4 Pressupostos conceituais _ 10

1.5 Síntese do capítulo e estrutura da dissertação __ 11

2 FUNDAMENTAÇÃO TEÓRICA _ 13

2.1 Inovação e desenvolvimento de novos produtos___ 13

2.2 Orientação para mercado___ 19

2.3 Interface inter-funcional __ 24

2.4 O papel do escritório de projetos na relação entre orientação para mercado e interface

inter-funcional. — 34

2.5 Síntese da revisão bibliográfica__ 44

3 METODOLOGIA _ 47

3.1 Natureza e método da pesquisa ___ 47

3.2 Modelo teórico, conceituação e operacionalização das variáveis ___ 51

3.3 Definição do Universo e Amostra___ 56

3.4 Estratégia de coleta de dados 59

3.4.1 Construção do instrumento e teste piloto _ 59

3.4.2 Validade e confiabilidade __ 60

3.4.3 Escalas de Mensuração __ 62

3.4.4 O procedimento de coleta de dados__ 63

3.5 Tratamento estatístico dos dados___ 64

3.6 Limitações da Pesquisa ___ 65

3.7 Síntese da metodologia _ 66

4 RESULTADOS _ 69

4.1 Dados Demográficos e Caracterização das Empresas dos Pesquisados ___ 69

4.2 Dados Demográficos e Caracterização do Respondente___ 72

4.3 Análise Descritiva da Orientação para Mercado____ 77

4.4 Análise Descritiva da Interface Inter-Funcional ___ 88

4.5 Análise das Correlações entre Orientação para Mercado e Interface Inter-Funcional 94

4.6 Síntese dos resultados _ 112

5 CONCLUSÕES

5.1 Síntese do Estudo _ 115

5.2 Principais Conclusões __ 117

5.3 Recomendações para a prática e para futuros estudos __ 122

REFERÊNCIAS 125

APÊNDICE I - Questionário de Pesquisa __ 133

APÊNDICE II - Tabelas de Análises Estatísticas dos Dados ___ 140 


\section{LISTA DE TABELAS}

Tabela 01 - Alpha de Crombach para Escalas do Instrumento 62

Tabela 02 - Setor de Atuação da Empresa

Tabela 03 - Quantidade de Projetos de Novos Produtos Desenvolvidos na Organização por Ano

Tabela 04 - Participação em Projeto de Desenvolvimento de Novos Produtos 74

Tabela 05 - Quantidade de Projetos de DNP que o Entrevistado Participa Atualmente _ 76

Tabela 06 - Principal Experiência do Entrevistado em Projetos de DNP nos Últimos 3 Anos

Tabela 07 - Outras Experiências dos Entrevistados em Projetos de DNP nos Últimos 3 Anos

Tabela 08 - Correlações Geração de Inteligência x Confiança - Critério: Existência de um EGP na Organização do Entrevistado

Tabela 09 - Correlações Geração de Inteligência x Integração - Critério: Existência de um EGP na Organização do Entrevistado

Tabela 10 - Correlações Disseminação da Inteligência x Confiança - Critério: Existência de um EGP na Organização do Entrevistado

Tabela 11 - Correlações Disseminação da Inteligência x Integração - Critério: Existência de um EGP na Organização do Entrevistado 106

Tabela 12 - Correlações Resposta à Inteligência x Confiança - Critério: Existência de um EGP na Organização do Entrevistado 108

Tabela 13 - Correlações Resposta à Inteligência x Integração - Critério: Existência de um EGP na Organização do Entrevistado 


\section{LISTA DE GRÁFICOS}

Gráfico 01 - Existência de um EGP na Organização do Indivíduo Pesquisado___ 70

Gráfico 02 - Sexo dos Entrevistados

Gráfico 03 - Faixa Etária __ 72

Gráfico 04 - Área da Empresa a que o Entrevistado Está Vinculado___ 73

Gráfico 05 - Tempo que o Funcionário Trabalha da Empresa Atual __ 74

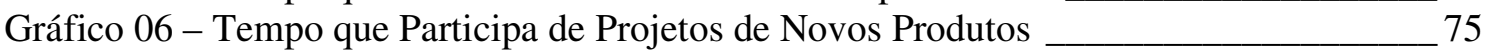

Gráfico 07 - Grau de Geração de Inteligência nas Empresas Estudadas __ 78

Gráfico 08 - Grau de Geração de Inteligência nas Empresas Estudadas _ 79

Gráfico 09 - Grau de Disseminação da Inteligência nas Empresas Estudadas___ 82

Gráfico 10 - Grau de Disseminação da Inteligência nas Empresas Estudadas___ 83

Gráfico 11 - Grau de Resposta à Inteligência nas Empresas Estudadas___ 85

Gráfico 12 - Grau de Resposta á Inteligência nas Empresas Estudadas___ 86

Gráfico 13 - Grau de Confiança nas Empresas Estudadas ___ 89

Gráfico 14 - Grau de Confiança nas Empresas Estudadas __ 90

Gráfico 15 - Grau de Integração nas Empresas Estudadas___ 91

Gráfico 16 - Grau de Integração nas Empresas Estudadas___ 92 


\section{LISTA DE FIGURAS}

Figura 01. Processo de Desenvolvimento de Novos Produtos. 17

Figura 02. Sequiência do processo de desenvolvimento de novos produtos.__ 18

Figura 03. Modelo de orientação para mercado como aspecto da cultura organizacional.__ 22

Figura 04. Interação entre as funções da organização na produção de inovação.___ 26

Figura 05. Modelo de Integração P\&D-Marketing de Gupta (1984). ___ 28

Figura 06. Modelo de construção de competências para gerenciamento de projetos. __ 34

Figura 07. Estrutura de Equipe Funcional. _ 36

Figura 08. P\&D como uma função individual/isolada.__ 37

Figura 09. Estrutura de Equipe Leve. 38

Figura 10. Estrutura de Equipe Pesada.__ 38

Figura 11. P\&D dentro de uma unidade de negócios.__ 39

Figura 12. Estrutura de equipe Autônoma.

Figura 13. Estrutura Cross-Funcional. __ 41 


\section{INTRODUÇÃO}

Este capítulo tem o objetivo inicial fazer uma contextualização dos principais temas abordados nesta dissertação e definir o problema de pesquisa a ser investigado neste estudo. Inicialmente, será abordado, de forma geral, o campo em que a pesquisa está inserida, tocando nos principais pontos, os quais serão detalhados posteriormente. Após a contextualização dos temas-chave, será definido e delimitado o problema central que levou à realização do estudo e a pergunta de pesquisa central a ser respondida mais adiante. Em um terceiro tópico, serão definidos os objetivos, tanto o geral quanto os específicos, a ser atingidos. No quarto tópico deste capítulo, serão definidos alguns pressupostos conceituais que formarão a base teórica para o estudo. Por fim, será feita uma síntese do capítulo, com a exposição dos principais pontos abordados até o momento e da estrutura básica proposta para a dissertação como um todo.

\subsection{A inovação e a necessidade de integração organizacional}

A inovação vem sendo reconhecida como uma das atividades que mais contribuem para o crescimento e para a manutenção da competitividade das organizações. As aceleradas mudanças no contexto global e o perfil cada vez mais exigente dos consumidores alavancam o processo de inovação nas empresas, as quais buscam a diferenciação de seus produtos, serviços e processos, seja de forma incremental ou radical.

Diante do exposto, a ânsia por colocar novos produtos no mercado pode esbarrar em riscos advindos da incerteza do sucesso e dos custos de falhas no processo de inovação. Em busca de minimizar tais riscos e obter resultados positivos para as organizações, o estabelecimento de processos e boas práticas para o desenvolvimento de novos produtos é um meio comum para que se atinja o mínimo de erro e o máximo de eficiência no processo de inovação.

Sabe-se ainda que as boas práticas para o sucesso de uma inovação podem ser desenvolvidas tanto no nível corporativo da organização, quanto no nível de execução do projeto (LITTLER, 1994). Os fatores de nível corporativo estão ligados à estratégia organizacional, com base na decisão do gerenciamento do topo e no longo prazo. Já os fatores de execução do projeto, como o próprio nome já diz, são relativos aos processos, dos quais faz parte o desenvolvimento de novos produtos. 
No nível corporativo, uma das estratégias utilizadas pelas organizações para fortalecer o desenvolvimento de novos produtos e a melhoria nos processos é a orientação para mercado. Segundo Rabechini Jr., Carvalho e Laurindo (2002, p. 30), "há pelo menos três variáveis a serem consideradas na gerência da inovação: informação, tempo e pessoas. As empresas que melhor gerenciam a inovação são aquelas que disponibilizam a informação certa para a pessoa certa na hora certa”. A estratégia de orientação para mercado consiste na captação de informações pertinentes às necessidades do consumidor e ao comportamento dos concorrentes, disseminação destas informações internamente, entre as funções da organização, e resposta a estas informações recebidas de forma adequada e pode ser aplicada ao desenvolvimento de inovações.

Neste sentido, para que a informação seja captada, disseminada e a resposta seja definida a contento, entende-se que as funções da organização devem estar em constante interface, especialmente, no nível de execução do projeto, em projetos de desenvolvimento de novos produtos. Conflitos e rupturas na integração entre as funções e na confiança entre os pares envolvidos nos projetos podem levar a organização a uma interpretação inadequada dos sinais do mercado e, conseqüentemente, a erros comprometedores nos resultados da inovação.

Nos modelos mais conhecidos de desenvolvimento de novos produtos, usualmente, encontram-se estruturas seqüenciais, contendo o passo a passo do processo ao longo da execução do projeto. Resumidamente, o processo se inicia com a idéia, pesquisam-se as possibilidades de desenvolvimento, cria-se um protótipo do produto, testa-se este protótipo, são feitos os reparos e, por fim, o lançam no mercado (COOPER, 1995). Esse arranjo, geralmente, não proporciona a interação necessária entre as funções, dificultando a comunicação e troca de experiências no decorrer do projeto.

O papel da execução de cada uma das fases no desenvolvimento de novos produtos é atribuído com mais ênfase, a depender do momento do projeto, a uma ou outra função da organização. Marketing, pesquisa e desenvolvimento, engenharia, manufatura, finanças, recursos humanos, entre outras, participam do processo, alternando suas posições e o seu grau de interferência quando necessário. Sendo assim, entende-se que a organização como um todo contribui para o desenvolvimento de uma inovação, em maior ou menor grau e que, quanto mais houver sinergia entre as funções envolvidas nos projetos, maiores serão suas chances de sucesso. 
A compreensão sistêmica do desenvolvimento de novos produtos esbarra no fato de que, muitas vezes, não se consegue obter a integração necessária entre as funções durante o processo. Freeman (1994) destaca que a integração entre as funções de P\&D, produção e marketing são essenciais para o sucesso das inovações, reduzindo o lead time e promovendo melhorias de produto e processo, simultaneamente. Apesar de a literatura reforçar a importância da boa relação entre as funções da organização para a realização de projetos de novos produtos, geralmente, a interação entre as partes, para a realização de determinadas tarefas, aqui chamada de interface inter-funcional, esbarra em conflitos diversos, em sua maioria, com origem em distúrbios de comunicação.

Neste sentido, um passo importante para que a interface inter-funcional ocorra de forma adequada é o estabelecimento de um bom fluxo de informações entre as funções envolvidas em projetos de desenvolvimento de novos produtos. É neste ponto que se insere a orientação para mercado e o desafio de gerar, disseminar e responder às informações do mercado adequadamente.

Diante deste cenário, entende-se que a estrutura da organização deve dar suporte às pessoas, para que estas façam o melhor proveito possível das informações, transformando-as em vantagem competitiva. Um dos meios para se atingir diferenciação e integração em projetos é a criação de um EGP (Project Management Office). Este elemento, desde que bem estruturado, pode auxiliar na melhoria da comunicação em projetos.

Após esta reflexão, entende-se que compreender como se dá a dinâmica de orientação para mercado versus interface inter-funcional em projetos de desenvolvimento de novos produtos pode ser um fator contribuinte para o sucesso das organizações. Esse será o desafio do estudo apresentado nesta dissertação.

\subsection{O problema da pesquisa}

Para que se entenda o problema a ser estudado nesta pesquisa, é necessário evidenciar a busca pela compreensão de dois elementos-chave que trazem no cerne de sua questão a comunicação e a forma como ela se dá dentro da organização, inseridos em um contexto específico: a orientação para mercado e a interface entre as pessoas que compõem as diversas 
áreas funcionais das organizações envolvidas com projetos de desenvolvimento de novos produtos.

A orientação para mercado é vista como uma estratégia de marketing, onde a empresa mantém seu foco no cliente e nos concorrentes e utiliza a informação externa como insumo para melhoria dos seus produtos e processos. Porém, apenas o estabelecimento desta estratégia e sua implementação pela organização não garantem o bom aproveitamento das informações captadas no mercado. Diante deste cenário, surge a necessidade de compreender se as funções da organização estão integradas para disseminar e responder às informações captadas no mercado e avaliar grau de confiança nos relacionamentos que ocorrem durante este processo.

Nesse contexto, surge um fator que enfatiza a necessidade de compreensão do mercado e da concorrência para a manutenção da competitividade da maioria das organizações: a inovação. Dia após dia, vem-se identificando nos ambientes de negócios uma grande valorização da inovação como fator diferencial nas organizações. Conseqüentemente, os estudos sobre este tema vêm ganhando destaque, tanto nas pesquisas originadas em meios acadêmicos, quanto no conturbado ambiente de mercado. Uma das linhas de pesquisa dentro desse escopo é a inovação de produtos. Diante dessa realidade, e da ciência da relevância do tema, o problema desta pesquisa adota como contexto de investigação os projetos de desenvolvimento de novos produtos. Esta escolha pode ser justificada pelo fato de os projetos, em sua maioria, mobilizarem grandes equipes inter-funcionais e trazerem um rico cenário de interação, que se apresenta bastante apropriado para o propósito deste estudo.

Nesse sentido, pretende-se apresentar, nesta dissertação, resultados que possibilitem entender se há alguma relação entre orientação para mercado e interface inter-funcional, quando as empresas se mobilizam para desenvolver um novo produto que será lançado no mercado. Em outras palavras, busca-se compreender se organizações mais orientadas para mercado possuem também uma maior interface inter-funcional, no ambiente de projetos de desenvolvimento de novos produtos das organizações pesquisadas.

Tomando como base pesquisas preliminares realizadas, nota-se que o campo de orientação para mercado já foi bastante explorado. Como poderá ser observado com detalhes na fundamentação teórica deste estudo (capítulo 2), há alguns modelos já estabelecidos, assim 
como escalas para sua mensuração. Algo semelhante ocorre com o campo que estuda a interface inter-funcional. Artigos nas áreas de estruturas organizacionais, comunicação e gerenciamento de equipes trazem informações relevantes sobre o tema que, apesar de bastante explorado, ainda possui uma teoria mais dispersa, em relação ao que foi encontrado sobre orientação para mercado.

Apesar de serem estes temas tradicionalmente explorados na academia, na fundamentação teórica feita para este estudo não foram encontradas pesquisas que se dedicassem diretamente a entender a existência de relação entre orientação para mercado e interface inter-funcional, ainda menos no contexto de desenvolvimento de novos produtos.

Considerando a existência desta lacuna e entendendo que tanto a estratégia de orientação para mercado, quanto a existência de interface inter-funcional carregam em sua essência a importância do fluxo de informações como base para suas teorias, o estudo pretende responder à seguinte pergunta central: Há relação entre orientação para mercado e interface inter-funcional no desenvolvimento de novos produtos?

\subsection{Objetivos}

O objetivo principal deste estudo é analisar as possíveis relações entre orientação para mercado e interface inter-funcional, no contexto de desenvolvimento de novos produtos. Para contemplar o objetivo geral da dissertação, faz-se necessário o estabelecimento dos seguintes objetivos específicos:

- Mensurar o grau de orientação para mercado, integração funcional e confiança no contexto de projetos de desenvolvimento de novos produtos;

- Descobrir possíveis relações entre de orientação para mercado e interface interfuncional em projetos de desenvolvimento de produtos.

- Propor alternativas para a concepção de estudos futuros. 


\subsection{Pressupostos conceituais}

Para a realização deste estudo, foram considerados alguns pressupostos conceituais, os quais serviram de alicerces para o trabalho e foram utilizados como parte das diretrizes teóricas do estudo. São eles:

- Orientação para o mercado é entendida como a geração, em toda a organização, de inteligência de mercado, relativa às atuais e futuras necessidades dos clientes, disseminação da inteligência entre os departamentos, e a resposta de toda a organização a esta inteligência (KHOLI E JAWORSKI, 1990; 1993);

- Orientação para mercado é diferente de orientação para marketing (market orientation \# marketing orientation). Kohli e Jaworski (1990, p. 2-3) destacam três razões que justificam esta afirmação: 1) O construto de orientação para mercado não diz respeito apenas à função de marketing, dado que a organização como um todo contribui para a geração, disseminação e resposta à inteligência de mercado, sendo assim, o termo orientação para marketing seria restritivo; 2) A denominação "orientação para mercado" possui um efeito politicamente mais correto, porque evita inflar a importância do marketing em detrimento das demais funções da organização; 3) A denominação orientação para mercado foca-se no mercado, o que inclui clientes e as forças que os afetam;

- Para este estudo, será utilizado o modelo de García, Sanzo e Trespalacios (2008), onde a interface inter-funcional é composta pelos construtos de confiança e integração interfuncional. Este modelo será explicado em mais detalhes no capítulo de Fundamentação Teórica desta dissertação.

- Apesar de Narver e Slater (1990) considerarem a interface inter-funcional ${ }^{1}$ parte do $^{-}$ seu construto de orientação para mercado, para este estudo, será a dotada a posição de Gatignon e Xuereb (1997) que a entendem como um aspecto da estrutura organizacional que é necessário para obter benefícios completos de um mix de orientação estratégica. A coordenação inter-funcional é definida pelos autores como

\footnotetext{
${ }^{1}$ Narver e Slater (1990) e Gatingnon e Xuereb utilizam a nomenclatura de coordenação inter-funcional para a interface inter-funcional.
} 
aspectos específicos da estrutura organizacional que facilitam a comunicação entre as diferentes funções da organização;

- No campo moderno do gerenciamento de projetos, um projeto é definido como uma atividade de duração finita, com a entrega final definida como uma meta. Neste sentido, o desenvolvimento de novos produtos se encaixa nesta definição e pode, portanto, ser considerado um projeto (DIEGEL, 2002, p. 1).

\subsection{Síntese do capítulo e estrutura da dissertação}

O capítulo 1 desta dissertação apresentou o problema pesquisa central a ser investigado neste estudo. Inicialmente, foi apresentada uma introdução, destacando a relevância dos principais temas que permeiam o tema proposto para este trabalho. Em um segundo momento, foi delimitado o problema de pesquisa e também foi apresentada a questão central a ser respondida pelo estudo, bem como os objetivos a serem cumpridos ao final da dissertação.

No próximo capítulo, será apresentada a fundamentação teórica utilizada para o estudo, que inclui as principais correntes teóricas levadas em consideração para a composição do arcabouço teórico da dissertação.

Em uma terceira seção, será feita a descrição metodológica do estudo, partindo das principais classificações sobre métodos e técnicas encontradas na literatura, até chegar aos procedimentos utilizados como norteadores do trabalho. Neste capítulo serão destacadas ainda as principais estatísticas utilizadas na análise dos dados e, por fim, as limitações mais relevantes da pesquisa.

No quarto capítulo, serão trazidos os perfis das empresas e dos indivíduos pesquisados, com a descrição dos resultados encontrados, referentes ao conteúdo sobre orientação para mercado e interface inter-funcional, bem como a diferenciação das correlações pela variável moderadora do modelo. Diferentemente da fundamentação teórica, trazida no capítulo 2, os resultados são o retrato da realidade dos indivíduos pesquisados.

Por fim, no quinto capítulo, serão apresentadas as principais conclusões da pesquisa, assim como as recomendações para estudos futuros sobre os temas aqui abordados. 


\section{FUNDAMENTAÇÃO TEÓRICA}

Este capítulo tem como objetivo apresentar pontos relevantes da bibliografia que serviu de fundamentação teórica para a realização deste estudo. Na primeira seção deste capítulo, será abordada a temática da inovação, com uma breve descrição da evolução histórica do tema, seus principais conceitos, passando pelos tipos de inovação e culminando no desenvolvimento de novos produtos. Na segunda seção, será abordada a orientação para mercado, seus principais conceitos e os modelos mais utilizados como referência em pesquisas da área. $\mathrm{Na}$ terceira seção, será abordada a temática da interface inter-funcional, destacando a importância da integração e da confiança para o bom funcionamento da organização. Por fim, será apresentado um resumo do capítulo, com as principais diretrizes teóricas que serão adotadas para esta dissertação.

\subsection{Inovação e desenvolvimento de novos produtos}

Questões ligadas ao novo sempre inspiraram o trabalho humano. Segundo Andreassi (2007), Adam Smith, no século XVIII, já mencionava a relação entre tecnologia produtiva e acúmulo de capital. Já no século XIX, List introduziu o conceito de investimento intangível. Porém, ainda segundo o autor, apenas no século XX, Schumpeter conferiu à inovação uma posição de destaque na economia. Neste sentido, cabe destacar que o processo de inovação já traça uma linha histórica, passando por diferentes tendências no decorrer dos anos.

Historicamente, o campo de estudo da inovação divide-se em duas áreas principais. A primeira, com uma abordagem voltada para a economia, para o exame de diferentes padrões de inovação em diferentes países e setores, bem como a evolução de tecnologias e a propensão intra-setores a inovar de diversas indústrias. A segunda área de estudo em inovação segue uma tradição voltada para a organização, focando questões de nível micro, sobre o desenvolvimento de novos produtos (BROWN E EISENHARDT, 1995).

Face ao exposto acima, deste ponto em diante, este estudo terá como foco a segunda área de estudos de inovação, tratando das relações intra-firma. Nesse contexto, Rothwell (1994) apresenta a evolução dos modelos do processo de inovação nas organizações. O primeiro modelo, chamado de Technology-Push surge no início da década de 50 e predomina até a metade dos anos 60. Esta primeira geração de processos inovadores consistia em um modelo 
linear simples, que partia de descobertas científicas, passando por desenho e engenharia, manufatura, marketing e terminava nas vendas. A principal característica deste primeiro modelo é que o mercado era visto, simplesmente, como o receptor dos frutos gerados por Pesquisa e Desenvolvimento, no início do processo.

Posteriormente, do final dos anos 60 até o início dos anos 70, surge o modelo denominado Marketing-Pull. Nesta segunda geração, onde o desenho do modelo também era linear, as necessidades do mercado eram colocadas como referência para o restante do processo. A partir das necessidades do mercado era desenvolvida a inovação, manufaturada e vendida. Sendo assim P\&D passou a assumir um papel reativo dentro do processo de inovação, dado que deveria ser pesquisado apenas o que o mercado sinalizasse como necessário.

Dando continuidade, ainda segundo Rothwell (1994), a terceira geração de modelos do processo de inovação trouxe uma crítica aos dois modelos anteriores, dada sua demasiada simplicidade. Com base na concepção de que a inovação exigia mais interação entre as diversas áreas do que havia sido apresentado até então, criou-se o chamado Coupling Model (Modelo Acoplado). O modelo recebia este nome porque buscava acoplar as dimensões de ciência, tecnologia e marketing. Desde então, o modelo não era mais linear e buscava associar o desenvolvimento de inovações à existência de novas idéias, em direção ao mercado, com base nas necessidades da sociedade e no estado da arte em tecnologia e produção. Outro diferencial, em relação às duas gerações anteriores é que o modelo da terceira geração representava relações de feedback durante todo o processo, o que não ocorria em desenhos lineares mais simples.

Seguindo uma linha evolutiva, nos anos 90, surge a quarta geração dos modelos de inovação, o chamado Integrated Model (Modelo Integrado). Sua grande característica é o paralelismo atividades que cortam as áreas funcionais da empresa, por meio do qual as informações são trocadas em reuniões periódicas. Como o próprio nome já diz, a integração é o forte deste modelo, que propões o desenvolvimento de atividades em paralelo, com forte integração as áreas funcionais.

Rothwell (1994) traz ainda a proposta de uma quinta geração dos modelos de inovação, baseada na integração dos sistemas e em redes de trabalho (Systems Integration and Networking). O autor afirma que a quinta geração é, essencialmente, o desenvolvimento da 
quarta geração no qual a tecnologia da mudança tecnológica muda por si própria. Em outras palavras, a quinta geração está em busca da redução de custos e tempo de desenvolvimento por meio de uma nova gestão da tecnologia existente.

Diante da evolução dos modelos apresentados, entende-se que a inovação pode ser útil na solução dos desafios enfrentado pelas organizações diante da constante necessidade de mudança, resultante de fatores como a globalização e o avanço tecnológico. Silocci (2001, p. 15) reforça esta constatação afirmando que "diante das mudanças e dos cenários cada vez mais competitivos, as empresas que pretendem manter-se 'vivas', necessitam de uma estratégia de inovação".

Diante desta pressão sobre as empresas para inovar, acabam surgindo uma série de iniciativas na direção da novidade. Porém, cabe destacar que para que o processo de inovação se dê por completo, é preciso ir além do insight inicial. A concepção da idéia é apenas o primeiro passo do desenvolvimento da inovação, o que pode ser reforçado pela fala de Schumpeter (1982, p. 62), segundo o qual "enquanto não forem levadas à prática, as invenções são economicamente irrelevantes”, ou seja, apenas a idéia não garante impactos econômicos para a organização. Segundo Bamber et al (2002), novos produtos e seu desenvolvimento bem sucedido podem ser a vida da companhia. Sendo assim, a inovação deve ser amparada por atividades que garantam o desenvolvimento e a entrega ao mercado da idéia inicial, para que a busca pelo novo não se transforme de benefício a prejuízo para a organização.

Neste sentido, para que haja inovações concretas, relevante para os resultados da organização, faz-se necessária a existência de uma intensa atividade inovativa. De acordo com as definições encontradas no manual Oslo (OECD, 2005), destaca a diferença entre inovação e atividade inovativa. Segundo o manual, um inovação é a implementação de um produto (bem ou serviço) ou processo novo, ou significativamente melhorado, um novo método de marketing, ou um novo método organizacional de práticas internas, de organização do local de trabalho, ou de relações externas. Já a atividade inovativa, segundo o manual, é composta por sete pontos principais, a saber: 1) Pesquisa e Desenvolvimento; 2) Engenharia; 3) Início da produção; 4) Marketing de novos produtos; 5) Aquisição de tecnologias intangíveis; 6) Aquisição de tecnologias tangíveis e 7) Design. Dentre entre as atividades que levam à inovação, Andreassi e Sbragia (2002, p. 23) destacam pesquisa e desenvolvimento como a 
mais clássica, visto que assume papel de destaque perante as demais, influenciando o processo de inovação ativamente e influenciando no estado da arte das novas tecnologias.

Adicionalmente, para Zawislak (1995, p. 12), "uma inovação é uma nova combinação de conhecimentos para gerar um novo, porém um novo conhecimento que tenha valor de troca e não só valor de uso". Neste sentido, entende-se por inovação o resultado de uma série de atividades inovativas, cujo objetivo final é criar valor adicional ao produto, serviço, processo ou estrutura da organização.

Diante do conceito de inovação, cabe ainda um esclarecimento. Inovar nem sempre significa romper totalmente com o que existia anteriormente. Muitas vezes, entende-se inovação como uma quebra de paradigmas, porém, nem sempre é necessária uma ruptura total dos conceitos já existentes para inovar. Neste sentido, Neely e Hii (1998) apresentam um modelo (Quadro 01), relacionando os tipos de inovação existentes e as dimensões que esta inovação pode assumir.

\section{Quadro 01 - Tipos versus Dimensões da Inovação}

\begin{tabular}{|l|l|l|}
\hline & \multicolumn{1}{|c|}{ Incremental } & \multicolumn{1}{|c|}{ Radical } \\
\hline Produto & $\begin{array}{l}\text { Chip de 32 bits para substituir um chip de 16 } \\
\text { bits }\end{array}$ & Lançamento do CD player \\
\hline Processo & $\begin{array}{l}\text { Melhoria na qualidade dos sistemas de } \\
\text { inspeção }\end{array}$ & Prototipagem de produtos no computador \\
\hline Organização & Implementação de ciclos de qualidade & Reunião por teleconferência \\
\hline
\end{tabular}

Fonte: Adaptado de Neely e Hii (1998, p. 9).

No modelo apresentado no Quadro 01, nota-se que as inovações podem ser classificadas como radicais ou incrementais. Sendo as primeiras aquelas que dão origem a algo totalmente novo e as segundas aquelas que, como o próprio nome já diz, apenas incremental o produto, adicionando um algo mais, significativo o suficiente para ser considerado inovador. Observase ainda, no Quadro 01, que a inovação pode ocorrer dentro de três dimensões: inovação no produto, inovação nos processos e inovação na estrutura organizacional. Os tipos de inovação podem, portanto, coexistir em diversas dimensões na organização, fato que torna a atividade inovadora diversificada e mais complexa.

Levando-se em consideração a classificação e os exemplos apresentados no capítulo, entendese, portanto, que a inovação pode ser dar de formas variadas na organização, envolvendo 
produtos, processos e/ou fatores organizacionais. Além disso, ela pode representar desde uma pequena alteração, até uma ruptura total, frente ao que já existia anteriormente.

Independentemente dos níveis em que a inovação é desenvolvida na organização, entende-se que, para sua realização, desde a concepção até a comercialização, configura-se um projeto, dado que se trata de um empreendimento composto por etapas definidas, com começo, meio e fim (DIEGEL, 2002).

Neste sentido, Cooper (1993) desenvolveu um modelo no qual busca representar as fases do projeto de desenvolvimento de novos produtos. Este modelo é conhecido como Stage Gate, por ser composto por uma série de estágios, intercalados por alguns pontos de revisão das fases do projeto (gates). Os estágios classificados por Cooper (1995) são representados em forma de etapas do projeto, enquanto os pontos situados entre um e outro estágio são paradas para feedback do que já foi feito, antes que se inicie a etapa seguinte. O modelo Satge Gate, adaptado de Cooper (1995) pode ser visualizado da seguinte forma (Figura 01):

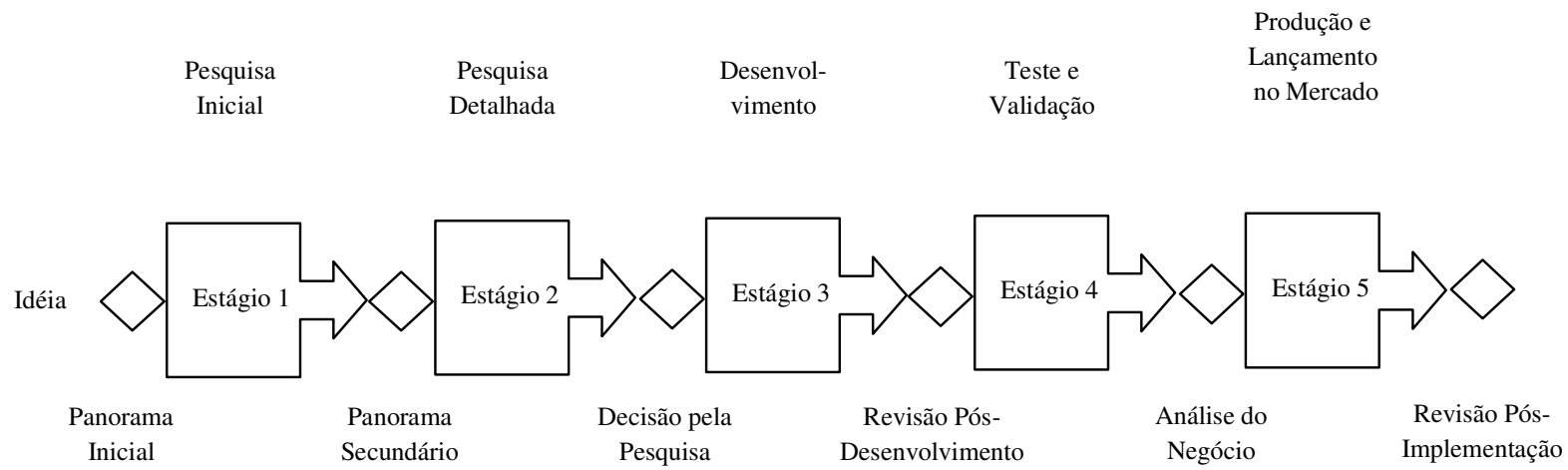

Figura 01. Processo de Desenvolvimento de Novos Produtos. Fonte: Adaptado de Cooper (1995).

Segundo Bremser e Barsky (2004), o modelo Stage Gate provê um mecanismo que conecte o desenvolvimento de novas tecnologias às vendas, ao mercado e ao consumidor. Isso significa que a necessidade de feedbacks constantes, a cada nova fase do projeto, caracteriza uma maior interação entre as áreas responsáveis pela concepção do novo produto, ou serviço.

Complementarmente, é possível encontrar em Bamber et al (2002) um modelo adaptado de Ulrich e Eppinger (1995) e Russsel e Taylor (1995) que seqüencia o processo de 
desenvolvimento de novos produtos e estabelece o papel de cada área da organização que deve estar envolvida nas ditas fases. Este processo pode ser observado na Figura 02.

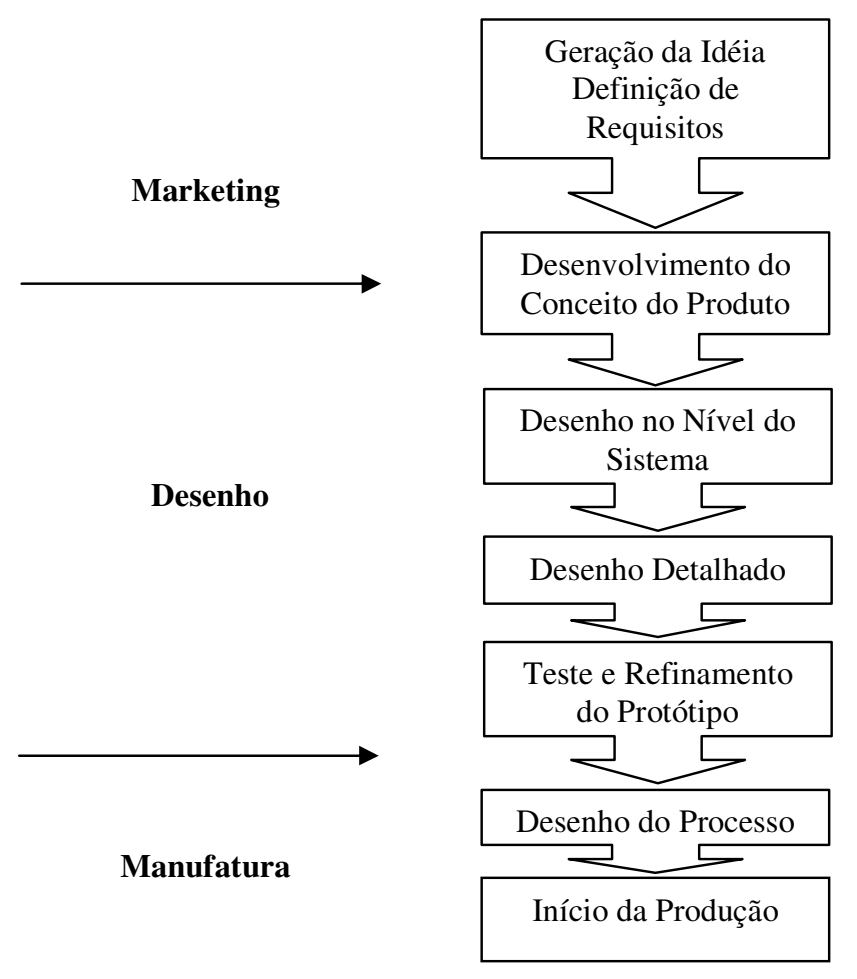

Figura 02. Seqüência do processo de desenvolvimento de novos produtos.

Fonte: Bamber et al (2002, p. 211) adaptado de Ulrich e Eppinger (1995) e Russsel e Taylor (1995).

Nota-se, por meio da visualização deste modelo em Bamber (2002), na Figura 02, que o processo de desenvolvimento de novos produtos envolve, de fato, diversas áreas da organização, cujas destacadas no esquema são marketing, desenho e manufatura. A figura não deixa clara, porém, a necessidade de interação entre as áreas e apresenta sua interferência no desenvolvimento de novos produtos como algo que ocorre em certo período e depois é passado para outra função. Neste sentido, associando os conceitos do modelo Stage Gate ${ }^{\mathrm{TM}}$, de Cooper (1995), e o encontrado em Bamber (2002), entende-se que os projetos de desenvolvimento de novos produtos são formados por etapas integradas, cuja participação de diversas funções da empresa é requerida para o sucesso da inovação.

Uma característica em comum entre os modelos de inovação apresentados neste tópico é que, a partir da segunda geração, todos eles destacam o marketing, de alguma forma, seja levando em consideração os desejos e necessidades do mercado, ou enfatizando a importância da função de marketing integrada às demais áreas da organização. Nesse sentido, a inclusão do 
marketing como fator estratégico nas organizações surgiu como aliada ao processo de inovação e pode manter sua posição de relevância ainda por muito tempo.

Neste sentido, cabe às organizações desenvolver estratégias que possam associar a valia das informações geradas pelo marketing ao desenvolvimento de novos produtos adequados aos desejos e necessidades dos consumidores, os quais podem se tornar mais competitivos, em relação aos produtos e serviços dos demais concorrentes do negócio. Uma das estratégias adotadas pelas organizações que seguem esta linha é a orientação para mercado. Mais detalhes sobre esta estratégia e sua aplicação para o sucesso das inovações poderão ser conhecidos no item seguinte desta fundamentação teórica.

\subsection{Orientação para mercado}

Diante do exposto no tópico anterior, a orientação para mercado surge como alternativa para as empresas que desejam se voltar para as necessidades do mercado e transformá-las em insumo para o aumento a capacidade competitiva das organizações. Em reforço a esta afirmação, Kara, Spillan, e Deshields Jr. (2005) afirmam que uma orientação para o mercado concede à empresa um melhor entendimento de seus clientes, concorrentes e ambiente, o que, conseqüentemente, leva a um desempenho superior. Desempenho este que pode ser representado, entre outros fatores, pela produção de inovações.

Neste sentido, como referência para esta pesquisa, foram encontrados diversos estudos sobre orientação para mercado e sua relação com inovação/capacidade inovativa (ATHUAENEGIMA, 1995; ATHUANE-GIMA, 1996; VASQUEZ, SANTOS E ÁLVARES, 2001; VERHEES, 2005; TAJEDDINI, TRUEMAN E LARSEN, 2006), orientação tecnológica (CURI, 2007), estratégia do negócio (RUEKERT, 1992), e indicadores de performance do negócio (SLATER E NARVER, 1994; NARVER E SLATER, 1990; KOHLI E JAWORSKI, 1990; JAWORSKI E KOHLI, 1993; PERIN E SAMPAIO, 2001; MÜLLER NETO, 2005; TAJEDDINI, TRUEMAN E LARSEN, 2006; JAIN E BHATIA, 2007). Cada um destes autores, bem como as principais conclusões dos seus trabalhos, será mencionado nos próximos parágrafos deste tópico.

Os estudos de Athuaene-Gima (1995; 1996), realizados com 275 empresas manufatureiras e de serviços, pesquisaram a relação de orientação para mercado com a inovação. Os resultados 
da pesquisa reforçaram a relação positiva entre uma boa orientação para mercado e atividades bem sucedidas na organização, em relação ao desenvolvimento de novos produtos. Os autores ressaltam que a orientação para mercado contribui mais para o sucesso das inovações quando estas são de caráter incremental, tanto para os clientes, quanto para a empresa, quando a intensidade da competição de marketing percebida e a hostilidade da indústria são altas e quando se está no estado mais inicial do ciclo de vida do produto. A pesquisa indicou ainda uma relação significativa entre orientação para mercado e algumas características da inovação, como adequação da inovação com o mercado, vantagem do produto e equipe de trabalho inter-funcional, porém, não foi encontrada relação significativa com o grau de novidade do produto, nem com a adequação da inovação à tecnologia.

Em complemento, o estudo de Vasquez, Santos e Álvares (2001) sinalizou para evidências empíricas de que as empresas mais orientadas para mercado tendem a ter uma melhor propensão a inovar e a comercializar um maior número de inovações que seus concorrentes. Seguindo a mesma linha, os estudos mais recentes de Verhees (2005), e Tajeddini, Trueman e Larsen (2006) também encontraram relações positivas entre orientação para mercado e inovação/propensão a inovar.

Quanto aos estudos que buscam relacionar orientação para mercado e performance do negócio, também foram identificados resultados positivos, levando em consideração diversas métricas, como o retorno sobre investimento, participação de mercado, lucratividade, entre outras. Assim, os resultados descritos acima reforçam a importância da exploração da temática de orientação para mercado em novas pesquisas, principalmente, no contexto do desenvolvimento de inovações.

Nesse sentido, para que se compreenda melhor o papel da orientação para mercado na organização e como se dá o seu funcionamento, faz-se necessário buscar e organizar neste estudo algumas definições do tema proposto. Day (1994) afirma que a orientação para mercado representa habilidades superiores de entender e satisfazer os consumidores. Dentro destas condições, em uma das mais importantes referências sobre orientação para mercado da literatura, Shapiro (1988) afirma que para uma companhia ser orientada para mercado, há três condições básicas: 1) Todos os seus membros devem compreender seus mercados-alvo e as influências de compras envolvidas; 2) Decisões táticas e estratégicas devem ser tomadas de 
forma inter-funcional e inter-divisional; 3) Divisões e funções devem tomar decisões bem coordenadas e executá-las com comprometimento.

Diante da bibliografia estudada, duas abordagens distintas chamam atenção como as mais difundidas dentro da teoria estudada: 1) Orientação para mercado como parte da cultura da organização; 2) Orientação para mercado como característica comportamental.

Na vertente cultural, os estudos de Narver e Slater (1990) e Slater e Narver (1994; 1995) são os mais representativos e serviram de inspiração para grande parte das pesquisas na área, que desejaram seguir esta abordagem. Os autores entendem a orientação para mercado como um fenômeno decorrente do ambiente e da cultura organizacional e afirmam que um negócio é orientado para mercado quando é sistematicamente e inteiramente comprometido com a criação contínua de valor superior para o consumidor. Na mesma linha de Narver e Slater, Deshpandé, Farley e Webster (1993) realizaram um estudo com gestores e consumidores de empresas japonesas e, em sua base toérica, associaram o conceito de orientação para mercado à cultura organizacional. Em complemento a esta visão, Athuaene-Gima (1996) define orientação para mercado como um conjunto de atividades que refletem um grau de adoção da filosofia do conceito de marketing pela organização.

O modelo de Narver e Slater (1990), que aborda os aspectos culturais da orientação para mercado e serviu de inspiração para a maioria das pesquisas contemporâneas e posteriores ao seu estudo, baseadas na abordagem cultural, é composto por cinco construtos principais e pode ser observado com mais detalhes na Figura 03. 


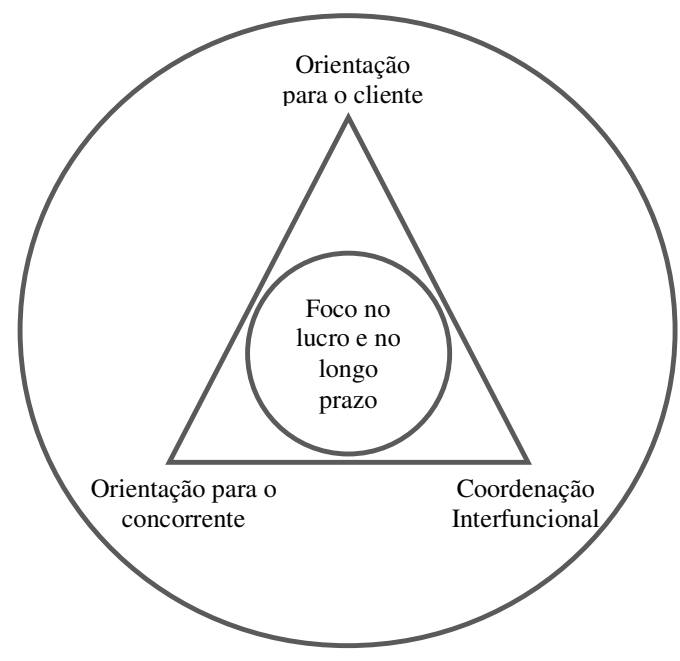

Mercado-alvo

Figura 03. Modelo de orientação para mercado como aspecto da cultura organizacional. Fonte: Adaptado de Narver e Slater (1990, p. 23).

Em seu modelo de orientação para mercado (Figura 03), Narver e Slater (1990) consideram cinco construtos principais: 1) Orientação para o cliente; 2) Orientação para o concorrente e; 3) Coordenação inter-funcional. Estes três pontos convergem para o: 4) Foco no lucro e 5) Longo prazo. Todas estas ações são desenvolvidas tendo como base as informações advindas do mercado alvo da organização.

Segundo Narver e Slater (1990), a orientação para o cliente trata-se da compreensão suficiente dos compradores de um determinado mercado para que seja possível criar valor superior para estes consumidores continuamente. Ainda de acordo com os autores, a orientação para o concorrente significa que um vendedor deve compreender as forças e fraquezas de curto prazo e as capacidades e estratégias de longo prazo, tanto dos atuais quanto dos potenciais concorrentes. Narver e Slater (1990) afirmam ainda que a coordenação inter-funcional, terceiro construto do modelo, refere-se à utilização coordenada dos recursos da organização para aumentar valor superior da empresa para os consumidores. Por fim, o foco da orientação para mercado deve estar no longo prazo e possibilitar lucratividade.

Compondo a vertente comportamental, em trabalhos praticamente contemporâneos aos de Narver e Slater, Kholi e Jaworski (1990) e Kholi; Jaworski e Kumar (1993) definem orientação para mercado como a geração em toda a organização de inteligência de mercado, relativa às atuais e futuras necessidades dos clientes, disseminação da inteligência entre os 
departamentos, e a resposta de toda a organização a esta inteligência. Diante desta definição, foi elaborado um modelo de mensuração da orientação para mercado, contendo os seguintes construtos:

- Geração de inteligência - refere-se à coleta e análise tanto das necessidades/preferências dos consumidores, quanto das forças (ex.: ambientes macro e de tarefas) que influenciam o desenvolvimento e refinamento destas necessidades;

- Disseminação de inteligência - consiste no processo e medida de troca de informação de mercado em uma dada organização. Pelo fato de o foco da disseminação da informação é a unidade estratégica de negócio (UEN) como um todo, as atenções devem ser balanceadas tanto entre as transmissões horizontais (ex.: interdepartamentais), quanto as transmissões verticais de informações do ambiente de mercado.

- Reação à inteligência - diz respeito à ação tomada em resposta à inteligência que é gerada e disseminada.

A partir de uma vasta revisão de literatura, os autores criaram uma escala, chamada por eles de MARKOR, que após diversos testes, foi confirmada com 32 itens, divididos entre os três construtos apresentados. Em um trabalho posterior, Kholi e Jaworski e Kumar (1993), validaram esta escala, por meio de um esforço investigativo mais avançado, o que deu ainda mais credibilidade ao trabalho e faz com que este instrumento seja grande referência para trabalhos, junto com Narver e Slater (1990).

Dada sua popularidade e aplicabilidade em diversos contextos organizacionais, a escala de Kholi e Jaworski foi utilizada e validada novamente, em dois estudos mais recentes. Matsuno, Mentzer e Rentz (2000) promoveram um refinamento da escala, o que resultou em uma diminuição de 32 para 20 itens, deixando-a mais condensada e viabilizando sua aplicação. No Brasil, a versão refinada de Matsuno, Mentzer e Rentz (2000) foi utilizada por Müller Neto (2005) em uma pesquisa voltada à compreensão da relação entre orientação para o mercado, inovação e desempenho da organização. Esta versão da escala foi traduzida para o português e adaptada por meio de entrevistas com executivos e pré-testes, para que adquirisse características próprias ao entendimento dos brasileiros. 
Com a apreciação das definições de orientação para mercado, nota-se que em estudos importantes (NARVER E SLATER, 1990; SHAPIRO, 1988; BIEMANS E HARMSEN, 1995), a interface entre as funções e os diferentes agentes da organização é considerada fator relevante para uma organização orientada para mercado. No tópico seguinte, serão trazidos estudos sobre interface inter-funcional e o seu papel no desenvolvimento de novos produtos, para que se entenda como deve ocorrer esta interação e quais as suas implicações para a organização.

\subsection{Interface inter-funcional}

Em diversos campos do estudo de administração, há o reconhecimento de que as funções devem estar interligadas para um melhor desempenho geral da organização. Neste tópico, será abordada a importância da interface inter-funcional para o sucesso das organizações, com foco no desenvolvimento de novos produtos.

Sendo assim, para que se compreenda com clareza do que se trata a interface inter-funcional, define-se função como "a agregação de atividades análogas, interdependentes, que se encadeiam num único campo especializado de trabalho..." (CURY, 2006, p. 192). Em outras palavras, atividades que possuem natureza semelhante e que possuem uma relação de interdependência em sua realização podem ser agregadas em um único campo e trabalho, geralmente, classificado como uma área funcional da organização. Sendo assim, todas as atividades ou tarefas ligadas à produção, por exemplo, seriam centralizadas em um único órgão, que geralmente é o departamento ou a área de produção. Ou seja, segundo Curry (2006, p. 237), em uma empresa com atividades industriais com base em funções, engenharia, produção e marketing, por exemplo, seriam departamentos independentes, cada um com seu conjunto de atividades análogas, porém, que podem lidar com todos os produtos da empresa. Desta forma, entende-se que, em muitos momentos, estas áreas podem interagir para cumprimento de um objetivo comum.

A partir deste conceito, entende-se, portanto, que as funções compõem os departamentos da empresa e desenvolvem atividades de acordo com suas especialidades: marketing, engenharia, recursos humanos, produção, entre outras. A intenção aqui é compreender como se dá a interação entre estas funções na organização como um todo, dando destaque para as áreas que mais contribuem para as atividades de desenvolvimento de novos produtos. 
Nessa linha, especificamente no contexto do desenvolvimento de inovações, Moenaert e Souder (1990a; 1990b) ressaltam que pelo fato de a inovação tecnológica ser uma seqüência de atividades informação-processamento ela requer a contribuição (inputs) de vários membros, de diferentes funções, desempenhando diversos papéis. Em complemento a esta afirmação, Song e Parry (1997) concluíram em sua pesquisa sobre o sucesso de novos produtos em empresas japonesas que a integração cross-funcional e a vantagem competitiva do produto são os fatores chave de sucesso das inovações. Estudos com opiniões semelhantes, em relação à importância da coordenação inter-funcional para o desenvolvimento de inovações, foram encontrados em Freeman (1994), Rothwell (1994), Littler (1994), Fredericks (2005) e Onoyama (2006). Adotando uma linha semelhante, Griffin e Hauser (1990); Müller Neto (1998) e Moenaert et al (2000) destacam a importância da integração inter-funcional para o sucesso de desenvolvimento de novos produtos.

Ainda no tocante à participação das funções da organização de forma integrada para o desenvolvimento de novos produtos, Vale e Avela (2003) destacam que as funções representadas em uma equipe inter-funcional variam de acordo com cada organização, porém, geralmente incluem-se as funções ligadas ao desenho, engenharia, produção e marketing do produto pelo qual elas são responsáveis. A pesquisa destes autores destaca ainda que empresas que utilizam equipes inter-funcionais no desenvolvimento de novos produtos, geralmente, obtêm uma melhor desempenho em seus projetos e, geralmente, um melhor processo de desenvolvimento de novos produtos. Todavia, os autores alertam que apenas o uso de equipes multidisciplinares não garante o sucesso do projeto por si só, este elemento é apenas um dos fatores contribuintes, sendo assim, visto que inúmeras outras variáveis influenciam nestes resultados.

Neste sentido, o modelo apresentado por Purdon (1996) ajuda a entender como se daria a integração entre as principais funções envolvidas no desenvolvimento de novos produtos. $\mathrm{O}$ autor traz o conceito de campo de trabalho que, segundo ele, é a arena de atividade e geração contínua do conhecimento, na qual um papel organizacional é inicialmente estabelecido, o domínio pode ser desenvolvido e a criatividade emerge. Sendo assim, entende-se que o campo de trabalho se forma a partir da interação das funções organizacionais e esta interação contribui para o processo de desenvolvimento de inovações. 
A Figura 04 mostra a interdependência entre as funções da organização para o desenvolvimento da inovação.

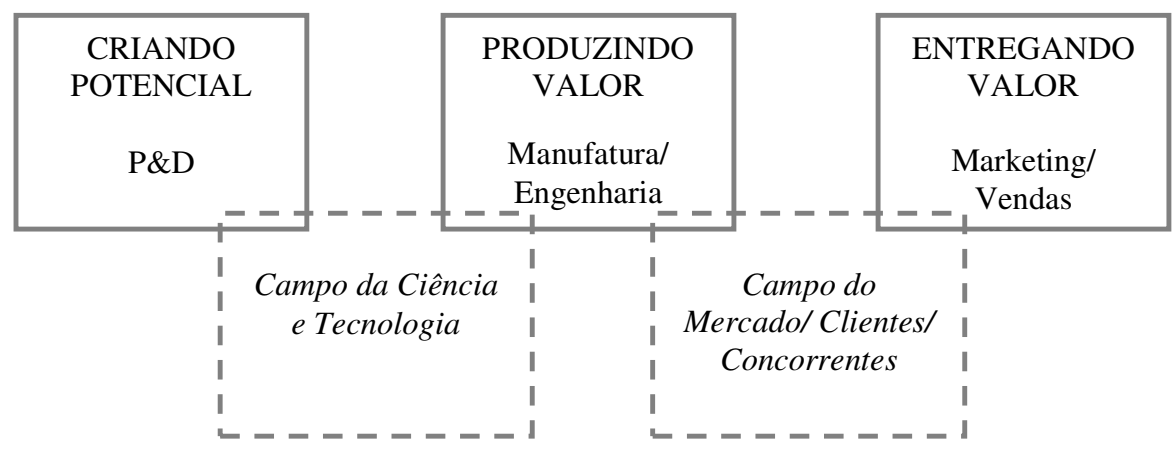

Figura 04. Interação entre as funções da organização na produção de inovação. Fonte: Adaptado de Purdon (1996, p. 49).

Observa-se na Figura 04 a interdependência existente entre as áreas funcionais que mais contribuem para a concepção e o desenvolvimento de inovações. Pelo modelo, pode-se perceber que a ligação entre $P \& D$ e Engenharia forma o campo de Ciência e Tecnologia, enquanto a ligação entre engenharia e Marketing/Vendas, forma o campo de Mercado, Clientes e Concorrentes. Sendo assim, caso haja falha em um dos campos supracitados, a função de desenvolvimento de novos produtos estará prejudicada, devido à quebra de sinergia entre as funções da organização.

Diante do exposto e considerando as peculiaridades de especialização em cada área, nota-se que a tentativa de estabelecer um relacionamento inter-funcional, pode resultar na geração de conflitos na organização. Esta crença é reforçada pela afirmativa de (Buss, 2002, p. 19), segundo a qual "o conflito interdepartamental é o grande 'efeito colateral' da interação interfuncional. Os fluxos de transação, ao mesmo tempo em que aproximam e integram as funções, geram conflitos e barreiras que, por sua vez, dificultam o bom andamento dos fluxos". Acredita-se, portanto, que os fenômenos negativos surgidos a partir da tentativa de integrar funções podem interferir na produção inovadora da organização.

Frente a essa problemática, Griffing e Hauser (1995) apresentaram alguns mecanismos que podem ser mobilizados a favor de uma interface menos conflituosa entre P\&D e marketing e que podem ser, de certa forma, estendidos a qualquer relação inter-funcional. São eles: 
- Realocação e desenho de facilidades físicas;

- Movimentação de pessoal;

- Sistemas sociais informais;

- Estrutura organizacional;

- Incentivos e recompensas;

- Processos de gerenciamento integrativo formais.

A partir da administração adequada destes recursos, a organização poderá reduzir o impacto dos conflitos causados pela interação entre as áreas funcionais. Estas soluções propostas por Griffin e Hauser (1995) se aplicam não só a marketing, como às relações inter-funcionais como um todo.

Entre os estudos sobre interface inter-funcional, boa parte dos artigos e teses encontrados enfatizam a relação entre pesquisa e desenvolvimento (P\&D) e marketing (GUPTA, 1984; MOENAERT E SOUDER, 1990a; MOENAERT E SOUDER, 1990b; MOENAERT ET AL, 1994; GRIFFIN E HAUSER, 1995; MOENAERT ET AL, 1995; MALTZ, SOUDER E KUMAR, 2001; LEENDERS E WIERENGA, 2002; SONG E THIEME, 2006; GARCÍA, SANZO E TRESPALACIOS, 2008).

Em suas pesquisas, Moenaert e Souder (1990a) e Moenaert et al (1994) afirmam que o sucesso das inovações tecnológicas requer contribuições tanto técnicas quanto de mercado e, com isso, enfatizam a importância da relação entre P\&D e marketing. Em complemento, Leenders e Wierenga (2002) ressaltam, entre as interações necessárias dentro da organização, a importância da interação P\&D-Marketing para o sucesso do negócio, especialmente, em empresa cujo desenvolvimento de inovações tecnológicas é o foco principal.

Gupta (1984) foi um dos pioneiros nas pesquisas envolvendo a interface P\&D-Marketing. Os resultados de sua pesquisa influenciaram as escalas mais relevantes que se tem até hoje para mensurar a interface P\&D-marketing em administração. Seu modelo de pesquisa pode ser observado na Figura 05. 


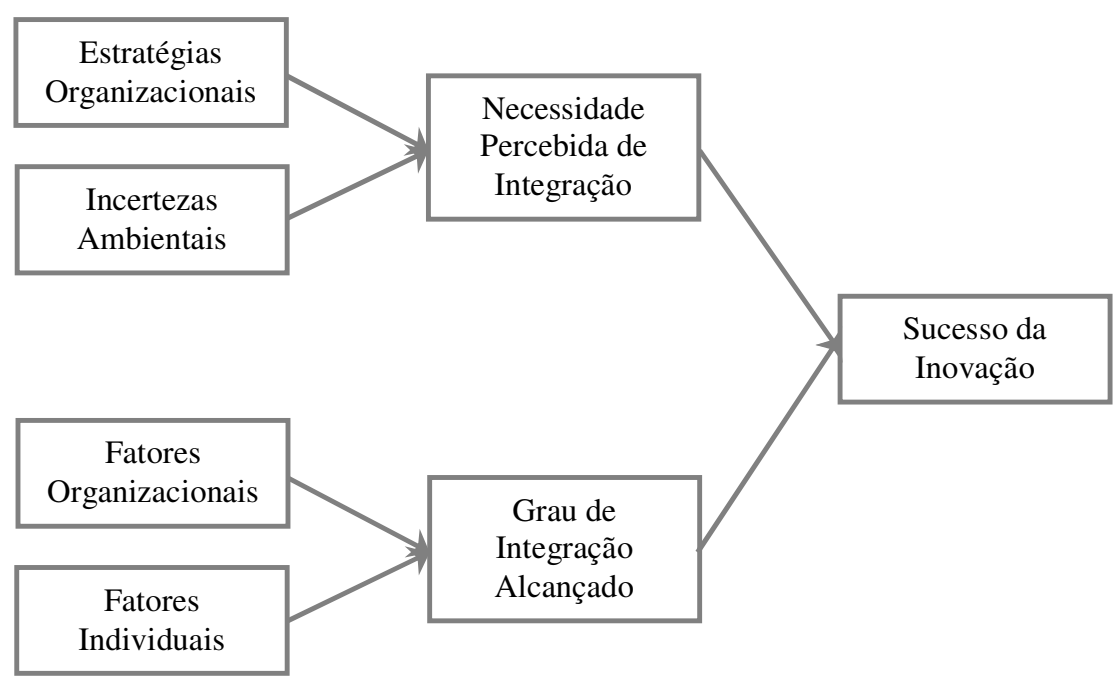

Figura 05. Modelo de Integração P\&D-Marketing de Gupta (1984).

Fonte: Adaptado de Gupta (1984).

Como pode ser observado na Figura 05, a integração P\&D e marketing foi avaliada no trabalho de Gupta sob duas perspectivas: necessidade percebida de integração e grau de integração alcançado. Enquanto o primeiro construto é determinado pelas estratégias organizacionais e pelas incertezas ambientais, o segundo, referente ao grau real de integração P\&D-marketing, é determinado pela análise de fatores organizacionais e individuais. Segundo Gupta (1984), estes fatores levariam a organização ao sucesso de suas inovações.

Um dos resultados encontrados por Gupta (1984) em sua pesquisa foram as áreas onde a integração P\&D-markeitng foram consideradas mais necessárias, a saber:

- O papel do marketing em prover informações para $\mathrm{P} \& \mathrm{D}$, sobre as necessidades dos clientes;

- O papel do marketing em prover feedback periódico para P\&D a respeito do desempenho dos produtos;

- O papel do marketing com P\&D em estabelecer novas metas e prioridades de produtos;

- O papel de P\&D com marketing em desenvolver novos produtos, de acordo com as necessidades do mercado; 
- A necessidade de marketing fornecer a P\&D informações sobre as estratégias dos concorrentes.

Gupta (1994) afirma que o montante de comunicação entre P\&D e marketing requerido depende do grau de incerteza ambiental percebida e da estratégia de inovação da organização. $\mathrm{O}$ estudo mostrou que, quanto mais arriscado for o desenvolvimento do produto e maior for a incerteza ambiental percebida, maior será também a necessidade de integração entre P\&D e marketing.

O modelo de Song e Thieme (2006) para verificação da interface P\&D-marketing carrega fortes características do modelo de Gupta (1984), mesmo tendo surgido vinte e dois anos depois, e sofre ainda influência de alguns trabalhos anteriores, como os de Ruekert e Walker Jr. (1987), Barker et al (1988), Song e Perry (1993). Song e Thieme (2006). Este modelo leva em consideração as variáveis: incerteza ambiental percebida, harmonia, formalização, centralização, participação na tomada de decisão, envolvimento marketing-P\&D, informação advinda de marketing, envolvimento P\&D-marketing como base para o seu modelo. O estudo de Song e Thieme (2006) validou o novo modelo e se tornou também uma ferramenta de avaliação da interface P\&D-marketing.

Entre as variáveis do modelo de Song e Thieme (2006) cabe, neste estudo, destacar a importância do fluxo de informações para o sucesso do projeto de inovação como elemento fundamental no modelo. Os autores entendem que uma formalização demasiada na organização pode dificultar e até impedir o fluxo de informações entre os departamentos. Nesse sentido, destaca-se a importância de proporcionar um ambiente favorável à interface inter-funcional nas organizações, para que a informação possa fluir de forma adequada e proporcionar subsídios para o bom andamento dos projetos de novos produtos.

Ainda no escopo dos estudos da relação entre $P \& D$ e marketing no campo das inovações, encontrou-se o estudo de García, Sanzo e Trespalacios (2008). Este estudo é recente e muito bem fundamentado e buscou investigar a interface entre P\&D e marketing durante um processo de desenvolvimento de novos produtos. Um aspecto interessante deste estudo é a composição do construto de interface inter-funcional. Segundo os autores a interface interfuncional é composta pela integração entre as funções e influenciada pela confiança existente entre os pares nestas duas áreas. 
Os resultados do estudo de García, Sanzo e Trespalacios (2008) apontaram para uma relação positiva entre confiança e integração entre as funções o que, em outras palavras, significa que quanto mais confiantes as pessoas estão, mais facilmente se dá a relação entre as funções da organização; constatação que aponta para a necessidade de as organizações promoverem a confiança em seus ambientes de trabalho, como meio de prover um melhor desempenho de seus projetos. Outro ponto importante do estudo é o foco voltado também para os resultados de mercado do produto desenvolvido e não apenas a análise do desempenho interno do projeto, o que traz à baila a preocupação com a influência do mercado no processo de desenvolvimento de novos produtos.

Ainda no campo da interface inter-funcional, encontrou-se o estudo de Buss (2002), o qual trata, por meio de um estudo de caso, da cooperação inter-funcional no desenvolvimento de novos produtos entre marketing e engenharia. A pesquisa foi desenvolvida com duas empresas localizadas no Rio Grande do Sul, e teve como resultado principal a identificação de onze fatores que afetam a interface inter-funcional no contexto específico pesquisado. Os fatores foram agrupados em três níveis, a saber:

- Nível 1 - Organização: 1) Envolvimento da alta administração; 2) Processo como prioridade da empresa; 3) Existência de uma estrutura global do processo;

- Nível 2 - Indivíduo: 1) Compreensão das atividades das demais áreas; 2) Objetivos e prioridades comuns; 3) Igualdade de poder entre as funções;

- Nível 3 - Equipe: 1) Responsabilidade e autonomia de decisões e ações; 2) Reuniões e contatos freqüentes; 3) Participação das reuniões de desenvolvimento; 4) Desenvolvimento de atividades em outras áreas; 5) Conhecimentos sobre o processo de desenvolvimento.

$\mathrm{Na}$ exploração da bibliografia estudada, foram também encontradas pesquisas relativas, especificamente, à interface marketing-manufatura (SHAPIRO, 1977; CALANTONE, DRÖGE E VICKERY, 2002).

Em um estudo pioneiro, Shapiro (1977) ressaltou a importância da interface marketing e manufatura e questionou a possibilidade de estas funções coexistirem. Segundo o autor, há 
uma grande probabilidade de haver conflitos na gestão da interface marketing-manufatura nas seguintes questões:

- Capacidade de planejamento e projeção de vendas a longo prazo;

- Agendamento da produção e projeção das vendas a curto prazo;

- Entrega e distribuição física;

- Garantia de qualidade;

- Extensão da linha de produtos;

- Controle de custos;

- Introdução de novos produtos;

- Serviços associados.

Entende-se, portanto, que estes conflitos podem ocorrer, principalmente, porque marketing é uma função que mais se volta para fora do que para dentro da organização, enquanto manufatura está mais preocupada com os processos internos e não possui grande preocupação com o mercado externo. Diante desse paradoxo, os conflitos passam a ser parte das negociações diárias, quando estas áreas precisam partilhar tarefas na organização.

Calantone, Dröge e Vickery (2002), ressaltam a importância de estudar as interfaces interfuncionais no desenvolvimento de novos produtos e também focam a natureza das relações marketing-manufatura. Os autores utilizaram quatro construtos para compor o modelo da pesquisa: 1) O conhecimento de marketing sobre a manufatura e; 2) Avaliação da manufatura sobre a qualidade e utilidade da comunicação de marketing com a manufatura; 3) Integração marketing-manufatura; 4) Qualidade da relação entre marketing e manufatura. As variáveis moderadoras do modelo foram: 1) Incerteza do ambiente; e 2) Taxa de desenvolvimento de novos produtos. 
Como contribuição geral, Calantone, Dröge e Vickery (2002) concluem que quanto mais marketing conhece e quanto mais está apto a se comunicar com a manufatura, melhores serão as relações funcionais, maior será a utilidade da relação e menor o potencial de conflito.

$\mathrm{Na}$ interface de marketing com outras funções da organização foram encontrados trabalhos de Ruekert e Walker (1987); Maltz e Kohli (1996); Maltz e Kohli (2000). Ruekert e Walker (1987) destacam que cada atividade de uma função afeta as atividades das outras que estão envolvidas no processo. Isto ocorre por meio dos fluxos de comunicação, de recursos, de trabalho e de assistência e gera uma rede de interdependências entre as áreas. Como centro do seu modelo, os autores trazem os flxuos de comunicação entre marketing e as demais funções da organização, o que reforça mais uma vez que este é o cerne das questões de coordenação inter-funcional.

Na operacionalização da pesquisa, Ruekert e Walker (1987) aplicaram questionários, em uma empresa descrita pelos autores como a maior manufatureira do meio-oeste, com gestores de marketing/vendas e pediram aos entrevistados que respondessem sobre sua relação com as áreas de $\mathrm{P} \& \mathrm{D}$, produção e contabilidade. Posteriormente, foi solicitado pelos pesquisadores que pessoas inseridas nestas três áreas também respondessem o questionário, falando de sua relação com marketing.

Em uma linha um pouco diferente, Maltz e Kohli (1996) estudaram a disseminação da inteligência de mercado por entre as funções da organização. Apesar de o escopo conceitual ser diferenciado, a abordagem metodológica foi semelhante, excluído-se o fato de que os gestores de marketing não foram entrevistados, mas sim apenas os gerentes ligados a marketing mais diretamente, ou seja, os que recebiam desta função algum tipo de informação. Nesta pesquisa, não se determinou a priori, quais seriam as funções entrevistadas, mas em comportamento semelhante ao que foi feito por Ruekert e Walker, a amostra acabou sendo composta, em sua maioria, por gerentes de P\&D, Produção e Finanças.

Já em 2000, Maltz e Kohli estudaram a redução dos conflitos entre marketing e as demais áreas da organização. Semelhantemente ao estudo de 1996, o foco foi na interface entre marketing-P\&D, marketing-manufatura e marketing-finanças, simultaneamente. 
Quanto à coordenação inter-funcional de $\mathrm{P} \& \mathrm{D}$ com as demais áreas da organização, foi encontrado o estudo de Kruglianskas (1981). O modelo deste autor relaciona o centro de P\&D com as áreas da alta administração, produção, administração financeira, engenharia, controle de qualidade e markeitng/vendas. Em seu panorama conceitual, o autor destaca a importância das interações para a eficácia do centro de $\mathrm{P} \& \mathrm{D}$ e traz uma interessante definição para interação, a qual considera como "fluxos entre as unidades organizacionais e o centro de P\&D, constituídos por elementos tangíveis e intangíveis” (KRUGLIANSKAS, 1981, p. 74).

Para a operacionalização de sua pesquisa, aplicada com executivos de centros de P\&D em empresas brasileiras, o autor selecionou nove elementos para delimitação do referido fluxo entre as unidades organizacionais, são eles: 1) Contribuições através de idéias e sugestões para projetos; 2) Benefícios oriundos das atividades do centro de P\&D; 3) Dificuldades nas comunicações; 4) Influência no processo de seleção de projetos; 5) Importância da interação para a aprovação do orçamento; 6) Dependência na obtenção de informações para projetos; 7) Freqüência nos contatos entre executivos; 8) Envolvimento requerido para o sucesso de projetos; 9) Participação nos projetos. A relação entre o centro de $\mathrm{P} \& \mathrm{D}$ e as demais áreas da organização, no tocante a estes nove itens formaram o conjunto de variáveis independentes, enquanto a variável dependente adotada para o estudo foi a eficiência do centro de P\&D.

Como reforço para a importância do estudo da interface entre $P \& D$ e as demais áreas da organização, cabe destacar a citação e Roussel, Saad e Bohlin (1991, p. 17), segundo os quais “administrar estrategicamente P\&D significa, antes e acima de tudo, integrá-la na tecnologia e na estratégia de negócio, depois administrar o processo de $\mathrm{P} \& \mathrm{D}$, incluindo amplamente as ligações com que as outras peças críticas da estrutura corporativa são administradas”.

Diante do exposto, chega-se a um ponto ainda não tocado neste projeto: a importância da gestão dos mecanismos de integração em projetos, especialmente, no desenvolvimento de novos produtos. de inovação estrutura da organização para a integração inter-funcional. Nesta linha, Moenaert e Souder (1990a) afirmam que o valor da informação extra-funcional (advinda de outra função) está associado ao canal, à mensagem, à fonte e ao receptor, como na maioria dos processos de comunicação. Os autores afirmam ainda que este valor pode variar dentro do processo de inovação, sendo afetado pelas características organizacionais, como formalização, centralização, clima e a estrutura do projeto. Tomando esta abordagem como ponto de partida, passa a fazer sentido a compreensão de como uma gestão experiente 
dos mecanismos de integração de projetos, no contexto do desenvolvimento de novos produtos, pode contribuir para que a informação advinda de mercado seja bem administrada no contexto inter-funcional da organização.

\subsection{O papel do escritório de projetos na relação entre orientação para mercado e interface inter-funcional.}

Diante do aumento da complexidade das organizações e da crescente necessidade de interface entre as funções, fato já abordado nos capítulos anteriores, cada vez mais, as empresas têm lançado mão de mecanismos de integração, especialmente, no âmbito do gerenciamento de projetos. Nesse sentido, a estrutura de projetos adotada pela organização é um dos fatores que influenciam na integração das atividades, como pode ser visto no modelo proposto por Rabechini Jr. E Carvalho (2008).

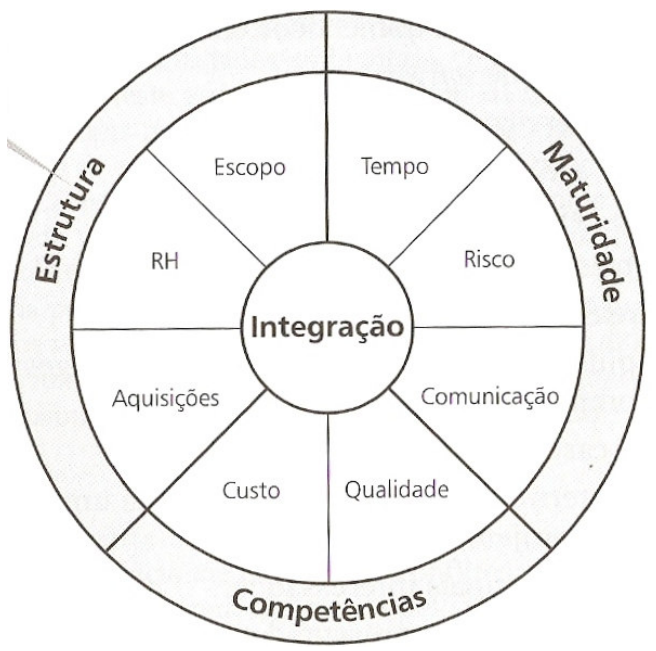

Figura 06. Modelo de construção de competências para gerenciamento de projetos. Fonte: Rabechini Jr. E Carvalho (2008, p.24).

A Figura 06 enfatiza a integração como elemento central do gerenciamento de projetos, o qual é composto pelo gerenciamento do escopo, do prazo/tempo, do custo, do risco, da qualidade, da comunicação e das aquisições. Permeando cada uma destas etapas, estão os conceitos de estruturas, de maturidade e de competências para projetos. Para fins da fundamentação teórica desta dissertação, serão tratados os tipos de estruturas de projetos e, posteriormente, o escritório de projetos como mecanismo de integração. A estrutura de uma organização pode 
explicar sobre como os demais processos se dão no ambiente empresarial. Vasconcellos e Hemsley (2003, p. 3) definem estruturas organizacionais como:

[...] o resultado de um processo através do qual a autoridade é distribuída, as atividades desde os níveis mais baixos até a Alta Administração são especificados e um sistema de comunicação é delineado permitindo que as pessoas realizem as atividades e exerçam a autoridade que lhes compete para o atingimento dos objetivos organizacionais.

Complementar mente, Cury (2006) define estrutura como "a disposição das diversas unidades que compõem a empresa - departamentos, divisões, seções, etc. - e as relações entre superiores e subordinados.

Diante destas definições, assume-se que a estrutura é importante, principalmente, para entender a forma como se dá a questão das relações de autoridade e o fluxo da informação entre as funções e pessoas da organização.

Especialmente, no tocante ao desenvolvimento de inovações, a integração entre as funções é um fator importante para o sucesso dos projetos, todavia, integrar é difícil na maioria das circunstâncias, principalmente, em se tratando de empresas grandes e maduras, com grupos funcionais fortes, grande especialização, grande número de pessoas e pressões múltiplas e contínuas de operação (CLARK E WHEELWRIGHT, 2001). Os autores afirmam ainda que os conflitos ocorrem porque as funções são organizadas segundo critérios muito próprios. Por exemplo, o marketing organiza-se em famílias de produtos e segmentos de mercado; engenharia em torno das disciplinas funcionais e foco técnico; e manufatura em uma mistura entre estruturas funcionais e produto mercado.

Uma alternativa para minimizar os problemas de interação entre as funções e as pessoas da organização, é a aplicação da estrutura adequada aos projetos. Nesse sentido, Clark e Wheelwright (2001) propõem quatro estruturas básicas de equipes de desenvolvimento de novos projetos: 1) Estrutura de Equipe Funcional; 2) Estrutura de Equipe Leve; 3) Estrutura de Equipe Pesada e 4) Estrutura de Equipe Autônoma. As quatro formas de estruturar equipes de projeto poderão ser observadas com mais detalhe, nas Figuras 07, 09, 10 e 12. Uma abordagem em paralelo é feita por Purdon (1996). Este autor foca, principalmente, a posição de P\&D na organização, dando origem a diferentes estruturas. Deste ponto em diante, será feita uma abordagem comparativa entre as visões destes dois autores. 


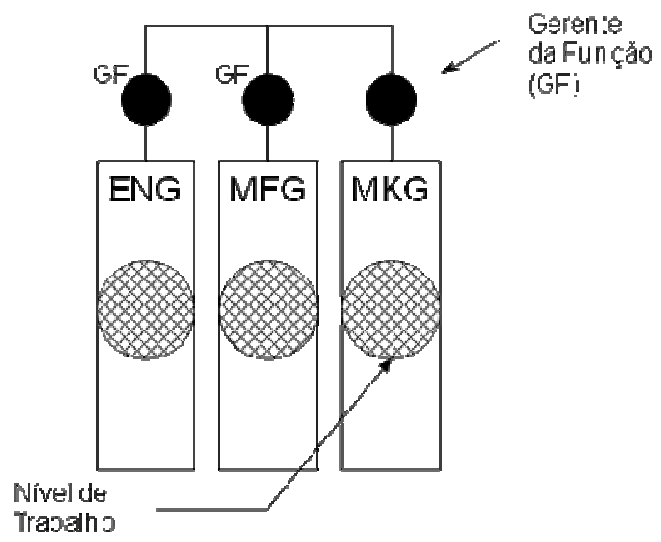

Figura 07. Estrutura de Equipe Funcional.

Fonte: Clark e Wheelwright (2001).

$\mathrm{Na}$ estrutura de equipe funcional, que aparece na Figura 07, as pessoas são agrupadas por disciplinas, cada uma trabalhando sob a direção de um gerente de subfunção especializado e um gerente funcional sênior. Ou seja, esta estrutura possui hierarquia forte, onde os funcionários respondem a um superior bem definido e são agrupados por especialidade (produção, marketing, finanças, entre outras, no nível superior da estrutura.

Segundo Clark e Wheelwright (2001), uma das vantagens desta estrutura é o fato de as mesmas pessoas que controlam os recursos destinados para o projeto, também controlarem a performance das tarefas em sua área funcional. Desta forma, responsabilidade e autoridade, geralmente, andam juntas. Em contrapartida, a coordenação e integração entre as áreas são prejudicadas, visto que as tarefas do projeto são executadas separadamente, neste tipo de estrutura. Outra vantagem neste tipo de estrutura é que as pessoas não podem ser julgadas justamente por resultados sob os quais elas possuem ouço ou nenhum controle. Em contrapartida, mesmo que o indivíduo esteja envolvido diretamente no projeto, não poderá ser responsabilizado por seus resultados.

Uma terceira questão é que o nível e especialização é maior na estrutura funcional, o que pode trazer benefícios na resolução de problemas específicos. Porém, as necessidades mudam de acordo com cada projeto e, por conta disso, a especialização não garante que o indivíduo será útil em grande parte dos momentos.

Estrutura semelhante é apresentada por Purdon (1996), como pode ser visto na Figura 08. 


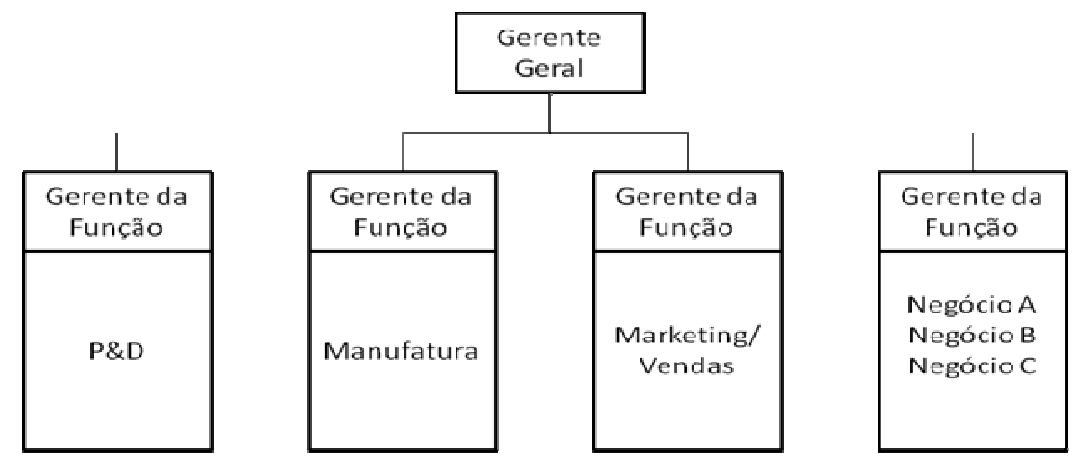

Figura 08. $P \& D$ como uma função individual/isolada. Fonte: Adaptado de Purdon (1996, p. 50).

Segundo o autor, as vantagens da estrutura apresentada na Figura 08 residem no fato de que ela proporciona um foco na atividade de tecnologia, visto que P\&D se encontra isolada. Neste sentido, as publicações científicas são encorajadas e os programas de pesquisa de longo prazo podem ser mais bem desenvolvidos. Por outro lado, a principal desvantagem é que as conexões do negócio tendem a ser mais fracas, o que resulta em um papel pouco representativo do pesquisador, enquanto homem de negócios; são registradas poucas patentes de impacto par ao negócio e não se considera o negócio como um sistema.

Após a apresentação de estruturas mais formais, surge a estrutura de equipes leve, apresentada na Figura 09. Ainda com resquícios da estrutura funcional, esta segunda versão dos autores Clark e Wheelwright (2001) para estruturas em projetos diferencia-se da anterior pelo surgimento da figura de um gerente de projetos e da figura do representante, que é designado a partir de cada função para ficar ligado ao gerente de projetos. Apesar disso, os participantes do projeto ainda se localizam fisicamente em suas áreas funcionais.

Destaca-se, porém, que o gerente de projetos, neste caso, ainda desempenha um papel "leve" em relação ao projeto e às pessoas. Ele não possui autoridade para realocar pessoas e recursos. 


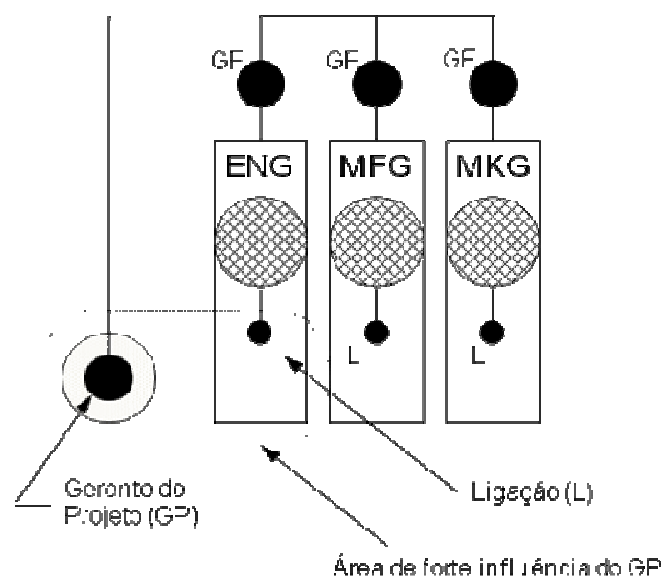

Figura 09. Estrutura de Equipe Leve.

Fonte: Clark e Wheelwright (2001)

As vantagens e desvantagens básicas desta estrutura são muito semelhantes às da estrutura funcional, com o ganho de um pouco mais de coordenação, proporcionado pela ligação de representantes das áreas funcionais com um gerente de projetos, mesmo que sua influência nos recursos decisivos do projeto ainda seja "leve". Neste sentido, o gerente de projetos aparece ainda discretamente, mais com uma função de coordenador do que com função efetiva de gerente., mas já facilita um pouco a coordenação inter-funcional.

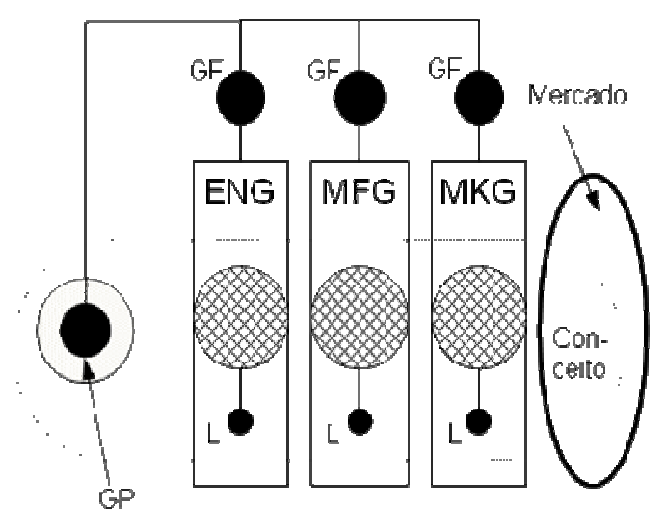

Figura 10. Estrutura de Equipe Pesada.

Fonte: Clark e Wheelwright (2001)

$\mathrm{Na}$ Figura 10, pode ser observada a estrutura de equipes pesada. Segundo Clark e Wheelwright (2001), este tipo de estrutura vai além da leve, apresentada anteriormente, à medida que o gerente de projetos passa a possuir autonomia e responsabilidade sobre o trabalho dos envolvidos no projeto. Enquanto nas estruturas leves (Figura 09) os gerentes de 
projetos são, geralmente, de nível médio ou júnior, na estrutura pesada, os gerentes são seniores, isto proporciona a eles uma maior autonomia natural sobre os membros da equipe.

Uma vantagem desta estrutura é que as pessoas que fazem parte do núcleo do projeto, deslocadas de sua função original, são co-alocadas junto ao gerente do projeto. Este deslocamento da função proporciona uma maior interação entre as pessoas e facilita a comunicação no desenvolvimento das atividades.

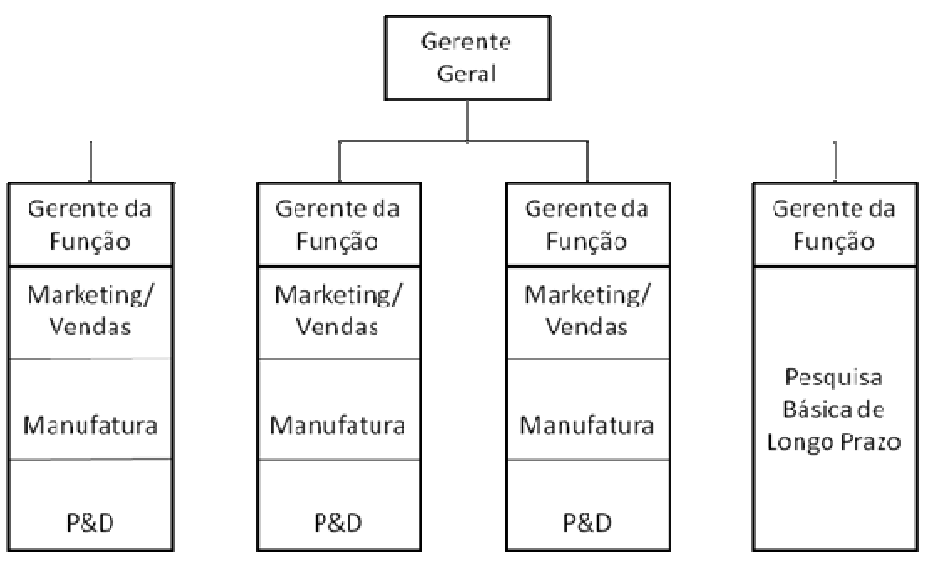

Figura 11. P\&D dentro de uma unidade de negócios. Fonte: Purdon (1996, p. 50).

Paralelamente, a versão intermediária de Purdon (1996) é a estrutura onde P\&D está inserida em uma unidade de negócios (Figura 11). Neste modelo, os programas de P\&D já passam a ser relevantes para o negócio como um todo. Além disso, a carreira do responsável por P\&D abre-se a novas possibilidades, por conta do contato com as demais áreas da organização.

Em contrapartida, a necessidade de obter resultados em um tempo mais reduzido faz com que os programas de desenvolvimento de inovações sejam curtos, o que pode prejudicar o desenvolvimento de pesquisas de longo prazo. Como conseqüência, há uma interrupção no desenvolvimento de massa crítica científica dentro da organização e gera uma dependência maior de consultores externos. Ademais, a falta de contato com a comunidade cientifica, aliada ao pouco tempo disponível para o desenvolvimento de tecnologias, pode tornar o conhecimento tecnológico básico de ciência e tecnologia obsoleto. 


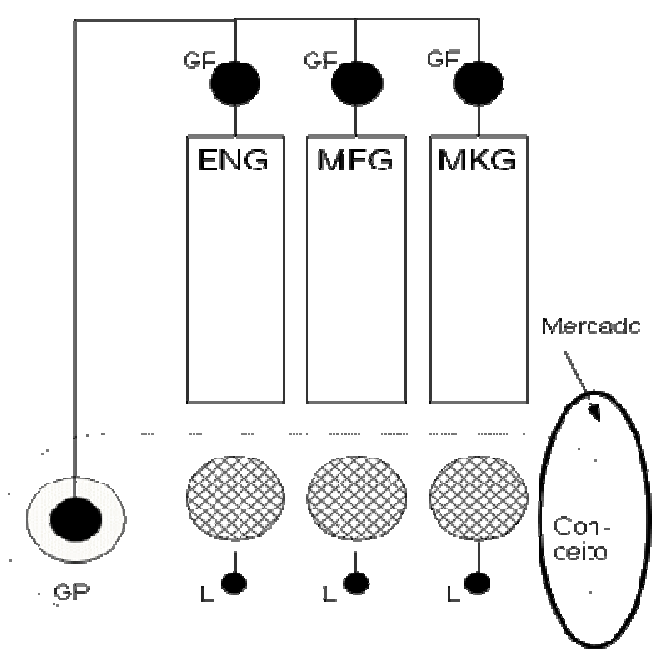

Figura 12. Estrutura de equipe Autônoma.

Fonte: Clark e Wheelwright (2001).

A estrutura organizacional autônoma, também conhecida como estrutura por projetos (Figura 12), é a que proporciona a maior dedicação dos envolvidos ao projeto, visto que, segundo Clark e Wheelwright (2001), neste caso, os membros da equipe são deslocados de sua área funcional e colocados juntos, para atuar exclusivamente pelo projeto. Neste caso, o grupo do projeto reporta diretamente ao gerente, o qual possui autoridade total sobre as decisões do projeto.

Segundo Clark e Wheelwright (2001), a vantagem fundamental deste tipo de estrutura é o foco, dado que a equipe está inteiramente voltada para a execução do projeto e pode, com isso, desenvolver produtos e processos de forma rápida e com excelência.

Diante do exposto, entende-se que é atingido um alto nível de coordenação inter-funcional, devido à facilidade de contato constante entre as pessoas e a troca de informações em um ambiente com hierarquia e diferenciação de funções mais leve. A diferenciação da equipe de projetos é tamanha que, em muitos casos, formam-se novas unidades de negócios a partir de um único projeto.

Um ponto crítico desta estrutura é a pressão sobre o gerente de projetos e a responsabilidade pelos resultados, que recai toda sobre a equipe de desenvolvimento. 


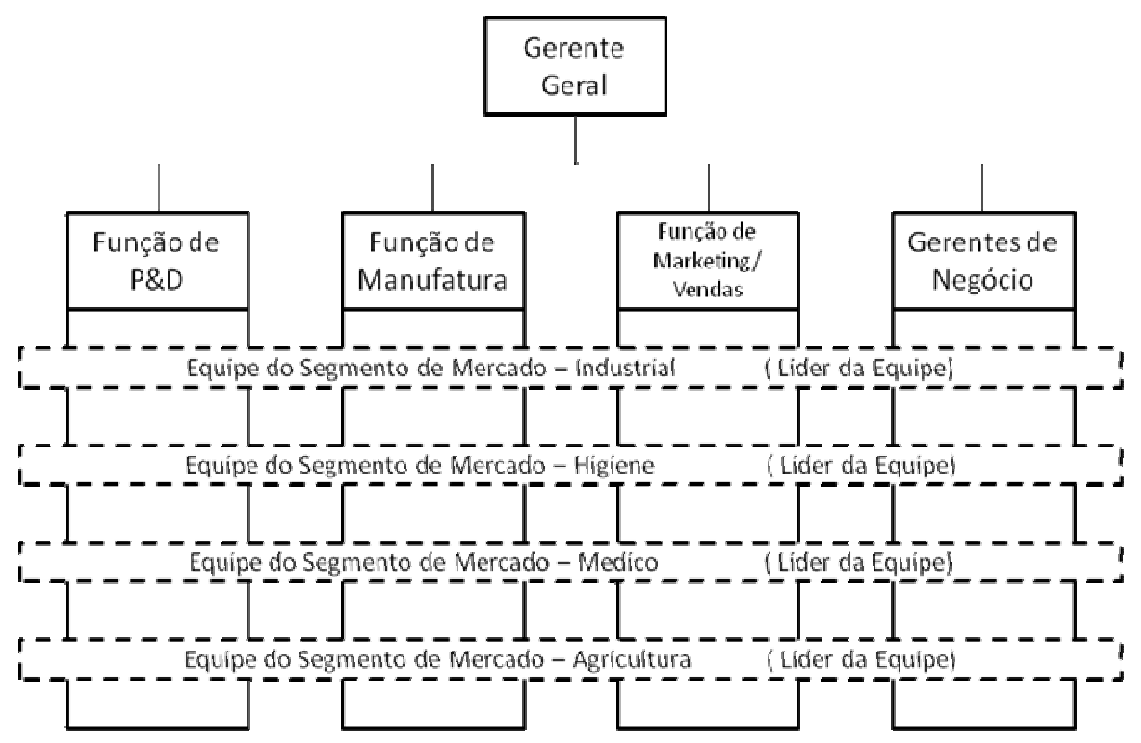

Figura 13. Estrutura Cross-Funcional. Fonte: Purdon (1996, p. 50).

Entre os modelos Purdon (1996), a proposta de uma estrutura organizacional inter-funcional é a que provoca maior integração entre as funções, como pode ser observado na Figura 13, visto que a organização trabalha organizada por segmentos de mercado e precisa compartilhar uma mesma função com os demais segmentos existentes no ambiente organizacional.

Nota-se, portanto que, além de uma maior interação entre as funções, à medida que a estrutura da organização vai se tornando mais projetizada, maiores são a autoridade e a responsabilidade do gerente de projetos e mais a equipe gerencial do projeto pode se dedicar à realização do mesmo. Sendo assim, entende-se que, quanto mais voltada para projetos for a estrutura, maior será a probabilidade de o projeto de desenvolvimento de produto, por exemplo, ter uma equipe de projeto mais completa e integrada, em termo de domínio das diversas funções da organização, e mais tempo dedicada a sua execução.

Dentro do estudo sobre alternativas estruturais de projetos de Rabechini Jr. e Carvalho (2008) apresentam o conceito de Escritório de Gestão de Projetos (EGP) como um núcleo de competências que possibilite criar uma cultura de projetos na organização. Mais adiante, serão trazidos alguns conceitos de escritórios de projetos, na tentativa de compreender o seu papel na relação entre orientação para mercado e interface inter-funcional em projetos de desenvolvimento de novos produtos. 
A origem do EGP advém dos departamentos de projetos existentes no final da década de 1950 e início dos anos 1960 (MARTINS et al, 2005, p. 407). De acordo com Do Valle, Silveira e Silvia e Soares (2008), o Project Management Office (EGP) é um conceito relativamente novo, que se tornou um fenômeno global, atingindo a estrutura de organizações em todo o mundo. Segundo Maximiano e Anselmo (2006) o Escritório de Gerenciamento de Projetos (EGP) seria a unidade organizacional responsável pela correção de problemas relativos a falhas no gerenciamento de projetos. O EGP seria, portanto, "responsável pela divulgação das práticas de gerenciamento de projetos para toda a organização, possibilitando a diminuição dos índices de falhas e garantindo que os projetos mais importantes para a organização sejam tratados de forma prioritária” (MAXIMIANO E ANSELMO, 2006, p. 395).

Em complemento a este conceito, Rodrigues, Rabechini Jr. e Csillag (2006, p. 274) afirmam que o "escritório de projetos, mediante a implementação de uma estrutura formal, auxilia as organizações a melhor gerenciar seus projetos, sejam eles de desenvolvimento de novos produtos/serviços ou de implantação de novos processos, ajudando-as a minimizar os riscos associados, diminuir os conflitos inerentes entre projetos e operações, prover metodologias adequadas". Diante desta afirmação, podemos entender que o conceito de escritório de projetos é abrangente, ou seja, os EGP, a projetos de desenvolvimento de novos produtos, o que torna o estudo adequado para esta dissertação.

Dinsmore (1998) classifica o Escritório de Projetos em quatro modelos diferentes, a saber: Project Support Office, Project Management Center of Excellence, Program Management Office e Chief Project Officer.

O Quadro 02 explica, resumidamente, a função de cada um dos escritórios de projetos citados por Dinsmore (1998), segundo Rabechini Jr. e Carvalho (2008). 


\section{Quadro 02 - Modelos de Escritórios de Projetos}

\begin{tabular}{|c|c|}
\hline Modelo de Escritório de Projetos & Função \\
\hline Project Support Office (PSO) & $\begin{array}{l}\text { Fornecer apoio técnico e administrativo, ferramentas e serviços aos } \\
\text { gerentes de projeto, simultaneamente. } \\
\text { Auxiliar no planejamento, programação e condução de mudanças de } \\
\text { escopo e no gerenciamento de custos do projeto. } \\
\text { A responsabilidade pelo sucesso do projeto não é do PSO, mas sim dos } \\
\text { gerentes de projetos, os quais utilizam seus serviços. }\end{array}$ \\
\hline $\begin{array}{l}\text { Project Management Center of } \\
\text { Excellence (PMCOE) }\end{array}$ & $\begin{array}{l}\text { É o núcleo de experiências em projetos, mas não assume as } \\
\text { responsabilidades sobre os mesmos. } \\
\text { Possui a natureza "missionária" de disseminar a idéia, converter os } \\
\text { incrédulos e transformar os adeptos em profissionais. } \\
\text { É o encarregado das metodologias a serem aplicadas. } \\
\text { Mantém o canal aberto entre os projetos e as comunidades externas ao } \\
\text { gerenciamento de projetos. }\end{array}$ \\
\hline $\begin{array}{lll}\text { Program } & \text { Management } & \text { Office } \\
(\text { PrgMO) } & & \end{array}$ & $\begin{array}{l}\text { Gerencia os gerentes de projetos e é, em última instância, o responsável } \\
\text { pelos resultados dos projetos. } \\
\text { Em grandes organizações, o PrgMO concentra seus esforços nos projetos } \\
\text { prioritários, sendo os projetos menores gerenciados por departamentos, ou } \\
\text { unidades, recebendo apoio do PrgMO, quando necessário. } \\
\text { Por natureza, compõe as funções do PMCOE e, em alguns casos, as do } \\
\text { PSO. }\end{array}$ \\
\hline Chief Project Officer & $\begin{array}{l}\text { Cuidar e alimentar o portfólio de projetos da organização. } \\
\text { Envolver-se nas decisões de negócios que resultem em novos projetos. } \\
\text { Planejamento estratégico de negócios. } \\
\text { Estabelecimento de prioridades e negociação de recursos para projetos. } \\
\text { Supervisão da implementação de projetos estratégicos. } \\
\text { Supervisão do gerenciamento de projetos no nível empresarial. } \\
\text { Desenvolvimento da conscientização e da capacidade de gerenciamento } \\
\text { de projetos através da organização. } \\
\text { Avaliação periódica de projetos. } \\
\text { Decisão pela continuidade e descontinuidade de projetos. } \\
\text { Gerenciamento de stakeholders de alto nível, facilitação e mentoring. }\end{array}$ \\
\hline
\end{tabular}

Fonte: Adaptado de Rabechini Jr. e Carvalho (2008, p. 37).

Considerando os conceitos apresentados sobre Escritórios de Projetos e os modelos apresentados por Rabechini Jr. e Carvalho (2008), entende-se que esta unidade organizacional pode funcionar como um importante mecanismo de integração em projetos de todos as naturezas. Em se tratando de projetos de desenvolvimento de novos produtos, além da integração de ferramentas, processos e informações, o EGP pode auxiliar na integração das diversas áreas organizacionais comumente envolvidas no processo. Neste sentido, além de prover ferramentas-padrão, o EGP cria uma consciência coletiva na organização em relação aos projetos e pode auxiliar na interface inter-funcional, bem como na captação, disseminação e resposta às informações necessárias para os projetos. Assim, parece fazer sentido a influência do escritório de gestão de projetos (EGP) como variável moderadora na relação entre orientação para mercado e interface inter-funcional. 


\subsection{Síntese da revisão bibliográfica}

Para que se compreenda melhor a essência do que foi estudado em cada tópico desta fundamentação teórica e que sejam traçadas as diretrizes do trabalho, segue uma breve revisão do aprendizado.

No tocante à inovação e ao desenvolvimento de novos produtos, observou-se, nos modelos apresentados por Rothwell (1994), foram uma das fontes de inspiração para a elaboração deste estudo. Em especial, os modelos da quarta e quinta geração evidenciam o valor da integração entre as funções da organização e o ambiente externo para o processo inovativo.

Ainda neste contexto, entendeu-se que a inovação pode ser desenvolvida de forma diversificada e pode atingir os níveis de produtos, processos ou organizacional, sendo que a mudança provocada por ela pode ser radical, ou apenas incremental. De posse desta classificação, decidiu-se que, para este estudo, foi utilizado como referência o desenvolvimento de novos produtos, estejam estes representando inovações radicais, ou incrementais para a organização. É válido destacar que, mesmo também podendo ser classificadas como inovações, a ruptura de conceitos ou o incremento em serviços e nos processos organizacionais não serão levados em consideração neste estudo.

Aprendeu-se ainda, no campo da inovação, que o desenvolvimento de novos produtos pode ser considerado um projeto, visto que é composto de atividade e possui começo, meio e fim. Em cada uma destas atividades, diversas funções da organização estão envolvidas e trabalham para a consecução de um objetivo em comum, neste caso, o desenvolvimento de um novo produto. Uma característica comum aos modelos de desenvolvimento de novos produtos é que o destino final das inovações será a comercialização. Sendo assim, é importante que as atividades de desenvolvimento estejam ligadas a uma estratégia mercadológica consistente.

Nesse sentido, estudou-se também para este projeto a estratégia de orientação para mercado, cujas duas vertentes de maior destaque são a cultura, comandada por Narver e Slater (1990) e a comportamental, comandada por Kholi e Jaworski (1990). Ambas as teorias são bastante difundidas e utilizadas em trabalhos sobre orientação para o mercado Para este estudo, entende-se que a abordagem comportamental aplica-se com mais prioridade, visto que se baseia no fluxo de informações advindas do mercado pela organização e sua posterior 
resposta às informações recebidas. Outro fator que motivou a adoção deste como modelo referência para o estudo foi o fato de ele já ter sido aplicado no Brasil, por Müller Neto (2005), em uma pesquisa que relacionava orientação para mercado, inovação e performance do negócio. No capítulo de metodologia da pesquisa deste projeto, as variáveis do construto de Kholi e Jaworski (1990) serão conceituadas e operacionalizadas, enquanto variáveis independentes do estudo.

No tópico referente à interface inter-funcional, aprendeu-se que este elemento pode ser considerado relevante para o desempenho da organização e dos processos de desenvolvimento de novos produtos. Apesar de sua importância, a integração entre as funções da organização é algo difícil de alcançar, seja por motivos estruturais, culturais, pessoais, entre outros. Estudou-se a interface inter-funcional como um todo, bem como sua relevância no campo gerencial e seus principais conceitos. Posteriormente, foram abordadas mais detalhadamente, as relações entre P\&D e marketing, marketing e engenharia e manufatura, marketing com as outras áreas da organização, $\mathrm{P} \& \mathrm{D}$ com engenharia e P\&D com as outras áreas da organização.

Considerando a orientação do estudo de García, Sanzo e Trespalacios (2008) voltada, também, para o as informações advindas do mercado; a consistência da construção da escala de mensuração de interface inter-funcional (integração inter-funcional + confiança), com a utilização de autores importantes para o tema e a obtenção de bons índices de validade e confiabilidade; e a recomendação da pesquisa para extensão do estudo para verificação de interface funcional entre outras áreas além de $\mathrm{P} \& \mathrm{D}$ e marketing, decidiu-se pela utilização desta escala para a mensuração do construto de interface inter-funcional desta dissertação

Estudaram-se ainda neste capítulo as estruturas organizacionais, em especial, estruturas de desenvolvimento de projetos, chegando ao mecanismo de integração conhecido como Project Management Office (PMO), ou Escritório de Gestão de Projetos, nomenclatura que será adotada para este estudo de agora em diante. Essa seção da revisão da bibliografia teve como objetivo entender o papel de um EGP na organização e sua possível relação com orientação para mercado e interface inter-funcional, entendimentos que trazem a possibilidade de incluir o escritório de gestão de projetos como variável moderadora do estudo. 


\section{METODOLOGIA}

\subsection{Natureza e método da pesquisa}

Segundo Malhotra (2001), as classificações mais relevantes em termos da natureza da pesquisa refletem em quatro tipos principais: exploratória, descritiva, conclusiva e causal. Andrade (1999) reforça esta classificação, afirmando que, quanto aos objetivos, a pesquisa pode ser: exploratória, descritiva ou explicativa. Ainda nesta linha, os estudos desenvolvidos por Selltiz et al. (1987) relatam que a metodologia a ser adotada pode ser classificada em três tipos: exploratórios, descritivos e causais, a depender da natureza do estudo.

Em complemento às classificações anteriores, Sampieri, Collado e Lucio (2006, p. 98) fazem a seguinte afirmação:

[...] o projeto, os dados coletados, a maneira de obtê-los, a amostragem e outros componentes do processo de pesquisa são classificados em estudos exploratórios, descritivos, correlacionais e explicativos, tanto em relação à pesquisa quantitativa quanto á qualitativa ou mista.

Os estudos exploratórios, segundo Sampieri, Collado e Lucio (2006), são realizados quando se busca examinar determinado problema, ou tema de pesquisa, ainda pouco estudado, que ainda não foi abordado, ou sobre o qual ainda se tem muitas dúvidas.

Um pouco além dos estudos exploratórios, a pesquisa de natureza descritiva procura “descobrir, com a precisão possível, a freqüência com que um fenômeno ocorre, sua relação e conexão com os outros, sua natureza e características" (CERVO E BERVIAN, 1996, p. 49). Em complemento, Sampieri, Collado e Lucio (2006) definem estudo descritivo como um meio de mensurar ou colher informações de forma independente, ou conjunta, sobre as variáveis ou conceitos a que o estudo se refere. Como fator adicional ao estudo exploratório, o descritivo possibilita a realização de previsões, ou relações entre as variáveis, mesmo que pouco elaboradas.

A pesquisa correlacional "tem como objetivo avaliar a relação entre duas ou mais variáveis ou conceitos" (SAMPIERI, COLLADO E LUCIO, 2006, p. 104). Ainda segundo os autores, a utilidade principal dos estudos correlacionais quantitativos está em entender como se 
comporta um conceito, ou uma variável, conhecendo o comportamento de outras variáveis relacionadas.

Uma variante mais complexa da pesquisa correlacional é o estudo explicativo, ou causal. Sua denominação varia de acordo com os autores pesquisados, mas a essência deste tipo de estudo está em identificar os fatores determinantes dos fenômenos estudados (ANDRADE, 1999, 107), Sampieri, Collado e Lucio (2006, p. 105) afirmam que a pesquisa explicativa "pretende estabelecer as causas dos acontecimentos, fatos ou fenômenos estudados".

É importante destacar que diversos tipos de estudos podem ocorrer ao longo do trajeto de uma mesma pesquisa. É possível, portanto, que uma pesquisa inclua elementos dos diferentes tipos de estudos. Uma pesquisa pode iniciar como exploratória ou descritiva e depois se tornar correlacional e até mesmo explicativa (SAMPIERI, COLLADO E LUCIO, 2006).

Levando em consideração os conceitos apresentados anteriormente, entende-se que uma pesquisa de natureza exploratória ou descritiva, por si só, é insuficiente para atingir aos resultados propostos nos objetivos deste estudo. Sendo assim, acredita-se que esta pesquisa possui naturezas exploratória, descritiva e correlacional, sendo esta ultima a definição do estudo que mais satisfaz os objetivos propostos. De fato, a pesquisa é, inicialmente, exploratória, pois busca propor, a partir dos resultados encontrados, novas perspectivas sobre a relação entre orientação para mercado e interface inter-funcional. Depois, será realizada uma análise descritiva, onde cada variável, a priori, será estudada isoladamente, para que se obtenham resultados a partir de cada um dos indicadores. Posteriormente, serão desenvolvidas análises em busca de estabelecer possíveis correlações entre os indicadores componentes dos construtos de orientação para o mercado e interface inter-funcional. Nesta classificação, portanto, a pesquisa não pode ser considerada explicativa/causal, visto que a proposta do estudo não é estabelecer, ou entender, relações de causa e efeito, entre as variáveis dos dois construtos, mas apenas verificar se há associações significativas entre os elementos estudados e como a variável moderadora pode diferenciar esta relação.

Quanto ao enfoque adotado para pesquisa, têm-se a possibilidade de utilizar as abordagens qualitativas e quantitativas. $\mathrm{O}$ enfoque qualitativo utiliza dados coletados sem medição numérica para investigar ou aperfeiçoar questões de pesquisa e, não necessariamente, prova hipóteses pré-estabelecidas. Enquanto isso, as pesquisas quantitativas exploram dados 
numéricos e testa hipóteses por meio da análise estatística, em busca de estabelecer padrões de comportamento. Uma diferenciação entre os dois enfoques pode ser observada no Quadro 03.

\section{Quadro 03 - Diferenças entre os Enfoques Qualitativo e Quantitativo}

\begin{tabular}{|l|l|l|}
\hline & \multicolumn{1}{|c|}{ Enfoque Quantitativo } & \multicolumn{1}{c|}{ Enfoque Qualitativo } \\
\hline Ponto de Partida & Há uma realidade a conhecer & Há uma realidade a descobrir \\
\hline Premissa & $\begin{array}{l}\text { A realidade do fenômeno social pode ser } \\
\text { conhecida com a mente }\end{array}$ & $\begin{array}{l}\text { A realidade do fenômeno social é a mente. } \\
\text { A realidade é construída pelo (s) indivíduo } \\
\text { (s) que dá (ão) significados ao fenômeno } \\
\text { social. }\end{array}$ \\
\hline Dados & Uso de medição e quantificação & Uso da linguagem natural \\
\hline Finalidade & $\begin{array}{l}\text { Busca relatar o que acontece. Fatos que } \\
\text { dêem informação específica da realidade } \\
\text { que podemos explicar e prever. }\end{array}$ & $\begin{array}{l}\text { Busca entender o contexto e/ou o ponto de } \\
\text { vista do ator social. }\end{array}$ \\
\hline
\end{tabular}

Fonte: Adaptado de Sampieri, Collado e Lucio (2006, p. 9)

Nota-se, no Quadro 03, que, enquanto o enfoque qualitativo preza a descoberta, a abordagem quantitativa busca conhecer uma realidade sobre a qual já se sabe alguma coisa, mesmo que minimamente.

Nos casos qualitativos, a premissa adotada é de que a realidade do fenômeno social é a mente, enquanto que nos casos quantitativos, a realidade do fenômeno social requer a utilização da mente para ser descoberta. Quanto ao tipo de dados utilizado apresentados no Quadro 03, assumem-se as técnicas de medição e quantificação, enquanto utiliza-se a linguagem natural para o enfoque qualitativo. Por fim, em relação à finalidade do estudo, ainda no Quadro 03, entende-se que a abordagem quantitativa busca relatar o que acontece, enquanto a abordagem qualitativa preocupa-se com como as coisas acontecem.

Há ainda a possibilidade de utilizar ambas as abordagens em uma mesma pesquisa, o que Sampieri, Collado e Lucio (2006) classificam como abordagem mista. A abordagem é também chamada por alguns autores de triangulação, cuja origem remonta ao método de fixar a posição de um objeto medindo-o por duas diferentes perspectivas (OPPERMANN, 2000). Para Greene, Caracelli e Graham (1989), algumas das vantagens de utilizar uma abordagem mista são:

- Triangulação - buscar uma maior convergência de resultados; 
- Complementaridade - suscitar diferentes aspectos do fenômeno;

- Desenvolvimento - permitir que a utilização de um método ajude na aplicação de outro método;

- Iniciação - informar que contradições e novas perspectivas podem surgir;

- Expansão - fornecer um aumento de escopo para o estudo.

Ainda quanto ao uso de métodos mistos de pesquisa, Morse (1991) destaca que a triangulação pode aparecer das seguintes formas:

- Triangulação simultânea - $\mathrm{O}$ pesquisador responde as questões de pesquisa quantitativa e qualitativas ao mesmo tempo no estudo. $\mathrm{O}$ resultado de uma não necessariamente serve para confirmar o resultado da outra.

- Triangulação seqüencial - $\mathrm{O}$ pesquisador conduz duas fases do projeto sendo que os resultados da primeira são essenciais para planejar a seguinte.

Diante do exposto, entende-se que o enfoque utilizado para esta pesquisa foi quantitativo, visto que foram utilizadas técnicas de análise estatística dos dados. A opção de uma pesquisa triangulada pode ser considerada para um maior aprofundamento do tema em pesquisas futuras. Mais adiante, neste capítulo, serão descritos os procedimentos utilizados para a coleta e análise dos dados do estudo.

Segundo Sampieri, Collado e Lucio (2006), no tocante ao modelo da pesquisa, pode-se desenvolver um experimento, ou um não-experimento. Dentro da categoria dos experimentos, têm-se o experimento "puro", o pré-experimento e o quase-experimento. Já em relação aos estudos não-experimentais, utilizam-se os de corte transversal (exploratório, descritivo e correlacional/causal) e os de corte longitudinal (de tendência, coorte e tipo painel) (SAMPIERI, COLLADO E LUCIO, 2006).

Os estudos de corte transversal são aqueles em que a pesquisa é realizada por meio de uma coleta única de dados. Enquanto os estudos longitudinais são desenvolvidos por meio da coleta de dados em diversos pontos temporais do estudo (SAMPIERI, COLLADO E LUCIO, 
2006). Assim, nesta dissertação, foi utilizado o modelo não-experimental com aplicação de um corte transversal, ou seja, a realização em uma única etapa da pesquisa.

Selltiz et al (1987), conceitua o método científico como um conjunto de passos determinados para a aquisição de conhecimento, os quais devem ser aceitos por outros que já atuaram na área em que a pesquisa está sendo realizada. Neste sentido, os métodos de pesquisa podem ser divididos em até seis classificações, a saber: pesquisa bibliográfica, survey, experimental, estudo de caso, pesquisa histórica e pesquisa-ação (BABBIE, 1990; JIMÉNEZ, 1995).

Para este estudo, inicialmente, foi realizada uma busca por dados secundários, provenientes de uma pesquisa bibliográfica em livros, artigos de eventos e de periódicos e sites, com o objetivo de compor a fundamentação teórica do estudo, referente às principais teorias norteadoras, bem como à metodologia mais adequada para a realização da pesquisa.

Quanto à pesquisa de campo, dentre os diversos métodos apresentados na literatura, para a primeira fase, foi escolhido o levantamento, também conhecido como survey. Este método consiste na obtenção de conhecimento através de dados quantitativos, com a coleta de dados ou informações sobre determinados sujeitos, atitudes ou opiniões, representantes de um público-alvo (PINSONNEAULT e KRAEMER, 1993). A escolha foi feita levando em consideração o fato de este ser o método mais indicado para o levantamento de dados quantitativos e possibilitar a utilização de diversas escalas métricas, além de poder ser aplicado tanto por meio de entrevistas pessoais, quanto à distância, por meio eletrônico, por exemplo.

\subsection{Modelo teórico, conceituação e operacionalização das variáveis}

Na definição de Schiffman e Kanuk (2000, p. 465) um modelo é "uma representação da realidade destinada a mostrar relacionamentos entre vários elementos de um sistema ou processo sob investigação". O modelo permite, portanto, explicar de forma gráfica, o comportamento esperado das variáveis independentes e dependentes do estudo.

Como já foi visto no tópico anterior, Sampieri, Collado e Lucio (2006) classificam os modelos em experimentais e não experimentais, sendo que o segundo tipo será o adotado para esta pesquisa. Os modelos transversais de estudos correlacionais, como o próprio nome já diz, 
procuram representar as correlações, positivas ou negativas, entre as variáveis independentes, dependentes e moderadoras. Sendo assim, o modelo teórico apresentado na Figura 14, representa graficamente um estudo não experimental, de corte transversal para pesquisas correlacionais.

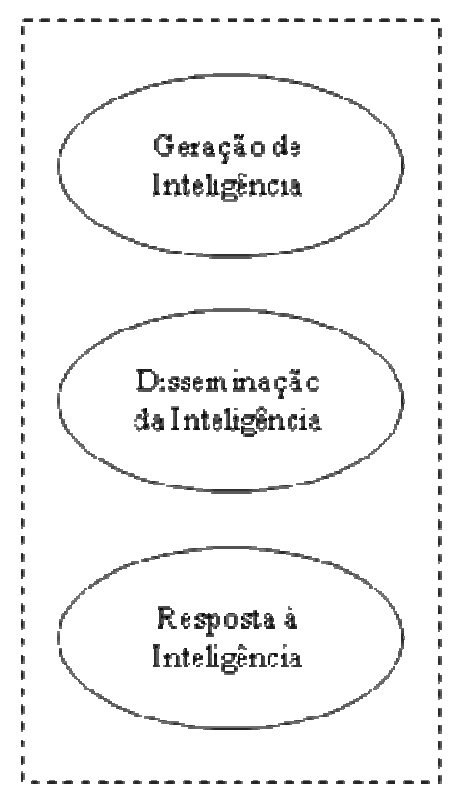

Orien:ą̧ãopara Mercado

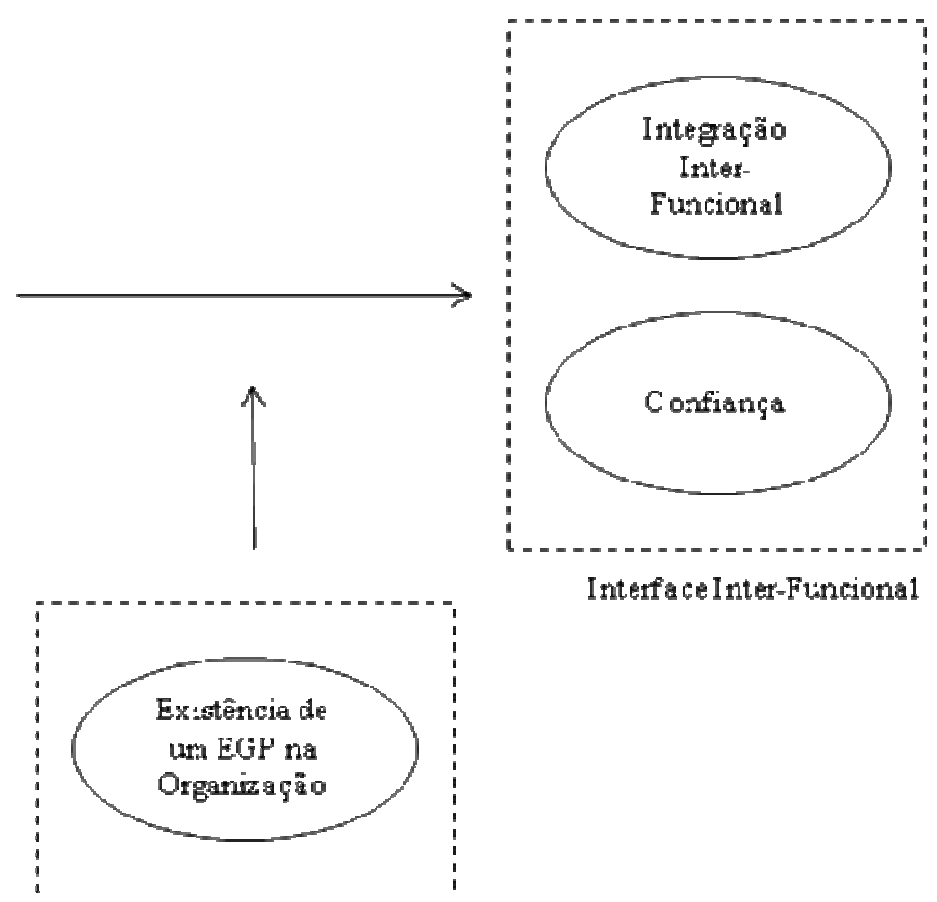

VariévelModeradora

Figura 14. Modelo Conceitual do Estudo.

Fonte: Elaborado pela autora.

Segundo Sampieri, Collado e Lucio (2006, p. 121), uma variável é a "propriedade que uma variação tem em poder ser medida, ou observada". De acordo com Andrade (1999, p. 126), variáveis recebem este nome "porque variam, podem assumir diferentes aspectos, abranger diferentes valores em cada caso, em cada pesquisa. Ainda segundo a autora, variável independente é aquela que exerce influência sobre a variável dependente. Sendo assim, a variável independente deverá ser manipulada para que sejam observados seus efeitos na variável dependente, considerando-se a influência das variáveis moderadoras.

Churchil (1999) classifica ainda as variáveis em duas categorias: 1) Variáveis observáveis são variáveis às quais podem ser atribuídos algarismos que possibilitem a mensuração de 
determinado atributo; 2) Variáveis latentes - representam conceitos mais abstratos, os quais não podem ser mensurados de forma objetiva. Para fins deste trabalho e com base em definições encontradas em Hair et al (1998), serão chamadas de variáveis os conjunto de indicadores que definirão geração da inteligência, disseminação da inteligência, resposta á inteligência, integração inter-funcional e confiança. A variável moderadora existência de um EGP já é, por si só, uma variável observável, visto que já compõe a parcela mensurável do objeto estudado.

Nesse sentido, para este estudo, o agrupamento das variáveis de geração, disseminação $e$ resposta à inteligência de mercado formará o construto de orientação para mercado. O grupo das variáveis de integração inter-funcional e confiança formará o construto de interface interfuncional. Ao passo que a variável moderadora (variável observável) será existência de um EGP (Escritório de Gestão de Projetos).

Como pode ser observado na Figura 14, no estudo em questão, as variáveis independentes pertencem ao construto de Orientação para o Mercado de Kholi e Jaworski (1993), refinado por Matsuno, Mentzer e Rentz (2000) e adaptado e validado ao contexto brasileiro por Müller Neto (2005). O construto de orientação para mercado é composto por três variáveis, a saber: 1) Geração de Inteligência; 2) Disseminação da Inteligência; 3) Resposta á Inteligência. Ao passo que as variáveis dependentes pertencem ao construto de Interface Inter-Funcional, desenvolvido e validado por García, Sanzo e Trespalacios (2008), adaptado para esta pesquisa. O construto de Interface é composto por duas variáveis, são elas: 1) Integração Inter-Funcional e Confiança.

Para que o modelo e suas relações sejam mais bem compreendidos, faz-se necessária a conceituação e operacionalização das variáveis dos construtos. Marconi e Lakatos (1982) reforçam a necessidade de definir e controlar as variáveis dependentes e independentes que podem interferir ou afetar o objeto de estudo, com o objetivo de tentar evitar que a pesquisa seja comprometida. O Quadro 03 apresenta e define as variáveis independentes, enquanto o Quadro 04, as variáveis dependentes. 


\section{Quadro 03 - Variáveis Independentes da Pesquisa}

\begin{tabular}{|c|c|c|c|}
\hline Id. & $\begin{array}{c}\text { Construtos e } \\
\text { Variáveis } \\
\end{array}$ & Definição Teórica & Operacionalização \\
\hline C1 & $\begin{array}{l}\text { Orientação } \\
\text { para Mercado }\end{array}$ & $\begin{array}{l}\text { Geração em toda a organização de } \\
\text { inteligência de mercado, relativa às atuais } \\
\text { e futuras necessidades dos clientes, } \\
\text { disseminação da inteligência entre os } \\
\text { departamentos, e a resposta de toda a } \\
\text { organização a esta inteligência (KHOLI E } \\
\text { JAWORSKI, 1990; 1993). }\end{array}$ & $\begin{array}{l}\text { Vinte e dois indicadores do modelo de } \\
\text { Kholi e Jaworski, (1993), adaptado para o } \\
\text { Brasil por Müller Neto (2005), em uma } \\
\text { escala ordinal de seis pontos ( } 1=\text { discordo } \\
\text { totalmente; } 6=\text { concordo totalmente), } \\
\text { como pode ser observado no Anexo I. }\end{array}$ \\
\hline V1 & $\begin{array}{l}\text { Geração de } \\
\text { Inteligência }\end{array}$ & $\begin{array}{l}\text { Refere-se à coleta e análise tanto das } \\
\text { necessidades/preferências dos } \\
\text { consumidores, quanto das forças (ex.: } \\
\text { ambientes macro e de tarefas), que } \\
\text { influenciam o desenvolvimento e } \\
\text { refinamento destas necessidades. (KHOLI } \\
\text { E JAWORSKI, 1990; 1993) }\end{array}$ & $\begin{array}{l}\text { Nove indicadores do modelo de Kholi e } \\
\text { Jaworski, (1993), adaptado para o Brasil } \\
\text { por Müller Neto (2005), em uma escala } \\
\text { ordinal de seis pontos ( } 1=\text { discordo } \\
\text { totalmente; } 6=\text { concordo totalmente), } \\
\text { como pode ser observado no Anexo I. }\end{array}$ \\
\hline V2 & $\begin{array}{l}\text { Disseminação } \\
\text { de } \\
\text { Inteligência }\end{array}$ & $\begin{array}{l}\text { Disseminação de inteligência - consiste } \\
\text { no processo e medida de troca de } \\
\text { informação de mercado em uma dada } \\
\text { organização. Pelo fato de o foco da } \\
\text { disseminação da informação é a unidade } \\
\text { estratégica de negócio (UEN) como um } \\
\text { todo, as atenções devem ser balanceadas } \\
\text { tanto entre as transmissões horizontais } \\
\text { (ex.: interdepartamentais), quanto às } \\
\text { transmissões verticais de informações do } \\
\text { ambiente de mercado (KHOLI E } \\
\text { JAWORSKI, 1990; 1993). }\end{array}$ & $\begin{array}{l}\text { Sete indicadores do modelo de Kholi e } \\
\text { Jaworski, (1993), adaptado para o Brasil } \\
\text { por Müller Neto (2005), em uma escala } \\
\text { ordinal de seis pontos ( } 1=\text { discordo } \\
\text { totalmente; } 6=\text { concordo totalmente), } \\
\text { como pode ser observado no Anexo I. }\end{array}$ \\
\hline V3 & $\begin{array}{l}\text { Resposta à } \\
\text { Inteligência }\end{array}$ & $\begin{array}{l}\text { Reação à inteligência - diz respeito à ação } \\
\text { tomada em resposta à inteligência que é } \\
\text { gerada e disseminada (KHOLI E } \\
\text { JAWORSKI, 1990; 1993). }\end{array}$ & $\begin{array}{l}\text { Seis indicadores do modelo de Kholi e } \\
\text { Jaworski, (1993), adaptado para o Brasil } \\
\text { por Müller Neto (2005), em uma escala } \\
\text { ordinal de seis pontos ( } 1=\text { discordo } \\
\text { totalmente; } 6=\text { concordo totalmente), } \\
\text { como pode ser observado no Anexo I. }\end{array}$ \\
\hline
\end{tabular}

Fonte: Adaptado de Kholi e Jaworski, (1993) e Müller Neto (2005). 


\section{Quadro 04 - Variáveis Dependentes da Pesquisa}

\begin{tabular}{|c|c|c|c|}
\hline Id. & Variável & Definição Teórica & Operacionalização \\
\hline C1 & $\begin{array}{l}\text { Interface Inter- } \\
\text { Funcional }\end{array}$ & $\begin{array}{l}\text { Junção dos conceitos de Integração Inter- } \\
\text { Funcional e Confiança (GARCÍA, } \\
\text { SANZO E TRESPALACIOS, 2008). }\end{array}$ & $\begin{array}{l}\text { Nove indicadores do modelo de García, } \\
\text { Sanzo e Trespalacios (2008), em uma } \\
\text { escala ordinal de seis pontos ( } 1=\text { discordo } \\
\text { totalmente; } 6 \text { = concordo totalmente), } \\
\text { como pode ser observado no Anexo I. }\end{array}$ \\
\hline V1 & $\begin{array}{l}\text { Integração } \\
\text { Inter- } \\
\text { Funcional }\end{array}$ & $\begin{array}{l}\text { Agrupamento das variáveis de } \\
\text { comunicação e cooperação, adaptado de } \\
\text { García, Sanzo e Trespalacios (2008), com } \\
\text { base na teoria de Millson and Wilemon } \\
\text { (2002) e Tessarolo (2007). }\end{array}$ & $\begin{array}{l}\text { Cinco indicadores do modelo de García, } \\
\text { Sanzo e Trespalacios (2008), em uma } \\
\text { escala ordinal de seis pontos ( } 1=\text { discordo } \\
\text { totalmente; } 6 \text { = concordo totalmente), } \\
\text { como pode ser observado no Anexo I. }\end{array}$ \\
\hline V2 & Confiança & $\begin{array}{l}\text { A percepção compartilhada pela maioria } \\
\text { dos membros da equipe que os indivíduos } \\
\text { na equipe desempenharão ações } \\
\text { particulares importantes para seus } \\
\text { membros e os indivíduos reconhecerão e } \\
\text { protegerão os direitos e interesses de } \\
\text { todos os membros da equipe engajados } \\
\text { em um esforço comum (GARCÍA, } \\
\text { SANZO E TRESPALACIOS, 2008), com } \\
\text { base em Webber (2002, p. 205). } \\
\text { Para a definição teórica desta variável, } \\
\text { utilizou-se o conceito de confiança } \\
\text { apresentado por García, Sanzo e } \\
\text { Trespalacios (2008), no contexto de } \\
\text { desenvolvimento de novos produtos. }\end{array}$ & $\begin{array}{l}\text { Quatro indicadores do modelo de García, } \\
\text { Sanzo e Trespalacios (2008), em uma } \\
\text { escala ordinal de seis pontos ( } 1=\text { discordo } \\
\text { totalmente; } 6=\text { concordo totalmente), } \\
\text { como pode ser observado no Anexo I. }\end{array}$ \\
\hline
\end{tabular}

Fonte: García, Sanzo e Trespalacios (2008).

Como pode ser observado nos Quadros 03 e 04, as variáveis independentes de orientação para mercado são geração da inteligência, disseminação da inteligência e resposta à inteligência. Todas elas foram extraídas do modelo de Kholi e Jaworski, (1993), adaptado por Müller Neto (2005). Cabe ainda aqui fazer uma observação: a linguagem da escala utilizada por Müller Neto (2005), aplicada e validada no Brasil, foi adaptada pela autora desta dissertação, com base nas sugestões obtidas nos testes piloto, para que se adequasse ao ambiente específico de desenvolvimento de novos produtos, no qual este estudo se propôs a trabalhar. As adaptações, no entanto, não alteraram o núcleo das sentenças, as quais mantiveram a essência da escala original. As variáveis independentes Integração e Confiança, foram extraídas do estudo de García, Sanzo e Trespalacios (2008) e as escalas também foram adaptadas, visto que tiveram que ser traduzidas para o português e trazidas para o contexto de projetos de novos produtos.

As variáveis intervenientes, ou moderadoras, são aquelas que podem influenciar a relação entre duas ou mais variáveis independentes e dependentes (SAMPIERI, COLLADO E LUCIO, 2006). Nesse sentido, entende-se que a variável moderadora da relação entre orientação para mercado e interface inter-funcional investigada na survey com os participantes 
de projetos de desenvolvimento de novos produtos, poderiam ser inúmeras, como: setor de atuação da empresa, porte da organização, existência de um EGP na organização, tipo de estrutura de projetos, grau de orientação para projeto, tempo de experiência com projetos de DNP, experiência como gerente de projeto na carreira, entre outras.

Todavia, para fins deste estudo, com base no que foi encontrado na literatura, optou-se por utilizar como variável moderadora da relação estudada nesta dissertação a existência do EGP na organização. A definições teóricas e operacionais desta variável podem ser observadas no Quadro 05.

\section{Quadro 05 - Variável Moderadora da Pesquisa}

\begin{tabular}{|c|c|c|c|}
\hline Id. & $\begin{array}{l}\text { Construtos e } \\
\text { Variáveis }\end{array}$ & Definição Teórica & Operacionalização \\
\hline V1 & $\begin{array}{l}\text { Escritório de } \\
\text { Gestão de } \\
\text { Projetos/Project } \\
\text { Management } \\
\text { Office }\end{array}$ & $\begin{array}{l}\text { O Escritório de Gerenciamento de } \\
\text { Projetos (EGP) seria a unidade } \\
\text { organizacional responsável pela correção } \\
\text { de problemas relativos a falhas no } \\
\text { gerenciamento de projetos [...] seria, } \\
\text { portanto, "responsável pela divulgação } \\
\text { das práticas de gerenciamento de } \\
\text { projetos para toda a organização, } \\
\text { possibilitando a diminuição dos índices } \\
\text { de falhas e garantindo que os projetos } \\
\text { mais importantes para a organização } \\
\text { sejam tratados de forma prioritária" } \\
\text { (MAXIMIANO E ANSELMO, 2006, p. } \\
\text { 395). }\end{array}$ & $\begin{array}{l}\text { Uma questão dicotômica sobre a } \\
\text { existência, ou não, de um escritório de } \\
\text { projetos na organização do entrevistado. }\end{array}$ \\
\hline
\end{tabular}

Fonte: Adaptado de Vasconcellos e Hemsley (2003) Clark e Wheelwright, (2001) e Curry (2006).

Após conhecidas as definições teóricas e operacionais das variáveis da pesquisa, a próxima seção explica como se deu o tratamento das proposições e hipóteses da pesquisa neste estudo.

\subsection{Definição do Universo e Amostra}

Segundo Sampieri, Collado e Lucio (2006, p. 250), antes mesmo de se delimitar a população ou universo da pesquisa, faz-se necessário determinar a unidade de análise do estudo, ou seja, "pessoas, organizações, jornais, comunidades, situações, eventos" entre outros, sobre os quais serão coletados os dados. Nesta pesquisa, as unidades de análise serão os participantes de projetos de desenvolvimento de novos produtos em empresas inovadoras. Nesse sentido, será entrevistado um ou mais indivíduo que tenha participado de projetos de DNP em empresas consideradas inovadoras e que possuem escritório no Brasil. 
Determinada a unidade de análise do estudo, passa-se para a definição da população. Para Sampieri, Collado e Lucio (2006, p. 253), população, ou universo da pesquisa, no enfoque quantitativo, trata-se do total de casos que se encaixam em determinadas especificações. Anderson, Sweeney e Williams (2008, p. 12) conceituam população como "o conjunto de todos os elementos de interesse de um determinado estudo. Neste sentido, entende-se que a população do estudo é o total de casos encontrados dentro do corte de interesse da pesquisa. Ainda segundo os autores, a população pode ser finita, quanto possui um número de casos possível de ser delimitado; ou infinita, quando a listagem ou contagem de cada elemento da população é impossibilitada.

Partindo do princípio de que o estudo utilizará como contexto para a pesquisa o desenvolvimento de novos produtos, houve uma preocupação de escolher como universo da pesquisa indivíduos empregados em empresas com foco em inovação. Desta feita, buscou-se o ranking de empresas que mais investem em inovação no mundo, o qual é composto atualmente, com última atualização em 2006, de 1.250 empresas globais, sediadas em setores e países diversificados (BERR, 2008), para que dele fossem retirados os indivíduos da amostra. Porém, a unidade de análise são os indivíduos, não nas organizações, e não é possível quantificar quantos indivíduos estão empregados nestas empresas e participam, ou já participaram, de projetos de desenvolvimento de novos produtos. Nesse sentido, a população deste estudo pode ser considerada infinita.

Segundo a definição de Sampieri, Collado e Lucio (2006, p. 250), uma amostra, no enfoque quantitativo, é um "subgrupo da população do qual se coletam os dados e deve ser representativo desta população". Diante o universo infinito de pessoas que participam, ou já participaram de projetos de desenvolvimento de novos produtos, definiu-se a amostra pelo critério de acessibilidade, ou conveniência (SAMPIERI, COLLADO E LUCIO, 2006).

O critério de aleatoriedade foi preterido, em detrimento da possibilidade de aplicar o máximo de questionários possível, visto que houve muita dificuldade de aceitação das empresas para aplicação do questionário com seus funcionários.

Segundo um estudo realizado por Weible e Wallace (1998) a taxa média de retorno de questionários enviados por Internet é de 26\%. Pesquisa semelhante foi realizada com professores da Universidade de São Paulo, por Hipólito et al (1996) e o retorno foi de apenas $8,6 \%$. Inicialmente, adotou-se a estratégia de disparo de e-mails para as empresas da lista, a 
fim de obter os contatos dos indivíduos com perfil para a pesquisa. Esta tentativa foi frustrada, visto que a maioria das respostas eram automáticas, procedentes dos SACs e assessores de imprensa das empresas. Diante do baixo índice de retorno obtido, adotou-se uma estratégia de indicações de contatos conhecidos, com o intuito de chegar o mais rápido possível ao entrevistado com o perfil desejado.

Foram entrevistadas 21 pessoas, sendo 66,7\% homens e 33,3\% mulheres; os quais estavam, em grande parte, na faixa dos 26 a 45 anos. A maioria dos pesquisados está alocada, originalmente, na área de $\mathrm{P} \& \mathrm{D}$ da organização e tem de 3 a 5 anos na empresa. 


\subsection{Estratégia de coleta de dados}

\subsubsection{Construção do instrumento e teste piloto}

Inicialmente, para construção e validação do questionário, é importante a realização de um teste piloto, com objetivo de verificar "se as instruções foram compreendidas e se os itens funcionam de forma adequada" (SAMPIERI, COLLADO E LUCIO, 2006, p. 305). Nos parágrafos seguintes, será descrito o processo de construção do questionário, dentro da descrição dos testes-piloto aplicados durante a pesquisa.

O teste foi realizado com especialistas da área de gestão de projetos e pessoas que já participaram de desenvolvimento de novos produtos. Foram necessários dois testes-piloto para este estudo, visto que houve uma mudança na unidade de análise no decorrer do mesmo.

A primeira versão elaborada do questionário contava com as variáveis de caracterização da empresa e do respondente, incluía também a escala de orientação para mercado de Kholi e Jaworski, (1993), as quais foram trazidas para o questionário final, com as devidas adaptações e serão descritas mais adiante. Todavia, as escalas adotadas para o construto de interface inter-funcional e para as variáveis moderadoras eram outras. Para interface, a escala escolhida no momento pré-qualificação foi adaptada de Kruglianskas (1981) e as variáveis moderadoras eram estruturas organizacionais de projetos e a função do respondente. Nesta primeira versão do questionário, as unidades de análise seriam as organizações inovadoras e seus projetos de desenvolvimento de novos produtos, sobre os quais seriam entrevistados gestores das áreas de marketing, $P \& D$ e manufatura.

Com esta estrutura, em um momento pré-qualificação, foi realizado o primeiro teste piloto, com 15 pessoas envolvidas direta e indiretamente com projetos de desenvolvimento de novos produtos. Após a aplicação do teste, foram realizadas modificações e o instrumento de pesquisa foi submetido à qualificação. Neste momento, a banca sugeriu algumas modificações, entre elas: 1) Revisão da unidade de análise da pesquisa; 2) Redução de algumas sentenças do questionário que estavam muito longas, mesmo após o primeiro testepiloto; 3) Busca por uma escala de interface inter-funcional (na época chamada de cooperação inter-funcional) por outra mais recente, visto que a pesquisa de Kruglianskas datava de 1981 e havia alguns termos que não mais se aplicavam à proposta do estudo. 
Desta feita, foram realizados os procedimentos de modificação sugeridos pela banca. Por meio de um novo esforço de pesquisa bibliográfica, foi encontrado o artigo de García, Sanzo e Trespalacios (2008), cuja escala de interface inter-funcional foi desenvolvida com base na teoria de diversos autores consagrados e aplicada em estudo mais recente, o que cabia para o estudo e era coerente com o que foi solicitado pela banca qualificadora. Além disso, a unidade de analise passou a ser as pessoas envolvidas com projetos de desenvolvimento de novos produtos. Este critério incluía: membros de equipes de projetos, gerentes de projetos, consultores e outras funções paralelas. Com isso, as variáveis demográficas do estudo foram divididas em: 1) Descrição da empresa do entrevistado e 2) Caracterização do Entrevistado. Ainda neste processo, as variáveis moderadoras antigas foram trocadas por: 1) Existência de um EGP na organização e 2) Experiência como Gerente de Projetos de DNP.

Depois de feitas as modificações pertinentes, foi aplicado um segundo teste piloto, com o intuito de verificar a compreensão das variáveis inseridas no questionário. O resultado de todo este processo foi um questionário quantitativo, com 25 questões, sendo 06 de caracterização da empresa, 12 de caracterização do respondente, 03 referentes à escala de orientação para mercado, 02 à escala de interface inter-funcional, 01 pedindo comentários adicionais e 01 perguntando se o respondente desejava receber um resumo dos resultados. A versão final do instrumento de pesquisa pode ser encontrada no APÊNDICE I desta dissertação.

\subsubsection{Validade e confiabilidade}

A validade é o "grau em que um instrumento mede, na verdade, a variável que se busca medir" (SAMPIERI, COLLADO E LUCIO, 2006, p. 290). Nesse sentido, ainda segundo os autores, a validade pode ser:

- De conteúdo - "refere-se ao grau em que o instrumento reflete um domínio específico de conteúdo do que se mede" (SAMPIERI, COLLADO E LUCIO, 2006, p. 289). Em outras palavras, a validade de conteúdo diz respeito ao quanto o instrumento representa, de fato, o conceito que se deseja medir. No caso desta pesquisa, por exemplo, para medir orientação para mercado, eram necessárias as variáveis geração de inteligência, disseminação da inteligência e resposta à inteligência. Se fossem utilizadas apenas uma, ou duas, das variáveis, a validade de conteúdo estaria comprometida. Neste caso, acredita-se que, com a realização do teste piloto com 
especialistas e com a forte consideração da teoria para a construção do instrumento, acredita-se que a validade de conteúdo foi contemplada na pesquisa.

- De critério - "estabelece a validade de um instrumento de medição comparando-a com algum critério externo" (SAMPIERI, COLLADO E LUCIO, 2006, p. 289). Neste caso, os resultados do instrumento devem ser comparados com resultados obtidos da mesma população em outro período. Nesse sentido, não foram fornecidos elementos suficientes no teste piloto para esta validação.

- De construto - "refere-se ao grau no qual uma medição se relaciona de forma coerente com outras medições, de acordo com hipóteses teoricamente derivadas e que se relacionam aos conceitos (ou constructos) que estão sendo medidos" (SAMPIERI, COLLADO E LUCIO, 2006, p. 290). Para validação dos construtos, inicialmente, é importante que as escalas já tenham sido aplicadas e validadas em outros estudos. Nesse sentido, a pesquisa contempla o critério, tanto para a escala de orientação para mercado, quanto para a de interface inter-funcional. Alem disso, faz-se necessário desenvolver uma "análise de fatores" ou "análise fatorial" (SAMPIERI, COLLADO E LUCIO, 2006; HAIR et al 1998). Esta é uma limitação deste estudo, visto que, não foi possível realizar a análise fatorial, pois o número de 21 questionários não chegava ao mínimo necessário para que o teste seja considerado válido ( $\geq 30$ respostas).

Depois de verificada a validade do instrumento de pesquisa, busco-se também atestar sua confiabilidade. Segundo Sampieri, Collado e Lucio (2006, p. 293-294), pode-se calcular a confiabilidade de um instrumento por diversas fórmulas que produzem indicadores, os quais devem estar entre 0 e 1 , sendo que quanto mais próximo de 1 , maior será a confiabilidade do instrumento. Dentre os quatro principais tipos de testes de confiabilidade citados pelos autores (medida de estabilidade - teste-reteste; método de formas aleternativas ou paralelas; método de metades partidas; coeficiente alpha de Crombach) escolheu-se este quarto.

A opção pelo teste de confiabilidade alpha de Crombach deu-se segundo duas razões principais: 1) o coeficiente necessita apenas de uma aplicação do instrumento com os respondentes e 2) Pode ser aplicado nas escalas de mensuração como um todo, sem dividir os itens do instrumento em duas metades (SAMPIERI, COLLADO E LUCIO, 2006). 
Sendo assim, foi calculado o coeficiente para as escalas de orientação para mercado e interface inter-funcional, obtendo-se os seguintes resultados (Tabela 01):

\section{Tabela 01 - Alpha de Crombach para Escalas do Instrumento}

\begin{tabular}{l|c|c}
\hline Escala & Alpha & Número de Indicadores \\
\hline Orientação para Mercado & 0,860 & 22 \\
\hline Geração de Inteligência & 0,773 & 9 \\
\hline Disseminação da Inteligência & 0,772 & 7 \\
\hline Resposta à Inteligência & 0,714 & 6 \\
\hline Interface Inter-Funcional & 0,834 & 9 \\
\hline Integração Inter-Funcional & 0,833 & 5 \\
\hline Confiança & 0,875 & 4 \\
\hline Total & 0,881 & 31 \\
\hline
\end{tabular}

Fonte: Elaborada pela Autora.

Como pode ser observado na Tabela 01, os coeficientes alpha obtidos para as escalas foram todos acima de 0,7 . Este seria o mínimo aceitável para que uma escala possa ser considerada confiável (HAIR et al, 1998).

\subsubsection{Escalas de Mensuração}

Segundo Malhotra (2001) as escalas podem ser de quatro tipos: Nominais, Ordinais, Intervalar e Razão. No Quadro 05, adaptado de Siegel (1988, p. 33) há uma síntese dos quatro tipos de escalas existentes, as relações definidoras de suas propriedades e as estatísticas aplicáveis a cada uma das escalas, a saber: 


\section{Quadro 05 - Escalas e Provas Estatísticas Equivalentes}

\begin{tabular}{|c|c|c|c|}
\hline Escala & Relações Definidoras & $\begin{array}{c}\text { Exemplo de Estatísticas } \\
\text { Apropriadas }\end{array}$ & $\begin{array}{c}\text { Provas Estatísticas } \\
\text { Adequadas }\end{array}$ \\
\hline Nominal & (1) Equivalência & $\begin{array}{l}\text { Moda } \\
\text { Freqüência } \\
\text { Coeficiente de } \\
\text { contingência }\end{array}$ & \multirow{2}{*}{$\begin{array}{l}\text { Provas estatísticas não- } \\
\text { paramétricas }\end{array}$} \\
\hline Ordinal & $\begin{array}{l}\text { (1) Equivalência } \\
\text { (2) Maior do que }\end{array}$ & $\begin{array}{l}\text { Mediana } \\
\text { Percentis } \\
r_{\mathrm{s}} \text { de Spearman } \\
\tau \text { de Kendall } \\
W \text { de Kendall } \\
\end{array}$ & \\
\hline Intervalar & $\begin{array}{l}\text { (1) Equivalência } \\
\text { (2) Maior do que } \\
\text { (3) Razão conhecida dos } \\
\text { dois intervalos quaisquer }\end{array}$ & $\begin{array}{l}\text { Média } \\
\text { Desvio-padrão } \\
\text { Correlação momento- } \\
\text { produto de Pearson } \\
\text { Correlação múltipla } \\
\text { momento-produto } \\
\end{array}$ & \multirow{2}{*}{$\begin{array}{l}\text { Provas estatísticas } \\
\text { paramétricas e não- } \\
\text { paramétricas }\end{array}$} \\
\hline Razão & $\begin{array}{l}\text { (1) Equivalência } \\
\text { (2) Maior do que } \\
\text { (3) Razão conhecida dos } \\
\text { dois intervalos quaisquer } \\
\text { (4) Razão conhecida de } \\
\text { dois valores quaisquer da } \\
\text { escala }\end{array}$ & $\begin{array}{l}\text { Média geométrica } \\
\text { Coeficiente de variação }\end{array}$ & \\
\hline
\end{tabular}

Fonte: Adaptado de Siegel (1988, p. 33).

Este estudo fez uso de escalas nominais, para as etapas de caracterização da empresa e do entrevistado. Além disso, foram utilizadas também, para mensuração de orientação para mercado e interface inter-funcional, escalas ordinais de concordância, com seis pontos, variando de Discordo Totalmente a Concordo Totalmente. Neste sentido, entende-se que a escala escolhida possui relações definidoras de equivalência e de "maior que", portanto, foram utilizadas algumas das estatísticas sugeridas por Siegel (1988), no Quadro 05, a saber: Mediana e $\rho_{\mathrm{s}}$ de Spearman.

\subsubsection{O procedimento de coleta de dados}

Depois dissertar sobre o teste piloto, a validade e a confiabilidade do instrumento de pesquisa, cabe ainda nesta metodologia a descrição do procedimento de coleta de dados propriamente dito.

A aplicação de questionários através da Internet tem sido realizada de duas maneiras no âmbito da coleta de dados primários, a saber: a) envio do questionário por e-mail, onde este é enviado como um arquivo anexo ou no corpo da mensagem, b) disponibilização de um 
questionário em uma página da Internet, onde o respondente é informado sobre o endereço da página do questionário na Internet, através de e-mail, carta ou anúncio (MATTAR, 1993).

A survey (levantamento de dados) deste estudo foi realizada por meio virtual, por conta dos obstáculos para a aplicação pessoal do instrumento, em razão da falta de tempo do públicoalvo, de problemas de ordem geográfica. Para a construção virtual e preenchimento pelos respondentes e tabulação automática das respostas, foi utilizado o software QuestionPro.

Para solicitação da participação do respondente, foi elaborada uma carta, também virtual, e enviada para o e-mail da empresa ou do próprio indivíduo, quando se conseguiram os contatos diretos. Com o objetivo de reforçar a importância da participação da empresa na pesquisa, foram enviadas malas diretas periódicas, visando à conscientização do público-alvo da pesquisa. Muitos dos respondentes auxiliaram na disseminação do link da survey, por meio de um efeito cascata, onde estes avisavam aos amigos e faziam com que aumentasse o número de respondentes.

\subsection{Tratamento estatístico dos dados}

A tabulação inicial dos dados foi realizada, automaticamente, pelo software QuestionPro, o qual permitiu exportar o arquivo de dados em formato Excel. Feita a transferência do arquivo, iniciou-se o processo de tratamento dos dados, eliminando os questionários incompletos e que não atendiam ao perfil requerido pela pesquisa. Após o tratamento dos dados, criou-se uma matriz no software de análise estatística SPSS (Statistic Package for Social Science), o qual possibilitou o desempenho de diversas análises estatísticas.

Inicialmente, foi calculado o coeficiente alpha de Crombach, utilizado para verificar a confiabilidade dos dados, como pode ser observado na Tabela 01. Posteriormente, calculou-se toda a estatística descritiva, incluindo: mediana, moda, valores mínimos, máximos e as médias (esta última não foi calculada para os dados nominais, nem ordinais). Calculou-se ainda a frequiência absoluta e relativa para cada um dos dados de caracterização da empresa e dos respondentes, com o objetivo de traçar um panorama inicial dos dados obtidos.

No campo das análises bivariadas, foram calculadas correlações entre cada indicador das variáveis, considerando o total de 21 casos e, também, separando os casos, de acordo com a 
existência, ou não, de escritório de projetos nas organizações dos entrevistados. Para o cálculo das correlações, utilizou-se o coeficiente de correlações posto-ordem de Spearman $\left(\rho_{\mathrm{s}}\right)$. Segundo Siegel e Castellan Jr. (2006, p. 266), este coeficiente é uma "medida de associação entre duas variáveis que requer que ambas as variáveis sejam medidas pelo menos em uma escala ordinal, de modo que os objetos ou indivíduos em estudo possam ser dispostos em postos, em duas séries ordenadas”. Este teste permite verificar se duas variáveis estão associadas positiva, ou negativamente, ou seja, elas variam de -1 (correlação negativa perfeita) a +1 (correlação positiva perfeita), sendo que, quanto mais parto destes valores, maior esta correlação (SAMPIERI, COLLADO E LUCIO, 2006). Há ainda que se considerar o nível de significância da análise, para o qual se adota como referência os valores de 0,05 (para 95\% de confiabilidade) e 0,01 (para 99\% de confiabilidade) dos resultados. Estes são os valores tidos como comuns na literatura (SIEGEL, 2006, p. 29). Para este estudo, o software SPSS calcula automaticamente os níveis de significância e também segue este padrão. Desta feita, os dados marcados com dois asteriscos (**) são significativos ao nível de 0,01 ; os dados marcados com apenas um asterisco (*), serão significativos ao nível de 0,05.

\subsection{Limitações da Pesquisa}

Como todo estudo, a presente dissertação oferece uma contribuição para o fortalecimento dos alicerces da ciência. Porém, há algumas limitações que devem ser consideradas no trabalho e que restringem o entendimento e inferência de seus resultados.

Um primeiro ponto a ser destacado é a impossibilidade de fazer a leitura da bibliografia total disponível sobre os temas abordados no trabalho. Certamente, o ideal seria conhecer todos os trabalhos anteriores sobre interface inter-funcional e orientação para o mercado. Porém, por razões de tempo e espaço, foi utilizado para composição desta pesquisa, apenas um recorte do que se tem de mais relevante na literatura.

Uma segunda limitação do estudo advém da quantidade de retorno dos questionários, que foi mito abaixo de nossas expectativas. Este fato implica em não ser possível desenvolver análises paramétricas dos dados, dado que o número de respostas foi insuficiente para tal procedimento. 
Desta feita, ficamos apenas com as estatísticas não-paramétricas, as quais, segundo Siegel (2006), são as bastante aplicáveis e surtem um bom efeito nas ciências do comportamento. Em contrapartida, resultados de estatísticas não-paramétricas não podem ser projetados para o todo, pois aceitam distribuições não normais (SAMPIERI, COLLADO E LUCIO, 2006). Portanto, os resultados apresentados nesta pesquisa podem servir de inspiração para estudos futuros e até refletir a situação das empresas pesquisadas, porém, não podem ser projetados para a população total de empresas com as mesmas características.

Um outro ponto a ser observado é o fato de a aplicação dos questionários ter sido realizada pela Internet, por conta, principalmente, de implicações geográficas. Neste caso, há sempre o risco maior de viés na utilização deste meio para surveys, em detrimento das pesquisas realizadas pessoalmente (VASCONCELLOS E GUEDES, 2007).

Apesar das limitações apresentadas, acredita-se que o estudo traz uma contribuição relevante para o meio acadêmico e prático, as quais serão mais bem detalhadas no capítulo de conclusões e recomendações desta dissertação.

\subsection{Síntese da metodologia}

Considerando o que foi apresentado neste capítulo, podemos entender esta pesquisa como um estudo de naturezas exploratória, descritiva e, posteriormente, correlacional; adotante de um enfoque quantitativo e modelo não experimental, de corte transversal. A coleta dos dados em campo foi realizada por meio do método de levantamento, também conhecido como survey. Os dados foram considerados confiáveis, pois todos os coeficientes alpha de Crombach foram acima de 0,7. Para análise quantitativa dos dados, foram utilizadas estatísticas descritivas, correlações bivariadas com o coeficiente de correlação de Spearman, considerando os níveis de significância de 0,05 e 0,01 para as correlações.

As principais limitações da pesquisa são: impossibilidade de fazer a leitura da bibliografia total disponível sobre os temas abordados no trabalho; baixa quantidade de retorno dos questionários (21 respostas); impossibilidade de desenvolver análises paramétricas dos dados e, portanto, de projetar os resultados para a população; alto risco de viés na utilização da Internet como veículo para a survey. O capítulo 3 apresentou, portanto, o método de 
concepção e desenvolvimento deste estudo. No capítulo 4 serão apresentados os principais resultados encontrados após as análises dados coletados. 


\section{RESULTADOS}

Neste capítulo, serão apresentados e analisados os resultados da pesquisa de campo realizada para esta dissertação. Primeiramente, serão expostas as estatísticas descritivas das variáveis investigadas. Em um segundo momento, serão estabelecidas relações entre as variáveis dependentes, independentes e moderadoras do modelo, no intuito de compreender a estrutura dos dados e como estes contribuem para o entendimento do problema da pesquisa. No capítulo seguinte, será desenvolvida uma síntese dos resultados aqui apresentados, seguida das conclusões e considerações finais do estudo.

\subsection{Dados Demográficos e Caracterização das Empresas dos Pesquisados}

\section{Tabela 02 - Setor de Atuação da Empresa}

\begin{tabular}{l|c|c}
\hline \multicolumn{1}{c|}{ Setor } & Freqüência & $\%$ \\
\hline Metalurgia e Mecânica & 6 & $28,6 \%$ \\
Petroquímico & 4 & $19,0 \%$ \\
Cosméticos & 3 & $14,3 \%$ \\
Alimentos & 2 & $9,5 \%$ \\
Farmacêutica e Biotecnologia & 1 & $4,8 \%$ \\
Aeroespacial e Defesa & 1 & $4,8 \%$ \\
Automóveis e Peças & 1 & $4,8 \%$ \\
Tecnologia da Informação & 1 & $4,8 \%$ \\
Químico & 1 & $4,8 \%$ \\
Telecomunicações & 1 & $\mathbf{4 , 8 \%}$ \\
\hline Total & $\mathbf{2 1}$ & $\mathbf{1 0 0 , 0} \%$ \\
\hline
\end{tabular}

Fonte: Elaborado pela autora.

Como pôde ser visto na metodologia deste estudo, o critério de amostragem utilizado foi o de acessibilidade, ou conveniência. Esta técnica consiste em escolher as empresas de acordo com a possibilidade de entrevistar seus colaboradores. Neste sentido, os setores não foram escolhidos aleatoriamente, porém, obtivemos, dentro de 21 entrevistas, uma diversidade razoável, relativa ao setor das empresas dos entrevistados.

Conforme a Tabela 02, 28,6\% das empresas dos entrevistados foram do setor de Metalurgia e Mecânica, seguidas por $19 \%$ do setor Petroquímico e 14,3\% do setor de cosméticos. As indústrias de Alimentos, Farmacêutica, Aeroespacial, Automóveis e Peças, Tecnologia da Informação, Química e de Telecomunicações também tiveram participação na composição da amostra dos respondentes. Esta tabela revela um forte caráter inovador em todos os setores pesquisados. Destaca-se ainda que todas as empresas pertencentes aos setores da Tabela 02 de 
onde foram selecionados os entrevistados da pesquisa pertencem ao ranking de empresas que mais investem em inovação no mundo, o qual é composto 1.250 empresas globais, sediadas em setores e países diversificados (BERR, 2008), o que leva a crer que os setores aqui listados possuem caráter inovador em algum grau.

\section{Gráfico 01 - Existência de um EGP na Organização do Indivíduo Pesquisado}

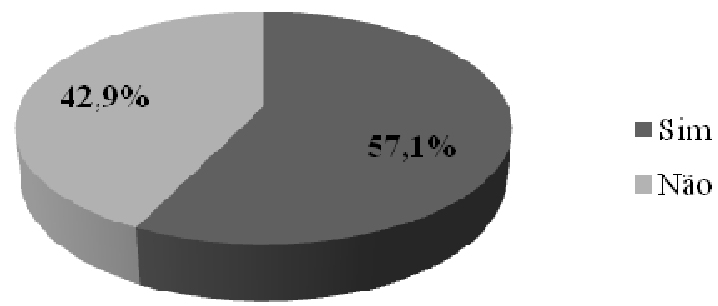

Fonte: Elaborado pela autora.

Quanto à existência de um Escritório de Projetos nas empresas dos pesquisados (Gráfico 01), encontrou-se o índice de 57,1\% para Sim e 42,9\% para Não. Este percentual pode indicar que as empresas inovadoras estão começando a se preocupar com a sistematização dos conhecimentos e práticas em projetos, dado que mais da metade das pesquisadas já possuem um escritório de projetos. Cabe ressaltar aqui que a pergunta foi feita de forma simples e dicotômica, não entrando em questão o nível de desenvolvimento do escritório de projetos e sua abrangência na organização dos entrevistados.

A proximidade percentual observada no Gráfico 01 ainda possibilita a divisão da amostra, praticamente, pela metade, o que proporcionará análises futuras, separando as empresas que possuem ou não Escritório de Projetos, para a compreensão de correlações específicas, entre orientação para mercado e interface inter-funcional, em cada caso. 
Tabela 03 - Quantidade de Projetos de Novos Produtos Desenvolvidos na Organização por Ano

\begin{tabular}{l|r}
\hline \multicolumn{1}{c|}{ Estatística Descritiva } & \multicolumn{2}{|r}{ Valor } \\
\hline Média & 300,5 \\
\hline Mediana & 30,0 \\
\hline Moda & 15,0 \\
\hline Mínimo & 1,0 \\
\hline Máximo & 5000,0 \\
\hline N & 21,0 \\
\hline
\end{tabular}

Fonte: Elaborado pela autora.

A amplitude dos projetos de desenvolvimento de novos produtos nas organizações dos entrevistados é considerada grande. Como pode ser observado na Tabela 03. O número máximo de projetos de desenvolvimento de novos produtos nas empresas pesquisadas foi de 5.000, enquanto o mínimo foi de 1 projeto por ano. Esta diferença se deu, principalmente, pela diversidade de características dos setores de atuação das empresas pesquisadas. As indústrias farmacêutica e aeroespacial, dado ao caráter de sua atividade, possuem um menor número de projetos de desenvolvimento de novos produtos por ano. Isto acontece pelo fato de este setor investir de forma considerável em inovações radicais, o que demanda, muitas vezes, mais tempo de desenvolvimento e foco em uma quantidade menor de projetos. Enquanto isso, as indústrias de cosméticos e de alimentos, por exemplo, podem ser valer de inovações incrementais em diversos itens de sua linha de produtos, o que resulta em um elevado número de projetos de desenvolvimento de novos produtos, simultaneamente, no decorrer do ano. $\mathrm{O}$ porte das empresas em questão não pode ser considerado como justificativa para esta variação, dado que todas as empresas dos entrevistados foram consideradas de grande porte, tanto em relação a número de funcionários, quanto ao critério de receita bruta anual. 


\subsection{Dados Demográficos e Caracterização do Respondente}

\section{Gráfico 02 - Sexo dos Entrevistados}

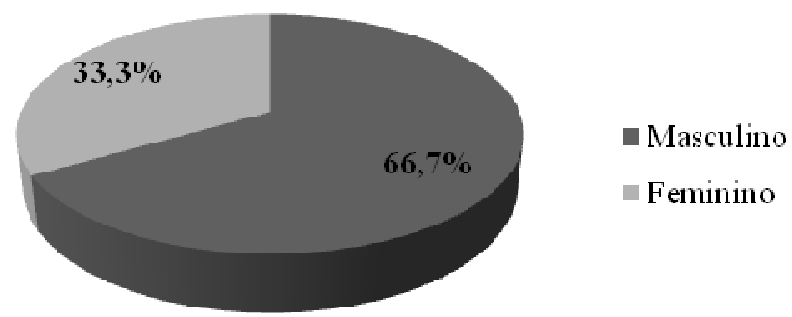

Fonte: Elaborado pela autora.

Quanto ao sexo dos entrevistados (Gráfico 02), na pesquisa, obteve-se a predominância dos homens como respondentes. Mais uma vez, ressalta-se que este percentual não pode ser projetado para o universo de membros de equipes de desenvolvimento de novos produtos. Os dados, portanto, servem apenas para identificação do perfil dos entrevistados. Perfil este que conta com um empate percentual na faixa etária predominante

\section{Gráfico 03 - Faixa Etária}

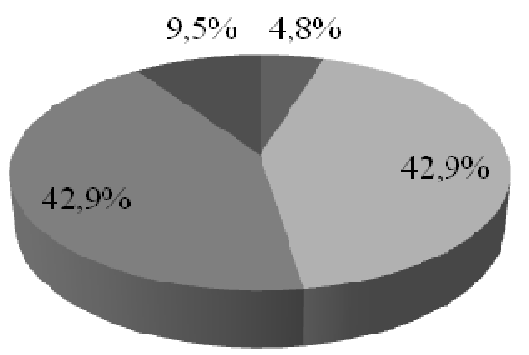

- 18 a 25 anos

-26 a 35 anos

- 36 a 45 anos

-46 a 55 anos

Fonte: Elaborado pela autora. 
Como pode ser observado no Gráfico 03 , cerca de $85 \%$ dos entrevistados estão na faixa de 26 a 45 anos, sendo que $42,9 \%$ possuem idade entre 26 a 35 anos e $42,9 \%$ entre 36 a 45 anos. Este perfil etário retrata com fidelidade a faixa de idade em que as pessoas estão empregados na empresa. A pesquisa contou ainda com 9,5\% de entrevistados com idade entre 46 a 55 anos e que já participaram de algum tipo de projeto de desenvolvimento de novo produto e com $4,8 \%$ dos entrevistados na faixa mais experiente de 18 a 25 anos. Este perfil encontrado garante, acima de tudo, a diversidade de opiniões em diversos estágios da vida dos respondentes.

\section{Gráfico 04 - Área da Empresa a que o Entrevistado Está Vinculado}

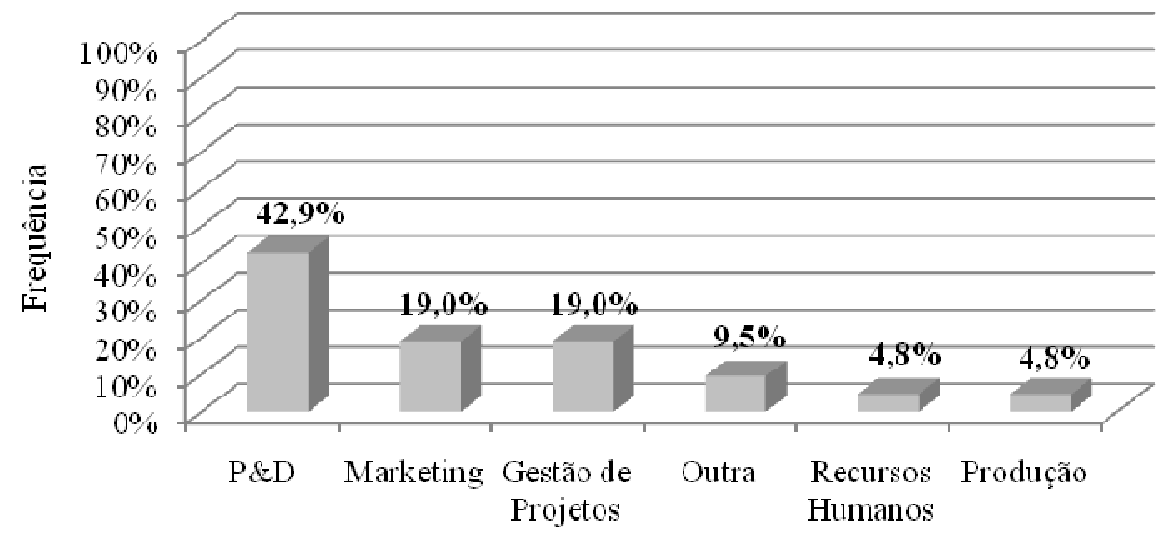

Área de Atuaçăo dos Entrevistados

Fonte: Elaborado pela autora.

Outro ponto a ser destacado na caracterização dos respondentes da pesquisa é a área de atuação da empresa a que os membros da amostra estavam vinculados, no momento da resposta do questionário. Como já era de se esperar, visto que a pesquisa se dá no âmbito da inovação, a maioria dos entrevistados encontrava-se na área de Pesquisa e Desenvolvimento da organização. Em segundo lugar, com percentuais de 19\% ficaram os respondentes das áreas de marketing e projetos. Os números nos levam a crer que estas seriam as três áreas envolvidas, diretamente, com desenvolvimento de novos produtos. Em seguida, encontramos outras áreas, com 9,5\% e RH e Produção com 4,8\% cada uma. 


\section{Gráfico 05 - Tempo que o Funcionário Trabalha da Empresa Atual}

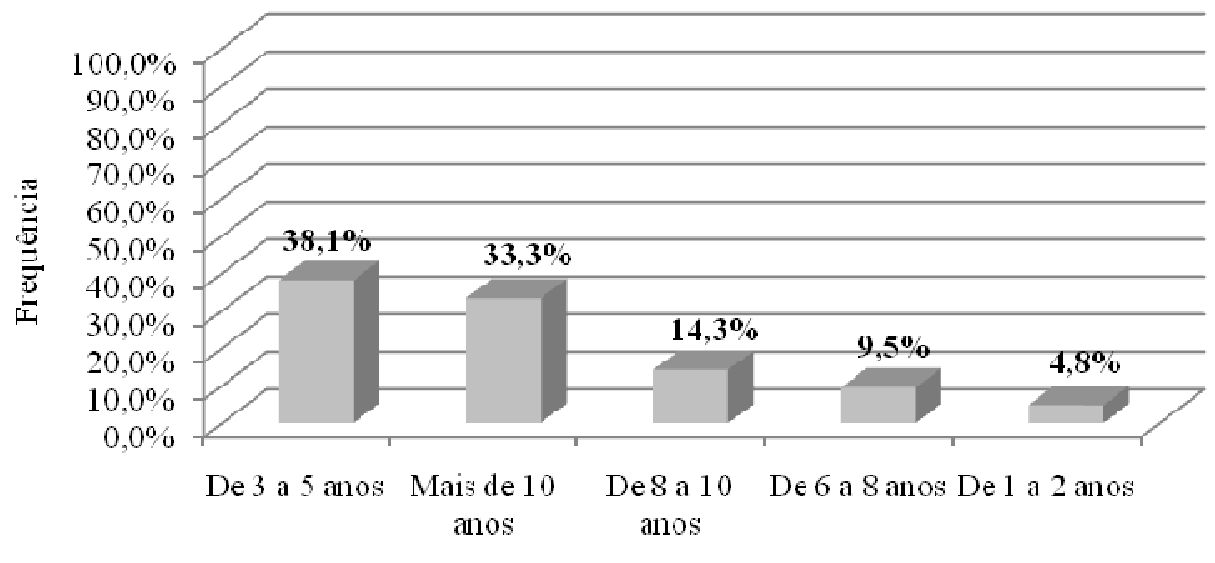

Tempo do Entrevistado na Empresa Atual

Fonte: Elaborado pela autora.

Outro elemento de caracterização do entrevistado foi o tempo que ele trabalhava na empresa em que se encontrava (Gráfico 05), no momento da realização da pesquisa. A maioria dos respondentes tem entre 3 e 5 anos de empresa, o que corresponde a 38,1\% dos entrevistados. Em seguida, aparecem os 33\% de indivíduos que já estão há mais de 10 anos na organização. Por fim, apenas 4,8\% são recém chegados.

Tabela 04 - Participação em Projeto de Desenvolvimento de Novos Produtos

\begin{tabular}{l|c|c}
\hline \multicolumn{1}{c|}{ Participação em Projetos de Desenvolvimento de Novos Produtos } & Freqüência & $\%$ \\
\hline $\begin{array}{l}\text { Sim, estou participando de um ou mais projetos de desenvolvimento de novo } \\
\text { produto na empresa em que estou atualmente }\end{array}$ & 11 & $52,4 \%$ \\
\hline $\begin{array}{l}\text { Sim, já participei de projetos de desenvolvimento de novos produtos na empresa em } \\
\text { que estou atualmente, mas não participo de nenhum no momento }\end{array}$ & 6 & $28,6 \%$ \\
\hline Nunca participei de nenhum projeto de desenvolvimento de novos produtos & 3 & $14,3 \%$ \\
\hline $\begin{array}{l}\text { Sim, já participei de projetos de desenvolvimento de novos produtos em outras } \\
\text { empresas, mas não na que estou atualmente }\end{array}$ & 1 & $4,8 \%$ \\
\hline Total & $\mathbf{2 1}$ & $\mathbf{1 0 0 , 0 \%}$ \\
\hline
\end{tabular}

Fonte: Elaborado pela autora.

Quanto à participação dos entrevistados em projetos de novos produtos (Tabela 04), 52,4\% estavam participando de algum projeto de DNP no momento da pesquisa, 28,6\% já participaram de projetos de novos produtos na empresa atual, mas não estavam engajados em 
nenhum no momento; $14,3 \%$ nunca participaram de projetos de novos produtos antes e apenas 4,8\% já participaram de projetos de DNP em momentos anteriores, mas não na empresa atual.

Optou-se, portanto, pela manutenção de todas as respostas, inclusive dos indivíduos que nunca participaram de projetos de novos produtos na organização, como forma de obter uma visão também de fora para dentro do contexto de projetos.

\section{Gráfico 06 - Tempo que Participa de Projetos de Novos Produtos}

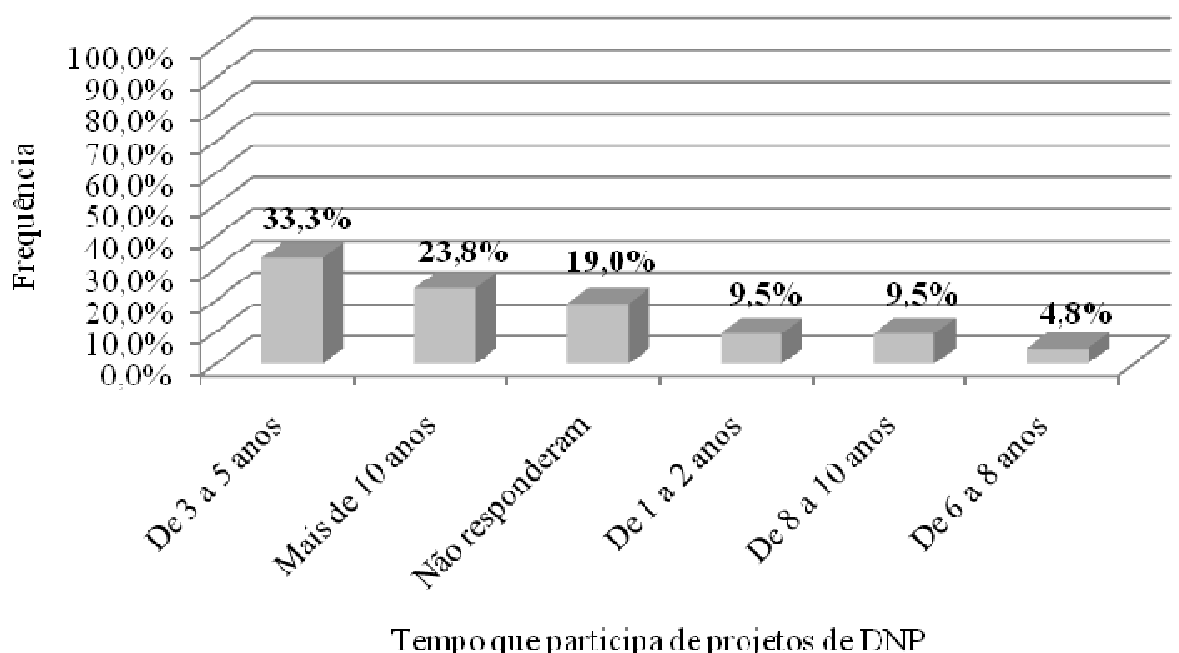

Fonte: Elaborado pela autora.

Uma variável considerada para que se tenha idéia da experiência do respondente é o tempo que participa de projetos de desenvolvimento de novos produtos, que pode ser observado no Gráfico 06. $\mathrm{Na}$ amostra pesquisada, 33,3\% dos indivíduos possuíam de 3 a 5 anos de experiência com desenvolvimento de novos produtos, seguidos de $23,8 \%$ com experiência de mais de 10 anos. Ainda neste gráfico, 19\% dos entrevistados não responderam, 9,5\% trabalham com DNP apenas de 1 a 2 anos, 9,5\% de 8 a 0 anos e apenas $4,8 \%$ de 6 a 8 anos. Os dados sobre experiência com desenvolvimento de novos produtos são semelhantes aos dados observados no Gráfico 05 , sobre o tempo que o funcionário trabalha na empresa atual, porém, não há dados suficientes para saber se há uma ligação entre as respostas nestes dois cenários. 
Tabela 05 - Quantidade de Projetos de DNP que o Entrevistado Participa Atualmente

\begin{tabular}{l|r}
\hline \multicolumn{1}{c|}{ Estatística Descritiva } & \multicolumn{1}{|c}{ Valor } \\
\hline Média & 13,4 \\
\hline Mediana & 5,0 \\
\hline Moda & 5,0 \\
\hline Mínimo & 2,0 \\
\hline Máximo & 95,0 \\
\hline N & 10,0 \\
\hline
\end{tabular}

Fonte: Elaborado pela autora.

A pesquisa buscou ainda mensurar a quantidade de projetos de desenvolvimento de novos produtos em que os entrevistados estão envolvidos atualmente (Tabela 05). A quantidade média foi de 13,4 projetos, enquanto a mediana foi de 5. A média foi elevada pelo máximo de 95 projetos. Cabe salientar que não foi solicitado ao respondente que especificasse o seu grau de envolvimento em cada projeto. Desta feita, em uma empresa cuja média de projetos de novos produtos, por ano, é de 5.000, por exemplo, uma pessoa pode estar envolvida, de forma indireta, em até 95 projetos, direta ou indiretamente, como foi alegado neste estudo por um dos respondentes.

\section{Tabela 06 - Principal Experiência do Entrevistado em Projetos de DNP nos Últimos 3}

Anos

\begin{tabular}{l|r|r}
\hline & Freqüiência & $\%$ \\
\hline Gerente do Projeto & 7 & $33,3 \%$ \\
Outra & 6 & $28,6 \%$ \\
Membro da Equipe de Projetos & 6 & $28,6 \%$ \\
Consultor & 2 & $9,5 \%$ \\
\hline Total & & $100,0 \%$ \\
\hline
\end{tabular}

Fonte: Elaborado pela autora.

Como pode ser observado na Tabela 06, considerando a amostra geral de 21 respondentes, 33,3\% deles já tiveram experiência (s) como gerentes de projetos. Considerando a participação dos entrevistados em projetos de desenvolvimento de novos produtos, perguntouse sobre sua principal experiência dos entrevistados em projetos desta natureza, nos últimos 3 anos de trabalho. Como resultado, encontrou-se que 33,3\% dos 21 entrevistados já haviam sido gerentes de projetos, $28,6 \%$ já participaram deste tipo de projetos como membros da equipe de projetos e $9,5 \%$ já haviam participado desse tipo de projetos como consultores. 
Tabela 07 - Outras Experiências dos Entrevistados em Projetos de DNP nos Últimos 3 Anos

\begin{tabular}{l|c|c}
\hline & Freqüência & $\%$ \\
\hline Não participei & 4 & $19,0 \%$ \\
Diretor & 1 & $4,8 \%$ \\
Marke Potenial/BI/ Business Development & 1 & $4,8 \%$ \\
\hline Total & 6 & $28,6 \%$ \\
\hline
\end{tabular}

Fonte: Elaborado pela autora.

Entre os demais $28,6 \%$, que estão na categoria "outra", estão os 3 indivíduos que nunca participaram de projetos de desenvolvimento de novos produtos $(19,0 \%)$, um dos pesquisados não teve experiência com DNP nos últimos 3 anos, estes quatro, somados, chegam ao índice de $19 \%$. As 2 outras respostas somadas $(9,6 \%)$ foram as que não se aplicavam a qualquer uma das categorias propostas no questionário, como pode ser observado na Tabela 07.

\subsection{Análise Descritiva da Orientação para Mercado}

Neste tópico será analisada a moda das variáveis de Geração de Inteligência, Disseminação da Inteligência e Resposta à Inteligência, com objetivo de mensurar o grau de orientação para mercado, de acordo com a visão dos respondentes. Para tanto, os gráficos apresentam, no eixo, vertical, a mesma escala utilizada no questionário, que segue a seguinte legenda: 1) Discordo Totalmente, 2) Discordo Muito, 3) Discordo Pouco, 4) Concordo Pouco, 5) Concordo Muito, 6) Concordo Totalmente. 


\section{Gráfico 07 - Grau de Geração de Inteligência nas Empresas Estudadas}

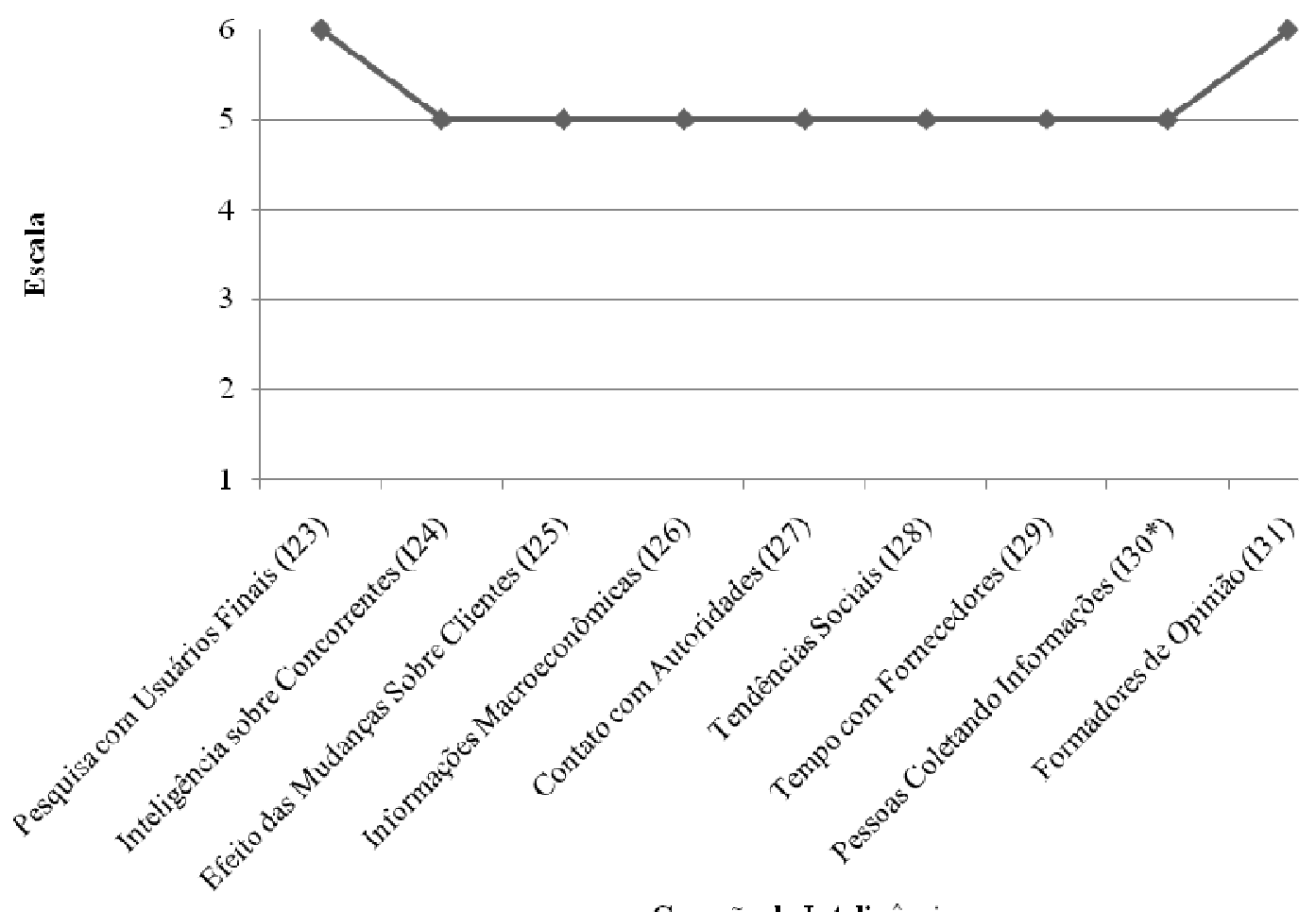

Geração de Inteligência

Fonte: Elaborado pela autora.

(*) Escala invertida.

OBS.: Gráfico construído com base na moda da distribuição.

A variável Geração da Inteligência (Gráfico 07) é composta por 9 indicadores. O primeiro deles, diz respeito a pesquisas com usuários finais (I23), para avaliação da qualidade dos produtos. Na escala de 1 a 6 pontos, a moda deste indicador ficou em 6 pontos, o que indica altos graus de concordância com a afirmativa. Em outras palavras, entende-se que a maioria dos entrevistados acredita que estão sendo feitas pesquisas com usuários finais para garantir a qualidade dos produtos resultantes dos projetos de novos produtos em que eles já tiveram experiência. Em reforço a esta afirmação, a soma máxima possível para esta variável seria de 126 pontos. As respostas obtidas alcançaram 105 pontos (Gráfico 08). Estas posições reforçam a alta concordância para este indicador. 


\section{Gráfico 08 - Grau de Geração de Inteligência nas Empresas Estudadas}

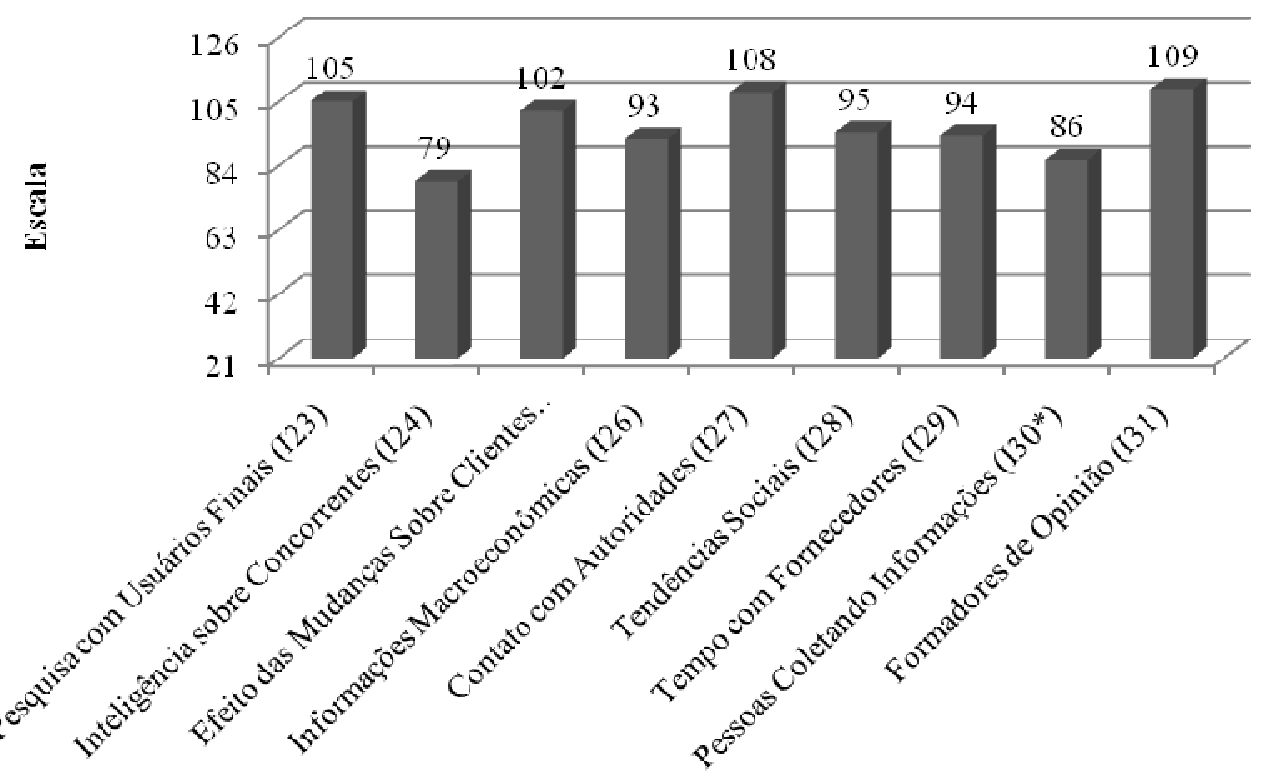

Geração da Inteligência

Fonte: Elaborado pela autora.

(*) Escala invertida.

OBS.: Gráfico construído com base na soma da distribuição.

Em relação à geração de inteligência sobre os concorrentes (I24) a somatória resultou em apenas 79 pontos (Gráfico 08) e moda de 5 pontos (Gráfico 07). Estes resultados indicam, segundo a sentença, que os departamentos tendem a produzir a produzir informações sobre os concorrentes de forma conjunta e não totalmente independente, como proposto na escala, visto que o valor de 79 corresponde quase à metade da somatória máxima da sentença. Esta é a menor somatória do grupo. Este indicador, no trabalho de Müller Neto (2005), teve a maior parte de sua freqüência relativa bem espalhada entre os 4,5 e 6 pontos da escala, o que traz um resultado bastante semelhante ao estudo em contexto de projetos, onde este é o indicador menos expressivo do construto.

De acordo com os Gráficos 07 e 08, os dados dos entrevistados permitem afirmar que, segundo sua experiência, o provável efeito das mudanças no ambiente de negócios sobre os clientes (I25) é considerado relevante nos projetos de desenvolvimento de novos produtos, 
com uma moda de 5 pontos (Gráfico 07) e uma somatória de 102 pontos (Gráfico 08). Neste sentido, entende-se que nos projetos em que os entrevistados estiveram envolvidos, a preocupação com o ambiente de negócios, como fonte geradora de informações que afeta aos clientes é considerada forte.

O indicador 26 da pesquisa (I26), que diz respeito à coleta e avaliação de variáveis macroeconômicas durante os projetos de desenvolvimento de novos produtos, também obteve índices médios e altos de resposta, com a moda situada nos 5 pontos, como pode ser observado no Gráfico 07, e uma soma de 93 pontos (Gráfico 08), no geral.

Em relação aos contatos com autoridades (I27) de organizações governamentais e regulamentadoras para coletar e avaliar informações pertinentes aos projetos, a soma geral do indicador foi de 108 pontos, a segunda mais alta da variável, como pode ser notado no Gráfico 08. A moda acompanha a somatória e também aparece alta, no Gráfico 07, chegando a 5 pontos. $\mathrm{O}$ alto índice de concordância com este indicador mostra a preocupação das equipes de projetos com questões legais e regulatórias em projetos de desenvolvimento de novos produtos e destaca que as relações políticas ultrapassam as barreiras da organização no momento da geração de inteligência para o projeto.

Ainda nos Gráficos 07 e 08, o indicador relativo a como as informações sobre tendências sociais (I28) gerais podem afetar os projetos de desenvolvimento de novos produtos, apresentou uma moda de 5 pontos e uma somatória de 95 pontos. Diante deste resultado, entende-se que há uma preocupação com este ponto dentro da geração de informação no projeto, mas que este não é o ponto-chave do construto, dado que a somatória encontra-se em um valor intermediário, em relação aos demais indicadores de geração da inteligência.

No que diz respeito ao tempo passado com fornecedores (I29) em busca de aprendizado sobre seus negócios, encontrou-se uma moda de 5 e um somatório de 94 pontos, o que indica também um alto índice de concordância dos respondentes com esta afirmativa.

$\mathrm{O}$ indicador $30\left(\mathbf{I 3 0}^{*}\right)$, que trata da existência de pessoas coletando informações para o projeto. A escala foi invertida, por conta da estrutura da pergunta, desta feita, todas as pessoas que responderam Concordo Totalmente, na verdade, estavam discordando totalmente com a situação. Para análise, neste caso, após todas as respostas tabuladas, a escala foi invertida, 
para que assumisse o verdadeiro sentido a que se propunha. Desta mesma forma, foram transformados todos os indicadores que contém um asterisco $(*)$. Com os resultados, obtevese uma moda de 5 e uma soma de 86 pontos, o que significa que, na opinião dos pesquisados, há pessoas nos projetos de desenvolvimento de novos produtos coletando informações sobre os concorrentes.

Por fim, o indicador que diz respeito a relações com formadores de opinião (I31), para saber as tendências atuais e usá-las nos projetos, obteve-se uma moda de 6 pontos e uma somatória de 109, a maior de todas as variáveis do construto, o que indica que os formadores de opinião possuem um papel importante na geração de inteligência para projetos de desenvolvimento de novos produtos.

Observou-se, portanto, nos Gráficos 07 e 08, a mensuração descritiva dos indicadores da variável Geração de Inteligência. Pelo fato de todas as modas serem iguais ou superiores a 5 pontos e as somas ficarem todas acima de 50\% do máximo possível (126 pontos), acredita-se que este construto possui uma alta manifestação, segundo as opiniões de pessoas envolvidas com projetos de desenvolvimento de novos produtos entrevistadas para esta pesquisa. 


\section{Gráfico 09 - Grau de Disseminação da Inteligência nas Empresas Estudadas}

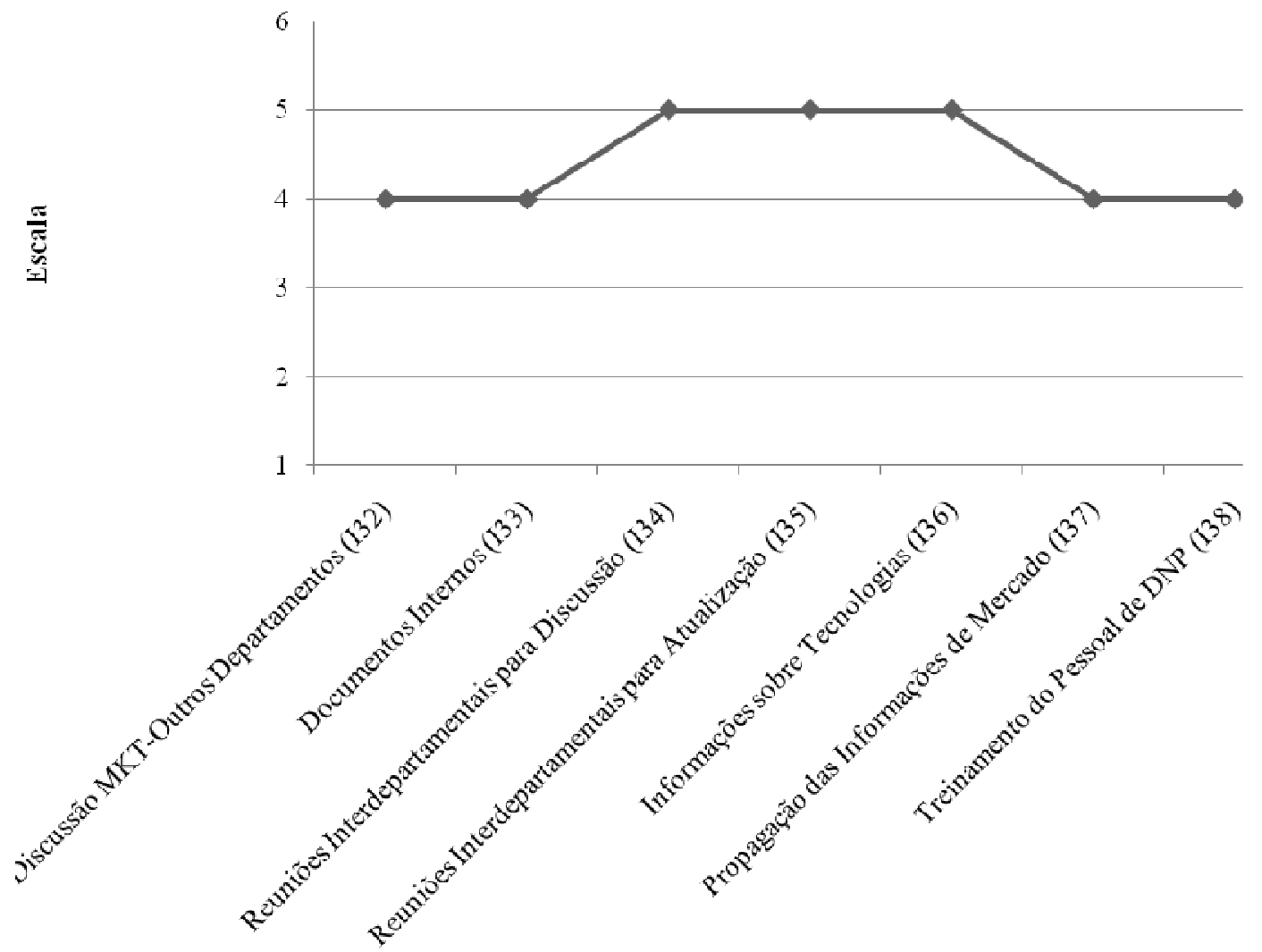

Disseminação da Inteligência

Fonte: Elaborado pela autora.

OBS.: Gráfico construído com base na moda da distribuição.

A Variável Disseminação da Inteligência é composta por 7 indicadores (Gráficos 09 e 10). O primeiro deles diz respeito a discussão de marketing com outros departamentos (I32), sobre as necessidades futuras dos clientes. Na escala de 1 a 6 pontos, a moda desta variável ficou em 4 pontos (Gráfico 09), o que indica um grau de concordância com a afirmativa de médio para alto. Considerando os 21 respondentes, a soma máxima possível para esta variável seria de 126 pontos. As respostas obtidas alcançaram 91 pontos (Gráfico 10), o que representa que a maioria dos entrevistados acreditam que há uma certa interface entre a área de marketing e as demais áreas da organização, como forma de transmitir as necessidades dos clientes para os participantes de projetos de novos produtos. 


\section{Gráfico 10 - Grau de Disseminação da Inteligência nas Empresas Estudadas}
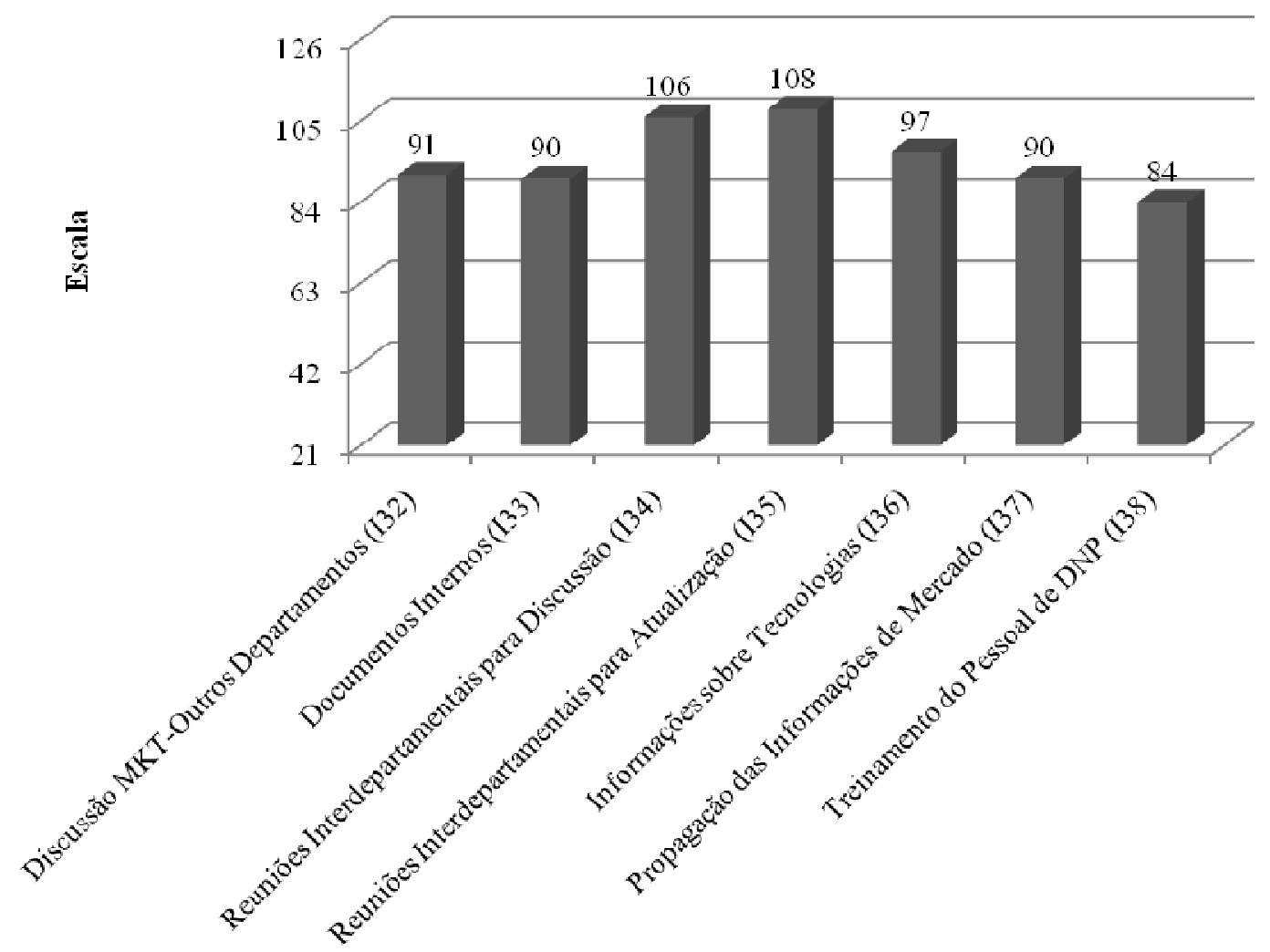

Disseminação da Inteligência

Fonte: Elaborado pela autora.

OBS.: Gráfico construído com base na soma da distribuição.

Em relação à circulação de documentos internos (I33) com informações sobre clientes, no Gráfico 10, a somatória resultou em 90 pontos (um ponto a menos que o I32) e moda, também, de 4 pontos. Estes números podem significar que, nos projetos de novos produtos onde os respondentes já tiveram experiências, a circulação de documentos internos com informações sobre clientes acontece, mas não de forma totalmente efetiva.

De acordo com os dados do Gráfico 09, os dados dos entrevistados permitem afirmar que ocorrem reuniões interdepartamentais para discussão (I34) de tendências e desenvolvimento de mercado, com uma concordância alta, visto que a moda foi de 5 pontos e 
a soma das respostas foi de 106 pontos, a segunda maior soma da variável de Disseminação da Inteligência.

Um pouco parecida com o indicador 34, o I35 buscou avaliar a posição dos respondentes em relação à existência de reuniões interdepartamentais para atualização dos participantes sobre as exigências pertinentes aos projetos. No indicador 35, como pode ser visto nos Gráficos 09 e 10, a moda foi de 5 pontos e a soma foi de 108 pontos para todas as respostas somadas. Considerando que a soma máxima seria de 126 pontos, 108 é o valor que mais se aproxima da pontuação máxima e também é muito próximo da soma 106, encontrada quando se trata das reuniões para discussão de tendências de mercado.

Em relação ao compartilhamento de informações sobre tecnologias (I36) de novos produtos, passadas pelo pessoal técnico para os demais departamentos, a soma geral da variável foi de 97 pontos (Gráfico 10) e a moda de 5 pontos (Gráfico 09), situada na classificação Concordo Muito. Os resultados para este indicador podem apontar para uma manifestação de moderada a alta da preocupação com a transmissão de informações técnicas sobre os produtos aos membros das equipes de projetos, porém, nem sempre os pesquisados concordam que esta transmissão de informações ocorra de forma adequada.

Ainda nos Gráficos 09 e 10, o indicador relativo à propagação de informações de mercado pelos níveis hierárquicos do projeto (I37), foi encontrada uma moda de 4 e uma somatória de 90 pontos. Diante deste resultado, entende-se que há uma preocupação com a propagação das informações de mercado pelo projeto, mas que deve haver certa dificuldade na disseminação dessas informações por todos os níveis, se destacada a baixa concordância dos respondentes.

No que diz respeito ao treinamento do pessoal de desenvolvimento de novos produtos (I38) para saber como atender ao cliente, encontrou-se a soma mais baixa de respostas totais, atingindo apenas 84 pontos (Gráfico 10), com moda de 4 pontos (Gráfico 09). Estes dados indicam que os respondentes concordam que há este tipo de treinamento nos projetos de desenvolvimento de novos produtos, mas questões como a constância (constantemente) e o fim (para atender melhor ao cliente) destes treinamento não sejam exatamente os afirmados na sentença, o que pode ter gerado a redução nos índices de concordância. 
Similarmente ao construto de Geração de Inteligência, na Disseminação da Inteligência Gerada, observou-se nos Gráficos 09 e 10 a mensuração descritiva das variáveis do construto que todas as modas foram iguais ou superiores a 4 e as somas foram maiores que a metade do máximo esperado (126 pontos). Os indicadores I34 e I35 apontam para a existência de reuniões entre os departamentos, tanto para discussão, quanto para atualização dos projetos. Em contrapartida, os indicadores I32 e I33, que abordam a discussão de marketing com outros departamentos e circulação de documentos internos, além dos indicadores I37 e I38, referentes à propagação de informações de mercado e treinamento do pessoal nos projetos, foram de baixa concordância e podem sinalizar uma deficiência na disseminação da informação captada no mercado, quando há necessidade de maior interação entre os envolvidos no projeto. Neste sentido, pode-se dizer que a variável Disseminação da Inteligência, pertencente ao construto de Orientação para Mercado, possui uma manifestação de média a alta, segundo as opiniões de pessoas envolvidas com projetos de desenvolvimento de novos produtos entrevistadas para esta pesquisa.

\section{Gráfico 11 - Grau de Resposta à Inteligência nas Empresas Estudadas}

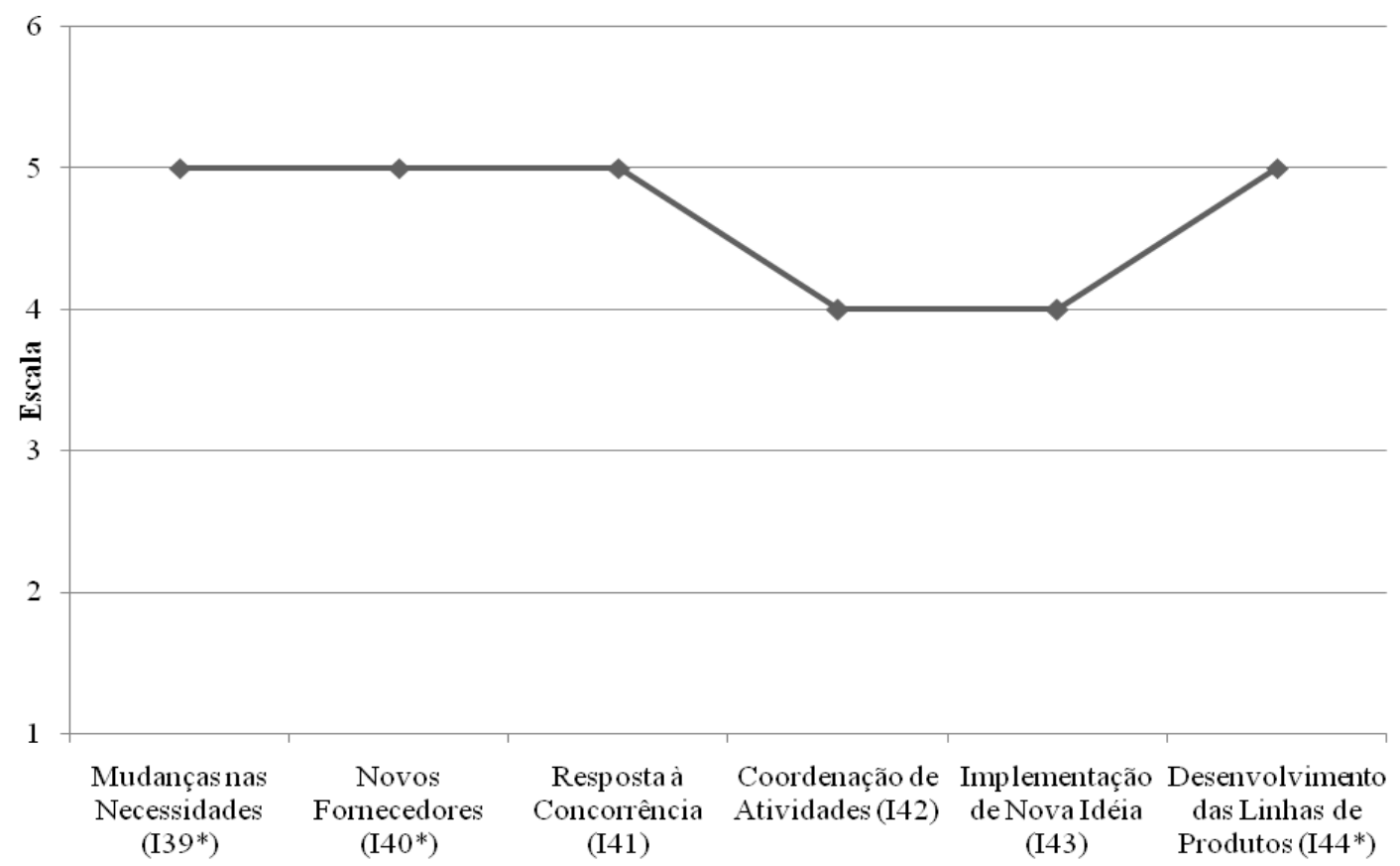

Resposta à Inteligência

Fonte: Elaborado pela autora.

(*) Escala invertida.

OBS.: Gráfico construído com base na moda da distribuição. 
A variável Resposta à Inteligência (Gráficos 11 e 12) é composta por 6 indicadores. $\mathrm{O}$ primeiro deles, trata da atenção prestada às mudanças nas necessidades de produtos advindas dos clientes (I39*), para os quais os produtos são desenvolvidos nos projetos. Esta escala também é invertida, ou seja, após realizada a pesquisa, foram invertidos os resultados quantitativos, para dar o verdadeiro sentido a que o indicador se propunha. A moda deste indicador ficou em 5 pontos (Gráfico 11), após a inversão, o que significa que, ao contrário do que afirma a sentença no questionário, há uma grande preocupação com as mudanças nas necessidades dos clientes no decorrer do projeto. A soma de todas as respostas chegou a 89 pontos (Gráfico 12), um índice de médio para alto, quando se considera que a pontuação geral poderia chegar a 126 pontos, o que reforça o comportamento da moda.

\section{Gráfico 12 - Grau de Resposta á Inteligência nas Empresas Estudadas}

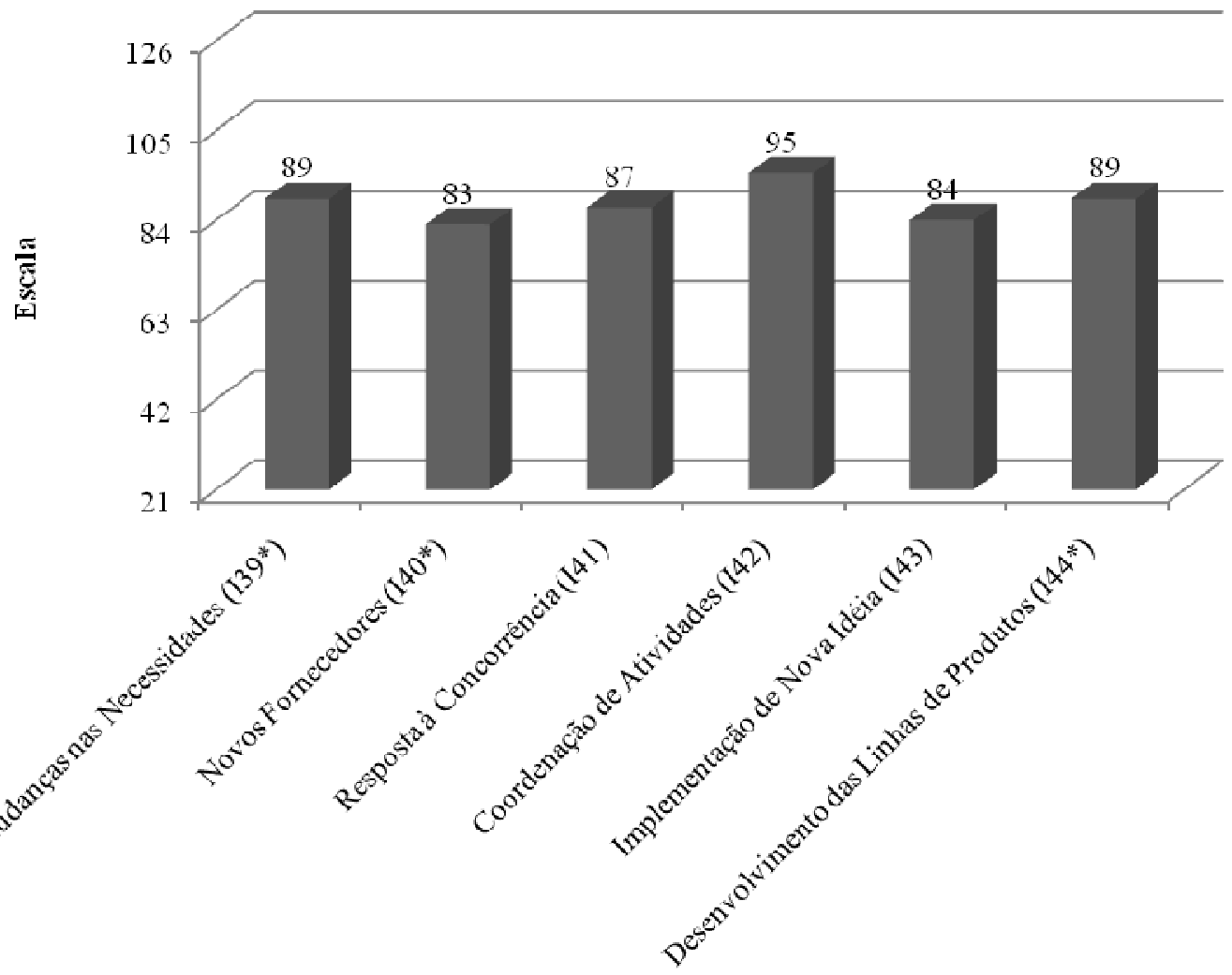

Resposta à Inteligência

Fonte: Elaborado pela autora.

(*) Escala invertida.

OBS.: Gráfico construído com base na soma da distribuição. 
Em relação à agilidade de início de negócios com novos fornecedores (I40*) para os projetos, a soma geral do indicador foi de 83 pontos, a menor do construto, com uma moda de 5 pontos (Gráfico 11). Estes resultados já estão com a escala invertida e já mensuram a variável em seu significado real, ou seja, os respondentes concordam com o fato de que há certa agilidade na troca de fornecedores, o que corresponde à moda de respostas, apesar de ter o somatório mais baixos da variável.

Ainda nos Gráficos 11 e 12, para o indicador relativo à resposta imediata à concorrência (I41), foi encontrada uma moda de 5 e uma somatória de 87 pontos. Diante deste resultado, entende-se que há certa agilidade na resposta às ações da concorrência no decorrer do projeto, porém, deve haver alguns entraves que façam com que esta resposta não seja tão rápida quanto se deseja para o projeto, segundo a opinião dos respondentes.

No que diz respeito à coordenação de atividades de diferentes departamentos (I42) envolvidos no projeto, encontrou-se uma moda de 4 pontos e um somatório de 95 pontos, a maior somatória entre as variáveis de Resposta à Inteligência. Este resultado indica que, apesar de a maioria dos respondentes estarem posicionados na coluna Concordo Pouco, houve uma maior amplitude entre as respostas, ou seja, houve algumas respostas de 6 pontos (Concordo Totalmente), para que a soma ultrapassasse, por exemplo, o Indicador 41, onde a moda é 5 , mas a somatória é a menor da variável. Neste sentido, pode-se entender que há leves divergências quando se trata da coordenação de atividades de diferentes departamentos, na opinião dos respondentes. Isto pode estar associado aos diferentes tipos de experiência dos entrevistados e ao tipo de projeto de desenvolvimento de novos projetos em que eles já estiveram inseridos.

Quando se trata da implementação de uma nova idéia (I43) a tempo no projeto, a moda de 4 e a soma de 84 pontos denotam uma capacidade de moderada a alta de responder rapidamente à necessidade de implementação de uma nova idéia.

O indicador 44 (I44), último da variável de Resposta à Inteligência, refere-se ao que é levado em consideração (se as políticas internas, ou informações de mercado) na decisão de desenvolvimento da linha de produtos da organização. A pergunta, mais uma vez, foi feita de forma invertida aos entrevistados da pesquisa, mas os resultados são apresentados aqui de forma a responder a questão afirmativamente. Sendo assim, com mediana de 5 e soma de 89 
pontos, após a escala já ter sido invertida, as respostas dos entrevistados permitem entender que há uma maior consideração das informações de mercado do que de políticas internas para decisões relativas à linha de produtos da organização, na visão dos entrevistados.

Fazendo uma análise geral da variável Resposta á Inteligência, pode-se dizer que esta foi identificada como a variável de menor representatividade, em se tratando das estatísticas, para a formação do construto de Orientação para Mercado, em relação às respostas dos pesquisados neste estudo. Comparando-o com os construtos de Geração e Disseminação da Inteligência, o de Resposta obteve o menor somatório geral entre as variáveis.

A avaliação das três variáveis do construto de Orientação para Mercado, segundo a análise descritiva dos dados, indica que, no contexto de projetos de desenvolvimento de novos produtos, há um maior esforço na geração e disseminação da inteligência de mercado, porém, com um menor rendimento na resposta a estas informações.

\subsection{Análise Descritiva da Interface Inter-Funcional}

No tópico 4.4 serão destrinchadas a moda e a soma para cada um dos indicadores das variáveis confiança e integração, pertencentes ao construto de interface inter-funcional, buscando identificar os graus de manifestação destes blocos, de acordo com a experiência dos membros de equipes de desenvolvimento de novos produtos entrevistados neste estudo. 


\section{Gráfico 13 - Grau de Confiança nas Empresas Estudadas}

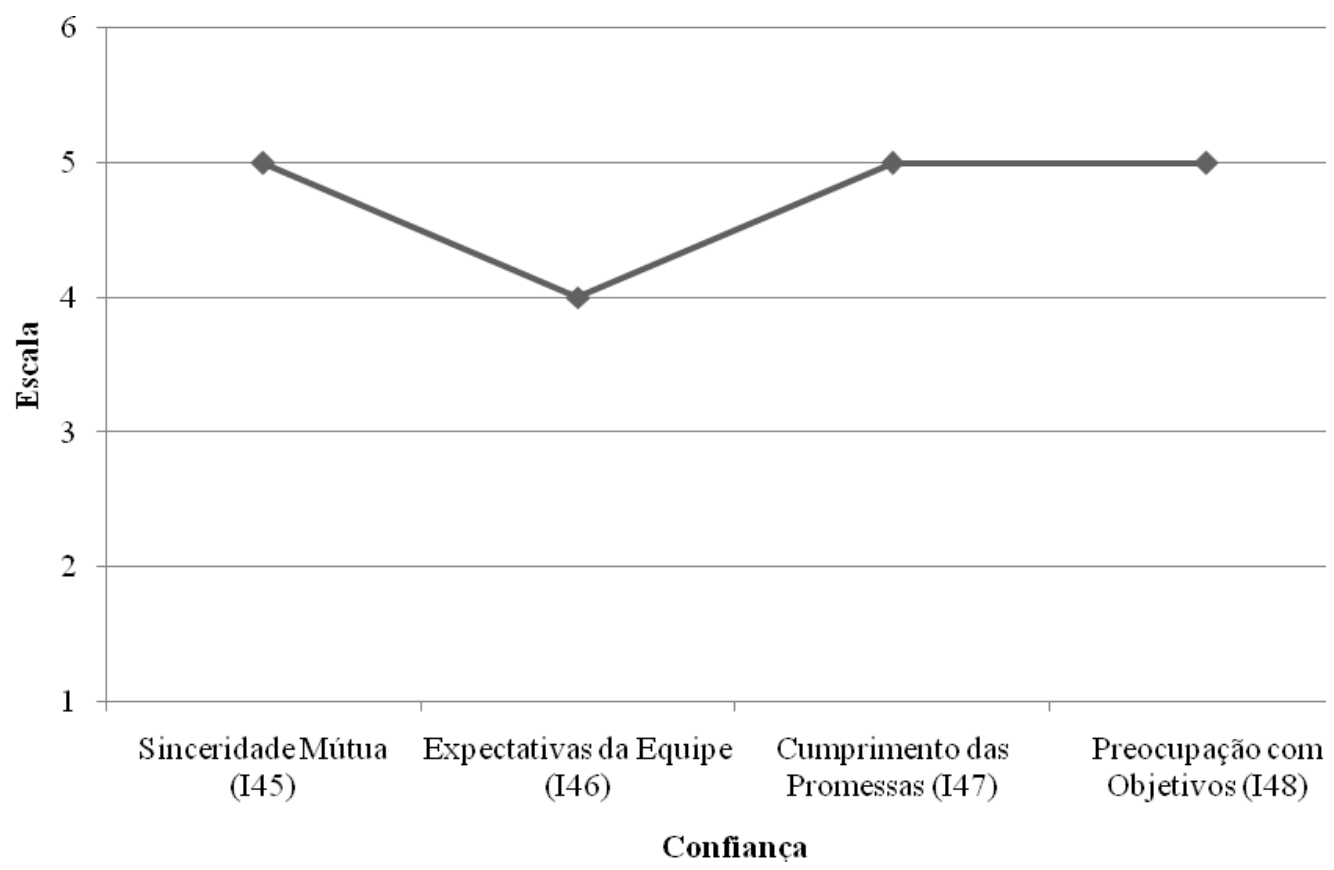

Fonte: Elaborado pela autora.

OBS.: Gráfico construído com base na moda da distribuição.

A variável Confiança é representada pelos Gráficos 13 e 14 e composta de 4 indicadores. O indicador 45, que representa o quesito sinceridade mútua (I45), obteve moda 5 (Gráfico 13) e somatório de 95 pontos, onde o máximo pode chegar a 126 (Gráfico 14). Estes dados permitem afirmar que os entrevistados da pesquisa acreditam que, por parte dos envolvidos com projetos de desenvolvimento de novos produtos, há um alto grau de sinceridade entre os departamentos envolvidos em projetos de novos produtos. 


\section{Gráfico 14 - Grau de Confiança nas Empresas Estudadas}

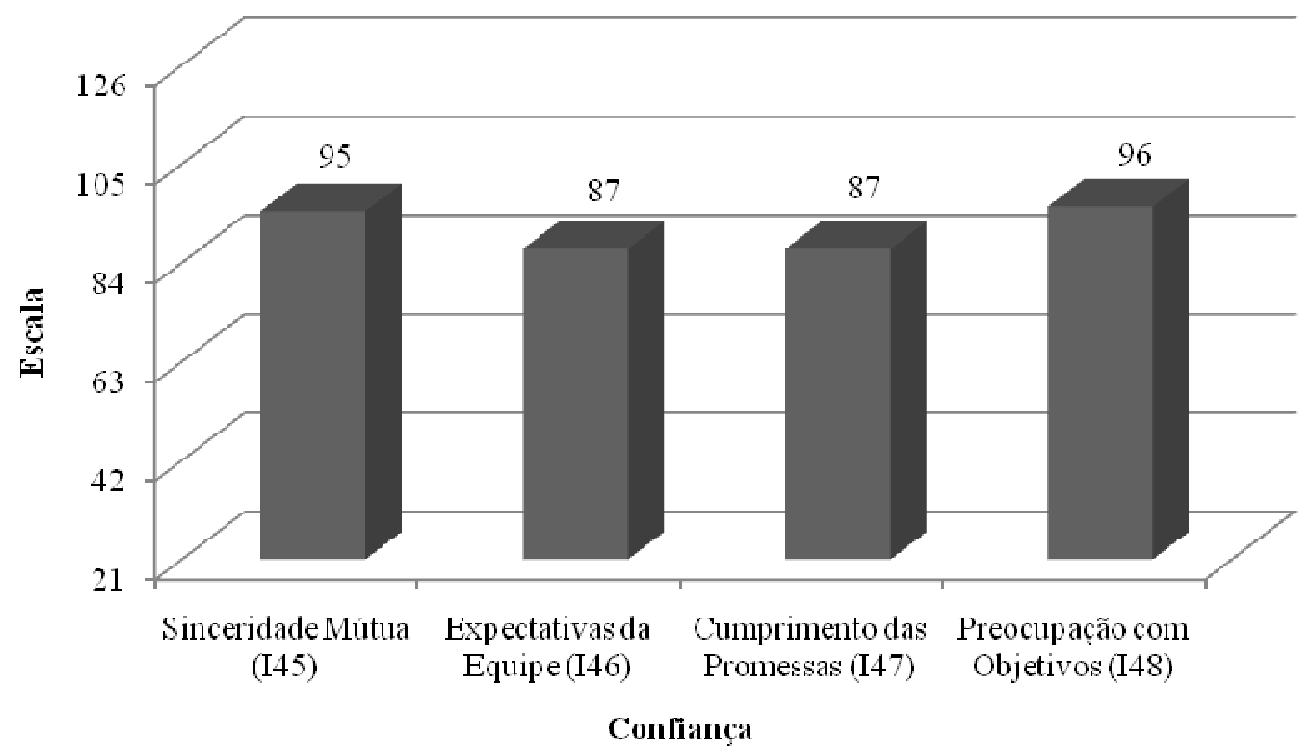

Fonte: Elaborado pela autora.

OBS.: Gráfico construído com base na soma da distribuição.

Em relação ao atendimento das expectativas da equipe de projetos (I46) por parte dos demais departamentos da organização, a somatória resultou em 87 , como pode ser observado no Gráfico 14. A moda encontrada foi a menor entre os indicadores da variável, ficando situada em 4 pontos, o que significa que a maioria dos entrevistados Concorda Pouco com a afirmação no I46. Estes resultados indicam que, a moda estar acima do corte central da escala e de a somatória também corresponder a mais da metade do total padrão de 126 pontos, há uma certa carência na satisfação das expectativas da equipe de projetos pelos demais departamentos das organizações, na opinião dos pesquisados. Apesar de ser um resultado menos expressivo que o encontrado no indicador 45, este dado ainda representa de forma positiva a satisfação das expectativas da equipe de projetos, no contexto de desenvolvimento de novos produtos, pelos demais departamentos da empresa.

De acordo com os dados do Gráfico 13, há uma alta concordância de que há um cumprimento das promessas (I47) por parte dos departamentos, na visão da maioria dos entrevistados, considerando-se o contexto de projetos de desenvolvimento de novos produtos. A moda de 5 pontos na escala e a soma 87 colocam esta variável no patamar das demais, o 
que significa um alto índice de cumprimento das promessas pelos departamentos em projetos de desenvolvimento de novos produtos dos quais os entrevistados participaram.

Em relação à preocupação com os objetivos do projeto (I48), identificou-se a mais alta pontuação da variável Confiança, com mediana de 5 e soma de 96 pontos. Esta pontuação indica que os entrevistados acreditam no comprometimento com os objetivos do projeto por parte da equipe. Pelo fato de este ser o indicador de manifestação mais expressiva, porém bastante alinhado com os demais, entende-se que as demais dimensões da confiança entre os membros da equipe pode ser vista pelos respondentes como elementos fundamentais para o cumprimento dos objetivos do projeto.

Ao observar a variável Confiança de forma global, entende-se que há uma opinião otimista dos entrevistados, em relação a todas as variáveis, as quais apresentam classificação de alta concordância. Houve apenas uma pequena queda na moda, em relação à satisfação das expectativas da equipe por outros departamentos, em relação ao projeto, o que pode estar relacionado com problemas na disseminação das informações dentro do projeto.

\section{Gráfico 15 - Grau de Integração nas Empresas Estudadas}

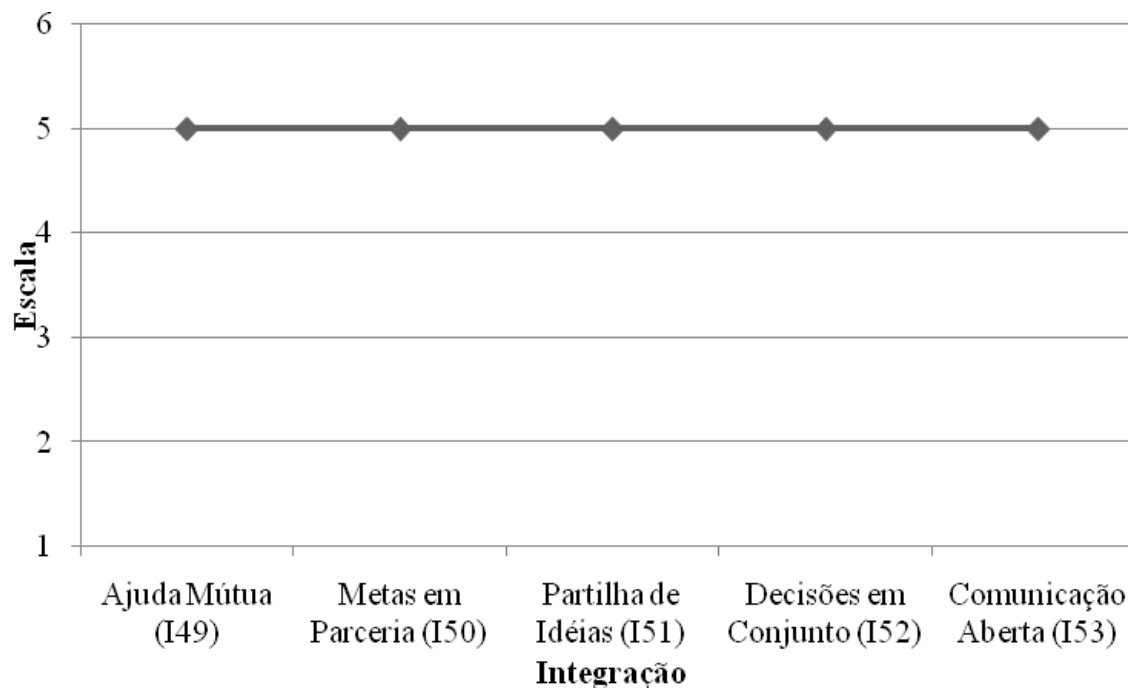

Fonte: Elaborado pela autora.

OBS.: Gráfico construído com base na moda da distribuição. 
A variável Integração é composta por 5 indicadores. O primeiro deles trata da ajuda mútua (I49) entre os departamentos envolvidos nos projetos. Esta variável traz a moda em 5 pontos (Gráfico 15) e também a menor soma total, de 91 pontos (Gráfico 16). Estes resultados indicam que há uma alta concordância de que as equipes se ajudam no cumprimento das tarefas do projeto.

\section{Gráfico 16 - Grau de Integração nas Empresas Estudadas}

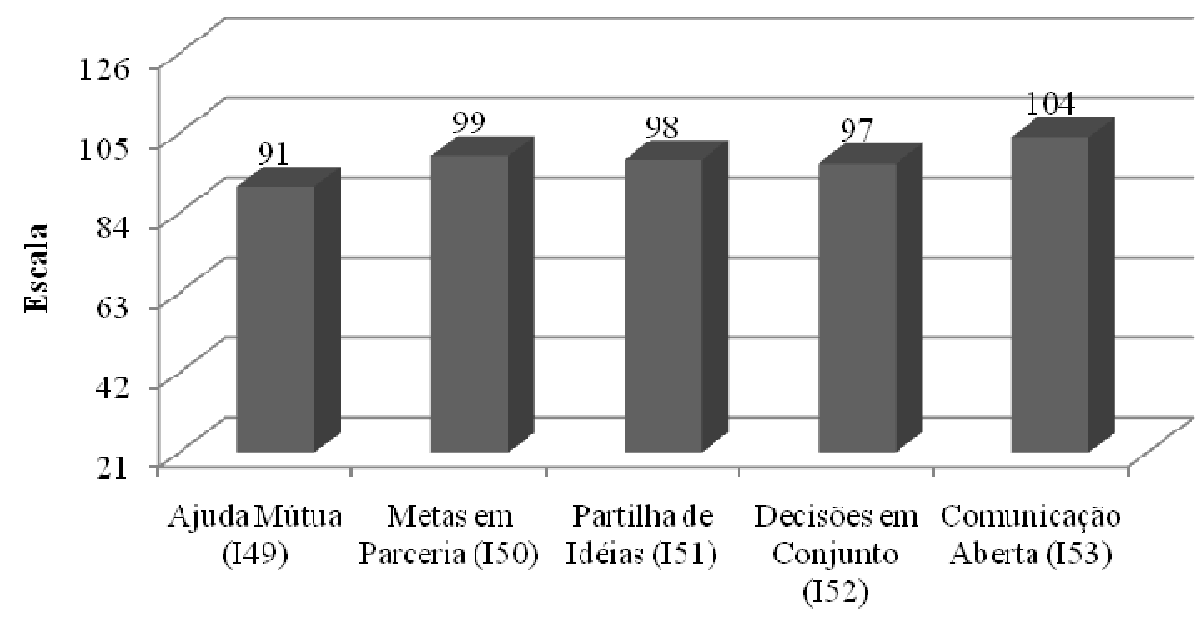

Integração

Fonte: Elaborado pela autora.

OBS.: Gráfico construído com base na moda da distribuição.

O segundo indicador da variável diz respeito à tentativa dos departamentos em atingir metas em parceria (I50), traz uma moda 5 e soma de 99 pontos. Os altos pontos atingidos por ambas as métricas indicam que, na opinião dos entrevistados, os departamentos tentam atingir as metas do projeto em parceria com as demais áreas envolvidas.

Em relação à partilha de idéias (I51) pelos departamentos durante os projetos, encontrou-se também uma moda de 5 e uma soma de 98 pontos, o que torna o cenário deste indicador muito parecido com o do anterior e indica que, nos projetos de desenvolvimento de novos produtos de que os entrevistados participaram, houve uma grande partilha de idéias entre os departamentos envolvidos no projeto. 
Ainda nos Gráficos 15 e 16, o indicador que trata da tomada de decisões em conjunto (I52) também obteve moda 5 e soma bem próxima às demais, com 97 pontos. Estes resultados permitem afirmar que, na visão dos pesquisados, muitas das decisões no projeto são tomadas em conjunto.

O último indicador da variável Integração trata da comunicação aberta (I53) entre os departamentos durante o projeto. Este indicador obteve a maior somatória da variável, com 104 pontos, e mediana 5, o que pode indicar que este indicador reforça os demais, no sentido de que, uma comunicação aberta leva a uma maior integração do grupo, no geral.

Analisando a variável de Integração de forma geral, nota-se que a maioria das respostas, nos cinco indicadores, localizaram-se na coluna do Concordo Muito. Além disso, as somas de cada indicador ficaram bem acima da metade do valor total esperado, que é de 126 pontos. Dado que as modas são todas iguais, os resultados da soma auxiliam na mensuração do grau de integração. Sendo assim, os indicadores que mais se destacam são o de ajuda mútua (I49), como o menos expressivo e o de comunicação aberta (I53), com a soma mais alta. Entende-se, portanto, que os departamentos estão integrados nos projetos de desenvolvimento de novos produtos, com uma comunicação bastante aberta, porém, com um índice de ajuda mútua abaixo dos demais indicadores que compõem a variável.

Em síntese, após análise das variáveis Confiança e Integração, entende-se que o construto de Interface Inter-Funcional apresenta altos níveis de manifestação, quando analisadas as estatísticas descritivas, visto que todas as modas, ou seja, onde se concentram a maioria das respostas, igualam-se ou estão acima de 4 pontos, o que indica que todos os indicadores obtiveram alta freqüência nos índices de concordância, baixo, médio ou alto. Este cenário positivo é confirmado pela soma das respostas possíveis de cada indicador, visto que todas ficaram acima de 63 pontos, o que seria a mediana para o valor total possível de cada indicador. Com base nestes dados, entende-se que houve um ato grau de manifestação da confiança e de integração das pessoas envolvidas em projetos de novos produtos, segundo a opinião dos entrevistados. 


\subsection{Análise das Correlações entre Orientação para Mercado e Interface Inter- Funcional}

Neste tópico serão analisadas as correlações existentes entre cada um dos indicadores das variáveis do construto de Orientação para Mercado (Geração da Inteligência, Disseminação da Inteligência e Resposta à Inteligência) e as variáveis do construto de Interface InterFuncional (Confiança e Integração). A análise das correlações toma como ponto de partida uma abordagem geral, onde os indicadores são correlacionadas diretamente, sem a consideração das variáveis moderadoras do estudo (Existência de EGP na Organização e Experiência como Gerente de Projetos). As tabelas trazem ainda as correlações, considerando a classificação, segundo o critério das duas variáveis moderadoras. Esta análise permite que se tenha uma visão dos resultados gerais, bem como dos resultados apenas para entrevistados que possuam EGP na Organização, posteriormente, apenas pra os pesquisados que já tiveram experiência como Gerentes de Projetos.

As tabelas apresentadas nos resultados expõem apenas as correlações significativas entre as variáveis de interesse.As tabelas completas podem ser encontradas no APÊNDICE II. 
Tabela 08 - Correlações Geração de Inteligência x Confiança - Critério: Existência de um EGP na Organização do Entrevistado

\begin{tabular}{|c|c|c|c|c|c|c|c|c|c|}
\hline & & & & \multicolumn{6}{|c|}{ Geração da Inteligência } \\
\hline & & & & $\begin{array}{l}\text { Pesquisa } \\
\text { com } \\
\text { Usuários } \\
\text { Finais }\end{array}$ & $\begin{array}{l}\text { Mudanças } \\
\text { sobre } \\
\text { Clientes }\end{array}$ & $\begin{array}{l}\text { Informações } \\
\text { Macroeconô } \\
\text { micas }\end{array}$ & $\begin{array}{l}\text { Tendências } \\
\text { Sociais }\end{array}$ & $\begin{array}{c}\text { Pessoas } \\
\text { Coletando } \\
\text { Informações }\end{array}$ & $\begin{array}{c}\text { Formadores } \\
\text { de Opinião }\end{array}$ \\
\hline \multirow{18}{*}{ 己్ٍ } & \multirow{4}{*}{ 宽 } & \multirow{2}{*}{$\begin{array}{l}\text { Com EGP } \\
(\mathrm{N}=12)\end{array}$} & $\rho$ &, 258 &, 514 & ,488 &, $638 *$ & ,409 & ,481 \\
\hline & & & Sign. & ,419 & 087 &, 107 &, 026 & ,187 &, 114 \\
\hline & & \multirow{2}{*}{$\begin{array}{l}\text { Sem EGP } \\
\quad(\mathrm{N}=9)\end{array}$} & $\rho$ &, $694^{*}$ &,$- 694^{*}$ &,- 323 &,- 228 &,- 597 &,- 567 \\
\hline & & & Sign. &, 038 & ,038 & ,397 &, 555 & 089 & ,111 \\
\hline & \multirow{4}{*}{ 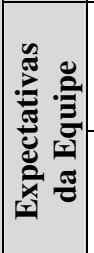 } & \multirow{2}{*}{$\begin{array}{c}\text { Com EGP } \\
(\mathrm{N}=12)\end{array}$} & $\rho$ &, 183 & ,464 &, $597 *$ &, 385 &, $579 *$ &, $615 *$ \\
\hline & & & Sign. &, 570 & ,129 &, 041 &, 217 & ,048 & 033 \\
\hline & & \multirow{2}{*}{$\begin{array}{c}\text { Sem EGP } \\
\quad(N=9)\end{array}$} & $\rho$ &, 511 &,- 521 &,- 329 &, 058 &,- 562 &,$- 698^{*}$ \\
\hline & & & Sign. &, 160 &, 151 & ,388 & ,882 &, 115 &, 037 \\
\hline & \multirow{6}{*}{ 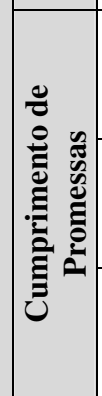 } & \multirow{2}{*}{$\begin{array}{c}\text { Todos os } \\
\text { Casos } \\
(\mathrm{N}=21)\end{array}$} & $\rho$ &, $\mathbf{5 5 2}^{* *}$ & ,086 & ,247 &, 287 &,- 152 & 016 \\
\hline & & & Sign. &, 010 & ,712 & ,280 & ,207 &, 511 & ,944 \\
\hline & & \multirow{2}{*}{$\begin{array}{c}\text { Com EGP } \\
(\mathrm{N}=12)\end{array}$} & $\rho$ &, 311 & ,384 & ,473 & ,465 & , 177 &, $707 *$ \\
\hline & & & Sign. &, 326 & ,218 &, 121 &, 128 &, 582 & 010 \\
\hline & & \multirow{2}{*}{$\begin{array}{c}\text { Sem EGP } \\
\quad(N=9)\end{array}$} & $\rho$ &, $824^{* * *}$ &,- 356 &,- 021 &, 088 &,- 502 &,$- 736^{*}$ \\
\hline & & & Sign. & ,006 & ,347 & ,958 &, 822 & ,169 & 024 \\
\hline & \multirow{4}{*}{ 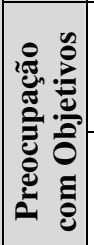 } & \multirow{2}{*}{$\begin{array}{c}\text { Com EGP } \\
(\mathrm{N}=12)\end{array}$} & $\rho$ &, 062 &, 524 &, 543 &, 430 & ,365 &, $782 * *$ \\
\hline & & & Sign. & ,848 &, 080 & ,068 &, 163 & ,243 & ,003 \\
\hline & & \multirow{2}{*}{$\begin{array}{c}\text { Sem EGP } \\
\quad(N=9)\end{array}$} & $\rho$ & ,306 &,$- 689^{*}$ & ,000 &, 126 &,- 239 &,- 563 \\
\hline & & & Sign. & ,423 &, 040 & 1,000 &, 747 &, 535 &, 115 \\
\hline
\end{tabular}

Fonte: Elaborada pela autora.

* Nível de significância $\leq 0,05$.

* Nível de significância $\leq 0,01$.

$\mathrm{Na}$ tabela 08, encontram-se as correlações entre Geração de Inteligência e Confiança. A primeira correlação encontrada foi de $0,694^{*}$, entre os indicadores que tratam da realização de Pesquisa com Usuários Finais e Sinceridade Mútua. Esta correlação foi observada entre os respondentes que não possuíam EGP na organização, o que pode indicar que, de alguma forma, as informações geradas a partir de pesquisas feitas com usuários finais, podem impactar na sinceridade entre os parceiros de projetos de desenvolvimento de novos produtos. Neste sentido, quanto mais pesquisa com usuários se faz, mas necessária é a sinceridade 
mútua na organização, para que as informações captadas circulem de forma adequada. Ainda com relação às Pesquisas com Usuários Finais, outra correlação positiva e significativa foi encontrada entre este indicador e o Cumprimento de Promessas pelos departamentos envolvidos no projeto, em todos os casos (,552**) e nos casos sem EGP (,824**). Estas correlações positivas podem significar que o Cumprimento das Promessas pelos departamentos envolvidos no projetos pode estar ligado, diretamente, com as informações sobre como as mudanças no ambiente do negócio podem afetar os clientes.

O indicador que trata da influência das Mudanças do ambiente sobre os Clientes do projeto está correlacionado, negativamente, com a Sinceridade Mútua (-,694*) entre os departamentos do projeto, o que indica que a sinceridade mútua entre os membros da equipe de projetos diminui, à medida que cresce a preocupação com o efeito das mudanças do ambiente sobre os clientes. Correlação semelhante, também negativa(-,689*), é encontrada entre a influência de Mudanças no ambiente de negócios do projeto sobre os Clientes e a Preocupação com os Objetivos do Projeto por parte dos envolvidos. Ambas as correlações negativas foram encontradas a partir das respostas de entrevistados que não possuíam EGP na organização, o que pode sinalizar uma menor noção de integração por parte dos entrevistados provenientes destas organizações.

Em relação à captação de Informações Macroeconômicas para o projeto e ao atendimento das Expectativas da Equipe pelos diversos departamentos, foi detectada uma correlação positiva, nos casos em que há EGP na organização $\left(, 597^{*}\right)$. Desta forma, entende-se que na visão dos entrevistados, com experiência em projetos de novos produtos, cuja organização atual possui um EGP, a captação de informações macroeconômicas está, de alguma forma, associada com o atendimento das expectativas da equipe, por parte dos departamentos.

A coleta de informações sobre Tendências Sociais gerais foi associada, positivamente, com o indicador Sinceridade Mútua, nos casos com EGP na organização (,579*). Este resultado leva a crer que quanto mais se coleta informações sobre tendências sociais e as leva para os projetos, mais haverá sinceridade entre os membros dos departamentos envolvidos no projeto.

Houve ainda uma correlação positiva de ,579* nos casos em que há EGP na organização entre as variáveis que dizem respeito a Pessoas Coletando Informações sobre a concorrência e Expectativas da Equipe de projetos correspondida pela atitude dos demais departamentos 
envolvidos. Este resultado leva a crer que, quanto mais houver pessoas coletando informações sobre a concorrência, maior será o grau de correspondência às expectativas da equipe de projetos pelos demais departamentos. Provavelmente, este resultado se dá porque, com a maior coleta, as informações também chegam mais facilmente ao pessoal de projetos, trazendo as informações necessárias para o trabalho.

A relação com Formadores de Opinião para obtenção de informações para o projeto está positivamente correlacionada $\left(, 615^{*}\right)$ com o indicador Expectativas na Equipe, em casos onde há EGP na organização e, negativamente $(-, 698)$, com este mesmo indicador. A leitura dos dados nos permite interpretar que os pesquisados que trabalham em empresas onde há EGP acreditam que quanto melhor for a relação com formadores de opinião, para buscar informações sobre os projetos, mais serão satisfeitas as expectativas da equipe de projetos, em relação ao trabalho dos demais departamentos. O indicador Formadores de opinião correlaciona-se ainda com o Cumprimento de Promessas dos departamentos para com o projeto, positivamente $(, 707)$, em casos onde há EGP e, negativamente $(-, 736)$, em casos que não há EGP na organização. Neste sentido, entende-se que, na visão dos entrevistados que possuem EGP na empresa em que trabalhavam, no momento em que foi feita a pesquisa, quanto maior for a relação com formadores de opinião, maior será também a satisfação das Expectativas da Equipe por parte das demais áreas envolvidas no projeto. Por outro lado, na opinião dos entrevistados de empresas que não possuem EGP, esta relação é inversamente proporcional, ou seja, quanto maior o relacionamento com formadores de opinião para captação de informações para o projeto, menor será a satisfação das Expectativas da Equipe do projeto por parte dos outros departamento.

Por fim, o indicador que mede a relação com Formadores de Opinião para captação de informações para o projeto correlaciona-se, positivamente, também nos casos em que há EGP na empresa, com o indicador que mede a Preocupação com os Objetivos dos projetos por parte dos departamentos envolvidos. Isso significa que, na opinião dos entrevistados com EGP nas organizações, quanto maior for a relação com Formadores de Opinião, maior também será a preocupação das áreas em cumprir os objetivos do projeto.

De uma forma geral, a análise da Tabela 08 permite entender que há uma relação entre seis, dos 9 indicadores de Geração de Inteligência, com a variável Confiança do modelo. Destacase que a maioria das correlações positivas corresponde às entrevistas feitas com indivíduos 
que possuíam EGP na organização em que trabalhavam, no momento da pesquisa, o que pode indicar que pessoas que trabalham em projetos de desenvolvimento de novos produtos que são integrados por um Escritório de Projetos, entendem melhor a relação entre Geração da Inteligência para a Organização e Confiança da Equipe de Projetos na Interface InterFuncional. 
Tabela 09 - Correlações Geração de Inteligência x Integração - Critério: Existência de um EGP na Organização do Entrevistado

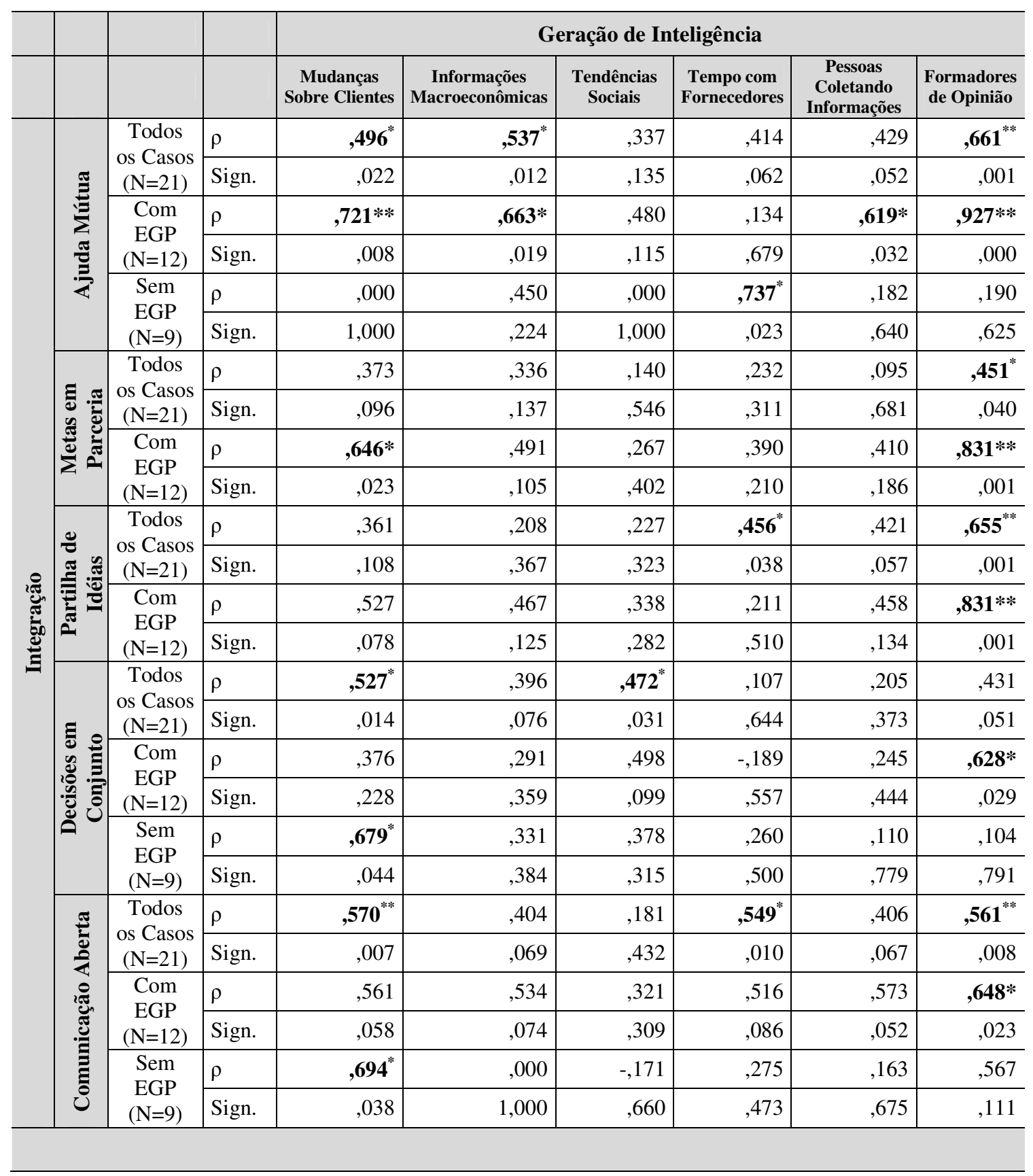

Fonte: Elaborada pela autora.

* Nível de significância $\leq 0,05$.

* Nível de significância $\leq 0,01$.

Na Tabela 09, encontram-se as correlações entre os indicadores de Geração de Inteligência e Integração. A primeira correlação observada é entre os efeitos das Mudanças no ambiente de negócios sobre os Clientes e Ajuda Mútua entre os departamentos, durante a realização do 
projeto. Foram encontradas correlações positivas entre estas duas variáveis, tanto em todos os casos, quanto nos casos em que há EGP na organização, sendo que, neste segundo caso, a correlação é ainda mais forte e significativa, passando de ,496* e todos os casos, para ,721** considerados apenas os casos com EGP.

O indicador Mudanças sobre Clientes correlaciona-se positivamente, também, com Metas em Parceria, em casos com EGP $\left(, 646^{*}\right)$ e Decisões em Conjunto, tanto em todos os casos $(, 527 *)$, quanto nos casos sem EGP (,679). Estas relações, na opinião dos entrevistados, indicam que quanto mais cresce a possibilidade das mudanças no ambiente de negócios afetar os clientes do projeto, maior é a necessidade dos departamentos de estabelecer metas em parceria e de tomar decisões em conjunto, principalmente, em empresas onde há EGP instalado. Isso pode indicar que os entrevistados de organizações com escritório de projetos podem ter uma noção maior da necessidade de fazer fluir a informação captada por meio da integração entre as funções.

Por fim, as Mudanças Sobre Clientes correlacionam-se ainda com Comunicação Aberta, em todos os casos $\left(, 570^{*}\right)$ e em casos com EGP $(, 694)$. Nota-se aqui uma correlação positiva, significando que, quanto mais é observado o efeito das mudanças no ambiente de negócios sobre os clientes, mais existe comunicação aberta entre os departamentos, na realização do projeto.

Em relação ao indicador que trata da coleta e avaliação de Informações Macroeconômicas para o projeto, encontraram-se duas correlações significativas com o indicador Ajuda Mútua, o que indica que os entrevistados associam, de alguma forma, estes dois componentes. $\mathrm{Ou}$ seja, quanto mais se busca conhecer informações macroeconômicas para o projeto, mais os departamentos envolvidos tendem a se ajudar.

A busca de informações sobre Tendências Sociais surge correlacionada com Decisões em Conjunto, quando são agrupados todos os casos. A correlação entre estas variáveis é de ,472*, considerada ligeiramente baixa, porém, estatisticamente significativa. Esta relação relata que, quanto mais se buscam informações sobre tendências sociais, mais as decisões são tomadas em conjunto nos projetos. 
O Tempo passado com Fornecedores, em busca de informações para o projeto, correlacionouse positivamente com Ajuda mútua, nos casos sem EGP $\left(, 737^{*}\right)$, o que pode significar que, neste tipo de ambiente, quanto mais se relaciona com fornecedor para captação de informações, mais a equipe de projetos tende a se ajudar. Tempo com Fornecedores correlaciona-se, também, com Partilha de Idéias (,456*) e Comunicação Aberta (,549*), ambas quando se considera todos os casos pesquisados. Estas relações podem significar que, quanto maior for a preocupação em passar mais tempo com fornecedores, para coletar informações para o projeto, maior será a partilha de idéias e mais aberta será a comunicação no ambiente de projetos.

Em relação à existência de Pessoas Coletando Informações durante o projeto, foi encontrada uma correlação (,619*) com o indicador Ajuda Mútua, nos casos de entrevistados que possuem EGP nas empresas em que trabalhavam no momento da pesquisa. Esta relação pode significar que, quanto maior for o esforço de pessoas coletando informações, maior será também a ajuda mútua entre os departamentos durante o projeto.

Em se tratando do contato com Formadores de Opinião para coletar informações para o projeto, foram encontradas correlações com todos os indicadores da variável Integração. Formadores de Opinião correlacionou-se com Ajuda Mútua em todos os casos pesquisados $(, 661 *)$ e nos casos com EGP $\left(, 927^{* *}\right)$. Neste segundo caso, a correlação foi bastante alta e significativa, o que pode significar que, quanto mais cresce a preocupação em se reunir com formadores de opinião para coletar informações para o projeto, mais intensamente se dá a ajuda mútua entre as áreas envolvidas com projetos.Formadores de Opinião obteve correlação positiva também com Metas em Parceria e Partilha de Idéias, tanto em todos os casos, com ,461* e ,655*, respectivamente, quanto apenas em casos com EGP, com ,831** para ambos os indicadores. A correlação forte de, $831^{* *}$, para os casos com projetos, sugere que, em empresas onde há EGP, na visão dos entrevistados, quanto mais cresce a relação com fornecedores, mais as metas são traçadas em parceria e há uma maior partilha de idéias, informações e recursos entre as áreas, durante o projeto.

A existência de contato com os Formadores de Opinião, para gerar informações para o projeto, correlacionou-se ainda com Decisões em Conjunto, nos casos com EGP (,628*), e Comunicação Aberta, em todos os casos (,561*) e nos casos com EGP (,648*). Estas correlações positivas podem significar que, quanto mais se dá importância às informações 
provenientes de fornecedores, mais as decisões são tomadas em conjunto e mais aberta é a comunicação entre as áreas no projeto.

Em resumo, na Tabela 09, foram encontradas muitas correlações significativas entre os indicadores de Geração da Inteligência e Integração, com destaque para o indicador Formadores de Opinião, que obteve as correlações mais altas e mais significativas com os demais indicadores. Ressalta-se também, assim como ocorreu nas correlações de Geração de Inteligência com Confiança, uma predominância de correlações positivas e estatisticamente significativas, quando se separam os casos em que há EGP nas organizações dos entrevistados. 
Tabela 10 - Correlações Disseminação da Inteligência x Confiança - Critério: Existência de um EGP na Organização do Entrevistado

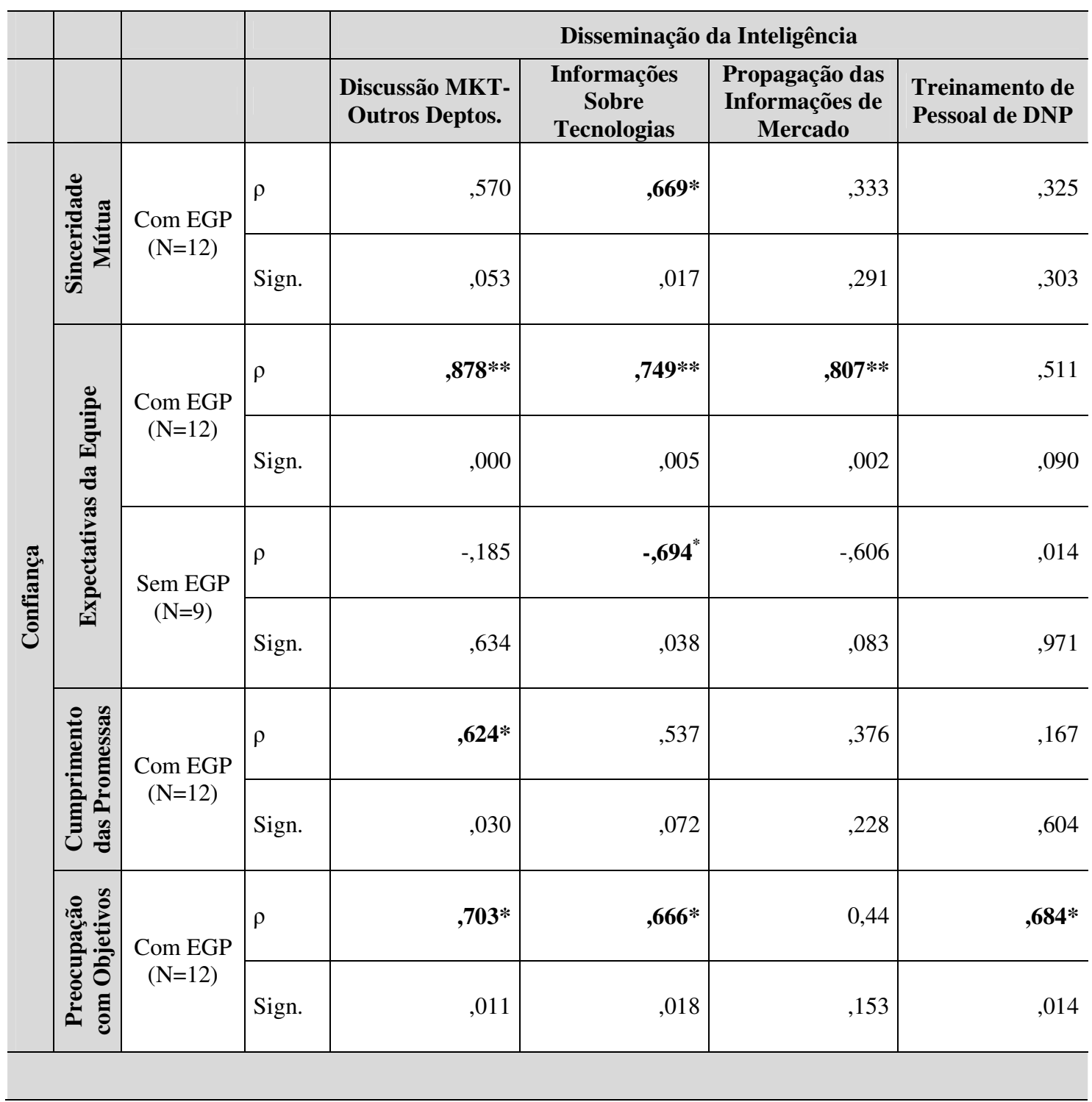

Fonte: Elaborada pela autora.

* Nível de significância $\leq 0,05$.

* Nível de significância $\leq 0,01$.

$\mathrm{Na}$ tabela 10, encontram-se as correlações entre os indicadores de Disseminação da Inteligência e Confiança.

Quando se analisa a Discussão entre Marketing e outros Departamentos, sobre as futuras necessidades dos clientes, encontra-se uma correlação positiva, entre os casos com EGP, com os indicadores Expectativas da Equipe $\left(, 878^{* *}\right)$, Cumprimento de Promessas $(, 624 *)$ e 
Preocupação com Objetivos (,703*). Estas relações permitem afirmar que, quanto maior a preocupação do marketing em informar aos outros departamentos sobre futuras necessidades de clientes, mais serão correspondidas as expectativas das equipes pelas áreas envolvidas no projeto, maior será o cumprimento de promessas por estas áreas e maior é a preocupação da equipe com os objetivos do projeto. Esta informação remete ao que foi observado na análise da moda do indicador expectativas da equipe, que teve uma manifestação mais baixa que os demais indicadores da variável. Possivelmente, há alguma falha na disseminação da inteligência nas equipes de projetos que interfira no indicador da confiança referente à satisfação das expectativas da equipe pelos departamentos envolvidos nos projetos.

Quanto ao compartilhamento de Informações sobre Tecnologias com outras departamentos da organização para utilização no projeto, foram encontradas correlações positivas e significativas com os indicadores Sinceridade Mútua (,669*), Expectativas da Equipe $\left(, 749^{* *}\right)$ e Preocupação com os Objetivos (,666*), em casos com EGP na organização. Entende-se, portanto, que, quanto mais os técnicos compartilham tecnologia com as demais áreas envolvidas no projeto, maior será a sinceridade mútua, as expectativas da equipe tendem a ser mais satisfeitas e maior será a preocupação em atender os objetivos do projeto.

Nota-se, porém, ainda com relação à correlação entre Informação sobre Tecnologias e Expectativas da Equipe, um índice negativo, de -,694, o que pode significar que, na visão das pessoas sem EGP em suas organizações, quanto mais os departamentos compartilham informações sobre tecnologias, menos as expectativas da equipe são satisfeitas.

Uma alta e significativa correlação foi identificada entre os indicadores de Propagação das Informações de Mercado entre os níveis hierárquicos do projeto e satisfação das Expectativas da Equipe de projetos pelos demais departamentos $\left(, 807^{* *}\right)$, o que significa, na visão dos entrevistados que, quanto mais se dissemina a informação de mercado na organização, mais são satisfeitas as expectativas da equipe.

Por fim, o Treinamento constante do Pessoal envolvido com Desenvolvimento de Novos Produtos está correlacionado, positivamente $\left(, 684^{*}\right)$, com a Preocupação com o cumprimento dos Objetivos do projeto, por parte da equipe. Esta relação permite entender que, possivelmente, na visão de pessoas que possuem EGP na empresa, quanto maior a 
preocupação com treinamento das pessoas envolvidas com os projetos de novos produtos, maior também será a preocupação em cumprir os objetivos do projeto.

Em resumo, entende-se que os indicadores da variável Disseminação da Inteligência possuem suas maiores correlações com os indicadores Expectativa da Equipe e Preocupação com os Objetivos do Projeto por parte da equipe, o que indica que, quanto maiores as ações para disseminar a inteligência na organização, serão mais bem atingidas as expectativas da equipe de projetos e maior será a preocupação das áreas envolvidas em atingir os objetivos do projeto. 
Tabela 11 - Correlações Disseminação da Inteligência x Integração - Critério: Existência de um EGP na Organização do Entrevistado

\begin{tabular}{|c|c|c|c|c|c|c|c|c|}
\hline & & & & \multicolumn{5}{|c|}{ Disseminação da Inteligência } \\
\hline & & & & $\begin{array}{c}\text { Discussão } \\
\text { MKT-Outros } \\
\text { Deptos. }\end{array}$ & $\begin{array}{c}\text { Reuniões } \\
\text { Interdep. } \\
\text { Atualização }\end{array}$ & $\begin{array}{l}\text { Informações } \\
\text { Sobre } \\
\text { Tecnologias }\end{array}$ & $\begin{array}{l}\text { Propagação } \\
\text { das } \\
\text { Informações } \\
\text { de Mercado }\end{array}$ & $\begin{array}{l}\text { Treinamento } \\
\text { de Pessoal de } \\
\text { DNP }\end{array}$ \\
\hline \multirow{16}{*}{ 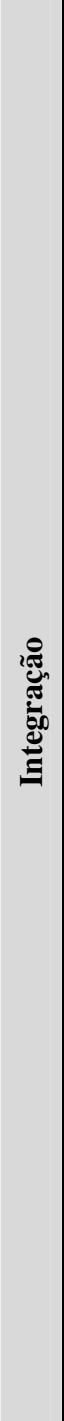 } & \multirow{4}{*}{ 竞 } & \multirow{2}{*}{$\begin{array}{c}\text { Todos os } \\
\text { Casos } \\
(\mathrm{N}=21)\end{array}$} & $\rho$ & ,246 & ,395 &, $620^{* *}$ &, $508^{*}$ & ,134 \\
\hline & & & Sign. & ,282 & ,076 & ,003 & ,019 & ,564 \\
\hline & & \multirow{2}{*}{$\begin{array}{c}\text { Com EGP } \\
(\mathrm{N}=12)\end{array}$} & $\rho$ & ,738** & ,272 &, $\mathbf{8 3 1} * *$ & ,510 &, 531 \\
\hline & & & Sign. & ,006 & ,393 & ,001 & ,090 & ,076 \\
\hline & \multirow{2}{*}{ 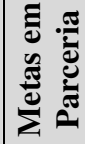 } & \multirow{2}{*}{$\begin{array}{c}\text { Com EGP } \\
(\mathrm{N}=12)\end{array}$} & $\rho$ & ,603* & ,425 & ,567 & ,366 & ,400 \\
\hline & & & Sign. & ,038 & , 168 & 055 & ,242 & 197 \\
\hline & \multirow{6}{*}{ 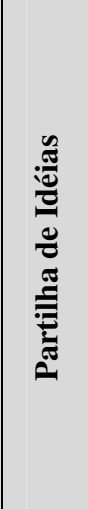 } & \multirow{2}{*}{$\begin{array}{c}\text { Todos os } \\
\text { Casos } \\
(\mathrm{N}=21)\end{array}$} & $\rho$ & ,300 &, $631^{* * *}$ &, $687^{* *}$ &, $\mathbf{4 5 7}^{*}$ & ,324 \\
\hline & & & Sign. & ,187 & ,002 & ,001 & ,037 & ,152 \\
\hline & & \multirow{2}{*}{$\begin{array}{c}\text { Com EGP } \\
(\mathrm{N}=12)\end{array}$} & $\rho$ & ,616* & , 450 &, $592 *$ & ,439 & ,655* \\
\hline & & & Sign. & ,033 & , 142 & ,043 & 153 &, 021 \\
\hline & & \multirow{2}{*}{$\begin{array}{c}\text { Sem EGP } \\
(N=9)\end{array}$} & $\rho$ & ,031 & ,569 & ,724* & ,530 &,- 048 \\
\hline & & & Sign. & ,938 &, 110 & ,027 & 142 & ,903 \\
\hline & \multirow{4}{*}{ 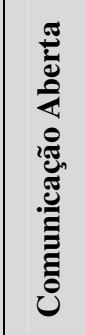 } & \multirow{2}{*}{$\begin{array}{c}\text { Todos os } \\
\text { Casos } \\
(\mathrm{N}=21)\end{array}$} & $\rho$ & ,474* & ,414 &, $687^{* *}$ & ,396 & ,485* \\
\hline & & & Sign. & ,030 & ,062 & ,001 & ,076 & ,026 \\
\hline & & \multirow{2}{*}{$\begin{array}{c}\text { Com EGP } \\
(\mathrm{N}=12)\end{array}$} & $\rho$ &, $773 * *$ & , 470 &, $709 * *$ & ,513 & ,678* \\
\hline & & & Sign. & ,003 & , 123 &, 010 & 088 & 015 \\
\hline
\end{tabular}

Fonte: Elaborada pela autora.

* Nível de significância $\leq 0,05$.

* Nível de significância $\leq 0,01$.

Na tabela 11, encontram-se as correlações entre Disseminação da Inteligência e Integração. 
As primeiras correlações encontradas foram entre Discussão MKT-Outros Departamentos e Ajuda Mútua (,738**), Metas em Parceria (,603*), Partilha de Idéias (,616*) e Comunicação Aberta $\left(773^{* *}\right)$. Todas estas correlações foram positivas, o que indica que, quanto maior a discussão entre marketing e outros departamentos, maior será a ajuda mútua entre as áreas, mais as metas serão definidas em parceria, maior será a partilha de idéias entre as áreas e mais aberta será a comunicação, no ambiente de projetos de novos produtos. Destaca-se ainda que todas estas correlações estão situadas nos casos em que havia EGP na organização dos entrevistados.

O indicador que trata das Reuniões Interdepartamentais para Atualização dos conhecimentos sobre as exigências do projeto está correlacionado, positivamente (,631**), em todos os casos, com a Partilha de Idéias, o que aponta para o fato de, quando há mais reuniões interdepartamentais para atualização, ocorre uma maior partilha de idéias entre as áreas envolvidas no projeto.

Em relação às Informações sobre Tecnologias trocadas entre os departamentos, houve correlação com Ajuda Mútua (,620** para todos os casos e ,831** para casos com EGP), Partilha de Idéias $(, 687 * *$ para todos os casos; ,592* para casos com EGP e ,724*, nos casos sem EGP), Comunicação Aberta (,687** em todos os casos e ,709** nos casos com EGP). Nesse sentido, entende-se que, quanto mais se trocam informações tecnológicas sobre os produtos entre as áreas envolvidas no projeto, maior será o grau de ajuda mútua, mais idéias serão partilhadas e a comunicação será mais aberta nos projetos de desenvolvimento de novos produtos.

A Propagação das Informações do Mercado por todos os níveis hierárquicos também obteve correlações positivas com os indicadores Ajuda Mútua (,508*) e Partilha das Idéias $\left(, 457^{*}\right)$, ambos quando considerados todos os casos pesquisados. Isto significa que, quanto mais as informações advindas do mercado são propagadas entre os variados níveis hierárquicos do projeto, mais as áreas se ajudarão e haverá também uma maior partilha de idéias entre os participantes da equipe do projeto.

Por fim, o indicador que trata do Treinamento do Pessoal Envolvido no Desenvolvimento de Novos Produtos, obteve correlações positivas com os indicadores Partilha de Idéias, nos casos com EGP (,655*), e Comunicação Aberta, no total dos casos $\left(, 485^{*}\right)$ e com EGP (,678*). 
Estes índices permitem entender que, quanto maior a preocupação em treinar constantemente os funcionários envolvidos nos projetos de novos produtos, maior é a partilha de idéias na equipe e mais aberta se torna a comunicação.

Após a análise das correlações entre as variáveis de Disseminação da Inteligência e Integração, entende-se que a Discussão de Marketing com Outros Departamentos e As Informações sobre Tecnologias são os indicadores que mais se correlacionam, obtendo destaque na formação das variáveis.

\section{Tabela 12 - Correlações Resposta à Inteligência x Confiança - Critério: Existência de um EGP na Organização do Entrevistado}

\begin{tabular}{|c|c|c|c|c|c|c|}
\hline & & & & \multicolumn{3}{|c|}{ Resposta à Inteligência } \\
\hline & & & & $\begin{array}{c}\text { Mudanças nas } \\
\text { Necessidades }\end{array}$ & $\begin{array}{c}\text { Coordenação das } \\
\text { Atividades }\end{array}$ & $\begin{array}{c}\text { Implementação de } \\
\text { Nova Idéia }\end{array}$ \\
\hline \multirow{6}{*}{ 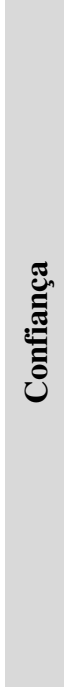 } & \multirow{2}{*}{ 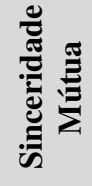 } & \multirow{2}{*}{$\begin{array}{l}\text { Com EGP } \\
(\mathrm{N}=12)\end{array}$} & $\rho$ &, $892 * *$ &, 524 & ,284 \\
\hline & & & Sign. & ,000 & ,081 & ,371 \\
\hline & \multirow{2}{*}{ 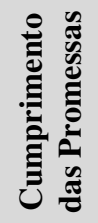 } & \multirow{2}{*}{$\begin{array}{l}\text { Com EGP } \\
(\mathrm{N}=12)\end{array}$} & $\rho$ & ,446 & ,356 &, $645^{*}$ \\
\hline & & & Sign. & ,146 & ,257 & ,023 \\
\hline & \multirow{2}{*}{ 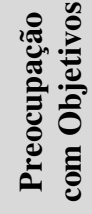 } & \multirow{2}{*}{$\begin{array}{l}\text { Com EGP } \\
(\mathrm{N}=12)\end{array}$} & $\rho$ &, $722 * *$ &, $681 *$ & 0,476 \\
\hline & & & Sign. & ,008 & ,015 & 118 \\
\hline
\end{tabular}

Fonte: Elaborada pela autora.

* Nível de significância $\leq 0,05$.

* Nível de significância $\leq 0,01$.

A Tabela 12 traz as principais correlações entre os indicadores das variáveis de Resposta à Inteligência e Confiança.

$\mathrm{O}$ indicador que trata da resposta à Mudança nas Necessidades de produtos dos clientes correlacionou-se positivamente, e com alta significância, com Sinceridade Mútua $(, 892 * *)$ e Preocupação com Objetivos $(722 *)$, ambas nos casos em que há EGP nas organizações. Esta 
relação permite entender que, quanto mais a equipe de projetos reponde às necessidades dos clientes, maior será a sinceridade mútua encontrada e maior também será a preocupação com os objetivos do projeto por parte da equipe.

A Coordenação das Atividades de diferentes departamentos no projeto correlacionou-se, positivamente, com Preocupação com os Objetivos do projeto (,681*). Isto pode significar que, quanto mais as atividades das diferentes áreas do projeto estão coordenadas, bem articuladas, maior será a preocupação com o cumprimento dos objetivos do projeto pelas áreas da organização.

Ainda na Tabela 12, pode ser observada a correlação positiva da velocidade para Implementação de uma Nova Idéia com Cumprimento das Promessas (,645*). Este índice representa que, quanto maior a preocupação com a agilidade na implementação de uma nova idéia, mais os departamentos se comprometem a cumprir as promessas feitas.

Em resumo, as correlações mais significativas da Tabela 12 estão entre os indicadores Mudanças nas Necessidades, Sinceridade Mútua e Preocupação com os Objetivos. Um dado importante, no caso desta tabela é que aparecem como relevantes apenas correlações obtidas com as repostas de pessoas que possuíam EGP na organização, na época da entrevista, o que pode dar a entender que, na relação de Resposta à Inteligência com Confiança se manifesta com mais clareza em ambientes que já possuem EGP instalado, segundo as repostas obtidas para esta pesquisa. 
Tabela 13 - Correlações Resposta à Inteligência x Integração - Critério: Existência de um EGP na Organização do Entrevistado

\begin{tabular}{|c|c|c|c|c|c|c|c|}
\hline & & & \multicolumn{5}{|c|}{ Resposta à Inteligência } \\
\hline & & & $\begin{array}{c}\text { Mudanças } \\
\text { nas } \\
\text { Necessidades } \\
\end{array}$ & $\begin{array}{c}\text { Novos } \\
\text { Fornecedores }\end{array}$ & $\begin{array}{l}\text { Coordenação } \\
\text { de Atividades }\end{array}$ & $\begin{array}{l}\text { Implementação } \\
\text { de Nova Idéia }\end{array}$ & $\begin{array}{c}\text { Des. De } \\
\text { Linhas de } \\
\text { Produtos } \\
\end{array}$ \\
\hline \multirow{2}{*}{ 㫣葛 } & \multirow{2}{*}{$\begin{array}{c}\text { Com EGP } \\
(\mathrm{N}=12)\end{array}$} & $\rho$ &, 424 &, 128 &, $756 * *$ &, $674 *$ &, $603 *$ \\
\hline & & Sign. &, 170 & ,693 &, 004 &, 016 & ,038 \\
\hline \multirow{4}{*}{ 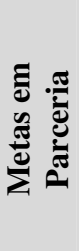 } & \multirow{2}{*}{$\begin{array}{c}\text { Todos os } \\
\text { Casos } \\
(\mathrm{N}=21)\end{array}$} & $\rho$ &, 120 &, 035 & ,404 &, $455^{*}$ & ,366 \\
\hline & & Sign. & ,603 & 879 & ,069 & ,038 &, 102 \\
\hline & \multirow{2}{*}{$\begin{array}{c}\text { Com EGP } \\
(\mathrm{N}=12)\end{array}$} & $\rho$ &, 524 &, 258 &, $638 *$ &, $657 *$ &, $623 *$ \\
\hline & & Sign. &, 080 & ,418 & ,026 &, 020 & ,031 \\
\hline \multirow{4}{*}{ 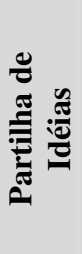 } & \multirow{2}{*}{$\begin{array}{c}\text { Todos os } \\
\text { Casos } \\
(\mathrm{N}=21)\end{array}$} & $\rho$ & ,230 &, 166 &, $437^{*}$ &, 112 & ,328 \\
\hline & & Sign. & ,317 & ,473 &, 048 & ,630 &, 146 \\
\hline & \multirow{2}{*}{$\begin{array}{c}\text { Com EGP } \\
(\mathrm{N}=12)\end{array}$} & $\rho$ & ,405 &, 161 &, $638 *$ &, $632 *$ &, 501 \\
\hline & & Sign. &, 191 & ,616 & ,026 &, 027 & ,097 \\
\hline \multirow{6}{*}{ 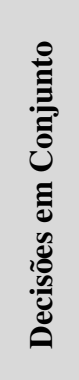 } & \multirow{2}{*}{$\begin{array}{c}\text { Todos os } \\
\text { Casos } \\
(\mathrm{N}=21)\end{array}$} & $\rho$ &, 351 &, $\mathbf{4 5 0} *$ &, 231 &, $\mathbf{5 6 7} 7^{* *}$ &, $511^{*}$ \\
\hline & & Sign. &, 119 &, 041 & ,313 & ,007 & ,018 \\
\hline & \multirow{2}{*}{$\begin{array}{c}\text { Com EGP } \\
(\mathrm{N}=12)\end{array}$} & $\rho$ &, 309 &, 274 & ,407 &, $734 * *$ & ,448 \\
\hline & & Sign. &, 328 & ,389 & ,190 & ,007 &, 144 \\
\hline & \multirow{2}{*}{$\begin{array}{l}\text { Sem EGP } \\
\quad(\mathrm{N}=9)\end{array}$} & $\rho$ & ,620 &, $764^{*}$ &,- 207 &, 572 &, $746^{*}$ \\
\hline & & Sign. & ,075 &, 017 &, 593 & ,107 & ,021 \\
\hline \multirow{4}{*}{ 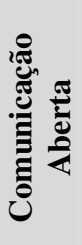 } & \multirow{2}{*}{$\begin{array}{c}\text { Todos os } \\
\text { Casos } \\
(\mathrm{N}=21)\end{array}$} & $\rho$ &, $640^{* *}$ & ,202 &, $672^{* *}$ & ,121 & ,387 \\
\hline & & Sign. &, 002 & ,381 & ,001 & ,602 & ,083 \\
\hline & \multirow{2}{*}{$\begin{array}{c}\text { Com EGP } \\
(\mathrm{N}=12)\end{array}$} & $\rho$ &, $826 * *$ &, 160 &, $764 * *$ & ,233 & ,396 \\
\hline & & Sign. & ,001 & ,620 & ,004 & ,467 & ,202 \\
\hline
\end{tabular}

Fonte: Elaborada pela autora.

* Nível de significância $\leq 0,05$.

* Nível de significância $\leq 0,01$.

Na tabela 13, são apresentadas as correlações entre Resposta à Inteligência e Integração.

O indicador que trata da Mudança nas Necessidades de produtos dos clientes está correlacionado, positivamente, com a Comunicação Aberta entre as áreas envolvidas no projeto, tanto em todos os casos $\left(, 640^{* *}\right)$, quanto em casos com EGP, onde o índice de 
correlação aumenta para ,826**, com alta significância. $\mathrm{O}$ que permite afirmar que, quanto mais os membros das equipes de projetos de novos produtos se preocupam com as mudanças nas necessidades dos clientes, mais aberta deverá ser a comunicação entre as áreas.

A segunda correlação se dá entre os indicadores Novos Fornecedores e Decisões em Conjunto. Quando considerados todos os casos, aparece uma correlação positiva de ,450*, enquanto que, nos casos sem EGP, a correlação cresce, chegando a 764*. Este resultado demonstra que, mesmo nos casos em que não há EGP nas empresas, quanto maior a preocupação em ser ágil ao iniciar negócios com novos fornecedores, mais os departamentos tendem a tomar decisões em conjunto.

O indicador Coordenação das Atividades está correlacionado com Ajuda Mútua (,756**), com Metas em Parceria $\left(, 638^{*}\right)$ e com Partilha de Idéias, sendo este último indicador com correlações em todos os casos (,437*) e em casos com EGP (,638*). Nesse sentido, pode-se dizer que, quanto mais cresce a preocupação com a coordenação das atividades entre as áreas envolvidas em projetos, haverá mais ajuda mútua entre as áreas, mais parcerias no estabelecimento de metas e as idéias serão mais partilhadas entre os envolvidos no projeto.

A velocidade para Implementação de Uma nova Idéia está associada, positivamente, a Ajuda Mútua (,674*), Metas em Parceria (,657*), Partilha de Idéias (632*) e Decisões em Conjunto (,734**). Sendo que, todas as correlações mais relevantes estão localizadas no grupo de análise com EGP na empresa. O que indica que, na visão dos entrevistados que possuem EGP na organização em que estavam na época da pesquisa, quanto maior a preocupação com a velocidade na implementação de uma idéia, mais as áreas devem ajudar umas as outras, as metas serão construídas em mais parceria, as idéias tendem a ser mais partilhadas e as decisões tomadas em conjunto.

Houve ainda correlações positivas entre o indicador que trata da relação entre políticas internas e necessidades do mercado, no Desenvolvimento de Linhas de Produtos, e os indicadores Ajuda Mútua (,603*) e Metas em Parceria (,623*), em casos onde há EGP nas empresas dos entrevistados. O Desenvolvimento de Linhas de Produtos está ainda associado, positivamente, a Decisões em Conjuntos, em todos os casos (,511*) e em casos sem EGP $\left(, 746^{*}\right)$. Este resultado permite entender que, à medida que as necessidades do mercado são mais valorizadas no desenvolvimento de produtos, mais as áreas envolvidas no projeto se 
ajudarão, e as metas tendem a ser traçadas em mais parceria. Além disso, na visão total do grupo e na os que não possuem EGP na organização, à medida que a preocupação se volta para o mercado, as decisões tendem a ser tomadas mais em conjunto.

Resumindo, as correlações entre Resposta à Inteligência e Integração foram expressivas, principalmente, nos grupo que possuíam EGP nas empresas, como já havia sido observado nos demais casos de correlação analisados neste capítulo. As principais correlações identificadas foram entre os indicadores Mudanças nas Necessidades e Comunicação Aberta; entre Novos Fornecedores e Decisões em Conjunto e entre Coordenação das Atividades e Comunicação Aberta. Estas relações permitem entender que a comunicação aberta entre as áreas envolvidas em projetos é uma das mais afetadas pela forma como os membros da equipe de projetos respondem às informações geradas e disseminadas sobre o mercado.

\subsection{Síntese dos resultados}

O capítulo dos resultados apresentou a análise descritiva e correlacional bivariada dos dados referentes aos construtos de Orientação para Mercado e Interface Inter-Funcional.

A análise da moda e da soma dos indicadores das variáveis de Orientação para mercado mostraram que todas as três variáveis (Geração de Inteligência, Disseminação da Inteligência e Resposta à Inteligência) obtiveram modas iguais ou acima de 4 pontos, o que significa que os entrevistados acreditam haver uma boa orientação para mercado nos projetos de desenvolvimento de novos produtos de que eles já participaram. Porém, quando comparadas as três variáveis, nota-se que, na opinião dos entrevistados, Geração e Disseminação da Inteligência dão-se de forma mais efetiva, enquanto a Resposta à Inteligência obteve moda e soma um pouco menores em seus indicadores, o que leva a crer que, em projetos de desenvolvimento de novos produtos, há certa dificuldade em responder à informações provenientes do mercado.

Estes parâmetros são bem parecidos com a pesquisa realizada por Müller Neto (2005), que serviu de modelo para o construto de Orientação para Mercado deste estudo, e também relatou altos índices em todos os indicadores de Geração, Disseminação e Resposta à Inteligência dos entrevistados. Considerando-se que as unidades de análise da pesquisa são diferentes, não há 
como fazer comparação, apenas entende-se que os resultados de ambos os estudos apontam para índices altos de orientação para mercado em empresas com atividade inovadora.

Em relação ao construto de Interface Inter-Funcional, as modas e somas também foram consideradas altas, com base nas respostas dos entrevistados. Comparativamente, a variável Confiança obteve uma das modas em 4 pontos, enquanto que, na Integração, todas as modas ficaram em 5 pontos. As somas de Confiança também foram menores, em média, do que as somas de Integração. Estes resultados permitem entender que os entrevistados consideram as equipes de projetos integradas, apesar da confiança, mesmo estando em um bom nível, ser abalada em alguns momentos.

Na teoria pesquisada sobre este tema, as informação ainda se encontram bastante dispersas, sem um indicador comum para integração e confiança. Porém, pode-se afirmar que, na maioria dos casos, encontra-se de médio a alto grau de confiança e integração, quando aplicadas as escalas de integração e/ou confiança. Encontrou-se ainda, na teoria, uma forte associação entre integração e confiança, segundo testes realizados com o modelo de Garcia, Sanzo e Trespalacios (2008).

$\mathrm{Na}$ análise conjunta dos dois construtos, as correlações bivariadas mais significativas foram encontradas quando foram analisados os dados dos entrevistados que possuíam EGP nas empresas de referência, o que pode indicar que pessoas envolvidas em projetos, em organizações que possuem EGP ativo tendem a compreender melhor as relações entre orientações para mercado e interface inter-funcional. 


\section{CONCLUSÕES}

Este capítulo apresentará uma síntese geral do estudo, passando pelos objetivos a que o trabalho se propunha cumprir, os principais aspectos da metodologia utilizada, os resultados mais relevantes encontrados, bem como as principais conclusões e recomendações passiveis de serem feitas.

\subsection{Síntese do Estudo}

Tendo em vista a crescente necessidade das organizações de investir em inovação, o estudo de projetos de desenvolvimento de novos produtos é pauta de diversas pesquisas, no Brasil e no exterior. Este tipo de projeto demanda, na maioria dos casos, um entendimento do mercado, para que os produtos desenvolvidos sejam ajustados à perspectiva do cliente. Para entender a demanda do mercado, fez necessária a coleta e disseminação de informações na organização, o que possibilitará uma futura resposta a estas informações captadas, na forma de produto acabado e colocado no mercado.

Diante deste cenário, o objetivo geral deste estudo consistiu em analisar as possíveis relações entre orientação para mercado e interface inter-funcional, no contexto de desenvolvimento de novos produtos. Com base na fundamentação teórica, construiu-se um modelo, onde construto de Orientação para Mercado foi composto por três variáveis: Geração de Inteligência, Disseminação da Inteligência e Resposta à Inteligência, cujo trabalho de Müller Neto serviu como base para utilização da escala. Outro componente do modelo, o construto de Interface Inter-Funcional, foi composto pelas variáveis Confiança e Integração, segundo modelo contido no estudo de Garcia, Sanzo e Trespalacios (2008).

Para cumprir o objetivo da dissertação, foi desenvolvido um estudo de naturezas exploratória, descritiva e posteriormente correlacional. A pesquisa foi exploratória, na medida em que não foram encontrados estudos específicos que tratassem da relação entre orientação para mercado e a interface inter-funcional. Portanto, um dos objetivos deste trabalho foi explorar a possível existência das relações entre os indicadores das variáveis dos construtos estudados, para que o campo seja aberto e possibilite futuros estudos na área. A natureza descritiva do estudo está associada à mensuração dos graus de orientação para mercado e de interface funcional, também levando em consideração cada um dos indicadores das variáveis. Por fim, o caráter 
correlacional está associado à utilização do coeficiente rho $(\rho)$ de Spearman, para explorar as associações existentes entre os indicadores das variáveis de cada construto.

Inicialmente, foi realizada uma pesquisa bibliográfica, com o objetivo de encontrar as correntes teóricas que tratavam dos assuntos-chave e proporcionassem a construção das bases conceituais do estudo. Desenhado o modelo e estabelecidas as variáveis a serem estudadas, aplicou-se uma survey, por meio eletrônico, com uma amostra de 21 entrevistados. A amostra para a pesquisa de campo foi selecionada pelo critério de acessibilidade, ou amostragem por conveniência. A escolha deste critério deu-se em razão do difícil acesso aos entrevistados, por bloqueios naturais colocados pelas instituições. A unidade de análise foi composta por participantes de projetos de desenvolvimento de novos produtos em empresas inovadoras. Foram entrevistados, portanto, indivíduos que tinham participado, ou estavam participando, de projetos de DNP, em empresas consideradas inovadoras, que possuíam escritório no Brasil no momento da pesquisa. Estas empresas foram selecionadas a partir do ranking de empresas que mais investem em inovação no mundo, composto de 1.250 empresas globais, sediadas em setores e países diversificados (BERR, 2008).

Tendo em vista as dificuldades em obter uma segunda resposta por parte dos entrevistados, optou-se por não aplicar o procedimento do teste-reteste para confirmação da confiabilidade das respostas da amostra. Em vez disso, foi utilizado o teste alpha de Crombach, que possui a mesma finalidade, mas dispensa a reaplicação de parte dos questionários. O alpha foi de 0,881 para os 31 indicadores e, considerando cada variável, separadamente, todos os alpha foram acima de 0,7, nível considerado adequado por Hair (1998) para considerar escalas confiáveis.

Após o período de aplicação e tratamento dos dados, os dados foram analisados por meio de estatísticas descritivas, com utilização da moda, com o objetivo de verificar as respostas de maior ocorrência entre os entrevistados, e da soma, para mensurar quais dos indicadores obtiveram pontuação mais relevante, em relação ao máximo possível. Além disso, foi utilizada estatística bivariada, por meio do cálculo do coeficiente de correlação rho de Spearman $(\rho)$. Este coeficiente foi calculado para todos os casos e, posteriormente, as entrevistas foram divididas pelo critério da variável moderadora (Existência de EGP na Organização), o que permitiu avaliar a correlação dos respondentes que possuíam escritório de projetos na organização e dos que não possuíam. 
Os principais resultados apontaram para um alto grau de Orientação para Mercado, com algumas restrições para Resposta à Inteligência e também um alto grau de Interface InterFuncional, no contexto dos projetos de desenvolvimento de novos produtos. As evidências apontaram ainda para uma forte relação entre muitos dos indicadores de Orientação para Mercado, com os Indicadores de Interface Inter-Funcional, principalmente, em se tratando dos casos em que os entrevistados afirmaram haver EGP na organização, onde se concentrou a maioria das correlações positivas obtidas por meio do cálculo do rho de Spearman.

Após apresentada a síntese do estudo, serão explicitados, a seguir, os principais resultados e as possíveis conclusões que se pode extrair do estudo aqui apresentado.

\subsection{Principais Conclusões}

Tendo em vista que o foco deste trabalho foi analisar possíveis relações entre orientação para mercado e interface inter-funcional, no contexto do desenvolvimento de novos produtos, as seguintes conclusões foram evidenciadas:

- A Geração de Inteligência obteve, em geral, alta manifestação no contexto de projetos de desenvolvimento de novos produtos. De forma mais específica, observou-se que no contato com usuários finais, autoridades e com formadores de opinião, em busca de informações para o projeto, houve uma maior concordância por parte dos entrevistados, em relação aos demais indicadores componentes da variável, que tratam de busca de informações em fontes secundárias. Este comportamento pode estar relacionada com a preocupação com a veracidade das informações que chegam à equipe, visto que as correlações observadas entre os indicadores de pesquisas com usuários finais, contatos com autoridades e formadores de opinião foram altas e significativas.

- A disseminação das informações captadas no mercado teve como pontos de destaques as reuniões interdepartamentais para discussão e atualização das informações, o que reforça a importância da equipe para que haja orientação para mercado no projeto. Nesse sentido, destaca-se a relação encontrada entre reuniões para atualização com a partilha de idéias entre as pessoas envolvidas nos projetos. Estas evidência trazem à tona a importância atribuída, no ambiente de desenvolvimento de novos produtos, às 
reuniões, como forma de partilhar idéias e descobrir soluções em conjunto, tendo em vista que, à luz da teoria, a comunicação é um dos elementos fundamentais para o sucesso de um projeto. Em contrapartida, ainda em relação à disseminação de informações, o treinamento do pessoal envolvido com desenvolvimento de novos produtos obteve a mais baixa pontuação da variável, o que permite supor que a disseminação das informações se dá de forma fluida, no dia a dia do projeto, não sendo tão valorizadas as paradas para treinamento. Ainda em relação ao treinamento de pessoas envolvidas com projetos de novos produtos, houve uma correlação forte desta indicador com a preocupação com o cumprimento dos objetivos por parte dos departamentos envolvidos no projeto. Esta relação pode indicar que, apesar de não considerar o treinamento o elemento mais importante para a disseminação da informação nos projetos, os entrevistados associam este elemento ao cumprimento adequado dos objetivos do projeto.

- A resposta à inteligência gerada no mercado e disseminada no ambiente de projetos apresentou os menores índices, se comparada às demais variáveis do construto. Com isso, pode-se entender que ainda há certa dificuldade em interpretar e transformar estas informações em produtos, ou até mesmo em ações do dia a dia no projeto. Observando mais detalhadamente, nota-se que a coordenação de atividades de diferentes departamentos foi a que recebeu maior pontuação, possivelmente, pelo fato de estar associada a uma mudança mais ligada ao cotidiano dos projetos. Enquanto isso, os indicadores de menor pontuação foram os que estão ligados a decisões que mexem bruscamente com o projeto, como é o caso de mudança de fornecedores e implementação de uma nova idéia. Acredita-se que, da mesma forma que são mais raras as inovações radicais, também são mais difíceis de implementar as respostas que arrisquem comprometer bruscamente o andamento do projeto.

- Em relação a interface inter-funcional, foi encontrado entre os entrevistados um alto grau de confiança, sem grandes diferenças entre os indicadores, o que não permite fazer elucubrações mais aprofundadas a respeito desta variável.

- A integração nos projetos de novos produtos, segundo os entrevistados, também pôde ser considerada alta. A comunicação aberta foi a que obteve a maior soma entre os indicadores, o que pode sinalizar que uma boa comunicação é considerada, no 
contexto pesquisado, como a chave para os demais elementos da integração entre os membros da equipe. Ou seja, havendo uma comunicação aberta, as decisões passam a ser tomadas em conjunto, há uma maior partilha de idéias, as decisões são tomadas em parceria e haverá mais ajuda mútua no projeto.

- Quando considerados apenas os entrevistados sem escritório de projetos na organização em que trabalhavam no momento da entrevista, houve uma alta correlação entre pesquisa com usuários finais e cumprimento de promessas. Esta relação pode indicar que, em ambientes onde não há escritórios de projetos, como mecanismo de integração, o cumprimento de promessas por parte dos departamentos está fortemente atrelado às informações provenientes dos usuários finais do produto que será desenvolvido no projeto. De alguma forma, os entrevistados acreditam que informações desta natureza possuem influência no comprometimento dos departamentos envolvidos no projeto.

- Um ponto em comum, ainda nos casos em que não há escritórios de projetos nas empresas dos entrevistados, foi a ocorrência de muitas correlações negativas entre os indicadores de geração de inteligência e confiança, o que pode significar que, entrevistados que não trabalham sob a regência de um EGP tendem a não relacionar as informações trazidas do mercado com a confiança entre os membros das equipes de projetos.

- Quando se trata das relações entre geração de inteligência e integração nos projetos de novos produtos, foram encontradas correlações positivas e altas, entre o indicador que trata de relação com empresas e pessoas formadoras de opinião e os indicadores de integração, quando analisados os casos em que havia escritório de projeto nas organizações dos pesquisados. Esta relação ratifica a importância dos formadores de opinião como fonte de informação que mantém a equipe de projetos integrada. Nesse sentido, acredita-se que as informações advindas de formadores de opinião podem interessar a boa parte da equipe do projeto e promover a integração na equipe, para compartilhamento e utilização da informação.

- Foi encontrada uma alta correlação entre alguns indicadores de disseminação da inteligência e o indicador que diz respeito à satisfação das expectativas da equipe 
pelos departamentos envolvidos no projeto, o que permite supor que a forma como a informação advinda do mercado é disseminada dentro do projeto, pode fazer com que as expectativas da equipe pelas demais áreas do projeto sejam satisfeitas em maior ou menor grau, principalmente, em se tratando dos departamentos de marketing e tecnologia, dos quais se tratavam os indicadores que manifestaram alta correlação com as expectativas da equipe.

- Foram encontradas fortes e significativas correlações entre alguns indicadores de disseminação da inteligência e a ajuda mútua entre os departamentos envolvidos no projeto e a comunicação aberta na equipe de projetos. Pode-se supor, neste caso, que quanto mais bem disseminada for a informação dentro do projeto, mais os departamentos terão chance de ajudar uns aos outros e será possível desenvolver uma comunicação mais aberta, suponde-se que todos os elementos do projeto estarão utilizando uma linguagem uniforme.

- Por fim, boa parte das correlações positivas encontradas entre os indicadores de orientação para mercado e interface inter-funcional foram atribuídas a todos os casos, ou apenas ao grupo de entrevistados que afirmaram possuir escritório de projetos na organização em que estavam, no momento da pesquisa. Esta descoberta pode significar que, de forma geral, os participantes de equipes projetos de novos produtos regidos por um escritório de projetos, possuem uma consciência mais clara de que informações geradas, disseminadas e respondidas de forma adequada podem proporcionar uma maior confiança e integração na equipe de projetos.

Após a apresentação das principais conclusões, fruto deste esforço investigativo, cabe mencionar algumas considerações acerca do estudo.

Primeiramente, é importante reforçar o caráter majoritariamente exploratório deste estudo, visto que não foram encontrados, na fundamentação teórica utilizada para esta dissertação, trabalhos que fizessem menção à relação entre orientação para mercado e interface inter funcional. Neste sentido, as conclusões aqui apresentadas não fazem menção a teorias anteriores e apenas levantam proposições que poderão ser investigadas em estudos futuros, com mais profundidade. Desta feita, entende-se que o produto final representa uma contribuição relevante para os campos de estudo dos projetos de desenvolvimento de novos 
produtos, especialmente, no tocante à administração estratégica do marketing, onde a orientação para mercado se insere, e à estrutura de projetos, onde pode ser inserida a abordagem de interface inter-funcional. O caráter incomum deste estudo não possibilita, porém, que ele seja comparado com estudos semelhantes.

Ainda por conta do caráter exploratório do estudo, não foram testadas hipóteses acerca da correlação entre variáveis. Como não foram encontradas bases comparativas em estudos anteriores, não havia suporte teórico para a criação de hipóteses. Sendo assim, o estudo correlacional foi realizado com o objetivo de levantar possíveis relações entre as variáveis, para indicações de estudos futuros.

Outro ponto importante a ser observado é que os resultados desta pesquisa não devem ser generalizados para todos os projetos de desenvolvimento de novos produtos. Uma das principais razões reside no fato de a amostra utilizada no estudo ser de apenas 21 respondentes, número que não é considerado representativo estatisticamente para projeções para o resto da população. Outra razão está relacionada à técnica de seleção da amostra utilizada. A não aleatoriedade com que as empresas foram selecionadas também reduz a possibilidade de projetar os resultados encontrados neste estudo para o todo. Nesse sentido, para que seja possível aplicar mais amplamente os entendimentos sobre a relação entre orientação para mercado e interface inter-funcional, sugere-se que as próximas pesquisas realizadas a respeito do tema abranjam uma quantidade maior de pessoas entrevistadas e sigam um critério de amostragem que permita inferências estatísticas para a população do estudo.

Um último ponto deve ser relembrado: os resultados deste estudo são fruto da opinião dos entrevistados, ou seja, todas as conclusões aqui apresentadas têm como base a opinião de pessoas, cada uma com suas características e experiências pessoais e profissionais, as quais, inevitavelmente, remetem a pontos de vista diferentes, mesmo quando se trata de um mesmo tema. O fato de os questionários terem sido aplicados via Internet também contribui para que haja possíveis vieses, advindos de interferências externas, que fogem ao controle do pesquisador. 


\subsection{Recomendações para a prática e para futuros estudos}

Os resultados encontrados nesta dissertação sugerem que, na prática, as equipes de projetos de desenvolvimento de novos produtos possuem uma alta orientação para mercado, ou seja, captam, disseminam e respondem às informações advindas do mercado de forma adequada. Foi identificado ainda um alto grau de confiança e integração entre estas equipes, o que significa que as relações entre a equipe durante a realização de projetos de DNP também é considerada boa pelos pesquisados. Além disso, foram encontradas relações positivas entre orientação para mercado e interface inter-funcional. Na prática, isso significa que, a captação e disseminação das informações provenientes do mercado bem como a resposta dada a estes inputs pode interferir na integração e na confiança entre os membros da equipe de projetos. Nesse sentido, entende-se que as organizações, ao iniciar um projeto de desenvolvimento de novos produtos, podem tomar alguns cuidados, a saber:

- Ficar atentas ao tipo de informação que é captada no mercado, sabendo que ela poderá impactar, positiva ou negativamente, na integração e na confiança dos membros da equipe de projetos;

- Utilizar mecanismos e ferramentas adequados de disseminação desta informação, para que não haja distorções no processo, visto que informações disseminadas de forma inadequadas também podem abalar a integração e a confiança entre as pessoas nos projetos.

- Buscar responder de forma adequada, e mais rapidamente, às informações geradas e disseminadas durante o projeto.

Em relação às recomendações para estudos teóricos, sugere-se que esta pesquisa, ou instrumento semelhante, seja aplicada com uma amostra mais representativa, para que algumas das proposições aqui surgidas sejam confirmadas estatisticamente.

Sugere-se ainda que sejam realizados estudos de causa e feito, para estabelecer, mais detalhadamente, os graus de influência das variáveis independentes nas variáveis independentes. Nesta mesma pesquisa pode também ser feita a tentativa de análise contrária, 
considerando interface inter-funcional como variável independente e orientação para mercado como variável dependente.

Por fim, sugere-se a realização de pesquisas qualitativas, em busca de compreender as razões mais profundas pelas quais os pesquisados encontram relações entre orientação para mercado e interface inter-funcional. 


\section{REFERÊNCIAS}

AMARATUNGA, D; BALDRY, D; SARSHAR, M; NEWTON, R. Quantitative and qualitative research in the built environment: application of "mixed" research approach. Work study, v. 51, n.1, p. 17-31, 2002.

ANDREASSI, T. Gestão da inovação tecnológica (coleção debates em administração). São Paulo: Thomson Learning, 2007.

ANDREASSI, T. Gestão da inovação tecnológica - coleção debates em administração. 1. ed. São Paulo: Thomson Learning, 2006

ANDREASSI, T; SBRAGIA, R. Relações entre indicadores de P\&D e de resultado empresarial. Revista de Administração, v. 37, n. 1, p. 72-84, janeiro/março 2002.

Fatores determinantes do grau de inovatividade das

empresas: um estudo utilizando a técnica da análise discriminante. Anais do XXV Enanpad, Campinas, setembro de 2001.

ATUAHENE-Gima, K. An exploratory analysis of the impact of market orientation on new product performance: a contingency approach. Journal of Product Innovation Management, v. 12, p. 275-293, 1995.

35, p. 93-106, 1996.

Market orientation and innovation. Journal of Business Research, v.

BAMBER, D.; OWENS, J.; DAVIES, J.; SULEMAN, A. Enabling the emergent entrepreneurial organization to develop new products. International Journal of Entrepreneurial Behavior \& Research, v. 8, n. 4, p. 203-221, 2002.

BARKER, J.; TJOSVOLD, D.; ANDREWS, I. R. Conflict approaches of effective and ineffective project managers: A field study in a matrix organization. Journal of Management Studies, v. 25, n. 2, p. 167-178, 1988.

BERR. Ranking of the top 1,250 global companies by R\&D investment. Disponível em: $<$ http://www.berr.gov.uk/index.html> Acesso em 19 de agosto de 2008.

BREMSER, W. G; BARSKY, N. P. Utilizing balanced scorecard for R\&D performance measurement. R\&D Management, v. 34, n. 3, p. 229-238, 2004.

BROWN , S. L; EISENHARDT, K. M. 1995). Product development: past research, present findings, and future directions. Academy of Management Review, v. 20, n. 2, p. 343-378, apr. 1995. 
BUSS, C. O. Cooperação interfuncional no desenvolvimento de novos produtos: a interface marketing-engenharia. 2002. Dissertação de Mestrado, Escola de Administração da UFRGS, Universidade Federal do Rio Grande do Sul, Porto Alegre, 2002, p. 84.

CALANTONE, R. J.; CAVUSGIL, S. T.; ZHAO, Y. Learning orientation, firm innovation capability, and firm performance. Industrial Marketing Management, v. 31, n. 6, p. 515$524,2002$.

CALANTONE, R. J.; Dröge, C; Vickery, S. Investigating the manufacturing-marketing interface in new product development: does context affect the strength of relationships?

Journal of Operations Management, v. 20, n. 1, p. 273-287, 2002.

CARVALHO, M. M.; RABECHINI JR.; R. Construindo competências para gerenciar projetos. 2 ed. São Paulo: Atlas, 2008.

CHURCHILL, Gilbert A. Marketing research: methodological foundations. 7 ed. Orlando: Harcourt, 1999.1027 p.

CLARK, K. B; WHEELWRIGHT, S. C. Organizing and Leading Heavyweight development teams. California Management Review, p. 9-29, spr. 2001.

COOPER, R. G. How to launch a new product successfully. CMA, v, 69, n. 8, p. 20-23, oct. 1995.

COOPER, R. G. et al. New product portfolio management : practices and performance. Journal of Product Innovation Management, v. 16, n. 1, p. 333-351, 1999.

CURI, D. P. A relação entre o grau de orientação para o mercado e a orientação tecnológica em empresas baseadas em tecnologia. Anais do XXXI Encontro da Anpad, Rio de Janeiro, setembro de 2007.

CURY, A. Organização e métodos: uma visão holística. 8 ed. São Paulo: Atlas, 2006.

DAY, G.S. The capabilities of market-driven organizations. Journal of Marketing, v. 58, n. 4, p. 37-52, oct. 1994.

. A empresa orientada para o mercado: compreender, atrair e manter clients valiosos. Porto Alegre: Bookman, 2001

DESHPANDÉ, R.; FARLEY, J. U.; WEBSTER, F. E. Corporate culture, customer orientation, and innovativeness in japanese firms: a quadrad analysis. Journal of Marketing, v. 57, n. 1, p. 23-27, 1993.

DIEGEL, O. Designing breakdown structures: an extension to the work breakdown structure to manage innovation in new product development projects. Proceedings of the Project Management Institute Annual Seminars \& Symposium. October 3-10, 2002. 
DINSMORE, P. C. Winning business with enterprise project management. New York: Amacom, 1998.

DO VALLE, J. A. S.; SILVIA, W. S.; SOARES, C. A. P. Project management office (PMO) - principles in practice. AACE International Transactions. PM. 07, 2008, p. 01-09.

DONNELLY, G. A P\&L for R\&D. CFO Magazine, February, p. 44-50, 2000.

FREEMAN, C. Innovation and growth. In: DODGSON, M ; ROTHWELL, R. (Ed.). The handbook of industrial innovation. Cheltenham: Edward Elgar, 1994, p. 78-93.

FREDERICKS, Corss-functional involvement in new product development. Qualitative Market Research, v. 8, n. 3, p. 327-341, 2005.

GARCÍA, N.; SANZO, M. J.; TRESPALACIOS, J. A. New product internal performance and market performance: evidence from Spanish firms regarding the role of trust, interfunctional integration and innovation type. Technovation, v 28, n. 11, p. 713-725, 2008.

GATIGNON, h; XUEREB, J. M. Strategic orientation of the firm new product performance. Journal of Marketing Research, v. 34, n. 1, p. 77-90, feb. 1997.

GRIFFIN A; HAUSER JR. Patterns of communications among marketing, engineering and manufacturing: a comparison between two new product teams. Journal of Product Innovation Management, v. 38, n. 3, p. 191-215, 1995.

GRIFFIN A; HAUSER JR. Integrating R\&D and marketing: a review and analysis of the literature. Journal of Product Innovation Management, v. 13, n. 3, p. 191-215, 1990.

GUPTA, A. K. A study of r\&d/marketing interface and innovation success in high technology firms. Ph.D. dissertation, Syracuse University, New York, 272 p., 1984.

HAIR, J.F. Jr; ANDERSON, R.E; TATHAM, R.L.; BLACK, W.C. Multivariate data analysis. 5 ed. Upper Saddle River: Prentice-Hall, 1998. 730 p.

HURLEY, R. F.; HULT, G. T. M. Innovation, market orientation, and organizational learning: an integration and empirical examination. Journal of Marketing, v. 62, n. 3, p. 4254, 1998.

JAIN, S. K; BATHIA, M. Market orientation and business performance: the case of indian manufacturing firms. The Journal of Business Perspective, v. 11, n. 1, p. 15-36, jan-mar. 2007.

JAWORSKI, B. J.; KOHLI, A. K. Market orientation: antecedents and consequences. Journal of Marketing, v. 57, n. 7, p. 53-70, 1993. 
KARA, A.; SPILLAN, J. E.; DESHIELDS Jr., O. W. The effect of a market orientation on business performance: a study of small-sized service retailers using MARKOR Scale.

Journal of Small Business Management, v. 43, n. 2, p. 105-118, 2005.

KOHLI, A. K.; JAWORSKI, B. J. Market orientation: the construct, research propositions, and managerial implications. Journal of Marketing, v. 54, n. 4, p. 1-8, apr. 1990.

KOHLI, A. K.; JAWORSKI, B. J.; KUMAR, A. MARKOR: a measure of market orientation. Journal of Marketing Research, v. 30, p. 467-477, nov. 1993.

KRUGLIANSKAS, I. Efeito da interação organizacional na eficácia do centro de pesquisas e desenvolvimento cativo. Tese de Doutorado em Administração. Faculdade de Economia, Administração e Contabilidade da USP, São Paulo, 218 p., 1981.

LENDERS, M; WIERENGA, B. The effectiveness of different mechanisms for integrating marketing and R\&D. Journal of Product Innovation Management, v. 19, n. 1, p. 305-317, 2002.

LITTLER, D. Marketing and innovation. In: DODGSON, M ; ROTHWELL, R. (Ed.). The handbook of industrial innovation. Cheltenham: Edward Elgar, 1994, p. 293-300.

MALHOTRA, N. K. Pesquisa em marketing: uma orientação aplicada. Porto Alegre: Bookman, 2001. 719 p.

MALTZ, Elliot \& KOHLI, Ajay K. Reducing marketing's conflict with other functions: the differential effects of integrating mechanisms. Journal of the Academy of Marketing Science, v. 28, n. 4. p. 479-492, 2000.

MALTZ, E; SOUDER, W. E; KUMAR, A. Influencing R\&D/marketing integration and the use of market information by R\&D managers: intended and unintended effects of managerial actions. Journal of Business Research, v. 52, n. 1, p. 69-82, 2001.

MARTINS, A. P.; MARTINS, M. R. PEREIRA, M. M. M; MARTINS, V. A. Imlnatação e consolidação de escritório de gerenciamento de projetos: um estudo de caso. Revista Produção, v. 15, n. 3, p. 404-415, set-dez, 2005.

MATSUNO, K.; MENTZER, J. T.; RENTZ, J. O. A Refinement and validation of the MARKOR scale. Journal of the Academy of Marketing Science , v. 28, n. 4, p. 527- 539, 2000 .

MATTAR, F. N. Pesquisa de marketing: metodologia, planejamento, execução e análise. 2 ed., v. 1, São Paulo: Atlas, 1993.

MAXIMIANO, A. C. A.; ANSELMO, J. L. Escritório de gerenciamento de projetos: um estudo de caso. 
MINISTÉRIO DO PLANEJAMENTO, ORÇAMENTO E GESTÃO; INSTITUTO BRASILEIRO DE GEOGRAFIA E ESTATÍSTICA - IBGE; DIRETORIA DE PESQUISAS; COORDENAÇÃO DE INDÚSTRIA. Pesquisa de Inovação Tecnológica (PINTEC). Rio de Janeiro, 2006.

MOENAERT, R.; SOUDER, W. An information transfer model for integrating marketing and R\&D personnel in new product development projects . Journal of Product Innovation Management, v. 7, n. 1, p. 91-107, 1990a.

An analysis of the use of extrafunctional information by

R\&D and marketing personnel: review and model. Journal of Product Innovation Management, v. 7, n. 1, p. 213-229, 1990 b.

MOENAERT, R.; SOUDER, W.; DE MEYER, A. \& DESCHOOLMEESTER, D. R\&D marketing integration mechanisms, communication flows, and innovation success. Journal of Product Innovation Management, v. 11, n. 1, p. 31-45, 1994.

MORSE, J. M. Approaches to qualitative-quantitative methodological triangulation. Nusring Research, n. 40, v. 2, 1991.

MÜLLER NETO, H. F. A comunicação organizacional no processo de desenvolvimento de novos produtos. 1998. Dissertação de Mestrado em Administração - Escola de Administração, Universidade Federal do Rio Grande do Sul, Porto Alegre, 1998, p. 107. . Inovação orientada para o mercado: um estudo da relação entre orientação para mercado, inovação e performance. Tese de Doutorado em Administração. Escola de Administração UFRGS, Porto Alegre, 169 p., 2005.

NARVER, J. C; SLATER, S. F. The effect of a market Orientation on business profitability. Journal of Marketing, v. 54, n. 10, p. 20-35, 1990.

NEELY, A; HII, J. Innovation and business performance. The Judge Institute of Management Studies, University of Cambridge, 1998.

OECD, Eurostat. Oslo manual: proposed guidelines for vollecting and interpreting technological innovation data. 3 ed. Paris: OECD, 2005.

ONOYAMA, S. S. Integração multifuncional no desenvolvimento de novos produtos: estudo de múltiplos casos em indústrias de laticínios mineiras. 2006. Dissertação de Mestrado, Universidade Federal de Minas Gerais, Belo Horizonte, 2006, p. 197.

OPPERMANN, M. Triangulation: a methodological discussion. International journal of tourism research, v. 2, n. 2, p. 141-146, 2000.

PERIN, Marcelo Gatterman; SAMPAIO, Cláudio Roffman; Froemming, Lurdes MarleneSeide; LUCE, Fernando Bins. A pesquisa survey em artigos de marketing nos 
ENANPADs da Década de 90. RIMAR - Revista Interdisciplinar de Marketing, v.1, n.1, p. 44-59, jan.-abr. 2002.

PURDON, W. A. B. Increasing R\&D effectiveness: researches as business people. Research Technology Management. v, 39, n. 4, p. 48-56, jul-aug. 1996.

ROGERS, E. Diffusion of innovations. 5 ed. The Free Press: New York, 2003.

ROTHWELL, R. Industrial innovation: success, strategy, trends In: DODGSON, M ; ROTHWELL, R. (Ed.). The handbook of industrial innovation. Cheltenham: Edward Elgar, 1994, p. 33-53.

ROUSSEL, Philip A.; SAAD, Kamal N.; BOHLIN, Nils. Pesquisa \& Desenvolvimento: como integrar P\&D ao plano estratégico e operacional das empresas como fator de produtividade e competividade. São Paulo: Makron Books, 1992.

RUEKERT, R. W; WALKER JR., O. C. Marketing's interaction with other functional units: a conceptual framework and empirical evidence. Journal of Marketing, v. 51, n. 1, p. 1-19, 1987.

RUEKERT, R. W. Developing a market orientation: an organizational strategy perspective. International Journal of Research in Marketing, v. 9, n. 1, p. 225-245, 1992.

SBRAGIA, R. A interface entre Gerentes de Projeto e Gerentes Funcionais em Projetos de Desenvolvimento de Novos Produtos, In: Bejerano, R.F e ALAIZA, M.C.F., Gestión de la Innovación, CYTED/INNRED, 2006.

SCHIFFMAN, L. G.; KANUK, L. L. Consumer behavior. New Jersey: Prentice-Hall, 2000.

SCHUMPETER, Joseph Alois. A teoria do desenvolvimento econômico. São Paulo: Abril, 1982.

SELLTIZ, C; JAHODA, M; DEUTSCH, M; COOK, S. W. Métodos de pesquisa nas relações sociais. São Paulo: E.P.U. Editora Pedagógica e Universitária, 1987.

SAMPIERI, R; COLLADO, C; LUCIO, P.. Metodología de la investigación. McGraw-Hill, 1991.

SAMPIERI, R; COLLADO, C; LUCIO, P. Metodología da pesquisa. 3 ed. McGraw-Hill, 2006.

SHAPIRO, B.P. Can marketing and manufacturing coexist? Harvard Business Review, v. 55, n. 5, p. 104-114, sep. 1977.

125, nov-dec. 1988.

What hell is market oriented? Harvard Business Review, v. 55, n. 5, p. 119- 
SIEGEL, S; CASTELLAN JR., N J. Nonparametric statistics for the behavioral sciences. New York: McGraw-Hill, 1988.

. Estatística não paramétrica para ciências do

comportamento. 2 ed. Porto Alegre: Artmed, 2006.

SILOCCHI, Paulo Roberto. Motivação à inovação de produtos: um estudo nas empresas industriais metal-mecânicas de Caxias do Sul . Dissertação (Mestrado) - UFRGS, Escola de Administração, 98 pág., 2002.

SLATER, Stanley F.; NARVER, John C. Market orientation, customer value and superior performance. Business Horizon, v. 37, n. 2, p. 22-28, mar-apr. 1994.

Market orientation and the learning organization.

Journal of Marketing, v. 59, n. 3, p. 63-74, jul. 1995.

SONG, X. M.; PARRY, M. R\&D-marketing interface in japanese high-technology firms: hypotheses and empirical evidence. Journal of Academy of Marketing Science, v. 21, n. 1, p. 125-133, 1993.

SONG, X. Michael; PARRY, Mark E. The determinants of japanese new product success". Journal of Marketing Research, v. 34, n.1, p. 64-76, feb. 1997.

SONG, X. M.; THIEME, R. J. A cross-national investigation of the R\&D-marketing interface in the product innovation process. Industrial Marketing Management, v. 35, n. 3, p. 308$322,2006$.

TAJEDDINI, K; TRUEMAN, M; LARSEN, G. Examining the effect of market orientation on innovativeness. Journal of Marketing Management, v. 22, n. 5/6, p. 529-551, jun. 2006.

VALLE, S; AVELLA, L. Cross-functionality and leadership of the new product development teams. European Journal of Innovation Management, v. 6, n. 1, p. 32-47, 2003.

VASCONCELLLOS, E; HEMSLEY, J. R. Estrutura das organizações. 4 ed. São Paulo: Pioneira Thomson Learning, 2002.

VASQUEZ, R; SANTOS, M. L; ÁLVARES, L. I. Market orientation, innovation and competitive strategies in industrial firms. Journal of Strategic Marketing, v, 9 n, 1, p. 6990, mar. 2001.

VERHEES, F. Market oriented product innovation in small firms. 2005. Tese de Doutorado, Wageningen University, Alemanha, 2005, p. 175.

WANG, C. L.; AHMED, P. K. The development and validation of the organizational innovativeness construct using confirmatory factor analysis. European Journal of Innovation Management, n. 7, v. 4, p. 303-313, 2004. 
WEIBLE, Rick; WALLACE, John. Cyber research: The impact of the Internet on data collection. Marketing Research, Chicago, v. 10, n. 3, Fall 1998, p. 19-24.

ZAWISLAK, Paulo A. A relação entre conhecimento e desenvolvimento: essência do progresso técnico. Análise, Porto Alegre, v.6, n. 1, p. 125-149, set. 1995. 


\section{APÊNDICE I - Questionário de Pesquisa}

Prezado (a) Senhor (a),esta é uma pesquisa acadêmica que está sendo realizada para fins da conclusão de uma dissertação de mestrado, no Programa de Pós-Graduação em Administração da Universidade de São Paulo. A pesquisa está sendo realizada sob a orientação do Professor Dr. Roberto Sbragia e conta com o apoio financeiro do Conselho Nacional de Desenvolvimento Científico e Tecnológico (CNPq). Estão sendo estudadas as relações entre orientação para mercado e interface inter-funcional no desenvolvimento de novos produtos, sob a ótica dos membros de equipes de projetos desta natureza, desenvolvidos nas empresas que mais investem em inovação e possuem atividade no Brasil. Gostaríamos de contar com a sua colaboração por meio da resposta a algumas perguntas. O tempo requerido para o preenchimento completo do questionário é de, aproximadamente, 15 minutos. Lembramos que sua participação é voluntária e que as informações aqui fornecidas serão mantidas em sigilo absoluto, sendo utilizadas apenas para fins acadêmicos, de forma agrupada, sem identificação individual/nominal.Para viabilizar a resposta do questionário, algumas instruções devem ser consideradas, a saber:- O respondente deve já ter participado, ou estar participando, algum projeto de desenvolvimento de novo produto, nesta ou em outra organização;- As questões devem ser respondidas tendo em mente os projetos de desenvolvimento de novos produtos que o (a) Sr (a) participa, ou já participou, nesta ou em outra organização;Devem ser considerados apenas projetos de desenvolvimento de produtos tangíveis. Inovações em serviços e em processos organizacionais não devem ser consideradas.

- O (a) Sr (a) deve levar em conta suas próprias experiências em projetos de novos produtos desenvolvidos atualmente, ou em um passado recente, e não responder em nome da empresa;

- Para a resposta das questões, o Sr (a) deve considerar situações reais dos projetos e não eventuais situações ideais;

- As questões marcadas com um (*) asterisco são de resposta obrigatória. O software não permite a conclusão da pesquisa caso algum (ns) dos itens obrigatórios não tenha(m) sido respondido(s).

- Procure reservar um tempo e responder o questionário sem interrupções. Após determinado período inativa, ocorre um time out (tempo esgotado) e a página exibe uma mensagem de erro. Caso isto ocorra, o (a) $\mathrm{Sr}$ (a) deverá reiniciar o preenchimento das respostas.

Desde já, agradecemos sua colaboração!

Atenciosamente,

Manuella Lima.

Mestranda em Administração

PPGA/FEA/USP

manuellalima@usp.br

Skype: manuella.o.lima 


\section{Caracterização da Empresa}

1. Empresa em que o(a) $\mathrm{Sr}$ (a) trabalha atualmente (O nome da empresa é opcional, está sendo solicitado apenas para controle interno da pesquisadora e não será divulgado sem autorização prévia):

2. Receita bruta anual da empresa (opcional) - OBS.: Utilize como referência o resultado do último exercício.

3. Quantidade média de funcionários, atualmente, na empresa:

4. Qual o setor de atuação de sua empresa?

1. Aeroespacial e Defesa

2. Alimentos

3. Automóveis e Peças

4. Consultoria

5. Engenharia

6. Farmacêutica e Biotecnologia

7. Metalurgia

8. Mineração

9. Petróleo e Gás

10. Publicidade e Propaganda

11. Seguros

12. Serviços de Suporte/Manutenção

13. Serviços Financeiros

14. Tabaco

15. Telecomunicações

16. Varejo

17. Other

5. Existe um PMO (Project Management Office - Escritório de Gerenciamento de Projetos) estruturado em sua organização?

1. Sim

2. Não 
6. Em média, quantos projetos de novos produtos são desenvolvidos, por ano, em sua organização?

\section{Caracterização do Respondente}

7. Nome (opcional):

8. E-mail para contato:

9. Telefone (opcional) para contato (DDD + número, sem espaços):

10. Sexo:

1. Masculino

2. Feminino

11. Faixa Etária:

1. 18 a 25 anos

2. 26 a 35 anos

3. 36 a 45 anos

4. 46 a 55 anos

5. Mais de 55 anos

12. A que área da empresa o (a) Sr (a) está vinculado (a)?

1. Finanças

2. Marketing

3. Produção

4. Recursos Humanos

5. $P \& D$

6. Outra 
13. Há quanto tempo o (a) $\mathrm{Sr}$ (a) está trabalhando nesta empresa?

1. Menos de 1 ano

2. De 1 a 2 anos

3. De 3 a 5 anos

4. De 6 a 8 anos

5. De 8 a 10 anos

6. Mais de 10 anos

14. O (a) Sr (a) já participou, ou participa atualmente, de projetos de desenvolvimento de novos produtos?

1. Sim, já participei de projetos de desenvolvimento de novos produtos em outras empresas, mas não na que estou atualmente

2. Sim, já participei de projetos de desenvolvimento de novos produtos na empresa em que estou atualmente, mas não participo de nenhum no momento

3. Sim, estou participando de um ou mais projetos de desenvolvimento de novo produto na empresa em que estou atualmente

4. Nunca participei de nenhum projeto de desenvolvimento de novos produtos

15. Se respondeu algum sim na questão anterior, há quanto tempo participa de projetos de desenvolvimento de novos produtos? (tempo total, incluindo participação em projetos de outras empresas - em anos).

1. Menos de 1 ano

2. De 1 a 2 anos

3. De 3 a 5 anos

4. De 6 a 8 anos

5. De 8 a 10 anos

6. Mais de 10 anos

16. De quantos projetos de desenvolvimento de novos produtos o (a) $\mathrm{Sr}$ (a) participa atualmente? (Caso não esteja participando de algum projeto de desenvolvimento de novos produtos no momento, ignore esta pergunta)

17. Qual foi sua principal experiência, nos últimos três anos, em projetos de desenvolvimento de novos produtos?

1. Gerente do projeto

2. Membro da equipe de projetos

3. Consultor

4. Outra

18. Qual foi sua principal experiência em projetos de desenvolvimento de novos produtos na empresa que faz parte atualmente?

1. Gerente do projeto

2. Membro da equipe de projetos

3. Consultor

4. Ainda não tive experiência com projetos de desenvolvimento de novos produtos na empresa em que estou atualmente

5. Outra 
Orientação para Mercado

19. Pensando nos projetos de desenvolvimento de novos produtos de que o (a) Sr (a) participa, ou já participou, marque abaixo a coluna que melhor descreve sua visão sobre a geração de inteligência nos projetos.

\begin{tabular}{|c|c|c|c|c|c|c|}
\hline $\begin{array}{c}\text { Nós fazemos pesquisa com os usuários finais } \\
\text { dos produtos resultantes de nossos projetos, para } \\
\text { avaliar a qualidade de nossos produtos lançados } \\
\text { no mercado. }\end{array}$ & $\square$ & $\square$ & $\square$ & $\square$ & $\square$ & $\square$ \\
\hline $\begin{array}{c}\text { Totalmente } \\
\begin{array}{c}\text { Anteligência sobre os nossos concorrentes, } \\
\text { utilizada nos projetos, é gerada } \\
\text { independentemente (sem depender } \\
\text { Muito }\end{array}\end{array}$ & $\begin{array}{c}\text { Discordo } \\
\text { Pouco }\end{array}$ & $\begin{array}{c}\text { Concordo } \\
\text { Pouco }\end{array}$ & $\begin{array}{c}\text { Concordo } \\
\text { Muito }\end{array}$ & $\begin{array}{c}\text { Concordo } \\
\text { Totalmente }\end{array}$ \\
$\begin{array}{c}\text { necessariamente de outros departamentos) por } \\
\text { vários de nossos departamentos. }\end{array}$ & $\square$ & $\square$ & $\square$ & $\square$ & $\square$ & $\square$ \\
\hline $\begin{array}{c}\text { Nós revisamos periodicamente, durante o } \\
\text { projeto, o provável efeito sobre os clientes das } \\
\text { mudanças em nosso ambiente de negócios (ex.: } \\
\text { legislação). }\end{array}$ & $\square$ & $\square$ & $\square$ & $\square$ & $\square$ & $\square$ \\
\hline $\begin{array}{c}\text { Nós coletamos e avaliamos freqüentemente } \\
\text { informações macro-econômicas gerais durante } \\
\text { os projetos (ex.: taxa de juros, taxas de câmbio, } \\
\text { PIB, taxa de crescimento da indústria, taxa de } \\
\text { crescimento da indústria, taxa de inflação). }\end{array}$ & $\square$ & $\square$ & $\square$ & $\square$ & $\square$ & $\square$ \\
\hline $\begin{array}{c}\text { Nós mantemos contatos com autoridades de } \\
\text { organizações governamentais e } \\
\text { regulamentadoras para coletar e avaliar } \\
\text { informações pertinentes aos projetos. }\end{array}$ & $\square$ & $\square$ & $\square$ & $\square$ & $\square$ & $\square$ \\
\hline $\begin{array}{c}\text { Nós coletamos e avaliamos informações } \\
\text { relativas a tendências sociais gerais (ex.: } \\
\text { consciência ambiental, estilos de vida } \\
\text { emergentes) que possam afetar nossos projetos. }\end{array}$ & $\square$ & $\square$ & $\square$ & $\square$ & $\square$ & $\square$ \\
\hline $\begin{array}{c}\text { Nós passamos muito tempo com nossos } \\
\text { fornecedores, durante os projetos, para aprender } \\
\text { mais sobre vários aspectos de seu negócio (ex.: } \\
\text { processos de manufatura, práticas da indústria, } \\
\text { clientes). }\end{array}$ & $\square$ & $\square$ & $\square$ & $\square$ & $\square$ & $\square$ \\
\hline $\begin{array}{c}\text { Poucas pessoas em nossos projetos estão } \\
\text { coletando informações sobre a concorrência. }\end{array}$ & $\square$ & $\square$ & $\square$ & $\square$ & $\square$ & $\square$ \\
\hline $\begin{array}{c}\text { Nós mantemos relações com empresas ou } \\
\text { pessoas formadores de opinião em nosso } \\
\text { mercado para saber as tendências atuais e usá- } \\
\text { las nos projetos. }\end{array}$ & $\square$ & $\square$ & $\square$ & $\square$ & $\square$ & $\square$ \\
\hline & $\square$ & $\square$ & $\square$ & $\square$ \\
\hline
\end{tabular}


20. Pensando nos projetos de desenvolvimento de novos produtos de que o(a) $\operatorname{Sr}(a)$ participa, ou já participou, marque abaixo a coluna que melhor descreve sua visão sobre a disseminação de inteligência nos projetos.

\begin{tabular}{|c|c|c|c|c|c|c|}
\hline $\begin{array}{c}\text { Discordo } \\
\text { Totalmente }\end{array}$ & $\begin{array}{c}\text { Discordo } \\
\text { Muito }\end{array}$ & $\begin{array}{c}\text { Discordo } \\
\text { Pouco }\end{array}$ & $\begin{array}{c}\text { Concordo } \\
\text { Pouco }\end{array}$ & $\begin{array}{c}\text { Concordo } \\
\text { Muito }\end{array}$ & $\begin{array}{c}\text { Concordo } \\
\text { Totalmente }\end{array}$ \\
$\begin{array}{c}\text { O pessoal de marketing passa muito tempo } \\
\text { futuras necessidades de nossos clientes para } \\
\text { incorporá-las aos projetos. }\end{array}$ & $\square$ & $\square$ & $\square$ & $\square$ & $\square$ & $\square$ \\
\hline $\begin{array}{c}\text { Durante nossos projetos, freqüentemente, } \\
\text { circulam internamente documentos (ex.: } \\
\text { relatórios e correspondências) com informações } \\
\text { sobre nossos clientes. }\end{array}$ & $\square$ & $\square$ & $\square$ & $\square$ & $\square$ & $\square$ \\
\hline $\begin{array}{c}\text { Durante os projetos, nós temos frequientemente } \\
\text { reuniões interdepartamentais para discutir } \\
\text { tendências e desenvolvimentos de mercado (ex.: } \\
\text { clientes, concorrentes, fornecedores). }\end{array}$ & $\square$ & $\square$ & $\square$ & $\square$ & $\square$ & $\square$ \\
\hline $\begin{array}{c}\text { Nós temos, regularmente, reuniões } \\
\text { interdepartamentais para atualizar nossos } \\
\text { conhecimentos sobre exigências pertinentes aos } \\
\text { projetos. }\end{array}$ & $\square$ & $\square$ & $\square$ & $\square$ & $\square$ & $\square$ \\
\hline $\begin{array}{c}\text { Durante os projetos, o pessoal técnico passa } \\
\text { muito tempo compartilhando informações sobre } \\
\text { tecnologias para novos produtos com outros } \\
\text { departamentos. }\end{array}$ & $\square$ & $\square$ & $\square$ & $\square$ & $\square$ & $\square$ \\
\hline $\begin{array}{c}\text { As informações de mercado espalham-se } \\
\text { rapidamente em todos os níveis hierárquicos dos } \\
\text { projetos. }\end{array}$ & $\square$ & $\square$ & $\square$ & $\square$ & $\square$ & $\square$ \\
\hline $\begin{array}{c}\text { Todo pessoal ligado a projetos de } \\
\text { desenvolvimento de novos produtos é } \\
\text { constantemente treinado para saber como } \\
\text { atender melhor o cliente. }\end{array}$ & $\square$ & $\square$ & $\square$ & $\square$ & $\square$ & $\square$ \\
\hline
\end{tabular}

21. Pensando nos projetos de desenvolvimento de novos produtos de que o(a) $\operatorname{Sr}(a)$ participa, ou já participou, marque abaixo a coluna que melhor descreve sua visão sobre a resposta à inteligência gerada nos projetos.

\begin{tabular}{|c|c|c|c|c|c|c|}
\hline & $\begin{array}{c}\text { Discordo } \\
\text { Totalmente }\end{array}$ & $\begin{array}{c}\text { Discordo } \\
\text { Muito }\end{array}$ & $\begin{array}{c}\text { Discordo } \\
\text { Pouco }\end{array}$ & $\begin{array}{c}\text { Concordo } \\
\text { Pouco }\end{array}$ & $\begin{array}{c}\text { Concordo } \\
\text { Muito }\end{array}$ & $\begin{array}{c}\text { Concordo } \\
\text { Totalmente }\end{array}$ \\
\hline $\begin{array}{c}\text { Por uma razão ou outra, em nossos projetos, nós } \\
\text { tendemos a ignorar mudanças nas necessidades } \\
\text { de produtos de nossos clientes. }\end{array}$ & $\square$ & $\square$ & $\square$ & $\square$ & $\square$ & $\square$ \\
\hline $\begin{array}{c}\text { Nós somos lentos para iniciar negócios com } \\
\text { novos fornecedores, mesmo quando sabemos } \\
\text { que eles serão melhores que os atuais. }\end{array}$ & $\square$ & $\square$ & $\square$ & $\square$ & $\square$ & $\square$ \\
\hline $\begin{array}{c}\text { Se um grande competidor estivesse para lançar } \\
\text { uma campanha intensiva sobre nossos clientes, } \\
\text { nós implementaríamos uma resposta } \\
\text { imediatamente. }\end{array}$ & $\square$ & $\square$ & $\square$ & $\square$ & $\square$ & $\square$ \\
\hline $\begin{array}{c}\text { As atividades de diferentes departamentos estão } \\
\text { bem coordenadas nos projetos. }\end{array}$ & $\square$ & $\square$ & $\square$ & $\square$ & $\square$ & $\square$ \\
\hline $\begin{array}{c}\text { Se nós tivéssemos uma idéia nova para um } \\
\text { projeto, provavelmente, seríamos capazes de } \\
\text { implementá-la a tempo. }\end{array}$ & $\square$ & $\square$ & $\square$ & $\square$ & $\square$ & $\square$ \\
\hline $\begin{array}{c}\text { As linhas de produtos que nós desenvolvemos } \\
\text { dependem mais de políticas internas do que das } \\
\text { reais necessidades de mercado. }\end{array}$ & $\square$ & $\square$ & $\square$ & $\square$ & $\square$ & $\square$ \\
\hline
\end{tabular}


Interface Interfuncional

22. Pensando nos projetos de desenvolvimento de novos produtos de que o(a) Sr(a) participa, ou já participou, marque abaixo a coluna que melhor descreve sua visão sobre a confiança no desenvolvimento de projetos.

\begin{tabular}{|c|c|c|c|c|c|c|}
\hline & $\begin{array}{c}\text { Discordo } \\
\text { Totalmente }\end{array}$ & $\begin{array}{c}\text { Discordo } \\
\text { Muito }\end{array}$ & $\begin{array}{c}\text { Discordo } \\
\text { Pouco }\end{array}$ & $\begin{array}{c}\text { Concordo } \\
\text { Pouco }\end{array}$ & $\begin{array}{c}\text { Concordo } \\
\text { Muito }\end{array}$ & $\begin{array}{c}\text { Concordo } \\
\text { Totalmente }\end{array}$ \\
\hline $\begin{array}{c}\text { Os departamentos envolvidos nos projetos são } \\
\text { sinceros e honestos uns com os outros. }\end{array}$ & $\square$ & $\square$ & & \\
\hline $\begin{array}{c}\text { As atitudes dos departamentos envolvidos } \\
\text { sempre correspondem às expectativas } \\
\text { estabelecidas pela equipe do projeto. }\end{array}$ & $\square$ & $\square$ & $\square$ & \\
\hline $\begin{array}{c}\text { Os departamentos cumprem as promessas feitas. } \\
\text { Os departamentos estão sinceramente } \\
\text { preocupados com os objetivos dos projetos. }\end{array}$ & $\square$ & $\square$ & $\square$ & $\square$ & \\
\hline
\end{tabular}

23. Pensando nos projetos de desenvolvimento de novos produtos de que o(a) Sr(a) participa, ou já participou, marque abaixo a coluna que melhor descreve sua visão sobre a interação interfuncional nos projetos.

\begin{tabular}{|c|c|c|c|c|c|c|}
\hline $\begin{array}{c}\text { Discordo } \\
\text { Totalmente }\end{array}$ & $\begin{array}{c}\text { Discordo } \\
\text { Muito }\end{array}$ & $\begin{array}{c}\text { Discordo } \\
\text { Pouco }\end{array}$ & $\begin{array}{c}\text { Concordo } \\
\text { Pouco }\end{array}$ & $\begin{array}{c}\text { Concordo } \\
\text { Muito }\end{array}$ & $\begin{array}{c}\text { Concordo } \\
\text { Totalmente }\end{array}$ \\
\hline $\begin{array}{c}\text { ajudam uns aos outros a realizar suas tarefas de } \\
\text { forma mais efetiva. }\end{array}$ & $\square$ & $\square$ & & \\
\hline $\begin{array}{c}\text { Os departamentos tentam atingir as metas dos } \\
\text { projetos em parceria. }\end{array}$ & $\square$ & $\square$ & $\square$ & $\square$ & \\
\hline $\begin{array}{c}\text { Os departamentos compartilham idéias, } \\
\text { informação e/ou recursos durante os projetos. }\end{array}$ & $\square$ & $\square$ & $\square$ & $\square$ & \\
\hline $\begin{array}{c}\text { Os departamentos tomam as decisões técnicas e } \\
\text { operacionais dos projetos juntos. }\end{array}$ & $\square$ & $\square$ & $\square$ & $\square$ & \\
\hline $\begin{array}{c}\text { Há comunicação aberta entre os departamentos } \\
\text { da organização durante o projeto. }\end{array}$ & $\square$ & $\square$ & $\square$ & $\square$ & $\square$ \\
\hline
\end{tabular}

24. Utilize o espaço abaixo para comentários adicionais, levando em conta o seu ponto de vista, sobre os porjetos de desenvolvimento de novos produtos que o(a) $\operatorname{Sr}($ a) participa(ou).

25. $\mathrm{O}$ (a) $\mathrm{Sr}$ (a) gostaría de receber o resumo dos resultados desta pesquisa?

1. Sim

2. Não 


\section{APÊNDICE II - Tabelas de Análises Estatísticas dos Dados}

\section{Estatísticas Descritivas: Geração de Inteligência}

\begin{tabular}{|c|c|c|c|c|c|c|c|}
\hline \multicolumn{3}{|c|}{ Variáveis } & \multicolumn{5}{|c|}{ Estatísticas Descritivas } \\
\hline Id & Palavra-Chave & Descrição & Mediana & Moda & Mínimo & Máximo & Soma \\
\hline V23 & $\begin{array}{l}\text { Pesquisa com } \\
\text { Usuários Finais }\end{array}$ & $\begin{array}{l}\text { Nós fazemos pesquisa com os } \\
\text { usuários finais dos produtos } \\
\text { resultantes de nossos } \\
\text { projetos, para avaliar a } \\
\text { qualidade de nossos produtos } \\
\text { lançados no mercado. }\end{array}$ & 5 & 6 & 2 & 6 & 105 \\
\hline V24 & $\begin{array}{l}\text { Inteligência sobre } \\
\text { Concorrentes }\end{array}$ & $\begin{array}{l}\text { A inteligência sobre os } \\
\text { nossos concorrentes, utilizada } \\
\text { nos projetos, é gerada } \\
\text { independentemente (sem } \\
\text { depender necessariamente de } \\
\text { outros departamentos) por } \\
\text { vários de nossos } \\
\text { departamentos. }\end{array}$ & 4 & 5 & 1 & 6 & 79 \\
\hline V25 & $\begin{array}{l}\text { Efeito das } \\
\text { Mudanças Sobre } \\
\text { Clientes }\end{array}$ & $\begin{array}{l}\text { Nós revisamos } \\
\text { periodicamente, durante o } \\
\text { projeto, o provável efeito } \\
\text { sobre os clientes das } \\
\text { mudanças em nosso ambiente } \\
\text { de negócios (ex.: legislação). }\end{array}$ & 5 & 5 & 2 & 6 & 102 \\
\hline V26 & $\begin{array}{l}\text { Informações } \\
\text { Macroeconômicas }\end{array}$ & $\begin{array}{l}\text { Nós coletamos e avaliamos } \\
\text { freqüentemente informações } \\
\text { macro-econômicas gerais } \\
\text { durante os projetos (ex.: taxa } \\
\text { de juros, taxas de câmbio, } \\
\text { PIB, taxa de crescimento da } \\
\text { indústria, taxa de crescimento } \\
\text { da indústria, taxa de } \\
\text { inflação). }\end{array}$ & 5 & 5 & 1 & 6 & 93 \\
\hline V27 & $\begin{array}{l}\text { Contato com } \\
\text { Autoridades }\end{array}$ & $\begin{array}{l}\text { Nós mantemos contatos com } \\
\text { autoridades de organizações } \\
\text { governamentais e } \\
\text { regulamentadoras para coletar } \\
\text { e avaliar informações } \\
\text { pertinentes aos projetos. }\end{array}$ & 5 & 5 & 3 & 6 & 108 \\
\hline V28 & Tendências Sociais & $\begin{array}{l}\text { Nós coletamos e avaliamos } \\
\text { informações relativas a } \\
\text { tendências sociais gerais (ex.: } \\
\text { consciência ambiental, estilos } \\
\text { de vida emergentes) que } \\
\text { possam afetar nossos } \\
\text { projetos. }\end{array}$ & 5 & 5 & 2 & 6 & 95 \\
\hline V29 & $\begin{array}{l}\text { Tempo com } \\
\text { Fornecedores }\end{array}$ & $\begin{array}{l}\text { Nós passamos muito tempo } \\
\text { com nossos fornecedores, } \\
\text { durante os projetos, para } \\
\text { aprender mais sobre vários } \\
\text { aspectos de seu negócio (ex.: } \\
\text { processos de manufatura, } \\
\text { práticas da indústria, }\end{array}$ & 5 & 5 & 2 & 6 & 94 \\
\hline
\end{tabular}




\begin{tabular}{|c|c|c|c|c|c|c|c|}
\hline & & clientes). & & & & & \\
\hline $\begin{array}{c}\mathrm{V} 30 \\
*\end{array}$ & $\begin{array}{l}\text { Pessoas Coletando } \\
\text { Informações }\end{array}$ & $\begin{array}{l}\text { Poucas pessoas em nossos } \\
\text { projetos estão coletando } \\
\text { informações sobre a } \\
\text { concorrência. }\end{array}$ & 4 & 5 & 2 & 6 & 86 \\
\hline V31 & $\begin{array}{l}\text { Formadores de } \\
\text { Opinião }\end{array}$ & $\begin{array}{l}\text { Nós mantemos relações com } \\
\text { empresas ou pessoas } \\
\text { formadores de opinião em } \\
\text { nosso mercado para saber as } \\
\text { tendências atuais e usá-las } \\
\text { nos projetos. }\end{array}$ & 5 & 6 & 2 & 6 & 109 \\
\hline
\end{tabular}

Fonte: Elaborado pela autora.

\section{Freqüências: Geração de Inteligência}

\begin{tabular}{|c|c|c|c|c|c|c|c|c|c|}
\hline \multicolumn{3}{|c|}{ Variáveis } & \multicolumn{3}{|c|}{ Discordo } & \multicolumn{3}{|c|}{ Concordo } & \multirow{2}{*}{ Total } \\
\hline Id & Palavra-Chave & Descriçãa & DT & DM & DP & $\mathbf{C P}$ & $\mathbf{C M}$ & CT & \\
\hline V23 & $\begin{array}{l}\text { Pesquisa com } \\
\text { Usuários Finais }\end{array}$ & $\begin{array}{l}\text { Nós fazemos pesquisa com os } \\
\text { usuários finais dos produtos } \\
\text { resultantes de nossos } \\
\text { projetos, para avaliar a } \\
\text { qualidade de nossos produtos } \\
\text { lançados no mercado. }\end{array}$ & - & 9,5 & - & 14,3 & 33,3 & 42,9 & 100 \\
\hline V24 & $\begin{array}{l}\text { Inteligência sobre } \\
\text { Concorrentes }\end{array}$ & $\begin{array}{l}\text { A inteligência sobre os } \\
\text { nossos concorrentes, utilizada } \\
\text { nos projetos, é gerada } \\
\text { independentemente (sem } \\
\text { depender necessariamente de } \\
\text { outros departamentos) por } \\
\text { vários de nossos } \\
\text { departamentos. }\end{array}$ & 9,5 & 19 & 9,5 & 14,3 & 42,9 & 4,8 & 100 \\
\hline V25 & $\begin{array}{l}\text { Efeito das } \\
\text { Mudanças Sobre } \\
\text { Clientes }\end{array}$ & $\begin{array}{l}\text { Nós revisamos } \\
\text { periodicamente, durante o } \\
\text { projeto, o provável efeito } \\
\text { sobre os clientes das } \\
\text { mudanças em nosso ambiente } \\
\text { de negócios (ex.: legislação). }\end{array}$ & - & 9,5 & 4,8 & 9,5 & 42,9 & 33,3 & 100 \\
\hline V26 & $\begin{array}{l}\text { Informações } \\
\text { Macroeconômicas }\end{array}$ & $\begin{array}{l}\text { Nós coletamos e avaliamos } \\
\text { freqüentemente informações } \\
\text { macro-econômicas gerais } \\
\text { durante os projetos (ex.: taxa } \\
\text { de juros, taxas de câmbio, } \\
\text { PIB, taxa de crescimento da } \\
\text { indústria, taxa de crescimento } \\
\text { da indústria, taxa de } \\
\text { inflação). }\end{array}$ & 4,8 & 4,8 & 9,5 & 23,8 & 38,1 & 19 & 100 \\
\hline V27 & $\begin{array}{l}\text { Contato com } \\
\text { Autoridades }\end{array}$ & $\begin{array}{l}\text { Nós mantemos contatos com } \\
\text { autoridades de organizações } \\
\text { governamentais e } \\
\text { regulamentadoras para coletar } \\
\text { e avaliar informações } \\
\text { pertinentes aos projetos. }\end{array}$ & - & - & 4,8 & 14,3 & 42,9 & 38,1 & 100 \\
\hline V28 & Tendências Sociais & $\begin{array}{l}\text { Nós coletamos e avaliamos } \\
\text { informações relativas a } \\
\text { tendências sociais gerais (ex.: } \\
\text { consciência ambiental, estilos } \\
\text { de vida emergentes) que }\end{array}$ & - & 4,8 & 14,3 & 19 & 47,6 & 14,3 & 100 \\
\hline
\end{tabular}




\begin{tabular}{|c|c|c|c|c|c|c|c|c|c|}
\hline & & $\begin{array}{l}\text { possam afetar nossos } \\
\text { projetos. }\end{array}$ & & & & & & & \\
\hline V29 & $\begin{array}{l}\text { Tempo com } \\
\text { Fornecedores }\end{array}$ & $\begin{array}{l}\text { Nós passamos muito tempo } \\
\text { com nossos fornecedores, } \\
\text { durante os projetos, para } \\
\text { aprender mais sobre vários } \\
\text { aspectos de seu negócio (ex.: } \\
\text { processos de manufatura, } \\
\text { práticas da indústria, } \\
\text { clientes). }\end{array}$ & - & 9,5 & 14,3 & 14,3 & 42,9 & 19 & 100 \\
\hline $\mathrm{V} 30^{*}$ & $\begin{array}{l}\text { Pessoas Coletando } \\
\text { Informações }\end{array}$ & $\begin{array}{l}\text { Poucas pessoas em nossos } \\
\text { projetos estão coletando } \\
\text { informações sobre a } \\
\text { concorrência. }\end{array}$ & - & 9,5 & 23,8 & 19 & 42,9 & 4,8 & 100 \\
\hline V31 & $\begin{array}{l}\text { Formadores de } \\
\text { Opinião }\end{array}$ & $\begin{array}{l}\text { Nós mantemos relações com } \\
\text { empresas ou pessoas } \\
\text { formadores de opinião em } \\
\text { nosso mercado para saber as } \\
\text { tendências atuais e usá-las } \\
\text { nos projetos. }\end{array}$ & - & 4,8 & - & 9,5 & 42,9 & 42,9 & 100 \\
\hline
\end{tabular}

Todos os valores desta tabela são medidos em percentual (\%).

Fonte: Elaborado pela autora.

\section{Estatísticas Descritivas: Disseminação da Inteligência}

\begin{tabular}{|c|c|c|c|c|c|c|c|}
\hline \multicolumn{3}{|c|}{ Variáveis } & \multicolumn{5}{|c|}{ Estatísticas Descritivas } \\
\hline Id & Palavra-Chave & Descrição & Mediana & Moda & Mínimo & Máximo & Soma \\
\hline V32 & $\begin{array}{l}\text { Discussão } \\
\text { Marketing-Outros } \\
\text { Departamentos }\end{array}$ & $\begin{array}{l}\text { O pessoal de marketing passa } \\
\text { muito tempo discutindo com } \\
\text { outros departamentos } \\
\text { funcionais futuras } \\
\text { necessidades de nossos } \\
\text { clientes para incorporá-las } \\
\text { aos projetos. }\end{array}$ & 4 & 4 & 2 & 6 & 91 \\
\hline V33 & $\begin{array}{l}\text { Documentos } \\
\text { Internos }\end{array}$ & $\begin{array}{l}\text { Durante nossos projetos, } \\
\text { freqüentemente, circulam } \\
\text { internamente documentos } \\
\text { (ex.: relatórios e } \\
\text { correspondências) com } \\
\text { informações sobre nossos } \\
\text { clientes. }\end{array}$ & 4 & 4 & 2 & 6 & 90 \\
\hline V34 & $\begin{array}{l}\text { Reuniões } \\
\text { Interdepartamentai } \\
\text { s para Discussão }\end{array}$ & $\begin{array}{l}\text { Durante os projetos, nós } \\
\text { temos freqüentemente } \\
\text { reuniões interdepartamentais } \\
\text { para discutir tendências e } \\
\text { desenvolvimentos de } \\
\text { mercado (ex.: clientes, } \\
\text { concorrentes, fornecedores). }\end{array}$ & 5 & 5 & 4 & 6 & 106 \\
\hline V35 & $\begin{array}{l}\text { Reuniões } \\
\text { Interdepartamentai } \\
\text { s para Atualização }\end{array}$ & $\begin{array}{l}\text { Nós temos, regularmente, } \\
\text { reuniões interdepartamentais } \\
\text { para atualizar nossos } \\
\text { conhecimentos sobre } \\
\text { exigências pertinentes aos } \\
\text { projetos. }\end{array}$ & 5 & 5 & 4 & 6 & 108 \\
\hline V36 & $\begin{array}{l}\text { Informações sobre } \\
\text { Tecnologias }\end{array}$ & $\begin{array}{l}\text { Durante os projetos, o pessoal } \\
\text { técnico passa muito tempo }\end{array}$ & 5 & 5 & 3 & 6 & 97 \\
\hline
\end{tabular}




\begin{tabular}{|c|c|c|c|c|c|c|c|}
\hline & & $\begin{array}{l}\text { compartilhando informações } \\
\text { sobre tecnologias para novos } \\
\text { produtos com outros } \\
\text { departamentos. }\end{array}$ & & & & & \\
\hline V37 & $\begin{array}{l}\text { Propagação das } \\
\text { Informações de } \\
\text { Mercado }\end{array}$ & $\begin{array}{l}\text { As informações de mercado } \\
\text { espalham-se rapidamente em } \\
\text { todos os níveis hierárquicos } \\
\text { dos projetos. }\end{array}$ & 4 & 4 & 2 & 6 & 90 \\
\hline V38 & $\begin{array}{l}\text { Treinamento do } \\
\text { Pessoal de DNP }\end{array}$ & $\begin{array}{l}\text { Todo pessoal ligado a } \\
\text { projetos de desenvolvimento } \\
\text { de novos produtos é } \\
\text { constantemente treinado para } \\
\text { saber como atender melhor o } \\
\text { cliente. }\end{array}$ & 4 & 4 & 2 & 5 & 84 \\
\hline
\end{tabular}

Fonte: Elaborado pela autora.

Freqüências: Disseminação da Inteligência

\begin{tabular}{|c|c|c|c|c|c|c|c|c|c|}
\hline \multicolumn{3}{|c|}{ Variáveis } & \multicolumn{3}{|c|}{ Discordo } & \multicolumn{3}{|c|}{ Concordo } & \multirow{2}{*}{ Total } \\
\hline Id & & Descrição & DT & DM & DP & $\mathbf{C P}$ & $\mathbf{C M}$ & CT & \\
\hline V32 & $\begin{array}{l}\text { Discussão } \\
\text { Marketing-Outros } \\
\text { Departamentos }\end{array}$ & $\begin{array}{l}\text { O pessoal de marketing passa } \\
\text { muito tempo discutindo com } \\
\text { outros departamentos funcionais } \\
\text { futuras necessidades de nossos } \\
\text { clientes para incorporá-las aos } \\
\text { projetos. }\end{array}$ & - & 4,8 & 9,5 & 42,9 & 33,3 & 9,5 & 100 \\
\hline V33 & $\begin{array}{l}\text { Documentos } \\
\text { Internos }\end{array}$ & $\begin{array}{l}\text { Durante nossos projetos, } \\
\text { freqüentemente, circulam } \\
\text { internamente documentos (ex.: } \\
\text { relatórios e correspondências) } \\
\text { com informações sobre nossos } \\
\text { clientes. }\end{array}$ & - & 4,8 & 14,3 & 38,1 & 33,3 & 9,5 & 100 \\
\hline V34 & $\begin{array}{l}\text { Reuniões } \\
\text { Interdepartamentai } \\
\text { s para Discussão }\end{array}$ & $\begin{array}{l}\text { Durante os projetos, nós temos } \\
\text { freqüentemente reuniões } \\
\text { interdepartamentais para discutir } \\
\text { tendências e desenvolvimentos } \\
\text { de mercado (ex.: clientes, } \\
\text { concorrentes, fornecedores). }\end{array}$ & - & - & - & 19 & 47,6 & 33,3 & 100 \\
\hline V35 & $\begin{array}{l}\text { Reuniões } \\
\text { Interdepartamentai } \\
\text { s para Atualização }\end{array}$ & $\begin{array}{l}\text { Nós temos, regularmente, } \\
\text { reuniões interdepartamentais } \\
\text { para atualizar nossos } \\
\text { conhecimentos sobre exigências } \\
\text { pertinentes aos projetos. }\end{array}$ & - & - & - & 19 & 47,6 & 33,3 & 100 \\
\hline V36 & $\begin{array}{l}\text { Informações sobre } \\
\text { Tecnologias }\end{array}$ & $\begin{array}{l}\text { Durante os projetos, o pessoal } \\
\text { técnico passa muito tempo } \\
\text { compartilhando informações } \\
\text { sobre tecnologias para novos } \\
\text { produtos com outros } \\
\text { departamentos. }\end{array}$ & - & - & 9,5 & 33,3 & 42,9 & 14,3 & 100 \\
\hline V37 & $\begin{array}{l}\text { Propagação das } \\
\text { Informações de } \\
\text { Mercado }\end{array}$ & $\begin{array}{l}\text { As informações de mercado } \\
\text { espalham-se rapidamente em } \\
\text { todos os níveis hierárquicos dos } \\
\text { projetos. }\end{array}$ & - & 4,8 & 14,3 & 38,1 & 33,3 & 9,5 & 100 \\
\hline V38 & $\begin{array}{l}\text { Treinamento do } \\
\text { Pessoal de DNP }\end{array}$ & $\begin{array}{l}\text { Todo pessoal ligado a projetos } \\
\text { de desenvolvimento de novos } \\
\text { produtos é constantemente } \\
\text { treinado para saber como atender } \\
\text { melhor o cliente. }\end{array}$ & - & 9,5 & 14,3 & 42,9 & 33,3 & - & 100 \\
\hline
\end{tabular}


Todos os valores desta tabela são medidos em percentual (\%).

Fonte: Elaborado pela autora.

\section{Estatísticas Descritivas: Resposta á Inteligência}

\begin{tabular}{|c|c|c|c|c|c|c|c|}
\hline \multicolumn{3}{|c|}{ Variáveis } & \multicolumn{5}{|c|}{ Estatísticas Descritivas } \\
\hline Id & & Descrição & Mediana & Moda & Mínimo & Máximo & Soma \\
\hline V39* & $\begin{array}{l}\text { Mudanças nas } \\
\text { Necessidades }\end{array}$ & $\begin{array}{l}\text { Por uma razão ou outra, em } \\
\text { nossos projetos, nós } \\
\text { tendemos a ignorar mudanças } \\
\text { nas necessidades de produtos } \\
\text { de nossos clientes. }\end{array}$ & 5 & 5 & 2 & 6 & 89 \\
\hline V40* & $\begin{array}{l}\text { Novos } \\
\text { Fornecedores }\end{array}$ & $\begin{array}{l}\text { Nós somos lentos para iniciar } \\
\text { negócios com novos } \\
\text { fornecedores, mesmo quando } \\
\text { sabemos que eles serão } \\
\text { melhores que os atuais. }\end{array}$ & 4 & 5 & 1 & 5 & 83 \\
\hline V41 & $\begin{array}{l}\text { Resposta à } \\
\text { Concorrência }\end{array}$ & $\begin{array}{l}\text { Se um grande competidor } \\
\text { estivesse para lançar uma } \\
\text { campanha intensiva sobre } \\
\text { nossos clientes, nós } \\
\text { implementaríamos uma } \\
\text { resposta imediatamente. }\end{array}$ & 5 & 5 & 2 & 5 & 87 \\
\hline V42 & $\begin{array}{l}\text { Coordenação de } \\
\text { Atividades }\end{array}$ & $\begin{array}{l}\text { As atividades de diferentes } \\
\text { departamentos estão bem } \\
\text { coordenadas nos projetos. }\end{array}$ & 4 & 4 & 3 & 6 & 95 \\
\hline V43 & $\begin{array}{l}\text { Implementação de } \\
\text { Nova Idéia }\end{array}$ & $\begin{array}{l}\text { Se nós tivéssemos uma idéia } \\
\text { nova para um projeto, } \\
\text { provavelmente, seríamos } \\
\text { capazes de implementá-la a } \\
\text { tempo. }\end{array}$ & 4 & 4 & 2 & 6 & 84 \\
\hline V44* & $\begin{array}{l}\text { Desenvolvimento } \\
\text { das Linhas de } \\
\text { Produtos }\end{array}$ & $\begin{array}{l}\text { As linhas de produtos que nós } \\
\text { desenvolvemos dependem } \\
\text { mais de políticas internas do } \\
\text { que das reais necessidades de } \\
\text { mercado. }\end{array}$ & 5 & 5 & 1 & 6 & 89 \\
\hline
\end{tabular}

Fonte: Elaborado pela autora.

\section{Freqüências: Resposta à Inteligência}

\begin{tabular}{c|l|l|c|c|c|c|c|c|c}
\hline \multicolumn{2}{c|}{ Variáveis } & \multicolumn{1}{c|}{ Discordo } & \multicolumn{3}{c|}{ Concordo } & Total \\
\hline V39* & $\begin{array}{l}\text { Mudanças nas } \\
\text { Necessidades }\end{array}$ & $\begin{array}{l}\text { Por uma razão ou outra, em } \\
\text { nossos projetos, nós } \\
\text { tendemos a ignorar mudanças } \\
\text { nas necessidades de produtos } \\
\text { de nossos clientes. }\end{array}$ & - & 4,8 & 33,3 & 9,5 & 38,1 & 14,3 & 100 \\
\hline V40* & $\begin{array}{l}\text { Novos } \\
\text { Fornecedores }\end{array}$ & $\begin{array}{l}\text { Nós somos lentos para iniciar } \\
\text { negócios com novos } \\
\text { fornecedores, mesmo quando } \\
\text { sabemos que eles serão } \\
\text { melhores que os atuais. }\end{array}$ & 4,8 & 4,8 & 23,8 & 23,8 & 42,9 & - & 100 \\
\hline V41 & Resposta à & Se um grande competidor & - & 14,3 & 9,5 & 23,8 & 52,4 & - & 100 \\
\hline
\end{tabular}




\begin{tabular}{|c|c|c|c|c|c|c|c|c|c|}
\hline & Concorrência & $\begin{array}{l}\text { estivesse para lançar uma } \\
\text { campanha intensiva sobre } \\
\text { nossos clientes, nós } \\
\text { implementaríamos uma } \\
\text { resposta imediatamente. }\end{array}$ & & & & & & & \\
\hline V42 & $\begin{array}{l}\text { Coordenação de } \\
\text { Atividades }\end{array}$ & $\begin{array}{l}\text { As atividades de diferentes } \\
\text { departamentos estão bem } \\
\text { coordenadas nos projetos. }\end{array}$ & - & - & 4,8 & 47,6 & 38,1 & 9,5 & 100 \\
\hline V43 & $\begin{array}{l}\text { Implementação de } \\
\text { Nova Idéia }\end{array}$ & $\begin{array}{l}\text { Se nós tivéssemos uma idéia } \\
\text { nova para um projeto, } \\
\text { provavelmente, seríamos } \\
\text { capazes de implementá-la a } \\
\text { tempo. }\end{array}$ & - & 14,3 & 9,5 & 42,9 & 28,6 & 4,8 & 100 \\
\hline V44* & $\begin{array}{l}\text { Desenvolvimento } \\
\text { das Linhas de } \\
\text { Produtos }\end{array}$ & $\begin{array}{l}\text { As linhas de produtos que nós } \\
\text { desenvolvemos dependem } \\
\text { mais de políticas internas do } \\
\text { que das reais necessidades de } \\
\text { mercado. }\end{array}$ & 4,8 & 4,8 & 28,6 & - & 47,6 & 14,3 & 100 \\
\hline
\end{tabular}

Todos os valores desta tabela são medidos em percentual (\%).

Fonte: Elaborado pela autora.

\section{Estatísticas Descritivas: Confiança}

\begin{tabular}{c|l|l|c|c|c|c|c}
\hline \multicolumn{2}{c|}{ Variáveis } & \multicolumn{4}{c}{ Estatísticas Descritivas } \\
\hline Id & \multicolumn{1}{c|}{ Descrição } & Mediana & Moda & Mínimo & Máximo & Soma \\
\hline V45 & Sinceridade Mútua & $\begin{array}{l}\text { Os departamentos envolvidos } \\
\text { nos projetos são sinceros e } \\
\text { honestos uns com os outros. }\end{array}$ & 5 & 5 & 2 & 6 & 95 \\
\hline V46 & $\begin{array}{l}\text { Expectativas da } \\
\text { Equipe }\end{array}$ & $\begin{array}{l}\text { As atitudes dos } \\
\text { departamentos envolvidos } \\
\text { sempre correspondem às } \\
\text { expectativas estabelecidas } \\
\text { pela equipe do projeto. }\end{array}$ & 4 & 4 & 2 & 5 & 87 \\
\hline Promessas & $\begin{array}{l}\text { Os departamentos cumprem } \\
\text { as promessas feitas. }\end{array}$ & 4 & 5 & 2 & 5 & 87 \\
V48 & $\begin{array}{l}\text { Preocupação com } \\
\text { Objetivos }\end{array}$ & $\begin{array}{l}\text { Os departamentos estão } \\
\text { sinceramente preocupados } \\
\text { com os objetivos dos } \\
\text { projetos. }\end{array}$ & 5 & 5 & 3 & 5 & 96 \\
\hline
\end{tabular}

Fonte: Elaborado pela autora.

\section{Frequiências: Confiança}

\begin{tabular}{|c|c|c|c|c|c|c|c|c|c|}
\hline \multicolumn{3}{|c|}{ Variáveis } & \multicolumn{3}{|c|}{ Discordo } & \multicolumn{3}{|c|}{ Concordo } & \multirow{2}{*}{ Total } \\
\hline Id & & Descrição & DT & DM & DP & $\mathbf{C P}$ & $\mathbf{C M}$ & CT & \\
\hline V45 & Sinceridade Mútua & $\begin{array}{l}\text { Os departamentos envolvidos } \\
\text { nos projetos são sinceros e } \\
\text { honestos uns com os outros. }\end{array}$ & - & 4,8 & 9,5 & 19 & 61,9 & 4,8 & 100 \\
\hline V46 & $\begin{array}{l}\text { Expectativas da } \\
\text { Equipe }\end{array}$ & $\begin{array}{l}\text { As atitudes dos } \\
\text { departamentos envolvidos } \\
\text { sempre correspondem às } \\
\text { expectativas estabelecidas }\end{array}$ & - & 4,8 & 14,3 & 42,9 & 38,1 & - & 100 \\
\hline
\end{tabular}




\begin{tabular}{|c|c|c|c|c|c|c|c|c|c|}
\hline & & pela equipe do projeto. & & & & & & & \\
\hline V47 & $\begin{array}{l}\text { Cumprimento das } \\
\text { Promessas } \\
\end{array}$ & $\begin{array}{l}\text { Os departamentos cumprem } \\
\text { as promessas feitas. }\end{array}$ & - & 14,3 & - & 42,9 & 42,9 & - & 100 \\
\hline V48 & $\begin{array}{l}\text { Preocupação com } \\
\text { Objetivos }\end{array}$ & $\begin{array}{l}\text { Os departamentos estão } \\
\text { sinceramente preocupados } \\
\text { com os objetivos dos projetos. }\end{array}$ & - & - & 9,5 & 23,8 & 66,7 & - & 100 \\
\hline
\end{tabular}

Todos os valores desta tabela são medidos em percentual (\%).

Fonte: Elaborado pela autora.

\section{Estatísticas Descritivas: Integração}

\begin{tabular}{|c|c|c|c|c|c|c|c|}
\hline \multicolumn{3}{|c|}{ Variáveis } & \multicolumn{5}{|c|}{ Estatísticas Descritivas } \\
\hline Id & & Descrição & Mediana & Moda & $\begin{array}{c}\text { Míni } \\
\text { mo }\end{array}$ & $\begin{array}{c}\text { Máxi } \\
\text { mo }\end{array}$ & Soma \\
\hline V49 & Ajuda Mútua & $\begin{array}{l}\text { Os departamentos envolvidos } \\
\text { nos projetos ajudam uns aos } \\
\text { outros a realizar suas tarefas } \\
\text { de forma mais efetiva. }\end{array}$ & 4 & 5 & 2 & 5 & 91 \\
\hline V50 & Metas em Parceria & $\begin{array}{l}\text { Os departamentos tentam } \\
\text { atingir as metas dos projetos } \\
\text { em parceria. }\end{array}$ & 5 & 5 & 3 & 6 & 99 \\
\hline V51 & Partilha de Idéias & $\begin{array}{l}\text { Os departamentos } \\
\text { compartilham idéias, } \\
\text { informação e/ou recursos } \\
\text { durante os projetos. }\end{array}$ & 5 & 5 & 3 & 6 & 98 \\
\hline V52 & $\begin{array}{l}\text { Decisões em } \\
\text { Conjunto }\end{array}$ & $\begin{array}{l}\text { Os departamentos tomam as } \\
\text { decisões técnicas e } \\
\text { operacionais dos projetos } \\
\text { juntos. }\end{array}$ & 5 & 5 & 3 & 6 & 97 \\
\hline V53 & $\begin{array}{l}\text { Comunicação } \\
\text { Aberta }\end{array}$ & $\begin{array}{l}\text { Há comunicação aberta entre } \\
\text { os departamentos da } \\
\text { organização durante o } \\
\text { projeto. }\end{array}$ & 5 & 5 & 4 & 6 & 104 \\
\hline
\end{tabular}

Fonte: Elaborado pela autora.

\section{Freqüências: Integração}

\begin{tabular}{|c|c|c|c|c|c|c|c|c|c|}
\hline \multicolumn{3}{|c|}{ Variáveis } & \multicolumn{3}{|c|}{ Discordo } & \multicolumn{3}{|c|}{ Concordo } & \multirow{2}{*}{ Total } \\
\hline Id & & Descrição & DT & DM & DP & $\mathbf{C P}$ & CM & CT & \\
\hline V49 & Ajuda Mútua & $\begin{array}{l}\text { Os departamentos envolvidos } \\
\text { nos projetos ajudam uns aos } \\
\text { outros a realizar suas tarefas } \\
\text { de forma mais efetiva. }\end{array}$ & - & 4,8 & 4,8 & 42,9 & 47,6 & - & 100 \\
\hline V50 & Metas em Parceria & $\begin{array}{l}\text { Os departamentos tentam } \\
\text { atingir as metas dos projetos } \\
\text { em parceria. }\end{array}$ & - & - & 4,8 & 28,6 & 57,1 & 9,5 & 100 \\
\hline V51 & Partilha de Idéias & $\begin{array}{l}\text { Os departamentos } \\
\text { compartilham idéias, } \\
\text { informação e/ou recursos } \\
\text { durante os projetos. }\end{array}$ & - & - & 9,5 & 23,8 & 57,1 & 9,5 & 100 \\
\hline V52 & $\begin{array}{l}\text { Decisões em } \\
\text { Conjunto }\end{array}$ & $\begin{array}{l}\text { Os departamentos tomam as } \\
\text { decisões técnicas e } \\
\text { operacionais dos projetos } \\
\text { juntos. }\end{array}$ & - & - & 4,8 & 38,1 & 47,6 & 9,5 & 100 \\
\hline
\end{tabular}




\begin{tabular}{|c|c|c|c|c|c|c|c|c|c|}
\hline V53 & $\begin{array}{l}\text { Comunicação } \\
\text { Aberta }\end{array}$ & $\begin{array}{l}\text { Há comunicação aberta entre } \\
\text { os departamentos da } \\
\text { organização durante o } \\
\text { projeto. }\end{array}$ & - & - & - & 23,8 & 57,1 & 19 & 100 \\
\hline
\end{tabular}

Todos os valores desta tabela são medidos em percentual (\%).

Fonte: Elaborado pela autora.

\section{Correlações Geração de Inteligência x Geração de Inteligência - Critério: Existência de um EGP na Organização do Entrevistado}

\begin{tabular}{|c|c|c|c|c|c|c|c|c|c|c|c|c|}
\hline & & & & \multicolumn{9}{|c|}{ Geração de Inteligência } \\
\hline & & & & $\mathbf{V 2 3}$ & V24 & V25 & V26 & V27 & V28 & V29 & V30 & V31 \\
\hline \multirow{32}{*}{ 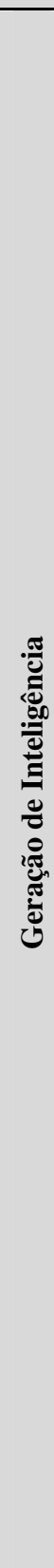 } & \multirow{6}{*}{$\stackrel{\pi}{>}$} & \multirow{2}{*}{$\begin{array}{c}\text { Todos os } \\
\text { Casos } \\
(\mathrm{N}=21)\end{array}$} & $\rho$ & 1,000 & ,418 & ,209 &, 314 &, 002 &, 200 &, 227 &,- 060 &,- 025 \\
\hline & & & Sign. & & ,059 &, 363 &, 165 & ,992 & ,384 &, 322 & ,795 & ,915 \\
\hline & & \multirow{2}{*}{$\begin{array}{c}\text { Com EGP } \\
(\mathrm{N}=12)\end{array}$} & $\rho$ & 1,000 & ,639* & 0,439 & 0,427 & 0,064 & 0,201 & 0,247 & 0,107 & 0,267 \\
\hline & & & Sign. & & 0,025 & 0,154 & 0,167 & 0,844 & 0,531 & 0,44 & 0,74 & 0,402 \\
\hline & & \multirow{2}{*}{$\begin{array}{c}\text { Sem EGP } \\
(\mathrm{N}=9)\end{array}$} & $\rho$ & 1,000 &, 059 &,- 208 &, 077 &,- 099 & ,328 &,- 040 &,- 313 &,- 592 \\
\hline & & & Sign. & & ,881 & ,591 & ,843 &, 800 & ,388 & ,919 & 412 & ,093 \\
\hline & \multirow{6}{*}{$\underset{>}{\mathbb{Z}}$} & \multirow{2}{*}{$\begin{array}{c}\text { Todos os } \\
\text { Casos } \\
(\mathrm{N}=21)\end{array}$} & $\rho$ &, 418 & 1,000 & ,025 &, 113 &, 173 &, $527^{*}$ & ,076 & ,386 &,- 120 \\
\hline & & & Sign. &, 059 & . & ,913 & ,625 & ,452 & ,014 & ,745 & ,084 & ,606 \\
\hline & & \multirow{2}{*}{$\begin{array}{c}\text { Com EGP } \\
(\mathrm{N}=12)\end{array}$} & $\rho$ &, $639 *$ & 1,000 & 0,056 & 0,077 & $-0,186$ & 0,355 & $-0,073$ & 0,066 & $-0,084$ \\
\hline & & & $\begin{array}{l}\text { Sign. } \\
\text {. }\end{array}$ & 0,025 & & 0,864 & 0,811 & 0,564 & 0,258 & 0,821 & 0,838 & 0,796 \\
\hline & & \multirow{2}{*}{$\begin{array}{c}\text { Sem EGP } \\
(\mathrm{N}=9)\end{array}$} & $\rho$ & ,059 & 1,000 & ,098 &, 050 &, 512 &, $890^{* * *}$ &, 070 &, $761^{*}$ &,- 235 \\
\hline & & & Sign. &, 881 & &, 802 & ,898 &, 159 &, 001 &, 858 &, 017 &, 543 \\
\hline & \multirow{6}{*}{$\stackrel{n}{>}$} & \multirow{2}{*}{$\begin{array}{c}\text { Todos os } \\
\text { Casos } \\
(\mathrm{N}=21) \\
\end{array}$} & $\rho$ & ,209 &, 025 & 1,000 &, $636^{* * *}$ & ,349 & ,385 &, 235 &, 400 &, $606^{* * *}$ \\
\hline & & & Sign. & ,363 & ,913 & & ,002 &, 121 & 085 & ,305 & ,072 & ,004 \\
\hline & & \multirow{2}{*}{$\begin{array}{c}\text { Com EGP } \\
(\mathrm{N}=12)\end{array}$} & $\rho$ & 0,439 & 0,056 & 1,000 &, $664 *$ & 0,285 & 0,479 & 0,214 & 0,543 &, $721 * *$ \\
\hline & & & $\begin{array}{l}\text { Sign. } \\
\end{array}$ & 0,154 & 0,864 & & 0,019 & 0,368 & 0,115 & 0,504 & 0,068 & 0,008 \\
\hline & & \multirow{2}{*}{$\begin{array}{c}\text { Sem EGP } \\
(\mathrm{N}=9)\end{array}$} & $\rho$ &,- 208 &, 098 & 1,000 &, 465 & ,397 & ,205 &, 188 & ,293 &, 459 \\
\hline & & & Sign. & ,591 &, 802 & & ,207 & ,291 &, 596 & ,627 &, 444 &, 214 \\
\hline & \multirow{6}{*}{$\stackrel{\text { ஸे }}{>}$} & \multirow{2}{*}{$\begin{array}{c}\text { Todos os } \\
\text { Casos } \\
(\mathrm{N}=21)\end{array}$} & $\rho$ &, 314 &, 113 &, $636^{* *}$ & 1,000 &, $433^{*}$ &, 345 & ,382 &, 190 &, 290 \\
\hline & & & Sign. & , 165 & ,625 & ,002 & & ,050 & ,125 & ,088 & ,408 & ,203 \\
\hline & & \multirow{2}{*}{$\begin{array}{c}\text { Com EGP } \\
(\mathrm{N}=12)\end{array}$} & $\rho$ & 0,427 & 0,077 &, $664 *$ & 1,000 & 0,04 & 0,378 & 0,166 & 0,466 & ,722*** \\
\hline & & & Sign. & 0,167 & 0,811 & 0,019 & & 0,902 & 0,226 & 0,606 & 0,127 & 0,008 \\
\hline & & \multirow{2}{*}{$\begin{array}{c}\text { Sem EGP } \\
(N=9)\end{array}$} & $\rho$ &, 077 &, 050 &, 465 & 1,000 &, $\mathbf{8 0 2} 2^{* *}$ &, 238 &, 549 &,- 118 &,- 218 \\
\hline & & & Sign. & ,843 & ,898 & ,207 & & ,009 & ,537 & , 126 & ,762 & ,573 \\
\hline & \multirow{6}{*}{$\stackrel{N}{>}$} & \multirow{2}{*}{$\begin{array}{c}\text { Todos os } \\
\text { Casos } \\
(\mathrm{N}=21) \\
\end{array}$} & $\rho$ & ,002 &, 173 & ,349 &, $433^{*}$ & 1,000 & ,205 &, $600^{* *}$ & ,297 &, 045 \\
\hline & & & Sign. & ,992 &, 452 &, 121 & 050 & & ,374 & ,004 & ,191 & ,846 \\
\hline & & \multirow{2}{*}{$\begin{array}{c}\text { Com EGP } \\
(\mathrm{N}=12)\end{array}$} & $\rho$ & 0,064 & $-0,186$ & 0,285 & 0,04 & 1,000 & $-0,076$ &, $708 * *$ & 0,233 & 0,305 \\
\hline & & & Sign. & 0,844 & 0,564 & 0,368 & 0,902 & & 0,815 & 0,01 & 0,466 & 0,336 \\
\hline & & \multirow{2}{*}{$\begin{array}{c}\text { Sem EGP } \\
(\mathrm{N}=9)\end{array}$} & $\rho$ &,- 099 &, 512 & ,397 &, $\mathbf{8 0 2} 2^{* * *}$ & 1,000 & ,605 & ,608 &, 344 &,- 277 \\
\hline & & & Sign. &, 800 &, 159 & ,291 &, 009 & &, 084 &, 082 & ,364 & ,471 \\
\hline & \multirow{2}{*}{ 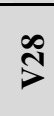 } & \multirow{2}{*}{$\begin{array}{c}\text { Todos os } \\
\text { Casos } \\
(\mathrm{N}=21)\end{array}$} & $\rho$ & ,200 &, $527^{*}$ &, 385 &, 345 & ,205 & 1,000 &, 027 & ,470* &, 139 \\
\hline & & & Sign. & ,384 &, 014 & ,085 &, 125 & ,374 & & ,907 & ,031 &, 547 \\
\hline
\end{tabular}




\begin{tabular}{|c|c|c|c|c|c|c|c|c|c|c|c|}
\hline & \multirow{2}{*}{$\begin{array}{c}\text { Com EGP } \\
(\mathrm{N}=12)\end{array}$} & $\rho$ & 0,201 & 0,355 & 0,479 & 0,378 & $-0,076$ & 1,000 & $-0,076$ & 0,461 & 0,432 \\
\hline & & Sign. & 0,531 & 0,258 & 0,115 & 0,226 & 0,815 & & 0,814 & 0,132 & 0,16 \\
\hline & \multirow{2}{*}{$\begin{array}{c}\text { Sem EGP } \\
\quad(\mathrm{N}=9)\end{array}$} & $\rho$ & ,328 &, $890^{* * *}$ & ,205 & ,238 & ,605 & 1,000 & ,259 &, 520 &,- 412 \\
\hline & & Sign. & ,388 & ,001 & ,596 & ,537 & ,084 & &, 502 &, 151 &, 270 \\
\hline \multirow{6}{*}{$\stackrel{\text { \े }}{>}$} & \multirow{2}{*}{$\begin{array}{c}\text { Todos os } \\
\text { Casos } \\
(\mathrm{N}=21)\end{array}$} & $\rho$ & 227 & 076 & ,235 & ,382 &, $600^{* * *}$ &, 027 & 1,000 &, 275 &, 176 \\
\hline & & Sign. & ,322 & ,745 & ,305 & ,088 & ,004 & ,907 & & ,227 & ,445 \\
\hline & \multirow{2}{*}{$\begin{array}{c}\text { Com EGP } \\
(\mathrm{N}=12)\end{array}$} & $\rho$ & 0,247 & $-0,073$ & 0,214 & 0,166 & ,708*** & $-0,076$ & 1,000 & 0,399 & 0,216 \\
\hline & & Sign. & 0,44 & 0,821 & 0,504 & 0,606 & 0,01 & 0,814 & & 0,199 & 0,5 \\
\hline & \multirow{2}{*}{$\begin{array}{c}\text { Sem EGP } \\
\quad(N=9)\end{array}$} & $\rho$ &,- 040 & ,070 & ,188 &, 549 & ,608 & ,259 & 1,000 &, 116 &,- 029 \\
\hline & & $\begin{array}{l}\text { Sign. } \\
\end{array}$ & ,919 & ,858 & ,627 &, 126 &, 082 & 502 & & ,766 & ,941 \\
\hline \multirow{6}{*}{$\stackrel{p}{>}$} & \multirow{2}{*}{$\begin{array}{c}\text { Todos os } \\
\text { Casos } \\
(\mathrm{N}=21) \\
\end{array}$} & $\rho$ &,- 060 & ,386 & ,400 &, 190 & ,297 & ,470* & ,275 & 1,000 &, 361 \\
\hline & & Sign. & ,795 & ,084 & ,072 & ,408 & ,191 & ,031 & ,227 & & ,108 \\
\hline & \multirow{2}{*}{$\begin{array}{c}\text { Com EGP } \\
(\mathrm{N}=12)\end{array}$} & $\rho$ & 0,107 & 0,066 & 0,543 & 0,466 & 0,233 & 0,461 & 0,399 & 1,000 & 0,405 \\
\hline & & Sign. & 0,74 & 0,838 & 0,068 & 0,127 & 0,466 & 0,132 & 0,199 & & 0,192 \\
\hline & \multirow{2}{*}{$\begin{array}{c}\text { Sem EGP } \\
(\mathrm{N}=9)\end{array}$} & $\rho$ &,- 313 &, $761^{*}$ & ,293 &,- 118 & ,344 &, 520 &, 116 & 1,000 &, 345 \\
\hline & & Sign. &, 412 &, 017 &, 444 &, 762 & ,364 & ,151 & ,766 & & ,363 \\
\hline \multirow{6}{*}{$\bar{m}$} & \multirow{2}{*}{$\begin{array}{c}\text { Todos os } \\
\text { Casos } \\
(\mathrm{N}=21)\end{array}$} & $\rho$ &,- 025 &,- 120 &, $606^{* * *}$ & ,290 &, 045 & ,139 & ,176 & ,361 & 1,000 \\
\hline & & Sign. & ,915 & ,606 & ,004 & 203 & ,846 & ,547 & ,445 & ,108 & \\
\hline & \multirow{2}{*}{$\begin{array}{c}\text { Com EGP } \\
(\mathrm{N}=12)\end{array}$} & $\rho$ & 0,267 & $-0,084$ &, $721 * *$ &, $722 * *$ & 0,305 & 0,432 & 0,216 & 0,405 & 1,000 \\
\hline & & Sign. & 0,402 & 0,796 & 0,008 & 0,008 & 0,336 & 0,16 & 0,5 & 0,192 & \\
\hline & \multirow{2}{*}{$\begin{array}{c}\text { Sem EGP } \\
\quad(N=9)\end{array}$} & $\rho$ &,- 592 &,- 235 &, 459 &,- 218 &,- 277 &,- 412 &,- 029 & ,345 & 1,000 \\
\hline & & Sign. & ,093 &, 543 & ,214 &, 573 & ,471 & ,270 & ,941 & ,363 & \\
\hline
\end{tabular}

Fonte: Elaborada pela autora.

* Nível de significância $\leq 0,05$.

* Nível de significância $\leq 0,01$.

\section{Correlações Geração de Inteligência x Disseminação de Inteligência - Critério: Existência de um EGP na Organização do Entrevistado}

\begin{tabular}{|c|c|c|c|c|c|c|c|c|c|c|c|c|}
\hline & & & & & & & Geração & la Intel & ência & & & \\
\hline & & & & V23 & V24 & V25 & V26 & V27 & V28 & V29 & V30 & V31 \\
\hline \multirow{14}{*}{ 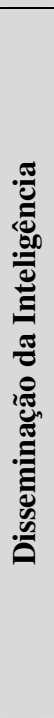 } & \multirow{6}{*}{ 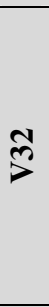 } & \multirow{2}{*}{$\begin{array}{c}\text { Todos os } \\
\text { Casos } \\
(\mathrm{N}=21) \\
\end{array}$} & $\rho$ &, 182 &, $461^{*}$ &, $468^{*}$ &, 267 &, 317 &, $453^{*}$ & ,233 &, $743^{* *}$ &, 327 \\
\hline & & & Sign. & ,431 & ,035 & ,032 & ,242 & ,161 & ,039 & ,309 & ,000 & , 148 \\
\hline & & \multirow{2}{*}{$\begin{array}{c}\text { Com EGP } \\
(\mathrm{N}=12)\end{array}$} & $\rho$ & 0,356 & 0,189 & ,618* &, $672 *$ & 0,31 & 0,292 & 0,442 & ,709** & ,738** \\
\hline & & & Sign. & 0,256 & 0,556 & 0,032 & 0,017 & 0,327 & 0,357 & 0,15 & 0,01 & 0,006 \\
\hline & & \multirow{2}{*}{$\begin{array}{l}\text { Sem EGP } \\
\quad(N=9)\end{array}$} & $\rho$ &, 057 & ,794* & ,344 &,- 071 & ,318 &, $706^{*}$ & ,077 &, $776^{*}$ &,- 047 \\
\hline & & & Sign. & ,883 & ,011 & ,365 & ,856 & ,404 &, 034 & ,843 &, 014 & ,905 \\
\hline & \multirow{6}{*}{$\stackrel{m}{\Rightarrow}$} & \multirow{2}{*}{$\begin{array}{c}\text { Todos os } \\
\text { Casos } \\
(\mathrm{N}=21)\end{array}$} & $\rho$ & ,086 & ,197 &,- 074 &,- 177 & ,089 &, 035 &, 134 &, 034 &, 061 \\
\hline & & & Sign. & ,712 & ,392 & ,749 & ,444 & ,700 & ,881 & ,561 & ,882 & ,794 \\
\hline & & \multirow{2}{*}{$\begin{array}{c}\text { Com EGP } \\
(\mathrm{N}=12)\end{array}$} & $\rho$ & 0,314 & 0,458 & 0,266 & $-0,016$ & 0,428 & 0,145 & 0,161 & $-0,079$ & 0,081 \\
\hline & & & Sign. & 0,32 & 0,134 & 0,403 & 0,961 & 0,165 & 0,652 & 0,617 & 0,806 & 0,802 \\
\hline & & \multirow{2}{*}{$\begin{array}{l}\text { Sem EGP } \\
\quad(N=9)\end{array}$} & $\rho$ & ,000 & ,045 &,- 335 &,- 164 &,- 200 &,- 094 & ,350 & , 135 & ,117 \\
\hline & & & Sign. & 1,000 & ,909 & ,379 & ,672 & ,606 & ,810 & ,355 & ,730 & ,764 \\
\hline & \multirow{2}{*}{$\stackrel{m}{\supset}$} & \multirow{2}{*}{$\begin{array}{c}\text { Todos os } \\
\text { Casos } \\
(\mathrm{N}=21)\end{array}$} & $\rho$ & ,082 & ,238 &, 170 & ,094 &, $482^{*}$ & ,154 & ,421 & , 108 & ,027 \\
\hline & & & Sign. & ,724 & ,300 & ,460 & 687 & ,027 & ,506 & ,058 & ,642 & ,908 \\
\hline
\end{tabular}




\begin{tabular}{|c|c|c|c|c|c|c|c|c|c|c|c|}
\hline & \multirow{2}{*}{$\begin{array}{c}\text { Com EGP } \\
(\mathrm{N}=12)\end{array}$} & $\rho$ & $-0,087$ & $-0,221$ & $-0,065$ & $-0,175$ & 0,411 & $-0,327$ & 0,305 & $-0,528$ & 0,135 \\
\hline & & Sign. & 0,788 & 0,49 & 0,841 & 0,586 & 0,185 & 0,299 & 0,335 & 0,077 & 0,675 \\
\hline & \multirow{2}{*}{$\begin{array}{c}\text { Sem EGP } \\
(\mathrm{N}=9)\end{array}$} & $\rho$ & ,239 & ,710* & ,369 & ,255 & ,550 & ,794* & ,564 & ,654 &,- 093 \\
\hline & & Sign. & ,536 & ,032 & ,329 & ,508 & , 125 & ,011 & ,114 & ,056 & 812 \\
\hline \multirow{6}{*}{$\stackrel{m}{>}$} & \multirow{2}{*}{$\begin{array}{c}\text { Todos os } \\
\text { Casos } \\
(\mathrm{N}=21) \\
\end{array}$} & $\rho$ & ,073 & ,275 & , 092 & , 124 & ,116 &,- 062 & ,422 & ,243 & ,362 \\
\hline & & Sign. & ,753 & ,227 & 690 & ,592 & ,616 & ,791 & ,057 & ,288 & ,107 \\
\hline & \multirow{2}{*}{$\begin{array}{c}\text { Com EGP } \\
(\mathrm{N}=12)\end{array}$} & $\rho$ & 0,048 & $-0,085$ & 0,063 & 0,132 & 0,133 & $-0,318$ & 0,239 & $-0,088$ & 0,395 \\
\hline & & Sign. & 0,883 & 0,793 & 0,845 & 0,683 & 0,68 & 0,313 & 0,455 & 0,785 & 0,204 \\
\hline & \multirow{2}{*}{$\begin{array}{c}\text { Sem EGP } \\
(\mathrm{N}=9)\end{array}$} & $\rho$ &,- 387 & ,500 & ,000 &,- 045 & ,230 & ,286 & ,415 & ,682 & 4,427 \\
\hline & & Sign. & ,303 & , 171 & 1,000 & ,908 & ,551 & ,456 & ,267 & ,043 & 2,252 \\
\hline \multirow{6}{*}{$\stackrel{2}{>}$} & \multirow{2}{*}{$\begin{array}{c}\text { Todos os } \\
\text { Casos } \\
(\mathrm{N}=21)\end{array}$} & $\rho$ & , 120 & ,086 & $\mathbf{5 5 3}^{* * *}$ &, 322 & ,007 &, 243 & ,408 &, $\mathbf{5 0 2}^{*}$ & $\mathrm{,793}^{* *}$ \\
\hline & & Sign. & 603 & ,712 & ,009 & ,154 & ,974 & ,289 & ,066 &, 020 &, 000 \\
\hline & \multirow{2}{*}{$\begin{array}{c}\text { Com EGP } \\
(\mathrm{N}=12)\end{array}$} & $\rho$ & 0,318 & 0,182 &, $813 * *$ & ,787** & 0,258 & 0,557 & 0,211 & ,691* &, $831 * *$ \\
\hline & & Sign. & 0,314 & 0,572 & 0,001 & 0,002 & 0,418 & 0,06 & 0,51 & \begin{tabular}{|l|}
0,013 \\
\end{tabular} & 0,001 \\
\hline & \multirow{2}{*}{$\begin{array}{c}\text { Sem EGP } \\
(N=9)\end{array}$} & $\rho$ &,- 354 &,- 221 & ,295 &,- 247 &,- 280 &,- 290 & ,336 & ,304 &, $\mathrm{837}^{* *}$ \\
\hline & & Sign. & 351 & ,567 & ,442 & ,522 & ,465 & ,449 & ,376 & ,426 & ,005 \\
\hline \multirow{6}{*}{$\stackrel{0}{>}$} & \multirow{2}{*}{$\begin{array}{c}\text { Todos os } \\
\text { Casos } \\
(\mathrm{N}=21)\end{array}$} & $\rho$ &,- 072 & ,261 & ,300 & , 184 & ,227 & ,242 & ,491* & ,548* &, 324 \\
\hline & & Sign. & ,758 & ,253 & , 186 & , 424 & ,323 & ,291 & ,024 &, 010 &, 153 \\
\hline & \multirow{2}{*}{$\begin{array}{c}\text { Com EGP } \\
(\mathrm{N}=12)\end{array}$} & $\rho$ & 0,062 & 0,22 &, $590 *$ & 0,298 & 0,236 & 0,33 & 0,297 & ,682* & 0,402 \\
\hline & & Sign. & 0,848 & 0,491 & 0,043 & 0,346 & 0,461 & 0,295 & 0,348 & 0,014 & 0,196 \\
\hline & \multirow{2}{*}{$\begin{array}{c}\text { Sem EGP } \\
(\mathrm{N}=9)\end{array}$} & $\rho$ &,- 295 & ,263 &,- 049 & ,032 & ,234 & , 145 & ,692* & ,465 & ,226 \\
\hline & & Sign. & ,442 & ,495 & ,900 & ,935 &, 545 & ,710 & ,039 & ,207 & ,559 \\
\hline \multirow{6}{*}{$\stackrel{\infty}{>}$} & \multirow{2}{*}{$\begin{array}{c}\text { Todos os } \\
\text { Casos } \\
(\mathrm{N}=21) \\
\end{array}$} & $\rho$ &,- 001 &,- 033 & , 119 & ,008 &,- 191 & ,304 & , 186 & ,306 & ,254 \\
\hline & & Sign. & ,995 & ,886 & 608 & ,974 & ,408 & , 180 & ,419 & , 177 & ,266 \\
\hline & \multirow{2}{*}{$\begin{array}{c}\text { Com EGP } \\
(\mathrm{N}=12)\end{array}$} & $\rho$ & $-0,251$ & $-0,086$ & 0,246 & 0,277 & $-0,008$ & 0,46 & 0,34 & 0,487 & 0,447 \\
\hline & & Sign. & 0,432 & 0,79 & 0,44 & 0,383 & 0,98 & 0,133 & 0,28 & 0,108 & 0,145 \\
\hline & \multirow{2}{*}{$\begin{array}{c}\text { Sem EGP } \\
(N=9)\end{array}$} & $\rho$ & ,456 & , 070 &,- 089 &,- 300 &,- 382 & ,054 & ,024 & , 121 &,- 010 \\
\hline & & Sign. & ,217 & ,858 & ,819 & ,433 & ,310 & ,891 & ,952 & ,757 & 9,980 \\
\hline
\end{tabular}

Fonte: Elaborada pela autora.

* Nível de significância $\leq 0,05$.

* Nível de significância $\leq 0,01$.

\section{Correlações Geração de Inteligência x Resposta à Inteligência - Critério: Existência de um EGP na Organização do Entrevistado}

\begin{tabular}{|c|c|c|c|c|c|c|c|c|c|c|c|c|}
\hline & & & & & & & Geração & da Int & gência & & & \\
\hline & & & & V23 & V24 & V25 & V26 & V27 & $\mathrm{V} 28$ & V29 & V30 & V31 \\
\hline \multirow{9}{*}{ 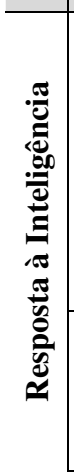 } & \multirow{6}{*}{ ले } & \multirow{2}{*}{$\begin{array}{c}\text { Todos os } \\
\text { Casos } \\
(\mathrm{N}=21) \\
\end{array}$} & $\rho$ & , 170 &, 169 & ,476 & ,198 & ,240 &, 423 & ,269 &, $5^{548}$ &, 256 \\
\hline & & & Sign. & , 462 & ,465 &, 029 & ,390 & ,296 &, 056 & ,238 &, 010 & ,264 \\
\hline & & \multirow{2}{*}{$\begin{array}{c}\text { Com EGP } \\
(\mathrm{N}=12)\end{array}$} & $\rho$ & 0,273 & 0,046 & 0,488 & 0,354 & 0,262 & 0,421 & 0,398 & 0,529 & 0,424 \\
\hline & & & Sign. & 0,391 & 0,887 & 0,108 & 0,259 & 0,41 & 0,173 & 0,199 & 0,077 & 0,17 \\
\hline & & \multirow{2}{*}{$\begin{array}{c}\text { Sem EGP } \\
(N=9)\end{array}$} & $\rho$ &, 159 & ,474 &, 515 &, 018 & ,269 &, 512 &, 226 & ,614 & ,058 \\
\hline & & & Sign. & ,684 & , 197 & , 156 & ,962 & ,484 & , 158 &, 558 & ,079 &, 882 \\
\hline & \multirow{3}{*}{$\stackrel{P}{>}$} & \multirow{2}{*}{$\begin{array}{c}\text { Todos os } \\
\text { Casos } \\
(\mathrm{N}=21) \\
\end{array}$} & $\rho$ & ,094 & , 026 & , 106 & , 180 & ,340 & 311 & ,270 & , 132 &,- 063 \\
\hline & & & Sign. & ,685 & ,911 & ,646 &, 434 & ,132 &, 171 & ,236 &, 568 &, 787 \\
\hline & & Com EGP & $\rho$ & $-0,215$ & $-0,172$ & $-0,169$ & $-0,077$ & 0,29 & 0,062 & $-0,015$ & 0,093 & 0,128 \\
\hline
\end{tabular}




\begin{tabular}{|c|c|c|c|c|c|c|c|c|c|c|c|}
\hline \multirow{3}{*}{\multicolumn{2}{|c|}{\begin{tabular}{|c}
$(\mathrm{N}=12)$ \\
$\begin{array}{c}\text { Sem EGP } \\
(\mathrm{N}=9)\end{array}$
\end{tabular}}} & Sign. & 0,501 & 0,593 & 0,6 & 0,811 & 0,36 & 0,849 & 0,962 & 0,773 & 0,693 \\
\hline & & $\rho$ & , 490 & ,287 & ,408 & ,370 & ,427 &, 593 & ,622 &, 153 &,- 260 \\
\hline & & Sign. &, 181 & ,453 & ,275 & 327 & ,251 & ,092 & ,074 & ,694 & ,499 \\
\hline \multirow{6}{*}{$\overline{7}$} & \multirow{2}{*}{$\begin{array}{c}\text { Todos os } \\
\text { Casos } \\
(\mathrm{N}=21) \\
\end{array}$} & $\rho$ & ,248 &,- 044 & ,372 & ,183 &,- 120 & ,236 &,- 196 & ,177 & ,223 \\
\hline & & Sign. & ,278 & ,848 & ,097 & ,427 & ,605 & ,303 & ,394 & ,444 & ,332 \\
\hline & \multirow{2}{*}{$\begin{array}{c}\text { Com EGP } \\
(\mathrm{N}=12)\end{array}$} & $\rho$ & 0,349 & $-0,042$ & 0,502 & 0,279 & $-0,172$ & 0,339 & $-0,308$ & 0,228 & 0,17 \\
\hline & & Sign. & 0,267 & 0,898 & 0,097 & 0,381 & 0,593 & 0,281 & 0,33 & 0,475 & 0,597 \\
\hline & \multirow{2}{*}{$\begin{array}{c}\text { Sem EGP } \\
(N=9)\end{array}$} & $\rho$ & , 177 & ,152 & ,226 & ,091 &,- 164 & ,058 &,- 075 & ,166 &, 346 \\
\hline & & Sign. & ,649 & ,696 & ,559 & ,815 & ,674 &, 882 & ,848 & ,670 & ,361 \\
\hline \multirow{6}{*}{$\frac{\mathcal{Y}}{7}$} & \multirow{2}{*}{$\begin{array}{c}\text { Todos os } \\
\text { Casos } \\
(\mathrm{N}=21) \\
\end{array}$} & $\rho$ &, 134 &,- 117 &, $560^{* * *}$ & ,269 &,- 194 & 053 & ,137 & ,257 &, $637^{* * *}$ \\
\hline & & Sign. & ,561 & ,615 & ,008 & ,238 & ,400 & ,821 &, 554 & ,261 & ,002 \\
\hline & \multirow{2}{*}{$\begin{array}{c}\text { Com EGP } \\
(\mathrm{N}=12)\end{array}$} & $\rho$ & 0,334 & $-0,076$ &, $\mathbf{8 0 3} * *$ &, $\mathbf{8 0 1} * *$ & 0,045 & 0,214 & 0,181 & 0,496 &, $756 * *$ \\
\hline & & Sign. & 0,289 & 0,815 & 0,002 & 0,002 & 0,889 & 0,504 & 0,574 & 0,101 & 0,004 \\
\hline & \multirow{2}{*}{$\begin{array}{c}\text { Sem EGP } \\
\quad(N=9)\end{array}$} & $\rho$ &,- 387 &,- 273 & ,000 &,- 585 &,- 599 &,- 381 &,- 138 &,- 045 & ,427 \\
\hline & & Sign. & ,303 & ,478 & 1,000 & ,098 &, 088 &, 311 &, 723 & ,908 &, 252 \\
\hline \multirow{6}{*}{$\underset{>}{2}$} & \multirow{2}{*}{$\begin{array}{c}\text { Todos os } \\
\text { Casos } \\
(\mathrm{N}=21) \\
\end{array}$} & $\rho$ & ,222 &,- 042 &, $\mathbf{5 8 2}^{* *}$ & ,355 & ,082 &, $447^{*}$ &, 024 &,- 001 & ,376 \\
\hline & & Sign. & ,333 & ,855 & ,006 &, 114 & ,724 &, 042 & ,919 & 995 & ,093 \\
\hline & \multirow{2}{*}{$\begin{array}{l}\text { Com EGP } \\
(\mathrm{N}=12)\end{array}$} & $\rho$ & 0,218 & 0,05 &, $671 *$ & 0,343 & 0,15 &, $671 *$ & $-0,01$ & 0,269 &, $674 *$ \\
\hline & & Sign. & 0,496 & 0,877 & 0,017 & 0,275 & 0,642 & 0,017 & 0,976 & 0,398 & 0,016 \\
\hline & \multirow{2}{*}{$\begin{array}{c}\text { Sem EGP } \\
\quad(N=9)\end{array}$} & $\rho$ & ,306 &, 000 &, 545 & ,427 & ,077 & ,207 & ,096 &,- 220 &, 075 \\
\hline & & Sign. & ,423 & 1,000 &, 129 & ,252 & ,843 &, 593 & ,807 &, 570 &, 848 \\
\hline \multirow{6}{*}{$\underset{>}{\mathbb{Z}}$} & \multirow{2}{*}{$\begin{array}{c}\text { Todos os } \\
\text { Casos } \\
(\mathrm{N}=21) \\
\end{array}$} & $\rho$ & , 156 &,- 083 &, $587^{* *}$ & ,153 & ,061 & ,211 &,- 079 & ,329 &, $567^{* * *}$ \\
\hline & & Sign. & ,500 & ,722 & ,005 & ,507 & ,791 & ,360 &, 735 &, 146 & ,007 \\
\hline & \multirow{2}{*}{$\begin{array}{c}\text { Com EGP } \\
(\mathrm{N}=12)\end{array}$} & $\rho$ & 0,139 & $-0,213$ & 0,533 & 0,244 & 0,218 & 0,201 & $-0,158$ & 0,179 &, $603 *$ \\
\hline & & Sign. & 0,667 & 0,506 & 0,075 & 0,444 & 0,496 & 0,531 & 0,623 & 0,577 & 0,038 \\
\hline & \multirow{2}{*}{$\begin{array}{c}\text { Sem EGP } \\
\quad(N=9)\end{array}$} & $\rho$ &, 205 &, 217 &, 646 &,- 019 &,- 078 & ,207 &,- 083 &, 477 &, 482 \\
\hline & & Sign. &, 596 &, 576 & ,060 & ,961 &, 842 &, 593 &, 832 & 195 & 188 \\
\hline
\end{tabular}

Fonte: Elaborada pela autora.

* Nível de significância $\leq 0,05$.

* Nível de significância $\leq 0,01$.

\section{Correlações Geração de Inteligência x Confiança - Critério: Existência de um EGP na Organização do Entrevistado}

\begin{tabular}{|c|c|c|c|c|c|c|c|c|c|c|c|c|}
\hline & & & & \multicolumn{9}{|c|}{ Geração da Inteligência } \\
\hline & & & & $\mathbf{V} 23$ & $\mathbf{V} 23$ & $\mathbf{V} 23$ & $\mathbf{V} 23$ & V23 & $\mathbf{V} 23$ & $\mathbf{V} 23$ & $\mathbf{V 2 3}$ & $\mathbf{V} 23$ \\
\hline \multirow{7}{*}{ نू. } & \multirow{6}{*}{$\stackrel{10}{7}$} & \multirow{2}{*}{$\begin{array}{c}\text { Todos } \\
\text { os Casos } \\
(\mathrm{N}=21)\end{array}$} & $\rho$ & ,381 &, 026 & ,091 &, 154 &,- 146 &, 347 &, 041 &,- 011 & ,087 \\
\hline & & & Sign. & ,088 & ,912 & ,694 &, 506 &, 529 & ,123 & ,861 & ,962 & ,708 \\
\hline & & \multirow{2}{*}{$\begin{array}{c}\text { Com } \\
\text { EGP } \\
(\mathrm{N}=12)\end{array}$} & $\rho$ & 0,258 & 0,189 & 0,514 & 0,488 & 0,158 & ,638* & 0,169 & 0,409 & 0,481 \\
\hline & & & Sign. & 0,419 & 0,556 & 0,087 & 0,107 & 0,624 & 0,026 & 0,6 & 0,187 & 0,114 \\
\hline & & \multirow{2}{*}{$\begin{array}{c}\text { Sem } \\
\text { EGP } \\
(\mathrm{N}=9)\end{array}$} & $\rho$ &, $694^{*}$ &,- 326 &,$- 694^{*}$ &,- 323 &,- 551 &,- 228 &,- 275 &,- 597 &,- 567 \\
\hline & & & Sign. & 038 & ,392 & 038 & ,397 &, 124 &, 555 & ,473 & ,089 & ,111 \\
\hline & $\nabla$ & Todos & $\rho$ & ,268 & , 130 & ,022 & ,056 &,- 133 & ,232 &,- 180 &,- 053 &,- 041 \\
\hline
\end{tabular}




\begin{tabular}{|c|c|c|c|c|c|c|c|c|c|c|c|}
\hline & $\begin{array}{c}\text { os Casos } \\
(\mathrm{N}=21)\end{array}$ & Sign. & 241 & ,575 & ,924 & 811 & 567 & 311 & ,435 & 820 & 858 \\
\hline & \multirow{2}{*}{$\begin{array}{c}\text { Com } \\
\text { EGP } \\
(\mathrm{N}=12)\end{array}$} & $\rho$ & 0,183 & 0,331 & 0,464 &, $597^{*}$ & 0,131 & 0,385 & 0,214 &, $579 *$ &, $615^{*}$ \\
\hline & & Sign. & 0,57 & 0,294 & 0,129 & 0,041 & 0,686 & 0,217 & 0,504 & 0,048 & 0,033 \\
\hline & \multirow{2}{*}{$\begin{array}{c}\text { Sem } \\
\text { EGP } \\
(\mathrm{N}=9)\end{array}$} & $\rho$ & ,511 &,- 069 &,- 521 &,- 329 &,- 379 & ,058 &,- 542 &,- 562 &,$- 698^{*}$ \\
\hline & & Sign. & ,160 & ,860 & ,151 & ,388 & ,315 & ,882 & ,132 & ,115 & ,037 \\
\hline \multirow{6}{*}{$\stackrel{7}{7}$} & \multirow{2}{*}{$\begin{array}{c}\text { Todos } \\
\text { os Casos } \\
(\mathrm{N}=21)\end{array}$} & $\rho$ &, $\mathbf{5 5 2}^{* * *}$ & ,102 & 086, & 247 &,- 046 & 287, & ,002 &,- 152 & ,016 \\
\hline & & Sign. & ,010 & 659, & ,712 & ,280 & 844 & ,207 & ,992 & ,511 & ,944 \\
\hline & \multirow{2}{*}{$\begin{array}{c}\text { Com } \\
\text { EGP } \\
(\mathrm{N}=12)\end{array}$} & $\rho$ & 0,311 & 0,215 & 0,384 & 0,473 & 0,193 & 0,465 & 0,039 & 0,177 &, $707 *$ \\
\hline & & Sign. & 0,326 & 0,501 & 0,218 & 0,121 & 0,549 & 0,128 & 0,903 & 0,582 & 0,01 \\
\hline & \multirow{2}{*}{$\begin{array}{l}\text { Sem } \\
\text { EGP } \\
(\mathrm{N}=9)\end{array}$} & $\rho$ &, $824^{* * *}$ &,- 094 &,- 356 &,- 021 &,- 233 & ,088 &,- 228 &,- 502 &,$- 736^{*}$ \\
\hline & & Sign. & ,006 & 810 & ,347 & ,958 & ,546 & 822 & ,555 & ,169 & ,024 \\
\hline \multirow{6}{*}{$\stackrel{\infty}{>}$} & \multirow{2}{*}{$\begin{array}{c}\text { Todos } \\
\text { os Casos } \\
(\mathrm{N}=21)\end{array}$} & $\rho$ & 200 & 077, & ,131 & ,291 & ,117 & ,320 & ,161 & ,132 & ,265 \\
\hline & & Sign. & ,385 & ,740 & ,572 & 201 & 613 & 157, & ,486 & ,567 & ,245 \\
\hline & \multirow{2}{*}{$\begin{array}{c}\text { Com } \\
\text { EGP } \\
(\mathrm{N}=12) \\
\end{array}$} & $\rho$ & 0,062 & $-0,175$ & 0,524 & 0,543 & 0,213 & 0,43 & 0,364 & 0,365 &, $782 * *$ \\
\hline & & Sign. & 0,848 & 0,587 & 0,08 & 0,068 & 0,506 & 0,163 & 0,245 & 0,243 & 0,003 \\
\hline & \multirow{2}{*}{$\begin{array}{c}\text { Sem } \\
\text { EGP } \\
(\mathrm{N}=9)\end{array}$} & $\rho$ & ,306 & ,204 &,$- 689^{*}$ & ,000 &,- 012 & , 126 &,- 316 &,- 239 &,- 563 \\
\hline & & Sign. & ,423 & 599, & ,040 & 1,000 & ,975 & 747 & ,408 & ,535 & , 115 \\
\hline
\end{tabular}

Fonte: Elaborada pela autora.

* Nível de significância $\leq 0,05$.

* Nível de significância $\leq 0,01$.

\section{Correlações Geração de Inteligência x Integração - Critério: Existência de um EGP na Organização do Entrevistado}

\begin{tabular}{|c|c|c|c|c|c|c|c|c|c|c|c|c|}
\hline & & & & \multicolumn{9}{|c|}{ Geração de Inteligência } \\
\hline & & & & V23 & V24 & V25 & V26 & V27 & V28 & V29 & V30 & V31 \\
\hline \multirow{11}{*}{ 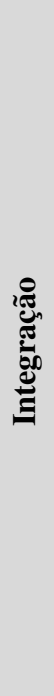 } & \multirow{6}{*}{$\stackrel{g}{>}$} & \multirow{2}{*}{$\begin{array}{c}\text { Todos os } \\
\text { Casos } \\
(\mathrm{N}=21)\end{array}$} & $\rho$ & ,002 &,- 014 & ,496* &, $537^{*}$ & ,343 & ,337 & ,414 & ,429 &, $661^{* *}$ \\
\hline & & & Sign. & ,995 & ,951 & ,022 & ,012 & ,128 & ,135 & ,062 &, 052 & ,001 \\
\hline & & \multirow{2}{*}{$\begin{array}{l}\text { Com EGP } \\
(\mathrm{N}=12)\end{array}$} & $\rho$ & 0,102 & $-0,179$ & ,721** &, $663 *$ & 0,181 & 0,48 & 0,134 & ,619* &, $927 * *$ \\
\hline & & & Sign. & 0,752 & 0,577 & 0,008 & 0,019 & 0,573 & 0,115 & 0,679 & 0,032 & 0 \\
\hline & & \multirow{2}{*}{$\begin{array}{c}\text { Sem EGP } \\
\quad(N=9)\end{array}$} & $\rho$ &,- 387 &, 000 & ,000 &, 450 &, 553 &, 000 &, $737^{*}$ &, 182 & ,190 \\
\hline & & & Sign. &, 303 & 1,000 & 1,000 & ,224 & ,123 & 1,000 & ,023 & ,640 & ,625 \\
\hline & \multirow{5}{*}{$\stackrel{\circ}{>}$} & \multirow{2}{*}{$\begin{array}{c}\text { Todos os } \\
\text { Casos } \\
(\mathrm{N}=21)\end{array}$} & $\rho$ & ,298 &,- 290 &, 373 & ,336 &, 150 &, 140 & ,232 & ,095 & ,451* \\
\hline & & & Sign. & ,189 & ,203 & ,096 & ,137 &, 518 &, 546 &, 311 & ,681 &, 040 \\
\hline & & \multirow{2}{*}{$\begin{array}{l}\text { Com EGP } \\
(\mathrm{N}=12)\end{array}$} & $\rho$ & 0,095 & $-0,448$ &, $646 *$ & 0,491 & 0,408 & 0,267 & 0,39 & 0,41 & ,831** \\
\hline & & & Sign. & 0,768 & 0,144 & 0,023 & 0,105 & 0,188 & 0,402 & 0,21 & 0,186 & 0,001 \\
\hline & & Sem EGP & $\rho$ & ,612 &,- 216 &,- 459 &, 000 &,- 364 &,- 151 &,- 437 &,- 575 &,- 375 \\
\hline
\end{tabular}




\begin{tabular}{|c|c|c|c|c|c|c|c|c|c|c|c|}
\hline & $(\mathrm{N}=9)$ & Sign. & ,080 & ,578 & ,214 & 1,000 & ,335 & 699 & ,239 & , 106 & ,320 \\
\hline \multirow{6}{*}{$\stackrel{\bar{n}}{>}$} & \multirow{2}{*}{$\begin{array}{c}\text { Todos os } \\
\text { Casos } \\
(\mathrm{N}=21) \\
\end{array}$} & $\rho$ & ,019 &,- 044 & ,361 & 208 & ,090 & ,227 & ,456* & ,421 &, $655^{* * *}$ \\
\hline & & Sign. & ,935 & 849 & , 108 & ,367 & 699 & ,323 & ,038 & ,057 &, 001 \\
\hline & \multirow{2}{*}{$\begin{array}{c}\text { Com EGP } \\
(\mathrm{N}=12)\end{array}$} & $\rho$ & $-0,095$ & $-0,399$ & 0,527 & 0,467 & 0,133 & 0,338 & 0,211 & 0,458 &, $\mathbf{8 3 1}$ *** \\
\hline & & Sign. & 0,768 & 0,198 & 0,078 & 0,125 & 0,68 & 0,282 & 0,51 & 0,134 & 0,001 \\
\hline & \multirow{2}{*}{$\begin{array}{l}\text { Sem EGP } \\
(\mathrm{N}=9)\end{array}$} & $\rho$ &,- 379 &,- 016 &,- 011 &,- 331 &,- 053 &,- 071 & ,435 & ,434 &, 551 \\
\hline & & Sign. &, 315 & ,968 & ,977 & ,384 & ,892 & 855 & ,243 & ,244 & ,124 \\
\hline \multirow{6}{*}{$\stackrel{N}{>}$} & \multirow{2}{*}{$\begin{array}{c}\text { Todos os } \\
\text { Casos } \\
(\mathrm{N}=21)\end{array}$} & $\rho$ & ,156 & ,020 &, $527^{*}$ & ,396 &, 015 &, $472^{*}$ &, 107 & ,205 & ,431 \\
\hline & & Sign. & ,499 & ,931 & ,014 & ,076 & ,949 & ,031 & ,644 &, 373 &, 051 \\
\hline & \multirow{2}{*}{$\begin{array}{c}\text { Com EGP } \\
(\mathrm{N}=12)\end{array}$} & $\rho$ & $-0,19$ & $-0,209$ & 0,376 & 0,291 & $-0,179$ & 0,498 & $-0,189$ & 0,245 &, $628 *$ \\
\hline & & Sign. & 0,554 & 0,514 & 0,228 & 0,359 & 0,578 & 0,099 & 0,557 & 0,444 & 0,029 \\
\hline & \multirow{2}{*}{$\begin{array}{l}\text { Sem EGP } \\
(\mathrm{N}=9)\end{array}$} & $\rho$ &, 512 & ,084 & ,679* & ,331 & ,201 & ,378 & ,260 &, 110 & ,104 \\
\hline & & Sign. & , 159 & 831 & ,044 & ,384 & ,603 & ,315 &, 500 & ,779 & ,791 \\
\hline \multirow{6}{*}{$\stackrel{n}{>}$} & \multirow{2}{*}{$\begin{array}{c}\text { Todos os } \\
\text { Casos } \\
(\mathrm{N}=21) \\
\end{array}$} & $\rho$ &, 123 &,- 060 &, $570^{* * *}$ & ,404 & ,137 & ,181 &, $\mathbf{5 4 9}^{*}$ & ,406 &, $561^{* *}$ \\
\hline & & Sign. & ,596 & ,795 & ,007 & ,069 & ,552 & ,432 &, 010 & ,067 & ,008 \\
\hline & \multirow{2}{*}{$\begin{array}{l}\text { Com EGP } \\
(\mathrm{N}=12)\end{array}$} & $\rho$ & 0,11 & $-0,146$ & 0,561 & 0,534 & 0,252 & 0,321 & 0,516 & 0,573 &, $648 *$ \\
\hline & & Sign. & 0,733 & 0,651 & 0,058 & 0,074 & 0,43 & 0,309 & 0,086 & 0,052 & 0,023 \\
\hline & \multirow{2}{*}{$\begin{array}{l}\text { Sem EGP } \\
(\mathrm{N}=9)\end{array}$} & $\rho$ &,- 231 &,- 272 & ,694* & ,000 &,- 055 &,- 171 & ,275 & ,163 & ,567 \\
\hline & & Sign. & ,549 & 480, & ,038 & 1,000 & ,888 & 660 & ,473 & 675, & ,111 \\
\hline
\end{tabular}

Fonte: Elaborada pela autora.

* Nível de significância $\leq 0,05$.

* Nível de significância $\leq 0,01$.

\section{Correlações Disseminação da Inteligência x Disseminação da Inteligência - Critério: Existência de um EGP na Organização do Entrevistado}

\begin{tabular}{|c|c|c|c|c|c|c|c|c|c|c|}
\hline & & & & \multicolumn{7}{|c|}{ Disseminação da Inteligência } \\
\hline & & & & V32 & V33 & V34 & V35 & V36 & V37 & V38 \\
\hline \multirow{6}{*}{ 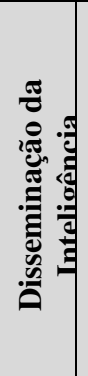 } & \multirow{6}{*}{ กี } & \multirow{2}{*}{$\begin{array}{c}\text { Todos os } \\
\text { Casos } \\
(\mathrm{N}=21)\end{array}$} & $\rho$ & 1,000 & ,216 & ,472* & ,349 & ,398 &, $493^{*}$ &, $454^{*}$ \\
\hline & & & Sign. & . &, 347 & ,031 &, 121 & ,074 &, 023 & ,039 \\
\hline & & \multirow{2}{*}{$\begin{array}{l}\text { Com EGP } \\
(\mathrm{N}=12)\end{array}$} & $\rho$ & 1 & 0,273 & 0 & 0,539 &, $849 * *$ &, $723 * *$ & 0,453 \\
\hline & & & Sign. & & 0,391 & 1 & 0,07 & 0 & 0,008 & 0,139 \\
\hline & & \multirow{2}{*}{$\begin{array}{c}\text { Sem EGP } \\
\quad(N=9)\end{array}$} & $\rho$ & 1,000 &, 154 &, $818^{* *}$ & ,311 &, 054 &, 356 &, 455 \\
\hline & & & Sign. & & 693 & ,007 & ,415 &, 890 & ,347 & ,219 \\
\hline
\end{tabular}




\begin{tabular}{|c|c|c|c|c|c|c|c|c|c|}
\hline \multirow{6}{*}{$\stackrel{m}{>}$} & \multirow{2}{*}{$\begin{array}{c}\text { Todos os } \\
\text { Casos } \\
(\mathrm{N}=21)\end{array}$} & $\rho$ & ,216 & 1,000 & ,345 & ,228 & ,233 &, $567^{* * *}$ & ,243 \\
\hline & & Sign. & ,347 & . & , 125 & ,321 & ,308 & ,007 & ,288 \\
\hline & \multirow{2}{*}{$\begin{array}{l}\text { Com EGP } \\
(\mathrm{N}=12)\end{array}$} & $\rho$ & 0,273 & 1 & 0,496 & 0,329 & 0,206 & 0,426 & $-0,184$ \\
\hline & & Sign. & 0,391 & & 0,101 & 0,296 & 0,521 & 0,168 & 0,568 \\
\hline & \multirow{2}{*}{$\begin{array}{l}\text { Sem EGP } \\
(\mathrm{N}=9)\end{array}$} & $\rho$ & ,154 & 1,000 & ,279 &, 578 & ,487 &, $811^{* * *}$ & ,687 \\
\hline & & Sign. & 693 & & ,468 & ,103 &, 184 & ,008 & ,041 \\
\hline \multirow{6}{*}{ ळ) } & \multirow{2}{*}{$\begin{array}{c}\text { Todos os } \\
\text { Casos } \\
(\mathrm{N}=21)\end{array}$} & $\rho$ & ,472* &, 345 & 1,000 &, $501^{*}$ & ,081 & ,253 & ,221 \\
\hline & & Sign. & ,031 &, 125 & & 021 & ,727 & ,268 &, 336 \\
\hline & \multirow{2}{*}{$\begin{array}{c}\text { Com EGP } \\
(\mathrm{N}=12)\end{array}$} & $\rho$ & 0 & 0,496 & 1 &, $639 *$ & $-0,137$ & $-0,045$ & 0,044 \\
\hline & & Sign. & 1 & 0,101 & . & 0,025 & 0,671 & 0,891 & 0,891 \\
\hline & \multirow{2}{*}{$\begin{array}{l}\text { Sem EGP } \\
(\mathrm{N}=9)\end{array}$} & $\rho$ &, $\mathbf{8 1 8}{ }^{* *}$ & ,279 & 1,000 & ,463 & , 197 & ,559 & ,422 \\
\hline & & Sign. & ,007 & ,468 & & 210 & ,611 &, 118 & ,258 \\
\hline \multirow{6}{*}{$\ddot{2}$} & \multirow{2}{*}{$\begin{array}{c}\text { Todos os } \\
\text { Casos } \\
(\mathrm{N}=21)\end{array}$} & $\rho$ & ,349 & ,228 &, $501^{*}$ & 1,000 & ,434* &, $\mathbf{5 0 5 ^ { * }}$ &, 156 \\
\hline & & Sign. & ,121 &, 321 &, 021 & . & ,049 & ,020 &, 501 \\
\hline & \multirow{2}{*}{$\begin{array}{c}\text { Com EGP } \\
(\mathrm{N}=12)\end{array}$} & $\rho$ & 0,539 & 0,329 &, $639 *$ & 1 & 0,183 & 0,346 & 0,214 \\
\hline & & Sign. & 0,07 & 0,296 & 0,025 & . & 0,568 & 0,271 & 0,504 \\
\hline & \multirow{2}{*}{$\begin{array}{l}\text { Sem EGP } \\
(\mathrm{N}=9)\end{array}$} & $\rho$ &, 311 &, 578 & ,463 & 1,000 & ,548 &, $776^{*}$ & ,092 \\
\hline & & Sign. & ,415 & , 103 & ,210 & . &, 127 & ,014 &, 814 \\
\hline \multirow{6}{*}{ లె } & \multirow{2}{*}{$\begin{array}{c}\text { Todos os } \\
\text { Casos } \\
(\mathrm{N}=21)\end{array}$} & $\rho$ & ,398 & ,233 & 081 & ,434* & 1,000 & ,626 &, 384 \\
\hline & & Sign. & ,074 & ,308 & ,727 & ,049 & . & ,002 & ,085 \\
\hline & \multirow{2}{*}{$\begin{array}{l}\text { Com EGP } \\
(\mathrm{N}=12)\end{array}$} & $\rho$ &, $849 * *$ & 0,206 & $-0,137$ & 0,183 & 1 &, $622 *$ & 0,461 \\
\hline & & Sign. & 0 & 0,521 & 0,671 & 0,568 & & 0,031 & 0,132 \\
\hline & \multirow{2}{*}{$\begin{array}{l}\text { Sem EGP } \\
(\mathrm{N}=9)\end{array}$} & $\rho$ & ,054 &, 487 & , 197 &, 548 & 1,000 &, 583 &, 336 \\
\hline & & Sign. & 890 &, 184 & ,611 & , 127 & & ,099 & ,376 \\
\hline \multirow{6}{*}{$\hat{\infty}$} & \multirow{2}{*}{$\begin{array}{c}\text { Todos os } \\
\text { Casos } \\
(\mathrm{N}=21)\end{array}$} & $\rho$ &, $493^{*}$ &, $567^{* *}$ & ,253 &, $505^{*}$ &, $626^{* *}$ & 1,000 & ,440* \\
\hline & & Sign. & 023 &, 007 & ,268 & ,020 & ,002 & &, 046 \\
\hline & \multirow{2}{*}{$\begin{array}{c}\text { Com EGP } \\
(\mathrm{N}=12)\end{array}$} & $\rho$ &, $723 * *$ & 0,426 & $-0,045$ & 0,346 &, $622 *$ & 1 & 0,507 \\
\hline & & Sign. & 0,008 & 0,168 & 0,891 & 0,271 & 0,031 & & 0,093 \\
\hline & \multirow{2}{*}{$\begin{array}{l}\text { Sem EGP } \\
(\mathrm{N}=9)\end{array}$} & $\rho$ &, 356 &, $811^{* * *}$ &, 559 &, $776^{*}$ &, 583 & 1,000 & ,397 \\
\hline & & Sign. & ,347 & ,008 &, 118 & ,014 & ,099 & . & ,290 \\
\hline \multirow{5}{*}{$\stackrel{\infty}{>}$} & \multirow{2}{*}{$\begin{array}{c}\text { Todos os } \\
\text { Casos } \\
(\mathrm{N}=21)\end{array}$} & $\rho$ & ,454* & ,243 & ,221 & , 156 &, 384 & ,440* & 1,000 \\
\hline & & Sign. & ,039 & ,288 &, 336 &, 501 &, 085 & ,046 & . \\
\hline & \multirow{2}{*}{$\begin{array}{c}\text { Com EGP } \\
(\mathrm{N}=12)\end{array}$} & $\rho$ & 0,453 & $-0,184$ & 0,044 & 0,214 & 0,461 & 0,507 & 1 \\
\hline & & Sign. & 0,139 & 0,568 & 0,891 & 0,504 & 0,132 & 0,093 & \\
\hline & Sem EGP & $\rho$ & ,455 &, $687^{*}$ & ,422 & ,092 &, 336 & ,397 & 1,000 \\
\hline
\end{tabular}




\begin{tabular}{l|l|l|l|l|l|l|l|l|l} 
& $(\mathrm{N}=9)$ & Sign. &, 219 &, 041 &, 258 &, 814 &, 376 &, 290 & $\cdot$ \\
\hline
\end{tabular}

Fonte: Elaborada pela autora.

* Nível de significância $\leq 0,05$.

* Nível de significância $\leq 0,01$.

\section{Correlações Disseminação da Inteligência x Resposta à Inteligência - Critério: Existência de um EGP na Organização do Entrevistado}

\begin{tabular}{|c|c|c|c|c|c|c|c|c|c|c|}
\hline & & & & \multicolumn{7}{|c|}{ Disseminação da Inteligência } \\
\hline & & & & V32 & V33 & V34 & V35 & V36 & V37 & V38 \\
\hline \multirow{25}{*}{ 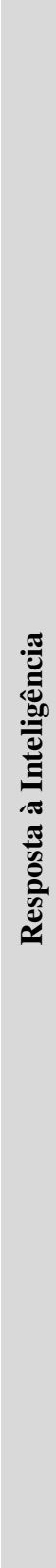 } & \multirow{6}{*}{ ले } & \multirow{2}{*}{$\begin{array}{c}\text { Todos os } \\
\text { Casos } \\
(\mathrm{N}=21)\end{array}$} & $\rho$ &, $760^{* *}$ & ,239 &, $453^{*}$ &, 129 &, 363 &, 320 &, 420 \\
\hline & & & Sign. &, 000 & ,297 & ,039 &, 578 &, 106 &, 158 &, 058 \\
\hline & & \multirow{2}{*}{$\begin{array}{c}\text { Com EGP } \\
(\mathrm{N}=12)\end{array}$} & $\rho$ &, $656 *$ & 0,353 & 0,131 & 0,31 & 0,572 & 0,407 & 0,312 \\
\hline & & & Sign. & 0,021 & 0,26 & 0,686 & 0,327 & 0,052 & 0,189 & 0,323 \\
\hline & & \multirow{2}{*}{$\begin{array}{l}\text { Sem EGP } \\
\quad(\mathrm{N}=9)\end{array}$} & $\rho$ &, $878^{* * *}$ & ,068 &, $806^{* *}$ & ,092 &, 224 & ,304 &, 524 \\
\hline & & & Sign. &, 002 &, 862 &, 009 &, 814 & ,562 & ,427 & , 148 \\
\hline & \multirow{6}{*}{$\stackrel{?}{>}$} & \multirow{2}{*}{$\begin{array}{c}\text { Todos os } \\
\text { Casos } \\
(\mathrm{N}=21)\end{array}$} & $\rho$ & ,388 &, 188 &, $526^{*}$ &, 125 &, 113 &, 171 & ,134 \\
\hline & & & Sign. & ,082 & ,414 & ,014 & ,589 & ,625 & ,459 & ,561 \\
\hline & & \multirow{2}{*}{$\begin{array}{c}\text { Com EGP } \\
(\mathrm{N}=12)\end{array}$} & $\rho$ & 0,247 & 0,319 & 0,177 & 0,323 & 0,065 & 0,031 & $-0,157$ \\
\hline & & & Sign. & 0,439 & 0,313 & 0,583 & 0,306 & 0,842 & 0,923 & 0,627 \\
\hline & & \multirow{2}{*}{$\begin{array}{c}\text { Sem EGP } \\
\quad(\mathrm{N}=9)\end{array}$} & $\rho$ &, 534 & ,131 &, 820 ** &, 000 &, 115 & ,318 & ,447 \\
\hline & & & Sign. & ,139 & ,737 & ,007 & 1,000 & ,767 & ,405 & ,228 \\
\hline & \multirow{6}{*}{$\underset{7}{7}$} & \multirow{2}{*}{$\begin{array}{c}\text { Todos os } \\
\text { Casos } \\
(\mathrm{N}=21)\end{array}$} & $\rho$ & ,055 &, 156 &,- 166 &,- 195 &, 210 &, 044 &,- 005 \\
\hline & & & Sign. &, 814 &, 500 & ,473 & ,396 &, 362 & ,849 & ,984 \\
\hline & & \multirow{2}{*}{$\begin{array}{c}\text { Com EGP } \\
(\mathrm{N}=12)\end{array}$} & $\rho$ & $-0,077$ & $-0,234$ &,$- 589 *$ & $-0,516$ & 0,172 & $-0,073$ & $-0,334$ \\
\hline & & & Sign. & 0,813 & 0,465 & 0,044 & 0,086 & 0,593 & 0,82 & 0,289 \\
\hline & & \multirow{2}{*}{$\begin{array}{c}\text { Sem EGP } \\
\quad(\mathrm{N}=9)\end{array}$} & $\rho$ &, 171 &, 518 & ,221 & ,411 & ,361 & ,227 & ,514 \\
\hline & & & Sign. & ,660 & ,153 & ,568 & ,272 &, 340 & ,557 & , 157 \\
\hline & \multirow{6}{*}{ 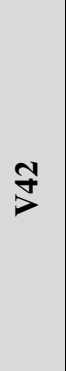 } & \multirow{2}{*}{$\begin{array}{c}\text { Todos os } \\
\text { Casos } \\
(\mathrm{N}=21)\end{array}$} & $\rho$ & ,418 &, 145 &,- 061 & ,280 &, $668^{* *}$ & ,413 & ,363 \\
\hline & & & Sign. & ,060 &, 530 & ,793 & ,218 & ,001 & ,063 & , 106 \\
\hline & & \multirow{2}{*}{$\begin{array}{c}\text { Com EGP } \\
(\mathrm{N}=12)\end{array}$} & $\rho$ & ,761** & 0,02 & 0 & 0,387 &, $823 * *$ & 0,484 & 0,367 \\
\hline & & & Sign. & 0,004 & 0,95 & 1 & 0,214 & 0,001 & 0,111 & 0,24 \\
\hline & & \multirow{2}{*}{$\begin{array}{c}\text { Sem EGP } \\
\quad(\mathrm{N}=9)\end{array}$} & $\rho$ & ,089 & ,444 &,- 139 &, 100 &, 548 &, 320 & ,415 \\
\hline & & & Sign. & ,820 & ,231 & ,722 & ,798 & , 127 & ,402 & ,267 \\
\hline & $\nabla c$ & Todos os & $\rho$ &, 131 & , 130 & , 108 &,- 011 & ,257 & , 157 & ,273 \\
\hline
\end{tabular}




\begin{tabular}{|c|c|c|c|c|c|c|c|c|c|}
\hline & $\begin{array}{c}\text { Casos } \\
(\mathrm{N}=21)\end{array}$ & Sign. &, 571 & ,575 & ,640 & ,962 & ,261 & ,495 & ,230 \\
\hline & \multirow{2}{*}{$\begin{array}{c}\text { Com EGP } \\
(\mathrm{N}=12)\end{array}$} & $\rho$ & 0,333 & 0,226 & 0 & 0,058 & 0,486 & 0,45 & 0,315 \\
\hline & & Sign. & 0,291 & 0,48 & 1 & 0,857 & 0,109 & 0,142 & 0,319 \\
\hline & \multirow{2}{*}{$\begin{array}{c}\text { Sem EGP } \\
\quad(\mathrm{N}=9)\end{array}$} & $\rho$ & 070 & ,092 & ,224 &,- 044 & ,108 &,- 077 & ,255 \\
\hline & & Sign. & ,858 & ,814 & ,562 & ,910 & ,782 & ,845 & ,508 \\
\hline \multirow{6}{*}{$\stackrel{8}{7}$} & \multirow{2}{*}{$\begin{array}{c}\text { Todos os } \\
\text { Casos } \\
(\mathrm{N}=21)\end{array}$} & $\rho$ &, $\mathbf{4 7 8 ^ { * }}$ & ,141 & ,273 & 203 &, $\mathbf{4 7 1}{ }^{*}$ & 093 & ,148 \\
\hline & & Sign. & ,028 & ,543 & ,232 & ,376 & ,031 & 690 & ,523 \\
\hline & \multirow{2}{*}{$\begin{array}{c}\text { Com EGP } \\
(\mathrm{N}=12)\end{array}$} & $\rho$ & 0,410 & 0,200 & 0,111 & 0,287 & 0,501 & 0,14 & $-0,124$ \\
\hline & & Sign. & 0,186 & 0,534 & 0,732 & 0,366 & 0,097 & 0,664 & 0,702 \\
\hline & \multirow{2}{*}{$\begin{array}{c}\text { Sem EGP } \\
\quad(\mathrm{N}=9)\end{array}$} & $\rho$ & ,555 & ,071 & ,500 &, 143 & ,464 & ,058 & ,537 \\
\hline & & Sign. &, 121 &, 857 &, 170 & ,714 & ,208 & ,882 & 136 \\
\hline
\end{tabular}

Fonte: Elaborada pela autora.

* Nível de significância $\leq 0,05$.

* Nível de significância $\leq 0,01$.

Correlações Disseminação da Inteligência x Confiança - Critério: Existência de um EGP na Organização do Entrevistado

\begin{tabular}{|c|c|c|c|c|c|c|c|c|c|c|}
\hline & & & & \multicolumn{7}{|c|}{ Disseminação da Inteligência } \\
\hline & & & & V32 & V33 & V34 & V35 & V36 & V37 & V38 \\
\hline \multirow{16}{*}{ ن⿺辶 } & \multirow{6}{*}{$\stackrel{10}{7}$} & \multirow{2}{*}{$\begin{array}{c}\text { Todos os } \\
\text { Casos } \\
(\mathrm{N}=21)\end{array}$} & $\rho$ & , 161 & ,342 &,- 065 &,- 037 & ,248 & , 107 & ,399 \\
\hline & & & Sign. & , 486 & , 129 & ,780 & ,874 & ,278 & ,645 & ,074 \\
\hline & & \multirow{2}{*}{$\begin{array}{c}\text { Com EGP } \\
(\mathrm{N}=12)\end{array}$} & $\rho$ & 0,57 & 0,431 & 0,114 & 0,154 &, $669 *$ & 0,333 & 0,325 \\
\hline & & & Sign. & 0,053 & 0,162 & 0,725 & 0,633 & 0,017 & 0,291 & 0,303 \\
\hline & & \multirow{2}{*}{$\begin{array}{l}\text { Sem EGP } \\
\quad(N=9)\end{array}$} & $\rho$ &,- 265 & ,265 &,- 277 &,- 478 &,- 327 &,- 218 & ,496 \\
\hline & & & Sign. & , 490 & ,490 & ,471 & , 193 & ,390 &, 573 &, 175 \\
\hline & \multirow{6}{*}{ 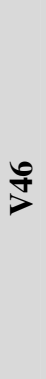 } & \multirow{2}{*}{$\begin{array}{c}\text { Todos os } \\
\text { Casos } \\
(\mathrm{N}=21)\end{array}$} & $\rho$ & ,235 & ,028 &,- 213 &,- 070 &,- 076 &, 022 & ,245 \\
\hline & & & Sign. & ,304 & ,903 &, 355 &, 762 & ,744 & ,925 & ,284 \\
\hline & & \multirow{2}{*}{$\begin{array}{c}\text { Com EGP } \\
(\mathrm{N}=12)\end{array}$} & $\rho$ &, $878 * *$ & 0,387 & 0 & 0,522 &, $749 * *$ &, $807 * *$ & 0,511 \\
\hline & & & Sign. & 0 & 0,214 & 1 & 0,082 & 0,005 & 0,002 & 0,09 \\
\hline & & \multirow{2}{*}{$\begin{array}{l}\text { Sem EGP } \\
\quad(N=9)\end{array}$} & $\rho$ &,- 185 &,- 270 &,- 376 &,- 639 &,$- 694^{*}$ &,- 606 & ,014 \\
\hline & & & Sign. & ,634 & ,482 & ,319 & ,064 & ,038 & ,083 & ,971 \\
\hline & \multirow{4}{*}{ 方 } & \multirow{2}{*}{$\begin{array}{c}\text { Todos os } \\
\text { Casos } \\
(\mathrm{N}=21)\end{array}$} & $\rho$ & ,239 & ,203 &, 074 & ,115 & ,059 &, 054 &, 335 \\
\hline & & & Sign. & ,296 & ,377 &, 750 & ,619 & ,800 & ,818 & ,138 \\
\hline & & \multirow{2}{*}{$\begin{array}{l}\text { Com EGP } \\
(\mathrm{N}=12)\end{array}$} & $\rho$ &, $624 *$ & 0,476 & 0,226 & 0,518 & 0,537 & 0,376 & 0,167 \\
\hline & & & Sign. & 0,03 & 0,118 & 0,48 & 0,084 & 0,072 & 0,228 & 0,604 \\
\hline
\end{tabular}




\begin{tabular}{|c|c|c|c|c|c|c|c|c|c|}
\hline & \multirow{2}{*}{$\begin{array}{c}\text { Sem EGP } \\
(\mathrm{N}=9)\end{array}$} & $\rho$ & ,031 & ,077 &,- 005 &,- 621 &,- 535 &,- 320 & ,514 \\
\hline & & Sign. & ,938 & ,845 & ,989 & ,074 & ,137 & ,401 & 157 \\
\hline \multirow{6}{*}{$\stackrel{\infty}{>}$} & \multirow{2}{*}{$\begin{array}{c}\text { Todos os } \\
\text { Casos } \\
(\mathrm{N}=21)\end{array}$} & $\rho$ &, 183 & ,083 &, 045 & ,379 & ,158 &, 143 &, 320 \\
\hline & & Sign. & ,427 & ,720 & ,847 & ,090 & ,493 & ,537 &, 158 \\
\hline & \multirow{2}{*}{$\begin{array}{c}\text { Com EGP } \\
(\mathrm{N}=12)\end{array}$} & $\rho$ & ,703* & 0,172 & 0,381 & 0,566 &, $666^{*}$ & 0,44 & ,684* \\
\hline & & Sign. & 0,011 & 0,593 & 0,221 & 0,055 & 0,018 & 0,153 & 0,014 \\
\hline & \multirow{2}{*}{$\begin{array}{c}\text { Sem EGP } \\
(\mathrm{N}=9)\end{array}$} & $\rho$ &,- 316 &, 000 &,- 317 & ,000 &,- 650 &,- 277 &,- 231 \\
\hline & & Sign. & ,407 & 1,000 & ,406 & 1,000 & ,058 & ,471 &, 550 \\
\hline
\end{tabular}

Fonte: Elaborada pela autora.

* Nível de significância $\leq 0,05$.

* Nível de significância $\leq 0,01$.

\section{Correlações Disseminação da Inteligência x Integração - Critério: Existência de um EGP na Organização do Entrevistado}

\begin{tabular}{|c|c|c|c|c|c|c|c|c|c|c|}
\hline & & & & \multicolumn{7}{|c|}{ Disseminação da Inteligência } \\
\hline & & & & V32 & V33 & V34 & V35 & V36 & V37 & V38 \\
\hline \multirow{19}{*}{ 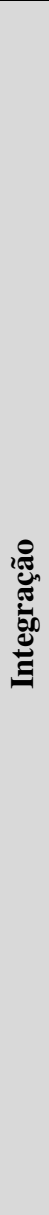 } & \multirow{6}{*}{$\stackrel{g}{\vec{D}}$} & \multirow{2}{*}{$\begin{array}{c}\text { Todos os } \\
\text { Casos } \\
(\mathrm{N}=21)\end{array}$} & $\rho$ & ,246 &,- 031 & ,002 & ,395 &, $620^{* *}$ &, $508^{*}$ & ,134 \\
\hline & & & Sign. & ,282 & ,894 & ,994 & ,076 & ,003 & ,019 &, 564 \\
\hline & & \multirow{2}{*}{$\begin{array}{l}\text { Com EGP } \\
(\mathrm{N}=12)\end{array}$} & $\rho$ & ,738** & $-0,114$ & $-0,135$ & 0,272 & ,831** & 0,51 & 0,531 \\
\hline & & & Sign. & 0,006 & 0,725 & 0,675 & 0,393 & 0,001 & 0,09 & 0,076 \\
\hline & & \multirow{2}{*}{$\begin{array}{l}\text { Sem EGP } \\
\quad(N=9)\end{array}$} & $\rho$ &,- 267 & ,133 & ,139 &, 550 & ,274 &, 502 &,- 461 \\
\hline & & & Sign. & ,488 & ,732 & ,722 & , 125 & ,476 & , 168 & ,212 \\
\hline & \multirow{6}{*}{$\stackrel{8}{>}$} & \multirow{2}{*}{$\begin{array}{c}\text { Todos os } \\
\text { Casos } \\
(\mathrm{N}=21)\end{array}$} & $\rho$ & ,141 &,- 015 &,- 020 & ,256 & ,261 & ,072 & ,256 \\
\hline & & & Sign. &, 542 & ,949 & ,930 & ,263 & ,253 & ,755 & ,262 \\
\hline & & \multirow{2}{*}{$\begin{array}{l}\text { Com EGP } \\
(\mathrm{N}=12)\end{array}$} & $\rho$ & ,603* & 0 & 0,228 & 0,425 & 0,567 & 0,366 & 0,4 \\
\hline & & & Sign. & 0,038 & 1 & 0,476 & 0,168 & 0,055 & 0,242 & 0,197 \\
\hline & & \multirow{2}{*}{$\begin{array}{l}\text { Sem EGP } \\
\quad(N=9)\end{array}$} & $\rho$ &,- 492 & ,000 &,- 439 &,- 316 &,- 433 &,- 505 & ,073 \\
\hline & & & Sign. &, 179 & 1,000 & ,237 & ,407 & ,244 &, 165 &, 852 \\
\hline & \multirow{6}{*}{$\stackrel{n}{i n}$} & \multirow{2}{*}{$\begin{array}{c}\text { Todos os } \\
\text { Casos } \\
(\mathrm{N}=21)\end{array}$} & $\rho$ & ,300 &,- 103 &, 215 &, $631^{* *}$ & $687^{* *}$ &, $457^{*}$ &, 324 \\
\hline & & & Sign. & ,187 & ,658 &, 350 & ,002 & ,001 & ,037 & ,152 \\
\hline & & \multirow{2}{*}{$\begin{array}{c}\text { Com EGP } \\
(\mathrm{N}=12)\end{array}$} & $\rho$ &, $616^{*}$ & $-0,198$ & 0,091 & 0,45 &, $592 *$ & 0,439 &, $655^{*}$ \\
\hline & & & Sign. & 0,033 & 0,538 & 0,778 & 0,142 & 0,043 & 0,153 & 0,021 \\
\hline & & \multirow{2}{*}{$\begin{array}{c}\text { Sem EGP } \\
\quad(N=9)\end{array}$} & $\rho$ & ,031 & ,204 & ,218 &, 569 &, $724^{*}$ & ,530 &,- 048 \\
\hline & & & Sign. & ,938 & ,598 & ,573 &, 110 & ,027 &, 142 & ,903 \\
\hline & in & Todos os & $\rho$ & ,358 &,- 129 & ,334 &, 421 & ,408 & ,261 & ,394 \\
\hline
\end{tabular}




\begin{tabular}{|c|c|c|c|c|c|c|c|c|c|}
\hline & $\begin{array}{c}\text { Casos } \\
(\mathrm{N}=21)\end{array}$ & Sign. &, 111 & ,579 & ,139 & ,057 & ,066 & ,254 & ,077 \\
\hline & \multirow{2}{*}{$\begin{array}{c}\text { Com EGP } \\
(\mathrm{N}=12)\end{array}$} & $\rho$ & 0,409 & $-0,004$ & 0,068 & 0,407 & 0,412 & 0,444 & 0,547 \\
\hline & & Sign. & 0,187 & 0,99 & 0,833 & 0,189 & 0,184 & 0,148 & 0,066 \\
\hline & \multirow{2}{*}{$\begin{array}{c}\text { Sem EGP } \\
\quad(\mathrm{N}=9)\end{array}$} & $\rho$ & ,337 &,- 204 & ,559 &,- 155 & ,220 &,- 110 & ,307 \\
\hline & & Sign. & ,375 & ,598 & ,118 & 690 & ,569 & ,778 & ,421 \\
\hline \multirow{6}{*}{$\stackrel{m}{p}$} & \multirow{2}{*}{$\begin{array}{c}\text { Todos os } \\
\text { Casos } \\
(\mathrm{N}=21)\end{array}$} & $\rho$ &, $\mathbf{4 7 4 ^ { * }}$ &,- 050 & ,224 & ,414 &, $687^{* *}$ & ,396 &, $485^{*}$ \\
\hline & & Sign. &, 030 & 829 & ,329 & ,062 & ,001 & ,076 & ,026 \\
\hline & \multirow{2}{*}{$\begin{array}{c}\text { Com EGP } \\
(\mathrm{N}=12)\end{array}$} & $\rho$ &, $773 * *$ & 0,102 & 0,226 & 0,47 &, $709 * *$ & 0,513 &, $678^{*}$ \\
\hline & & Sign. & 0,003 & 0,753 & 0,48 & 0,123 & 0,01 & 0,088 & 0,015 \\
\hline & \multirow{2}{*}{$\begin{array}{c}\text { Sem EGP } \\
\quad(N=9)\end{array}$} & $\rho$ & ,265 & ,000 &, 277 &,- 060 & ,655 & ,218 &, 275 \\
\hline & & Sign. & ,490 & 1,000 & ,471 & 879 & 056 & ,573 & ,473 \\
\hline
\end{tabular}

Fonte: Elaborada pela autora.

* Nível de significância $\leq 0,05$.

* Nível de significância $\leq 0,01$.

\section{Resposta à Inteligência $x$ Resposta à Inteligência - Critério: Existência de um EGP na Organização do Entrevistado}

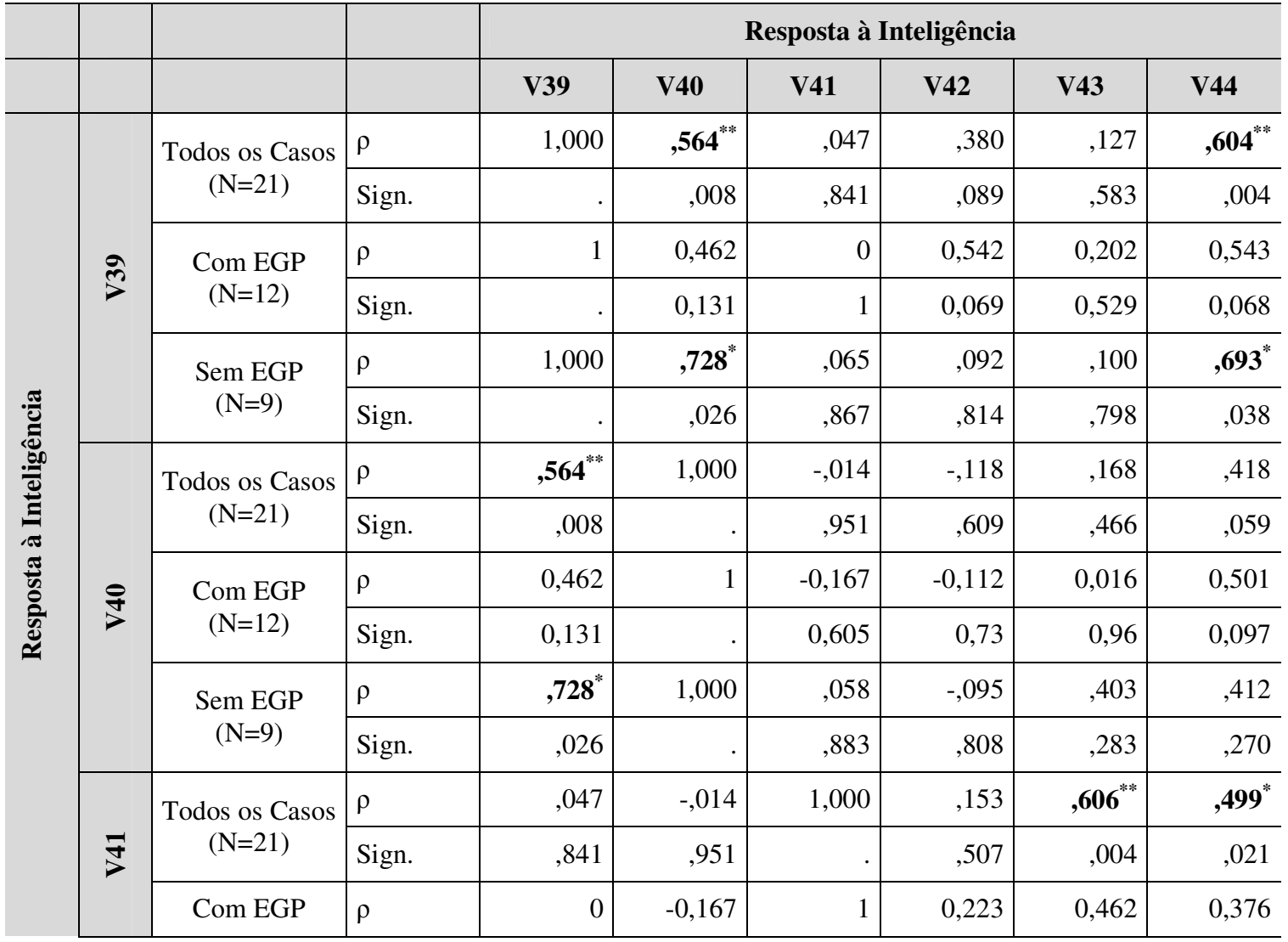




\begin{tabular}{|c|c|c|c|c|c|c|c|c|}
\hline & $(\mathrm{N}=12)$ & Sign. & 1 & 0,605 & & 0,486 & 0,131 & 0,229 \\
\hline & \multirow{2}{*}{$\begin{array}{l}\text { Sem EGP } \\
(\mathrm{N}=9)\end{array}$} & $\rho$ & ,065 &, 058 & 1,000 & ,137 &, $685^{*}$ & ,600 \\
\hline & & Sign. & 867 & ,883 & &, 725 &, 042 & ,088 \\
\hline \multirow{6}{*}{$\frac{1}{7}$} & \multirow{2}{*}{$\begin{array}{l}\text { Todos os Casos } \\
\quad(\mathrm{N}=21)\end{array}$} & $\rho$ & ,380 &,- 118 &, 153 & 1,000 & 211 & ,397 \\
\hline & & Sign. & ,089 & ,609 & ,507 & &, 358 & ,075 \\
\hline & \multirow{2}{*}{$\begin{array}{c}\text { Com EGP } \\
(\mathrm{N}=12)\end{array}$} & $\rho$ & 0,542 & $-0,112$ & 0,223 & 1 & 0,331 & 0,517 \\
\hline & & Sign. & 0,069 & 0,73 & 0,486 & & 0,294 & 0,085 \\
\hline & \multirow{2}{*}{$\begin{array}{l}\text { Sem EGP } \\
(\mathrm{N}=9)\end{array}$} & $\rho$ & ,092 &,- 095 &, 137 & 1,000 & ,089 & ,095 \\
\hline & & Sign. &, 814 & ,808 & ,725 & &, 820 & ,807 \\
\hline \multirow{6}{*}{$\stackrel{m}{7}$} & \multirow{2}{*}{$\begin{array}{c}\text { Todos os Casos } \\
\quad(\mathrm{N}=21)\end{array}$} & $\rho$ & , 127 &, 168 &, $606^{* *}$ & ,211 & 1,000 &, 414 \\
\hline & & Sign. &, 583 & ,466 &, 004 &, 358 & & ,062 \\
\hline & \multirow{2}{*}{$\begin{array}{c}\text { Com EGP } \\
(\mathrm{N}=12)\end{array}$} & $\rho$ & 0,202 & 0,016 & 0,462 & 0,331 & 1 & 0,413 \\
\hline & & Sign. & 0,529 & 0,96 & 0,131 & 0,294 & & 0,182 \\
\hline & \multirow{2}{*}{$\begin{array}{l}\text { Sem EGP } \\
(\mathrm{N}=9)\end{array}$} & $\rho$ &, 100 & ,403 & ,685* &, 089 & 1,000 & ,457 \\
\hline & & Sign. & ,798 & ,283 & ,042 & 820 & & ,217 \\
\hline \multirow{6}{*}{$\stackrel{7}{>}$} & \multirow{2}{*}{$\begin{array}{c}\text { Todos os Casos } \\
(\mathrm{N}=21)\end{array}$} & $\rho$ &, $604^{* *}$ &, 418 & ,499* & ,397 & ,414 & 1,000 \\
\hline & & Sign. &, 004 &, 059 &, 021 &, 075 &, 062 & \\
\hline & \multirow{2}{*}{$\begin{array}{l}\text { Com EGP } \\
(\mathrm{N}=12)\end{array}$} & $\rho$ & 0,543 & 0,501 & 0,376 & 0,517 & 0,413 & 1 \\
\hline & & Sign. & 0,068 & 0,097 & 0,229 & 0,085 & 0,182 & \\
\hline & \multirow{2}{*}{$\begin{array}{l}\text { Sem EGP } \\
(\mathrm{N}=9)\end{array}$} & $\rho$ & ,693* &, 412 & ,600 & ,095 & ,457 & 1,000 \\
\hline & & Sign. & ,038 & ,270 & ,088 & 807 & ,217 & \\
\hline
\end{tabular}

Fonte: Elaborada pela autora.

* Nível de significância $\leq 0,05$.

* Nível de significância $\leq 0,01$.

\section{Correlações Resposta à Inteligência x Confiança - Critério: Existência de um EGP na Organização do Entrevistado}

\begin{tabular}{|c|c|c|c|c|c|c|c|c|c|}
\hline & & & & \multicolumn{6}{|c|}{ Resposta à Inteligência } \\
\hline & & & & V39 & V40 & V41 & V42 & V43 & V44 \\
\hline \multirow{6}{*}{ 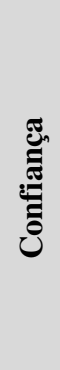 } & \multirow{6}{*}{$\stackrel{10}{7}$} & \multirow{2}{*}{$\begin{array}{l}\text { Todos os Casos } \\
\qquad(\mathrm{N}=21)\end{array}$} & $\rho$ & ,427 & ,206 &,- 042 & ,396 & ,110 & ,199 \\
\hline & & & Sign. & ,053 & ,371 & 857 & ,075 & ,636 & ,387 \\
\hline & & \multirow{2}{*}{$\begin{array}{l}\text { Com EGP } \\
(\mathrm{N}=12)\end{array}$} & $\rho$ &, $\mathbf{8 9 2} * *$ & 0,403 & 0,011 & 0,524 & 0,284 & 0,5 \\
\hline & & & Sign. & 0 & 0,194 & 0,974 & 0,081 & 0,371 & 0,098 \\
\hline & & \multirow{2}{*}{$\begin{array}{l}\text { Sem EGP } \\
(\mathrm{N}=9)\end{array}$} & $\rho$ &,- 220 & ,000 & ,000 & ,060 &,- 053 &,- 228 \\
\hline & & & Sign. &, 569 & 1,000 & 1,000 & ,879 &, 892 &, 555 \\
\hline
\end{tabular}




\begin{tabular}{|c|c|c|c|c|c|c|c|c|}
\hline \multirow{6}{*}{ 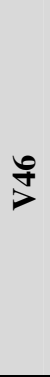 } & \multirow{2}{*}{$\begin{array}{l}\text { Todos os Casos } \\
\qquad(\mathrm{N}=21)\end{array}$} & $\rho$ & ,066 & ,027 &,- 258 & ,301 & , 143 &,- 123 \\
\hline & & Sign. & ,775 & ,909 & ,258 & , 186 &, 535 & ,595 \\
\hline & \multirow{2}{*}{$\begin{array}{l}\text { Com EGP } \\
(\mathrm{N}=12)\end{array}$} & $\rho$ & 0,436 & 0,236 & $-0,213$ & 0,567 & 0,393 & 0,182 \\
\hline & & Sign. & 0,157 & 0,46 & 0,505 & 0,054 & 0,206 & 0,572 \\
\hline & \multirow{2}{*}{$\begin{array}{l}\text { Sem EGP } \\
(\mathrm{N}=9)\end{array}$} & $\rho$ &,- 299 &,- 135 &,- 273 & ,000 &,- 018 &,- 406 \\
\hline & & Sign. & ,434 & ,730 & ,477 & 1,000 & ,963 & ,278 \\
\hline \multirow{6}{*}{$\stackrel{f}{>}$} & \multirow{2}{*}{$\begin{array}{l}\text { Todos os Casos } \\
\qquad(\mathrm{N}=21)\end{array}$} & $\rho$ & , 194 & ,390 & ,016 & ,174 &, 332 & ,210 \\
\hline & & Sign. & ,399 & ,080 & ,944 & ,451 &, 141 & ,361 \\
\hline & \multirow{2}{*}{$\begin{array}{c}\text { Com EGP } \\
(\mathrm{N}=12)\end{array}$} & $\rho$ & 0,446 & 0,551 & 0,024 & 0,356 &, $645^{*}$ & 0,512 \\
\hline & & Sign. & 0,146 & 0,063 & 0,942 & 0,257 & 0,023 & 0,089 \\
\hline & \multirow{2}{*}{$\begin{array}{l}\text { Sem EGP } \\
(\mathrm{N}=9)\end{array}$} & $\rho$ & ,085 & ,306 & ,037 &,- 104 & , 199 &,- 027 \\
\hline & & Sign. & ,828 & ,424 & ,925 & ,791 & 607 & ,944 \\
\hline \multirow{6}{*}{$\stackrel{\infty}{>}$} & \multirow{2}{*}{$\begin{array}{l}\text { Todos os Casos } \\
\qquad(\mathrm{N}=21)\end{array}$} & $\rho$ & , 108 &,- 094 &,- 112 & ,308 & , 192 & ,073 \\
\hline & & Sign. & ,643 & ,685 & ,627 & ,174 & ,404 & ,752 \\
\hline & \multirow{2}{*}{$\begin{array}{l}\text { Com EGP } \\
(\mathrm{N}=12)\end{array}$} & $\rho$ &, $722 * *$ & 0,27 & $-0,18$ & ,681* & 0,476 & 0,458 \\
\hline & & Sign. & 0,008 & 0,397 & 0,576 & 0,015 & 0,118 & 0,134 \\
\hline & \multirow{2}{*}{$\begin{array}{l}\text { Sem EGP } \\
(\mathrm{N}=9)\end{array}$} & $\rho$ &,- 631 &,- 450 & ,060 &,- 474 &,- 140 &,- 528 \\
\hline & & Sign. & ,068 & ,224 & ,878 & , 197 & ,718 & ,144 \\
\hline
\end{tabular}

Fonte: Elaborada pela autora.

* Nível de significância $\leq 0,05$.

* Nível de significância $\leq 0,01$.

\section{Correlações Resposta à Inteligência x Integração - Critério: Existência de um EGP na Organização do Entrevistado}

\begin{tabular}{|c|c|c|c|c|c|c|c|c|c|}
\hline & & & & \multicolumn{6}{|c|}{ Resposta à Inteligência } \\
\hline & & & & V39 & V40 & V41 & V42 & V43 & V44 \\
\hline \multirow{9}{*}{ 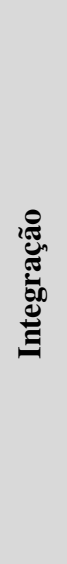 } & \multirow{6}{*}{$\stackrel{g}{>}$} & \multirow{2}{*}{$\begin{array}{c}\text { Todos os } \\
\text { Casos } \\
(\mathrm{N}=21) \\
\end{array}$} & $\rho$ &, 136 & ,078 &, 103 & ,413 &, 219 &, 276 \\
\hline & & & Sign. &, 558 & ,738 & ,656 &, 062 &, 341 & ,226 \\
\hline & & \multirow{2}{*}{$\begin{array}{c}\text { Com EGP } \\
(\mathrm{N}=12)\end{array}$} & $\rho$ & 0,424 & 0,128 & 0,298 &, $756 * *$ &, $674 *$ &, $603 *$ \\
\hline & & & Sign. & 0,17 & 0,693 & 0,348 & 0,004 & 0,016 & 0,038 \\
\hline & & \multirow{2}{*}{$\begin{array}{c}\text { Sem EGP } \\
(\mathrm{N}=9)\end{array}$} & $\rho$ &,- 230 & ,000 &,- 183 &,- 350 &,- 267 &,- 334 \\
\hline & & & Sign. &, 551 & 1,000 & 638 &, 356 & ,488 & ,380 \\
\hline & \multirow{3}{*}{$\stackrel{8}{7}$} & \multirow{2}{*}{$\begin{array}{c}\text { Todos os } \\
\text { Casos } \\
(\mathrm{N}=21) \\
\end{array}$} & $\rho$ &, 120 & ,035 &, 241 & ,404 &, $455^{*}$ & ,366 \\
\hline & & & Sign. & ,603 & 879 & ,293 &, 069 & ,038 &, 102 \\
\hline & & Com EGP & $\rho$ & 0,524 & 0,258 & 0,237 &, $638^{*}$ &, $657 *$ &, $623 *$ \\
\hline
\end{tabular}




\begin{tabular}{|c|c|c|c|c|c|c|c|c|}
\hline & $(\mathrm{N}=12)$ & Sign. & 0,08 & 0,418 & 0,459 & 0,026 & 0,02 & 0,031 \\
\hline & \multirow{2}{*}{$\begin{array}{c}\text { Sem EGP } \\
(\mathrm{N}=9)\end{array}$} & $\rho$ &,- 583 &,- 300 & ,361 &,- 316 & ,281 &,- 151 \\
\hline & & Sign. & , 100 & ,433 & ,340 & ,407 & , 464 & ,699 \\
\hline \multirow{6}{*}{$\stackrel{\vec{n}}{>}$} & \multirow{2}{*}{$\begin{array}{c}\text { Todos os } \\
\text { Casos } \\
(\mathrm{N}=21)\end{array}$} & $\rho$ & ,230 & , 166 &,- 076 & ,437" & ,112 &, 328 \\
\hline & & Sign. & ,317 & ,473 & ,743 & ,048 & ,630 & ,146 \\
\hline & \multirow{2}{*}{$\begin{array}{l}\text { Com EGP } \\
(\mathrm{N}=12)\end{array}$} & $\rho$ & 0,405 & 0,161 & 0,108 &, $638^{*}$ &, $632 *$ & 0,501 \\
\hline & & Sign. & 0,191 & 0,616 & 0,739 & 0,026 & 0,027 & 0,097 \\
\hline & \multirow{2}{*}{$\begin{array}{l}\text { Sem EGP } \\
(\mathrm{N}=9)\end{array}$} & $\rho$ & ,148 & ,055 &,- 215 & 207, &,- 450 & ,060 \\
\hline & & Sign. & ,703 & 889, & ,578, & 593, & ,225 & ,878 \\
\hline \multirow{6}{*}{$\stackrel{N}{>}$} & \multirow{2}{*}{$\begin{array}{c}\text { Todos os } \\
\text { Casos } \\
(\mathrm{N}=21) \\
\end{array}$} & $\rho$ & ,351 & ,450* & , 128 & ,231 &, $567^{* *}$ &, $511^{*}$ \\
\hline & & Sign. & ,119 & ,041 & ,581 & ,313 & ,007 & ,018 \\
\hline & \multirow{2}{*}{$\begin{array}{c}\text { Com EGP } \\
(\mathrm{N}=12)\end{array}$} & $\rho$ & 0,309 & 0,274 & 0,129 & 0,407 & ,734** & 0,448 \\
\hline & & Sign. & 0,328 & 0,389 & 0,69 & 0,19 & 0,007 & 0,144 \\
\hline & \multirow{2}{*}{$\begin{array}{l}\text { Sem EGP } \\
\quad(N=9)\end{array}$} & $\rho$ & ,620 & ,764* & ,268 &,- 207 &, 572 &, $746^{*}$ \\
\hline & & Sign. & ,075 & ,017 & , 486 & ,593 & , 107 & ,021 \\
\hline \multirow{6}{*}{$\stackrel{\infty}{>}$} & \multirow{2}{*}{$\begin{array}{c}\text { Todos os } \\
\text { Casos } \\
(\mathrm{N}=21) \\
\end{array}$} & $\rho$ &, $640^{* * *}$ & ,202 &,- 191 &, $672^{* * *}$ & ,121 & ,387 \\
\hline & & Sign. & ,002 & ,381 & ,406 & ,001 & 602 & ,083 \\
\hline & \multirow{2}{*}{$\begin{array}{c}\text { Com EGP } \\
(\mathrm{N}=12)\end{array}$} & $\rho$ &, $826 * *$ & 0,16 & $-0,181$ &, $764 * *$ & 0,233 & 0,396 \\
\hline & & Sign. & 0,001 & 0,62 & 0,573 & 0,004 & 0,467 & 0,202 \\
\hline & \multirow{2}{*}{$\begin{array}{l}\text { Sem EGP } \\
\quad(N=9)\end{array}$} & $\rho$ & ,606 & ,454 & 000, & ,478 & ,212 &, 570 \\
\hline & & Sign. & ,084, & ,220 & 1,000 & 193, & ,583 & 109 \\
\hline
\end{tabular}

Fonte: Elaborada pela autora.

* Nível de significância $\leq 0,05$.

* Nível de significância $\leq 0,01$.

\section{Correlações Confiança x Integração - Critério: Existência de um EGP na Organização do Entrevistado}

\begin{tabular}{|c|c|c|c|c|c|c|c|c|c|c|c|c|}
\hline & & & & \multicolumn{4}{|c|}{ Confiança } & \multicolumn{5}{|c|}{ Integração } \\
\hline & & & & V45 & V46 & V47 & V48 & V49 & V50 & V51 & V52 & V53 \\
\hline \multirow{6}{*}{ 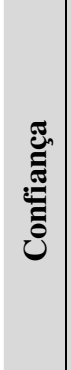 } & \multirow{6}{*}{$\stackrel{10}{7}$} & \multirow{2}{*}{$\begin{array}{c}\text { Todos os } \\
\text { Casos } \\
(\mathrm{N}=21)\end{array}$} & $\rho$ & 1,000 &, $556{ }^{* *}$ &, $659^{* * *}$ &, $611^{* *}$ & ,126 &, $\mathbf{4 5 3}^{*}$ & ,099 & ,165 & ,435* \\
\hline & & & Sign. & & ,009 & ,001 & ,003 & ,587 & ,039 & ,668 & ,474 & ,049 \\
\hline & & \multirow{2}{*}{$\begin{array}{c}\text { Com EGP } \\
(\mathrm{N}=12)\end{array}$} & $\rho$ & 1 & 0,48 & 0,529 &, $\mathbf{7 1 7} * *$ & 0,419 & 0,391 & 0,316 & 0,336 &, $\mathbf{7 3 0} * *$ \\
\hline & & & Sign. & & 0,114 & 0,077 & 0,009 & 0,175 & 0,209 & 0,317 & 0,285 & 0,007 \\
\hline & & \multirow{2}{*}{$\begin{array}{c}\text { Sem EGP } \\
(\mathrm{N}=9)\end{array}$} & $\rho$ & 1,000 & ,709* &, $866^{* * *}$ & ,425 &,- 478 & 661 &,- 371 &,- 124 &,- 357 \\
\hline & & & Sign. & & ,032 & ,003 & ,254 & 193 &, 052 &, 325 & ,751 &, 345 \\
\hline
\end{tabular}




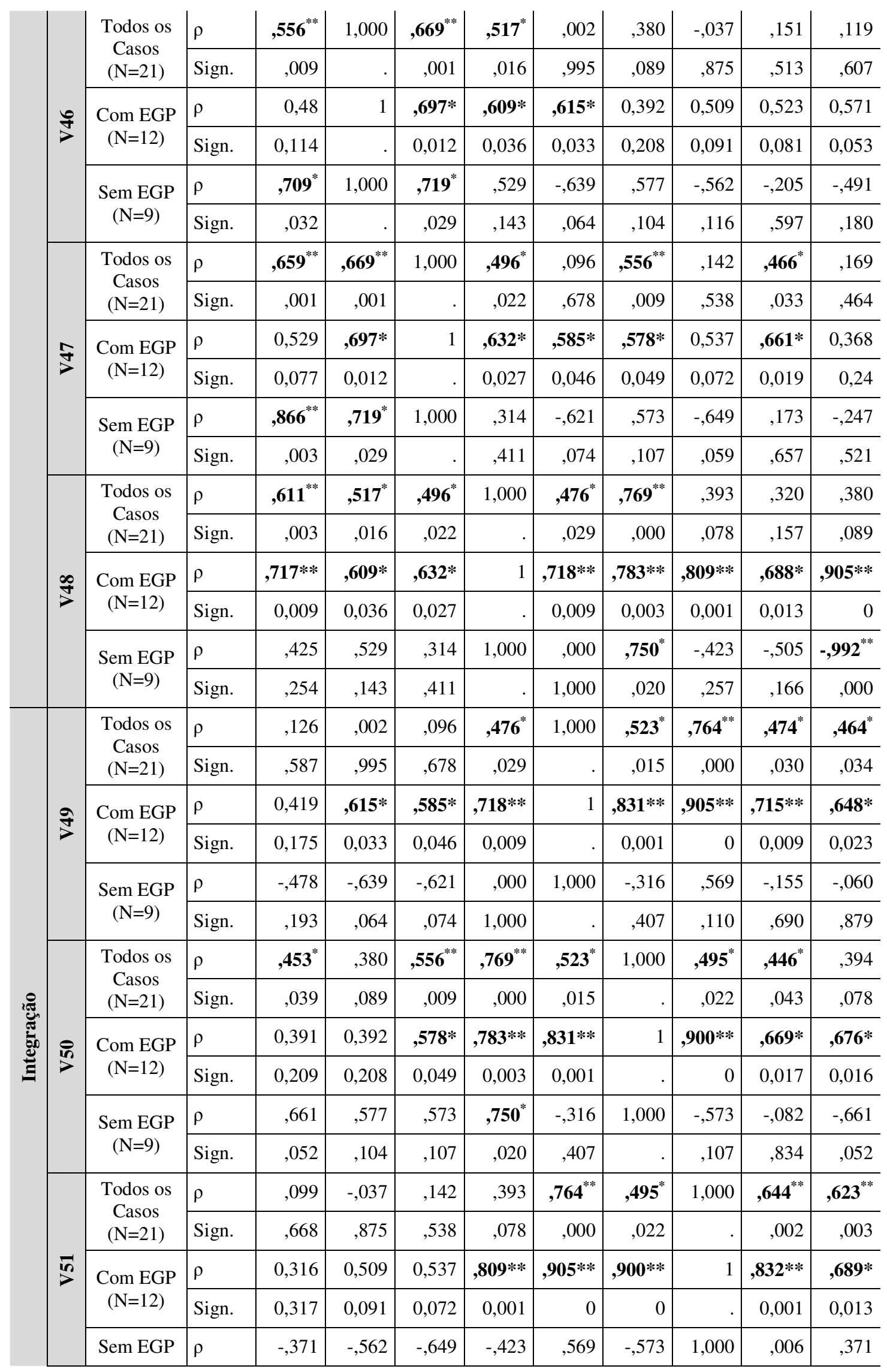




\begin{tabular}{|c|c|c|c|c|c|c|c|c|c|c|c|}
\hline & $(\mathrm{N}=9)$ & Sign. & ,325 & ,116 & 059 & ,257 & ,110 & , 107 & & ,988 & ,325 \\
\hline \multirow{6}{*}{$\stackrel{\tilde{n}}{>}$} & \multirow{2}{*}{$\begin{array}{c}\text { Todos os } \\
\text { Casos } \\
(\mathrm{N}=21)\end{array}$} & $\rho$ & , 165 & , 151 & ,466* & , 320 & ,474* & ,446* &, $644^{* *}$ & 1,000 & ,458* \\
\hline & & Sign. & , 474 & ,513 & ,033 & ,157 & ,030 & ,043 & ,002 & & ,037 \\
\hline & \multirow{2}{*}{$\begin{array}{c}\text { Com EGP } \\
(\mathrm{N}=12)\end{array}$} & $\rho$ & 0,336 & 0,523 &, $661^{*}$ & ,688* & ,715** &, $669 *$ &, $832 * *$ & 1 & 0,44 \\
\hline & & Sign. & 0,285 & 0,081 & 0,019 & 0,013 & 0,009 & 0,017 & 0,001 & & 0,152 \\
\hline & \multirow{2}{*}{$\begin{array}{c}\text { Sem EGP } \\
(\mathrm{N}=9)\end{array}$} & $\rho$ &,- 124 &,- 205 & ,173 &,- 505 &,- 155 &,- 082 & ,006 & 1,000 & ,557 \\
\hline & & Sign. & ,751 & ,597 & 657, & , 166 & ,690 & ,834 & ,988 & & ,119 \\
\hline \multirow{6}{*}{$\stackrel{n}{>}$} & \multirow{2}{*}{$\begin{array}{c}\text { Todos os } \\
\text { Casos } \\
(\mathrm{N}=21)\end{array}$} & $\rho$ & ,435* & ,119 & , 169 & ,380 & ,464* & ,394 &, $623^{* * *}$ & ,458* & 1,000 \\
\hline & & Sign. & ,049 & ,607 & ,464 & ,089 & ,034 & ,078 & ,003 & ,037 & . \\
\hline & \multirow{2}{*}{$\begin{array}{c}\text { Com EGP } \\
(\mathrm{N}=12)\end{array}$} & $\rho$ &, $\mathbf{7 3 0} * *$ & 0,571 & 0,368 &, $905 * *$ &, $648 *$ &, $676^{*}$ &, $689 *$ & 0,44 & 1 \\
\hline & & Sign. & 0,007 & 0,053 & 0,24 & 0 & 0,023 & 0,016 & 0,013 & 0,152 & . \\
\hline & \multirow{2}{*}{$\begin{array}{c}\text { Sem EGP } \\
(\mathrm{N}=9)\end{array}$} & $\rho$ &,- 357 &,- 491 &,- 247 &,$- 992^{* *}$ &,- 060 &,- 661 & ,371 & ,557 & 1,000 \\
\hline & & Sign. & ,345 & , 180 & ,521 & ,000 & ,879 & ,052 & ,325 & , 119 & \\
\hline
\end{tabular}

Fonte: Elaborada pela autora.

* Nível de significância $\leq 0,05$.

* Nível de significância $\leq 0,01$. 